Fall 2011

\title{
Translation and National clinical validation of the Nursing Management Minimum Data Set (NMMDS) in hospitals in the country of Iceland
}

Gudrun Audur Hardardottir

University of lowa

Follow this and additional works at: https://ir.uiowa.edu/etd

Part of the Nursing Commons

Copyright 2011 Gudrun A. Hardardottir

This dissertation is available at lowa Research Online: https://ir.uiowa.edu/etd/3464

\section{Recommended Citation}

Hardardottir, Gudrun Audur. "Translation and National clinical validation of the Nursing Management Minimum Data Set (NMMDS) in hospitals in the country of Iceland." PhD (Doctor of Philosophy) thesis, University of lowa, 2011.

https://doi.org/10.17077/etd.c75tpacw

Follow this and additional works at: https://ir.uiowa.edu/etd

Part of the Nursing Commons 


\title{
TRANSLATION AND NATIONAL CLINICAL VALIDATION OF THE NURSING MANAGEMENT MINIMUM DATA SET (NMMDS) IN HOSPITALS IN THE COUNTRY OF ICELAND
}

\author{
by \\ Gudrun Audur Hardardottir
}

\begin{abstract}
$\underline{\text { An Abstract }}$
Of a thesis submitted in partial fulfillment of the requirements for the Doctor of Philosophy degree in Nursing in the Graduate College of The University of Iowa
\end{abstract}

December 2011

Thesis Supervisor: Professor Diane L. Huber 


\begin{abstract}
Rising health care costs place increased burden on patients, health care personnel, administrators and policymakers. Decisions in health care are influenced by data which can be transferred into valuable information and knowledge. Data sets that facilitate data collection, information management and knowledge building are needed by nurse managers to support administrative decision-making. The Nursing Management Minimum Data Set (NMMDS $@$ C) offers a standardized method to capture core data that can be collected in information systems, shared and reused for multiple purposes to support safe and cost-effective care.

The purpose of this descriptive study was to adapt to Iceland and clinically test the NMMDS-ICE in all adult inpatient care units in the country of Iceland. The aims were to 1) translate the NMMDS from source language (English) to target language (Icelandic); 2) to validate the translated instrument; and 3) to describe the environment, nursing care resources, and financial resources across acute adult inpatient care units in Iceland.

Instrument development consisted of translation, expert validation, and psychometric testing. The target population was all adult acute care units in hospitals in Iceland, and the nurse managers $(n=38)$ representing these units. Data collection included a mailed survey. The sample equaled the population. Furthermore, 134 staff nurses on these units (excluding staff nurses at Landspitali) completed a job satisfaction survey. For nurse managers the return rate was $74 \%$, however $53 \%$ was usable. Return rate was $71 \%$ for staff nurses.

Semantic and content equivalence of the NMMDS-ICE was established. Five of seven subscales of the instrument received Cronbach's alpha score of 0.70 or higher. Results indicated that it was feasible to collect the NMMDS-ICE in hospitals in Iceland, albeit, there was an issue with time commitment to do so. The specialty services that best
\end{abstract}


described the patient population were medical/surgical services, birthing, and geriatrics. Furthermore, nurse managers seem to perceive good control on their units, and both nurse managers and staff nurses are satisfied with their jobs. A positive correlation was found between autonomy and satisfaction with nursing management, nursing administration, and own level of autonomy. Collecting financial data was a challenge due to unavailability to nurses.

Abstract Approved:

Thesis Supervisor

Title and Department

Date 


\title{
TRANSLATION AND NATIONAL CLINICAL VALIDATION OF THE NURSING MANAGEMENT MINIMUM DATA SET (NMMDS) IN HOSPITALS IN THE COUNTRY OF ICELAND
}

\author{
by \\ Gudrun Audur Hardardottir
}
A thesis submitted in partial fulfillment of the requirements for the Doctor of Philosophy degree in Nursing in the Graduate College of The University of Iowa

December 2011

Thesis Supervisor: Professor Diane L. Huber 
Copyright by

GUDRUN AUDUR HARDARDOTTIR

2011

All Rights Reserved 


\author{
Graduate College \\ The University of Iowa \\ Iowa City, Iowa
}

\title{
CERTIFICATE OF APPROVAL
}

\section{PH.D. THESIS}

This is to certify that the Ph.D. thesis of

\section{Gudrun Audur Hardardottir}

has been approved by the Examining Committee for the thesis requirement for the Doctor of Philosophy degree in Nursing at the December 2011 graduation.

Thesis Committee:

Diane L. Huber, Thesis Supervisor

\section{Connie Delaney}

\section{Der-Fa Lu}

\section{Sue Moorhead}

\section{Janet Specht}

Thor Aspelund 
To Andrea, Siggi and Rakel who have been my motivation throughout my PhD journey.

To my late sister Maddý who, although no longer with us, has been my strength, inspiration, and dedication to complete this journey. 
Nurses bring comfort where there is pain, courage where there is fear, and hope where there is despair. We heal, reassure, educate, inspire, and give confidence. We are courageous and caring. No health-care system can function without us.

(Hancock, C., 2004, ICN conference in Geneva, p. 13). 


\section{ACKNOWLEDGMENTS}

I am grateful to so many people who made it possible for me to accomplish this thesis. First of all, I express my sincerest thanks and eternal gratitude to Dr. Huber, chair of my committee for her guidance, endless patience and continuous encouragement throughout this process. Dr. Delaney I am forever grateful for her support, encouragement, inspiration, and friendship throughout the years. My sincere thanks to Dr. Lu for all her helpful remarks, and support; Dr. Specht for her comments, encouragement and friendship throughout the years; Dr. Moorhead for her comments and scholarly support; and Dr. Aspelund for his time and great help. Dr. Gail Keenan and Dr. John Schneider, who were with me at the beginning of my PhD journey, I want to thank for their support and guidance.

My sincerest thanks to Jennifer Clougherty for watching over me all those years and making sure I would be aware of all important deadlines. I also want to thank the Minister of Welfare, Guðbjartur Hannesson, Anna Lilja Gunnarsdóttir, Vilborg Ingólfsdóttir, Sigurjón Haraldsson, and my co-workers for their support. Special thanks to my co-workers Sigurður Davíðsson, who helped me with formatting the thesis; and to Guðrún Gunnarsdóttir and Margrét Björk Svavarsdóttir, who, besides keeping me company, made sure I had food while writing my thesis. I am forever grateful to my friends Ásta Thoroddsen, Brynja Örlygsdóttir, Pórdís Dórisdóttir, and Kristín Óskarsdóttir for their outstanding help and support during this journey.

I thankfully acknowledge the nurse experts, Hrund Scheving Thorsteinsson, Lilja Stefánsdóttir, Guðlaug Rakel Gudjónsdóttir, Hildur Helgadóttir, Birna Flygenring, and Guðrún Björg Sigurbjörnsdóttir for their contribution. I also thank the nurse managers and staff nurses who participated in the study; the nurse managers who pilot tested the instrument, and the nurse executives who gave their permission for the study. 
I want to thank my children for their patience, encouragement, and for standing by me. Special thanks to my mom, my sister Erla Ruth Hardardóttir, Logi Kjartansson, and my dear friends Vicki and J.R. Concha, for their outstanding support.

Last but not least, I gratefully acknowledge The Icelandic Nurses Association (Félag Î́lenskra Hjúkrunarfræðinga) and Sigma Theta Tau International for supporting this study. 


\begin{abstract}
Rising health care costs place increased burden on patients, health care personnel, administrators and policymakers. Decisions in health care are influenced by data which can be transferred into valuable information and knowledge. Data sets that facilitate data collection, information management and knowledge building are needed by nurse managers to support administrative decision-making. The Nursing Management Minimum Data Set (NMMDSC) offers a standardized method to capture core data that can be collected in information systems, shared and reused for multiple purposes to support safe and cost-effective care.
\end{abstract}

The purpose of this descriptive study was to adapt to Iceland and clinically test the NMMDS-ICE in all adult inpatient care units in the country of Iceland. The aims were to 1) translate the NMMDS from source language (English) to target language (Icelandic); 2) to validate the translated instrument; and 3) to describe the environment, nursing care resources, and financial resources across acute adult inpatient care units in Iceland.

Instrument development consisted of translation, expert validation, and psychometric testing. The target population was all adult acute care units in hospitals in Iceland, and the nurse managers $(n=38)$ representing these units. Data collection included a mailed survey. The sample equaled the population. Furthermore, 134 staff nurses on these units (excluding staff nurses at Landspitali) completed a job satisfaction survey. For nurse managers the return rate was 74\%, however 53\% was usable. Return rate was $71 \%$ for staff nurses.

Semantic and content equivalence of the NMMDS-ICE was established. Five of seven subscales of the instrument received Cronbach's alpha score of 0.70 or higher. Results indicated that it was feasible to collect the NMMDS-ICE in hospitals in Iceland, albeit, there was an issue with time commitment to do so. The specialty services that best 
described the patient population were medical/surgical services, birthing, and geriatrics. Furthermore, nurse managers seem to perceive good control on their units, and both nurse managers and staff nurses are satisfied with their jobs. A positive correlation was found between autonomy and satisfaction with nursing management, nursing administration, and own level of autonomy. Collecting financial data was a challenge due to unavailability to nurses. 


\section{TABLE OF CONTENTS}

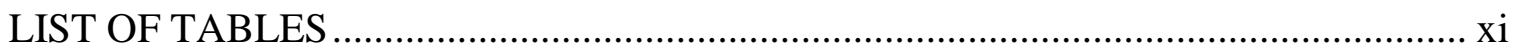

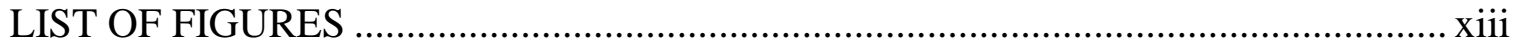

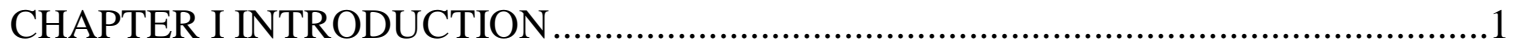

Research Problem / Significance of Study ….................................................5

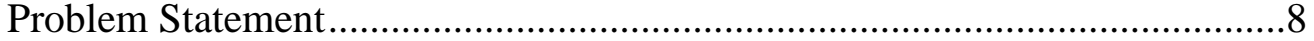

Purpose of Study .....................................................................................

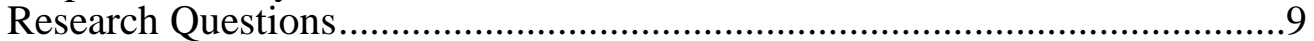

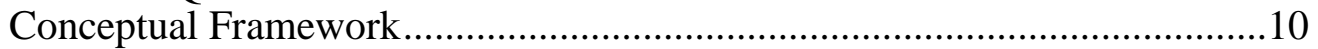

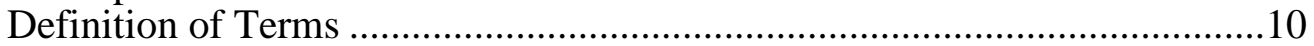

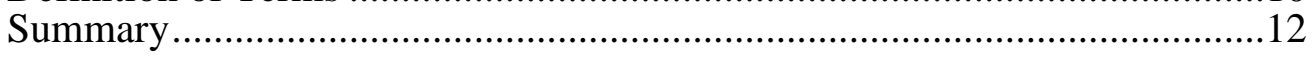

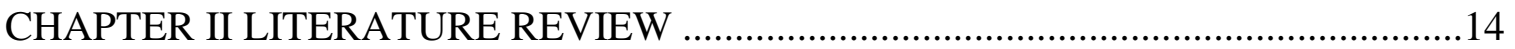

Background of Instrument and Conceptual Framework...............................15

Data and Information.....................................................................18

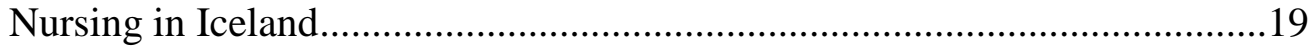

National Health Information Infrastructure ..............................................22

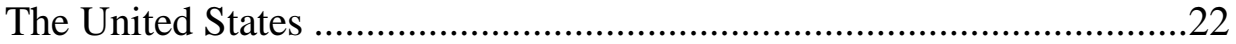

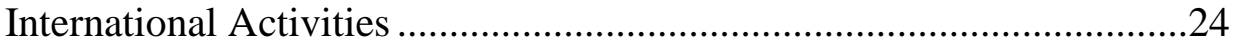

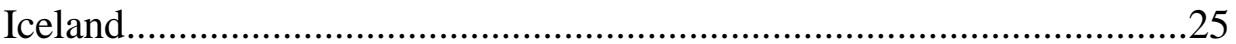

Electronic Health Record (EHR) _..................................................28

Health Care Data Standards.................................................................29

Standardized Nursing Languages ........................................................31

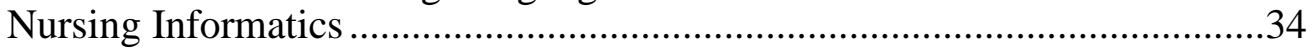

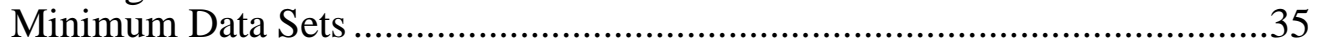

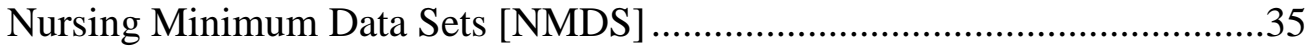

The Nursing Management Minimum Data Set [NMMDS] ............................38

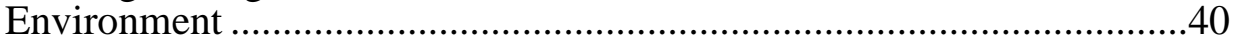

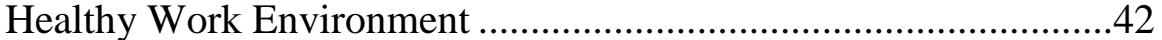

Nursing Care Resources ................................................................47

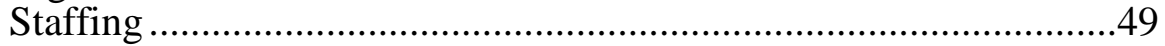

Job Satisfaction and Turnover........................................................51

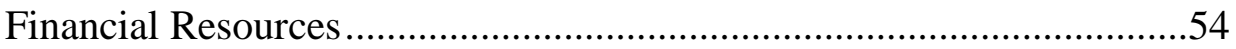

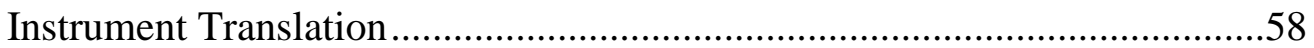

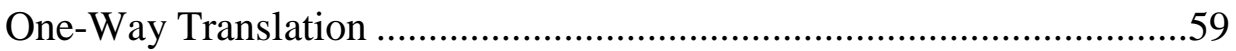

Translation by Committee ..................................................................59

Back-Translation Technique ............................................................60

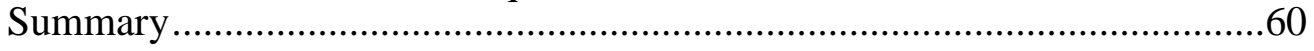

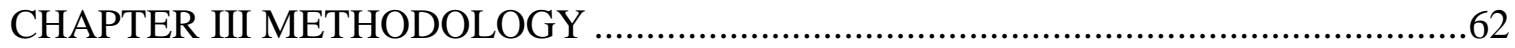

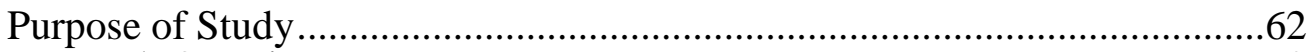

Research Questions.................................................................................62

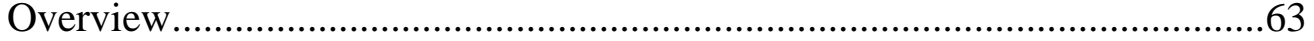

Instrument Translation and Adaptation .......................................................63

Study Design ................................................................................63

Expert Sample .........................................................................63

Translation Procedure....................................................................64 


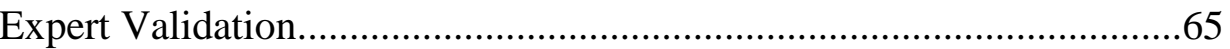

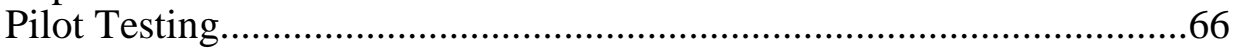

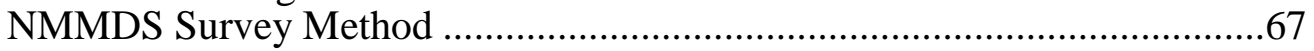

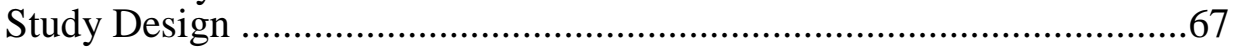

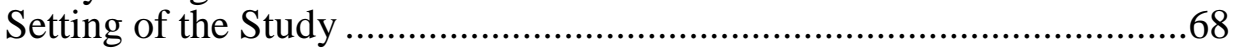

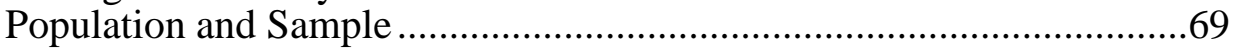

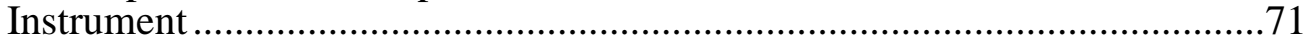

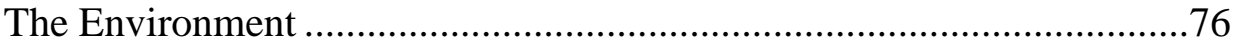

Nursing Care Resources ......................................................................

Financial Resources ………………………………………………..... 81

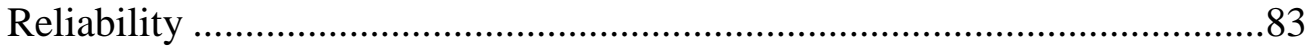

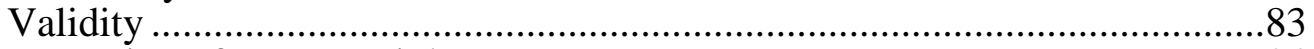

Protection of Human Rights ........................................................................84

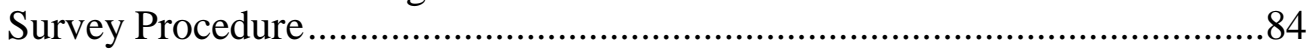

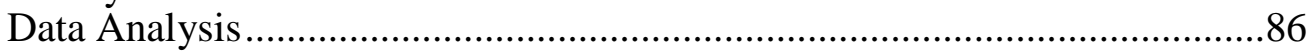

Research Question Number One ..........................................................86

Research Question Number Two.............................................................87

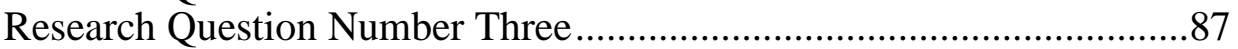

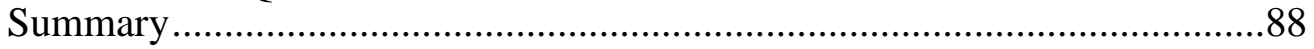

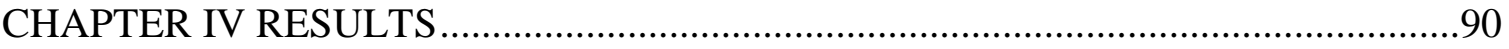

Research Questions....................................................................................99

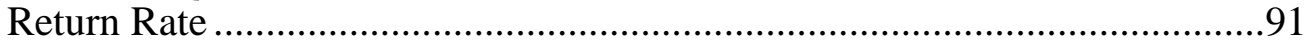

Research Question Number One .................................................................91

Research Question Number Two ....................................................................96

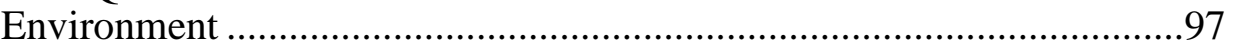

Type of Nursing Delivery Unit/Service ...........................................97

Patient/Client Population...................................................................98

Volume of Nursing Delivery Unit/Service.......................................102

Care Delivery Structure and Outcomes..........................................103

Clinical Decision Making Complexity............................................106

Environmental Complexity .........................................................108

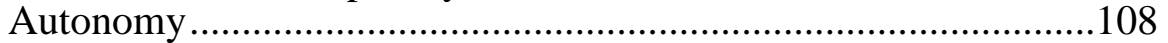

Nursing Care Resources .................................................................111

Management Demographic Profile .................................................111

Staff Demographic Profile................................................................112

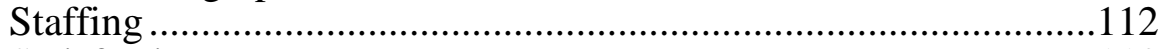

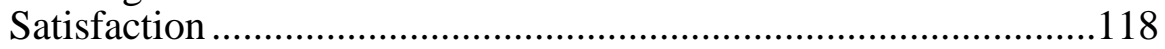

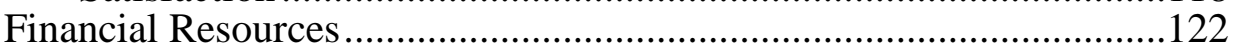

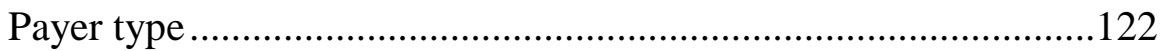

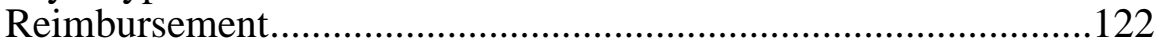

Nursing Delivery Unit/Service Budget ..........................................123

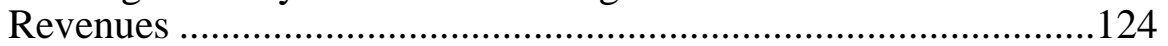

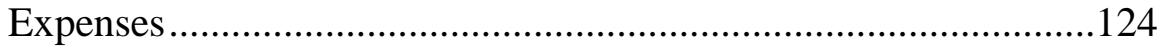

Research Question Number Three..............................................................125

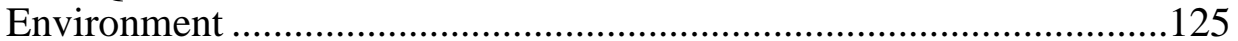

Nursing Care Resources ..................................................................127

Financial Resources ………………………………………………......127

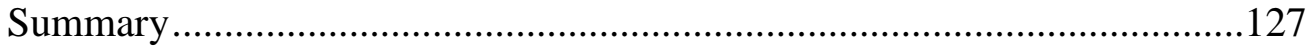

CHAPTER V DISCUSSION ……………………………....................................129

Research Question Number One ..................................................................129 
Research Question Number Two .........................................................131

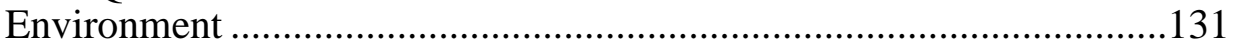

Nursing Care Resources .............................................................134

Financial Resources .......................................................................136

Research Question Number Three..............................................................137

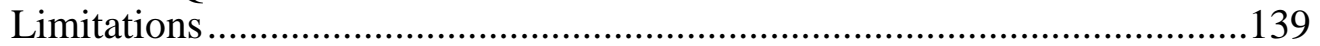

Implications for Practice and Future Research ..........................................140

Recommendations on NMMDS ...........................................................141

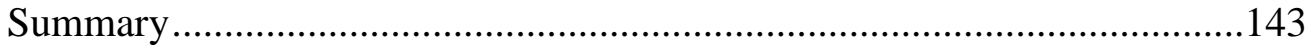

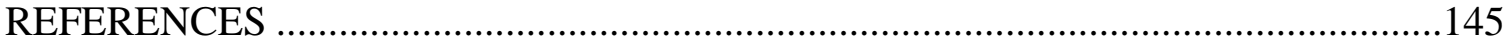

APPENDIX A INSTRUMENT: THE NURSING MANAGEMENT MINIMUM

DATA SET (NMMDS) SURVEY ${ }^{\complement}$ DHUBER \& CDELANEY, 2005 .......159

APPENDIX B INSTRUMENT: THE NURSING MANAGEMENT MINIMUM

DATA SET-ICE (NMMDS-ICE) SURVEY ${ }^{\odot}$ DHUBER \&

CDELANEY, 2005 TRANSLATED BY GAHARDARDOTTIR, 2011.....203

APPENDIX C: STATISTICAL ANALYSIS TABLES C1, C2, C3 AND C4 ..............230

APPENDIX D: SCRIPT USED IN TELEPHONE CALLS .......................................233

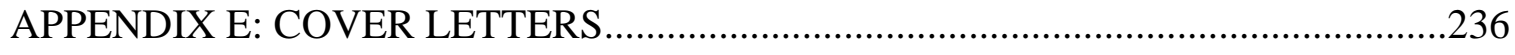

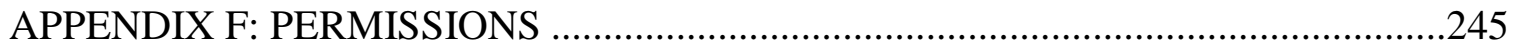




\section{LIST OF TABLES}

Table 1. The Nursing Management Minimum Data Set Elements...................................39

Table 2. Number of Targeted Hospital Units and Staff Nurses ..........................................70

Table 3. NMMDS Variables Excluded from the NMMDS-ICE Version..........................73

Table 4. Additional Variables Included in the NMMDS-ICE ...........................................75

Table 5. The NMMDS Instrument, Items, Subscales and Measurement of the Environment Category ………………………………………..........................77

Table 6. The NMMDS Instrument, Items, Subscales and Measurement of the Nursing Care Resources Category

Table 7. The NMMDS Instrument, Items, Subscales and Measurement of the Financial Resources Category .....

Table 8. Research Questions and Statistical Analysis ......................................................8

Table 9. Expert Panel Ratings......................................................................................93

Table 10. Internal Consistency Testing/Cronbach’s alpha ..................................................96

Table 11. Type of Nursing Delivery Unit/Service...............................................................95

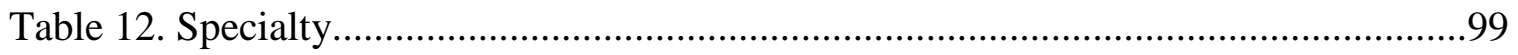

Table 13. Developmental Focus ………………………............................................100

Table 14. Interaction Focus.............................................................................................101

Table 15. Population Focus........................................................................................101

Table 16. Volume of Nursing Delivery Unit/Service ........................................................102

Table 17. Care Delivery Structure …………………………........................................103

Table 18. Outcomes - Professional ................................................................................104

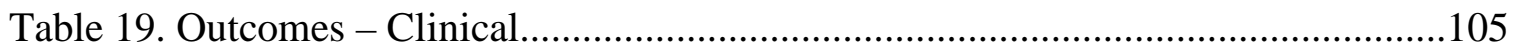

Table 20. Patient/Client Care..........................................................................................107

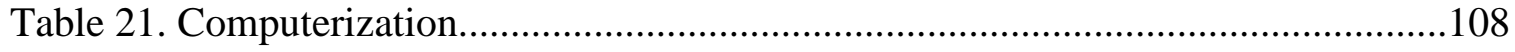

Table 22. Environmental Complexity …………………….............................................109

Table 23. Autonomy/Unit/Service Manager......................................................................109

Table 24. Autonomy/Department of Nursing ..............................................................110 
Table 25. Autonomy/Organization e.g. Chief Nurse Executive

Table 26. Management Demographic Profile/Experience

Table 27. Staffing/Quantity .114

Table 28. Staffing/Turnover...... .115

Table 29. Staffing/Retention.... 116

Table 30. Satisfaction/Position Nurse Managers ..... .119

Table 31. Satisfaction/Position Staff Nurses .119

Table 32. Satisfaction/Context Nurse Managers

Table 33. Satisfaction/Context Staff Nurses .120

Table 34. Spearman's rho Correlations between Autonomy and Satisfaction of Nurse Managers.

Table 35. Mann-Whitney U Test Summary of Significance for Environment .125

Table 36. Mann-Whitney U Test Summary of Significance for Nursing Care Resources

Table C1. Descriptive Statistical Analysis of the NMMDS-ICE Elements .231

Table C2. Mann Whitney U Test for Statistical Analysis of the NMMDS-ICE Elements

Table C3. Spearman's Rank Order Statistical Analysis of the NMMDS-ICE Elements

Table C4. Cronbach's Alpha Analysis of the NMMDS-ICE Elements. .232 


\section{LIST OF FIGURES}

Figure 1. Gudrun Informatics and Quality Conceptual Model ..........................................16

Figure 2. Translation Process and Adaptation of the NMMDS ............................................65

Figure 3. Management Demographic Profile/Education ..................................................112 


\section{CHAPTER I}

\section{INTRODUCTION}

Health care costs and expenditures continue to grow in developed countries all over the world (Junger, Berthou, \& Delaney, 2004), where the total costs of health care are rising faster than economic growth. Factors contributing to higher costs include new technology, population aging and population expectations (Organization for Economic Co-Operation and Development [OECD], 2010a). Rising health care costs, coupled with an economic crisis, place increased burden on patients, health care personnel, administrators and policymakers. This raises concerns about access to care, the quality of health care delivery, and patient safety. In addition, there is global concern about the nursing workforce and the availability of well-prepared nurses to deliver care in complex health care delivery systems (Institute of Medicine [IOM], 2010). Both the International Council of Nurses (ICN, 2006) and the World Health Organization (WHO, 2006) address the nursing workforce as a high priority.

Since the release of the Institute of Medicine (IOM, 1999) report "To Err is Human: Building a Safer Health System”, increased attention has been given to patient safety. The report suggested that 44,000-98,000 deaths per year in the U.S. might be due to adverse events or preventable errors. However, the report emphasized that errors should be blamed on organizational failure, not people failure. According to the Directorate of Health (2009a) in Iceland, the exact number of adverse events in hospitals in Iceland is not known. However, if figures from the IOM (1999) report would be translated and approximated to the Icelandic health care system, it can be assumed that 50-100 preventable deaths occur in hospitals in Iceland every year. The total population in Iceland is only $318,452$.

A subsequent report, “Crossing the Quality Chasm” (IOM, 2001) identified serious and extensive quality problems in the U.S. health care system. According to the 
IOM (2001) the quality problems exist because of the lack of an appropriate environment, processes and capabilities in the current health care system that are needed to ensure patient-centered, safe, effective and timely services. Many health care settings lack basic equipment such as computer systems to process clinical information, although current initiatives such as the Electronic Health Record are propelling forward computerization in health care. Improvements in quality would be achieved by redesigning health care systems with greater emphasis on information technology, thus increasing automation of clinical, financial and administrative transactions as a way to standardize and capture efficiencies. In order for this to take place successfully, the development and application of more sophisticated information systems are essential to support data collection, retrieval, and analysis.

A recent report on the performance of the Icelandic health care system identified considerable improvements needed in planning and performance management of the health care system. The report highlighted the need for increased attention to information technology to improve data collection, retrieval and analysis of clinical, financial, and administrative data (Boston Consulting Group, 2011).

Health care in Iceland is nationalized, with health services primarily financed by the government, mainly through taxes. The country is divided into seven health care regions. Each region has one or more health care centers and one or more regional hospitals. Health care centers run local regional hospitals and are also responsible for primary health care, home nursing, and school nursing services. The regional hospitals provide general inpatient and outpatient care with a certain degree of specialty services. Some of the regional hospitals are small in size, and their function is more like a nursing home than an acute care hospital. The main hospital in Iceland is Landspitali, the University Hospital in Reykjavik, providing highly specialized inpatient and outpatient services for the whole country. Landspitali collaborates with the University of Iceland. The main hospital for the North of Iceland is Akureyri Hospital, which is defined as a 
teaching hospital that collaborates with the University of Akureyri. Akureyri Hospital provides specialized inpatient and outpatient services for the whole country. Hence, there are three layers of types of hospitals in Iceland: two university hospitals, six regional hospitals, and six hospitals where the service is mostly long term care with 2-4 acute care beds. The total number of hospitals in Iceland is 14 . There is great variation in the size of the hospitals among the three levels.

Since the closure of the Icelandic School of Nursing in 1986, the entry level into professional nursing practice has, solely been at the BSN level. Nurse administrators are accountable by law for all professional nursing services provided in the country.

An important issue in nursing informatics has been and still is the design of information systems to help capture, store and retrieve nursing data (Graves \& Corcoran, 1989). Data that are collected, organized, and analyzed in an information system could improve the quality and efficiency of data collection and give timely information needed to support decision-making. Another advantage of electronic capture of clinical and administrative data is that it facilitates information exchange within and across health care institutions, as well as reuse of the data for quality improvement (Westra et al., 2010).

Standardization of health care data involves defining what to collect (i.e. data sets), how to collect the data (i.e. coding of data elements, classification systems, terminologies), how to represent the data, and data interchange formats (electronic encoding, document architecture for structuring data elements, information models that define relationships among data). Without data standards it is difficult to share information across institutions (IOM, 2004a). To ensure data comparability and interchange, data types must be universal. Data standards and common policies are necessary to build a national and international health information infrastructure where data are collected and reused for multiple purposes to support new knowledge and quality improvements in health care (Halamka et al., 2005; IOM, 2004a). 
Nurses comprise one of the largest occupations in the health care system (Directorate of Health, 2009b; IOM, 2010; Westra et al., 2010), and the demand for nurses continues to grow,due to the aging population and increased burden of chronic diseases (ICN, 2006). A shortage of nurses has become a global concern in terms of the serious affects the nursing shortage has on the well-being of patients and populations (ICN, 2006; INA, 2007).

Nurse managers and administrators worldwide face significant leadership responsibilities requiring that they be able to justify budgets and minimize the cost of staff and supplies in an environment of limited resources and increased health demands. Hence, nurse managers and administrators need timely, accurate, and relevant data to support effective decision-making. The managerial data needs for nurse administrators include data to support decisions involving resource allocation, activity planning, and financial management (Delaney \& Huber, 1996).

The Nursing Management Minimum Data Set (NMMDS) is a research-based minimum data set, developed to meet the information needs of nurse administrators. The data set includes standardized terms to support the measurement of contextual factors and their relationship to quality and cost-effectiveness of nursing care (Delaney \& Huber, 1996; Huber, Delaney, Crossley, Mehmert, \& Ellerbe, 1992). The NMMDS conforms to the standards set by the American Nurses Association's Steering Committee for Nursing Practice Information Infrastructure (American Nurses Association [ANA], 2002). Furthermore, the NMMDS has been registered with Health Level 7 (HL7), the recommended standard in the U.S. to ensure computerized communication of data and information across all information systems. Moreover, the first three NMMDS data elements have been mapped to Logical Observation Identifier Names and Codes [LOINC] a U.S. federally recognized data set which is publicly available (Westra et al., 2010). The NMMDS includes eighteen elements grouped into three categories; Environment, Nursing Care Resources, and Financial Resources. The NMMDS and the 
International Minimum Data Set [iNMMDS], both incorporate the capture of nursing workforce characteristics, thus advancing the ability to use these data for quality and safety management.

\section{Research Problem / Significance of Study}

Hospital restructuring in response to cost containment in the last two decades includes changes in staffing and skill mix, reduced hospital lengths of stay, increased use of outpatient services, unit close down and merging of hospitals. This is of major concern in relation to the effects on processes of care and patient outcomes.

Recent studies have suggested that lower RN staffing is associated with adverse patient outcomes (Aiken, Clarke, Sloane, Lake, \& Cheney, 2008; Clarke \& Aiken, 2006; Hugonnet, Chevrolet, \& Pittet, 2007; Kane, Shamliyan, Mueller, Duval, \& Wilt, 2007; Rafferty et al., 2006; Seki \& Yamazaki, 2006; Tourangeau et al., 2007; Unruh, 2008; Van den Heede et al., 2009a).

Nurses play a critical role in providing continuous and safe patient care within a complex environment involving multidisciplinary health professionals in various health care settings. The total number of practicing nurses in Iceland in 2009 was 2,686, and midwives were 250. Licensed practical nurses were 2,185 (Directorate of Health, 2010). The number of practicing nurses (and midwives) was 9.2 per 1000 population which is a 4.2\% decrease from the year 2007, when there were 9.6 nurses (and midwives) per 1000 population. The average number of practicing nurses within Organization for Economic Co-Operation and Development [OECD] countries in 2008 was 9.8 nurses per 1000 population [OECD, 2010b].

The decrease in total number of nurses per 1000 population is of concern. According to a recent report from the Icelandic Nurses’ Association (2007), it is estimated that the need for nurses in Iceland will increase by $2.2 \%$ every year for the next ten years. Moreover, due to the economic crisis that hit the country in fall of 2008, 
hospitals and health care centers have been suffering major financial cutback. Furthermore, due to reorganization of the health care system, hospitals have been merged, units downsized, and a number of health care professionals have been laid off, including nurses. This raises concern in relation to staff morale, staffing, workload and job stress, which are empirically linked to patient safety and quality of nursing care (Kramer \& Schmalenberg, 2008).

A landmark report by the Institute of Medicine (IOM, 2004b) raised serious concerns about the impact of nurses' work environments on patient safety. The report identified negative work environments and inadequate management practices as considerable threats to the quality of patient care. Research indicates that the environment of health care affects patient, nurse, and institutional outcomes. Patient outcomes include satisfaction with care, injury or adverse events, failure to rescue or readmission; nurse outcomes include job satisfaction, stress, burnout, turnover and absenteeism; and intuitional outcomes include increased costs due to lower productivity, turnover , agency costs, longer lengths of stay, and higher treatment costs (Unruh, 2008).

A recent report, The Future of Nursing: Leading Change, Advancing Health (IOM, 2010), identified key issues for nurses to better be able to respond to the rapidly changing health care environment. Recommendations included increasing the proportion of both baccalaureate and doctorally prepared nurses; to expand opportunities for nurses to lead and manage collaborative efforts with other health care members to improve health systems and practice environments; to prepare nurses to lead change to advance health; and to build an infrastructure for the collection and analysis of interprofessional health care data to ensure timely and publicly available health information.

Every health care organization collects some nurse management data; however, often the data are not coded and lack uniform definitions for comparison. Nursing management data that describe the context of care delivery need to be standardized and included in data warehouses (Westra et al., 2010) because this provides specific 
information needed to empower nurse managers and executives to design and implement the optimal work environment for nurses to deliver safe and effective care. The NMMDS was developed to help nurse managers and administrators capture the data needs within the system in which health care is delivered (Delaney et al., 1994).

The NMMDS has standardized definitions and measures and offers a standard format to collect essential data to provide nurse managers with the information they need for safety and quality improvement, at unit- or service level within and across health care organizations (Huber \& Delaney, 1997, 1998). When linked to clinical data bases, the NMMDS can be used to compare the effects of staffing, skill mix and education on patient outcomes like morbidity, mortality and patient falls. The NMMDS is also useful to compare staffing, nursing care delivery models, organizational climate and wages to nurse outcomes such as job satisfaction, autonomy, and turnover (Westra et al., 2010). Moreover, the NMMDS supports the recommendations by the International Council of Nurses [ICN] (2006) on the development of international standards to address the global nursing shortage problem. These include staffing and skill mix, nurse education, retention and turnover. Emphasis is on collaboration of health professionals, cost and effectiveness of health care delivery, and optimal nurse outcomes, such as job satisfaction and career development. The ICN recommendations are in congruence with the World Health Organization's [WHO] (2006) plans on building national health workforce strategies.

Nurse managers and administrators play a key role in creating a safe work environment. Studies to describe the work environment of Icelandic nurses are very limited. Former studies have indicated that unit level managerial support, staffing adequacy, and nurse-doctor relationship are associated with job satisfaction and nurses' perceived quality of care (Gunnarsdóttir, Clarke, Rafferty, \& Nutbeam, 2009). Sveinsdóttir, Biering and Ramel (2006) found that occupational stress was associated with lack of opportunities to practice the professional role of nursing (i.e. teamwork, 
caring, professional development, teaching, decision-making, research, continuing education, mental support, and the development of specific nursing interventions), unscheduled work, lack of experience, and insufficient support from co-workers and nurse managers. Other studies have found that increased workload, perceived stress and staff position have negative impact on job satisfaction (Biering \& Flygenring, 2000; Biering \& Sveinsdóttir, 2001).

\section{$\underline{\text { Problem Statement }}$}

Although Iceland is known for its extensive use of computer technology, where 92\% of households own a computer and 93\% access the Internet daily (Statistics Iceland, 2009), hospitals lag behind in the use of information technology (Boston Consulting Group, 2011). Paper-based data collection systems have known inefficiencies and the potential for human error when processing complex data. Currently, a standardized method to collect and analyze administrative nursing data in hospitals in Iceland does not exist at a national level. A national study to describe the work environment, nursing care resources, and financial resources of nurse managers working in hospitals in Iceland has never been conducted. Hence, this study is a beginning step to better enable comparisons of resource allocation and utilization across nursing units and hospitals in Iceland. Moreover, it would allow comparisons on quality of care if linked to clinical databases. The problem is highly relevant to Iceland because this study provided relevant, comparative information and knowledge building, which could be used for quality improvement and policymaking. This study is of value to patients, nurses, health care institutions, and society as it could provide information which can be used to enhance work environments and quality care in hospitals in Iceland. Work environments that foster quality work life are likely to provide services that enhance patients’ safety and quality health outcomes. Furthermore, this study is of significance as it facilitates international comparisons and cross-cultural knowledge building. Previously, a pilot 
study using the Icelandic version of the NMMDS (NMMDS-ICE) was conducted in four pediatric units within two hospitals in Iceland. The results indicated that all but one (reimbursement) of the NMMDS elements were collectable at the pediatric unit level in hospitals in Iceland (Thorlacius, 2011).

\section{Purpose of Study}

The purpose of this study was to adapt to Iceland and clinically test the Nursing Management Minimum Data Set (NMMDS $\odot$ 2005) in all acute adult inpatient care units in the country of Iceland (excluding psychiatry). The specific aims of the study were:

1. To translate the Nursing Management Minimum Data Set (NMMDS@) from source language (English) to target language (Icelandic).

2. To validate the translated instrument.

3. To describe the environment, nursing care resources, and financial resources across acute adult inpatient care units in the country of Iceland, using the Icelandic version (NMMDS-ICE $\odot$ ) of the Nursing Management Minimum Data Set (NMMDS@).

\section{$\underline{\text { Research Questions }}$}

The study's research questions were:

1. Does the NMMDS-ICE demonstrate semantic equivalence and content equivalence?

2. What is the aggregate profile of the 1) environment, 2) nursing care resources, and 3) financial recourses across acute adult inpatient units in hospitals in Iceland?

3. Are there measurable differences in environmental, nursing care resources, and financial resources among hospitals in Iceland, depending on their geographic location and size? 


\section{Conceptual Framework}

The focus of the Nursing Management Minimum Data Set (NMMDS) is to identify key context variables that influence the quality of nursing care (Huber \& Delaney, 1998). An integrated model based on empirical evidence, Donabedian’s (1966) components for quality measurement, and nursing informatics (ANA, 2008) was developed and served as the framework for the NMMDS-ICE instrument in this study.

Donabedian’s (1966) three components for quality measurement: structure, process and outcomes of care, has for decades been one of the most widely acknowledged model for quality evaluations in health care (Stone et al., 2007). No single definition of quality exists, but before quality can be assessed it has to be defined. The Institute of Medicine (2001) defined quality as "the degree to which health services for individuals and populations increase the likelihood of desired health outcomes and are consistent with current professional knowledge” (p. 21). According to Donabedian (1980; 1988) quality is defined depending on where people are located in the system of care (e.g. patient, provider, and community), how broadly the concept of health is defined, and peoples' responsibilities for it. The elements of quality of care can be assessed using structure, process, and outcome. A structure of good quality increases the likelihood of quality processes, which increase the likelihood of a desirable outcome. The background of the NMMDS instrument and how it relates to the conceptual framework is discussed in Chapter 2.

\section{Definition of Terms}

The conceptual and operational definitions of variables and terms used in this study are as follows:

Semantic equivalence: Semantic equivalence indicates that the meaning of each variable remains the same in each culture after translation (Flaherty et al., 1988). For the purpose of this study, it will be measured by expert panel ratings, where each variable 
was rated as having either "exactly the same meaning”, “almost the same meaning” or "a different meaning”.

Content equivalence: Content equivalence indicates that the content of each variable of the instrument is relevant in each culture under study (Flaherty et al., 1988). For the purpose of this study, it was measured by expert panel ratings where each variable was rated on a five point Likert scale ranging from 1 (low) to 5 (high) on necessity, clarity, and collectability.

Necessity: Necessity refers to a concept that is needed. For the purpose of this study, necessity is defined as data elements relevant to Icelandic nurse managers and administrators for effective administrative decision-making. It is measured on a five point Likert scale ranging from 1 (low necessity) to 5 (high necessity).

Clarity: Clarity refers to how clearly a concept is being defined, or how easy it is to understand what the item exactly is measuring. For the purpose of this study, clarity is measured on a five point Likert scale ranging from 1 (not clear) to 5 (clear).

Collectability: Collectability refers to how easy it is to collect the data variables. For the purpose of this study, collectability is measured on a five point Likert scale ranging from 1 (not collectable) to 5 (easily collectable).

The Nursing Minimum Data Set (NMDS): “a minimum set of items of information with uniform definitions and categories concerning the specific dimension of nursing which meets the information needs of multiple data users in the health care system” (Werley, Devine, Zorn, Ryan, \& Westra, 1991, p. 422). It is measured by nursing care elements, client demographic elements, and service elements.

The Nursing Management Minimum Data Set (NMMDS): “the research-based management data set that meets the nurse executive's need for a specific nursing management data capture system that will produce accurate, reliable, and useful data for decision-making” (Huber, Schumacher, \& Delaney, 1997, p. 43). It is measured by the NMMDS survey instrument (Appendix A), which includes seventeen contextual 
variables that describe the external environment of care delivery, nursing care resources, financial resources and one variable that is the unique identifier.

Environment: "forms the context of the care delivery that the nurse executive assesses, coordinates, leads, and manages” (Huber et al., 1997, p. 44). For the purpose of this study, it is measured by nine contextual variables that form the external environment of health care delivery. Those include unit/service unique identifier, type of nursing delivery unit/service, patient/client population, volume of nursing delivery unit/service, care delivery structure and outcomes, patient/client accessibility, clinical decision making complexity, environmental complexity and autonomy.

Nursing care resources: "describe the human resources aspects of delivering nursing care to patients/clients” (Huber et al., 1997, p. 44). For the purpose of this study, they are measured by four contextual variables that describe the nursing care resources of the organization. Those include Management demographic profile, Staff demographic profile, Staffing, and Staff satisfaction.

Financial resources: "provide the most basic data needs for describing the unit level of monetary resources for an organization” (Huber et al., 1997, p. 44). For the purpose of this study, they are measured by four contextual variables that describe the financial resources of the organization. Those include payer type, reimbursement, nursing delivery unit/service budget, and expense.

\section{Summary}

The use of information technology in health care, where a variety of sources can be transferred into valuable information and knowledge, is a key to the success of health care organizations to provide high quality and cost-effective care. Data sets that facilitate data collection, information management and knowledge building are especially important to nurse administrators, as they need evidence to show their contribution to cost-effective and safe patient care and to lead and manage using the evidence base. A 
standardized data set and data captured in data warehouses is needed to support management and administrative decision-making in Iceland. The NMMDS could help nurse administrators in Iceland capture the core data needed for providing safe, costeffective, and high quality patient care. Furthermore, by translating and developing a culturally equivalent Nursing Management Minimum Data Set, the opportunity for crosscultural research is established. The purpose of this study was to adapt to Iceland and clinically test the Nursing Management Minimum Data Set (NMMDS-ICE@) in acute adult inpatient care units in the country of Iceland. In the next chapter, the theoretical framework of the NMMDS instrument and the literature base to support it are presented. 


\section{CHAPTER II}

\section{LITERATURE REVIEW}

Information is the lifeblood of health care, communication is the heart that pumps it

(Toussaint \& Coiera, 2005).

Health care systems are huge, complex, and continuously changing. Huber (2000, 2006) defined organizational structure as "the linkage of jobs and positions into coordinated network through which communication, delegation, power, and authority flow” (p. 470). Health care organizations function in a dynamic environment and hence must be able to collect data, process information, and apply new and existing knowledge in order for managers and clinicians to make informed decisions quickly and effectively (Hovenga, Garde, \& Heard, 2005).

Decisions in health care are influenced by data, and health care organizations depend on the environment for information. Health statistics on patient care provided by nurses are necessary to assess the quality of care and to provide evidence-based nursing practice (Maas \& Delaney, 2004). However, the lack of availability of nursing data to support administrative decision-making has been acknowledged internationally for more than a decade (Huber \& Delaney, 1998; Junttila et al., 2007; Moorhead \& Delaney, 1998). Albeit, health care data are systematically collected around the world, nursing data are usually not included in large national data sets. Hence, nursing data are often not available for effective planning and policymaking (Maas \& Delaney, 2004). In the absence of a systematic collection, the storing, retrieving, and analyzing of nursing data is not systematized and valuable information is lost. Therefore, nursing needs a standardized data set that can be incorporated into management information systems to support decision making and policy development in such areas as job satisfaction, turnover, comparison of nursing care delivery models, cost of nursing services, and 
allocation of nursing personnel. This would facilitate comparison of nursing outcomes within and across health care organizations (Huber, 2006).

\section{Background of Instrument and Conceptual Framework}

The NMMDS provides a framework to collect essential data elements that are needed by nurse managers and administrators to support knowledge management and administrative decision-making and to compare the cost and effectiveness of nursing care within and across health care settings (Huber et al., 1997). The NMMDS builds on the Iowa Model for Nursing Administration (Johnson et al., 1991), the NMDS (Werley et al., 1991), and Donabedian's (1966) components for measuring quality: structure, process and outcome. No single definition of quality exists, but before quality can be assessed it has to be defined. The Institute of Medicine (2001) defined quality as "the degree to which health services for individuals and populations increase the likelihood of desired health outcomes and are consistent with current professional knowledge” (p. 21). According to Donabedian $(1980,1988)$ quality is defined depending on where people are located in the system of care (e.g. patient, provider, and community), how broadly the concept of health is defined, and peoples' responsibilities for it. The elements of quality of care can be assessed using structure, process, and outcome. A structure of good quality increases the likelihood of quality processes, which increases the likelihood of a desirable outcome.

The framework that was developed by the investigator to guide this study, was an integrated model (see Figure 1) based on Donabedian's (1966) components for quality measurement, which has for decades been one of the most widely acknowledged model for quality evaluations in health care (Kramer \& Schmalenberg, 2008), nursing informatics (ANA, 2008), and empirical evidence (Aiken et al., 2002; Currie \& Watterson, 2007; McGillis Hall et al., 2004; O’Brien-Pallas et al., 2006; Pappas, 2007, 
2008; Patrician et al., 2011; Rafferty et al., 2006; Tourangeau et al., 2007; Unruh, 2008;

Van den Heede et al., 2007).

Figure 1. Gudrun Informatics and Quality Conceptual Model

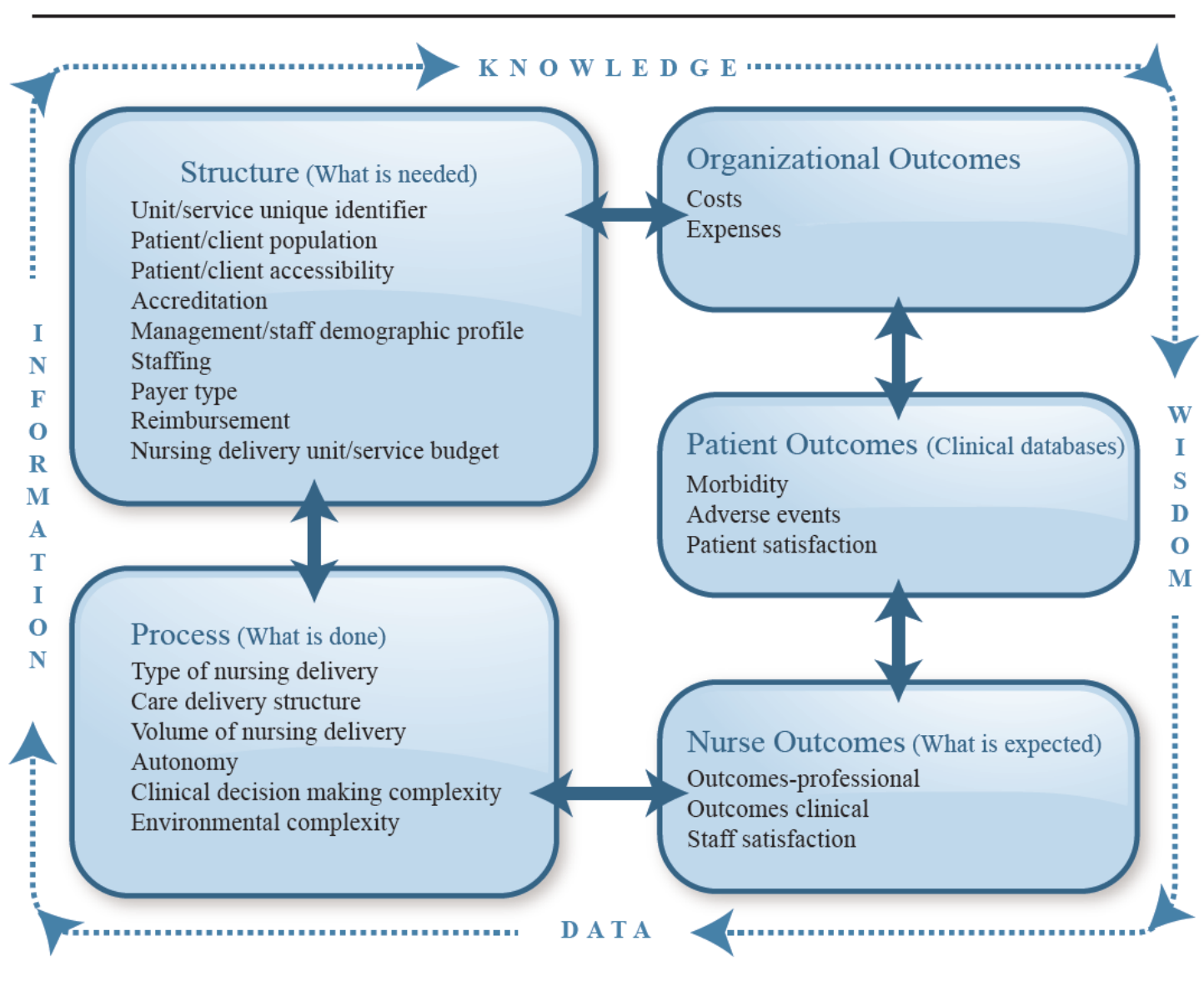

Data and information are within each of the "boxes" of the model (Figure 1).

Data are the facts, and information is the interpretation of the data. Knowledge is the result of the interaction of one or more data or information within or across boxes.

Wisdom is the understanding or ability to know when and how to use knowledge (ANA, 2008; Nelson, 2002). 
Structure is the environment in which health care takes place. Structure is defined as "the relatively stable characteristics of the providers of care, of the tools and resources they have at their disposal, and of the physical and organizational settings in which they work” (Donabedian, 1980, p. 81). Structural measures relate to the capacity of the organization to provide quality care. Those measures include material resources (e.g. facility size, buildings, equipment, technology, payment and funding sources), human resources (e.g. number and qualifications of personnel), and organizational structure (e.g. licensure, compliance with safety regulations, standards and guidelines, staff/patient ratio, case mix, and access to patient care).

Process refers to the interpersonal aspects and technical skills in health care delivery and describes the care that is being delivered (Donabedian, 1980). Process is "what is actually done in giving and receiving care" (Donabedian, 1988, p. 1745). Process measures include, for example, assessment, medication administering, pain management, and wound care. The NMMDS includes process variables like method of care delivery, type of services that are available, timeliness, patterns and trends, quality indicators, complexity of care, and adverse event reporting.

Outcomes are "the effect of care on the health status of patients and populations" (Donabedian, 1988, p. 1745). Outcome measures refer to whether the services provided by the organization make any difference, that is, what works and what doesn't work. Outcome variables include infection and complication rates, mortality rate, and pain control, length of stay, readmission, staff quality improvement and patient/staff satisfaction.

The concepts of structure, process and outcome can be applied to the NMMDS. Elements of structure include unit/service unique identifier, patient/client population, patient/client accessibility, nursing delivery unit/service accreditation, management demographic profile, staff demographic profile, staffing levels, qualification and skill mix, and financial resources. Elements of process include type and method of nursing 
delivery, volume of nursing delivery, nurse autonomy, complexity of clinical decisionmaking, and environmental complexity. Elements of nurse outcomes include outcomesprofessional, outcomes-clinical, and staff satisfaction. Elements of organizational outcomes include costs of care and expenses.

Nurse outcomes, such as job dissatisfaction, stress and burnout, turnover and absenteeism affect both patient outcomes and financial outcomes. Organizational economic outcomes include health care costs, lost productivity, turnover costs, absenteeism costs, malpractice claims, and increased length of stay (Unruh, 2008). Patient outcomes include morbidity, adverse events such as unexpected mortality, failure to rescue, patient falls, infection, skin breakdown, medication error, inadequate pain management, and patient satisfaction. The NMMDS can empower nurse managers and administrators by facilitating the collection of nurse outcomes and organizational outcomes that can be linked to patient outcomes in clinical databases within data warehouses. The NMMDS therefore gives nurse managers and administrators information they previously did not have, either available or analyzed, which canbe used for benchmarking and quality improvements in health care.

\section{Data and Information}

Graves and Corcoran (1989) proposed the first framework for nursing informatics. The core concepts of their framework are data, information, and knowledge. The management and processing components of the model include the ability to "collect, aggregate, organize, move, and represent information efficiently” (p. 227). Processing is considered to be a transformation of data into information and information into knowledge.

Several definitions of data exist. Blum (1986) defined a datum as a discrete entity without interpretation. Graves and Corcoran (1989) defined a datum as information about a variable that has attributes of value as it represents something that has a measure 
or a description in the real world. Shortliffe and Barnett (2001) defined a datum as any single observation of fact, which can have value (i.e. red blood cell count) for an object (i.e. patient) at any given point in time. Data processing is the transformation of "raw" data into organized and meaningful data with the end product of information (Graves \& Corcoran, 1989).

Information indicates organized data with meaning and has attributes of timeliness, accuracy, utility, relevance, and quality. Information processing may result in different information or new knowledge. Knowledge can be transformed into decisions and discoveries, or new knowledge. Knowledge is formed from the laws and relationships that exist and the connection of the elements of data as well as the rules used to combine the facts (interpretation) to make decisions (Graves \& Corcoran, 1989).

\section{Nursing in Iceland}

Nursing in Iceland, like in most countries, is mainly a women’s profession. The first diploma school of nursing was affiliated with the University Hospital in Reykjavik but became an independent institution in 1931. The University of Iceland has offered nursing education at the baccalaureate level since 1973, and the University of Akureyri since 1987 (Snæbjörnsdóttir, 1989). Iceland was the first Nordic country to offer nursing education at an academic level (Laiho, 2010). Since the closure of the Icelandic School of Nursing in 1986, the entry level into professional nursing practice has solely been at the baccalaureate level. Education at the Master's level has been available from both universities for the past thirteen years, and the University of Iceland has been offering a three year PhD program for nurses for a few years. Many nurses also go abroad to seek further education at the doctoral level, mostly in Scandinavian countries and Great Britain, although currently many seek further education in North America. Nurse specialty education programs, such as nurse anesthetist and perioperative nursing, are 
being offered at the University of Iceland in two stages, either as a diploma without a master's degree or by taking additional courses and finish with a master's degree.

A majority of Icelandic nurses, practicing in Iceland (91\%), are members of the Icelandic Nurses Association [INA] (A. Finnbogadóttir, personal communication, October 4, 2011). The INA is a professional organization and labor union for nurses. It has international affiliations with a number of nursing organizations, like the Northern NursesFederation (SSN), the European Federation of Nurses (EFN), the International Council of Nurses (ICN), the Workgroup of European Nurse Researchers (WENR) and the European Forum of National Nursing and Midwifery Associations (EFNNMA) (Icelandic Nurses Association [INA], 2011).

According to the Health Service Act No. 40 of 2007, health care organizations in Iceland shall have both a medical and a nursing director who are accountable, in their respective professional fields, to the chief executive, for the health services provided at the organization. Furthermore, a three person executive board shall operate within each organization. The chief executive and both the director of nursing services and the director of medical services are board members. The chief executive is directly accountable to the Ministry of Welfare (Ministry of Welfare, 2007).

Nurse managers provide the link between staff nurses and the director of nursing services and need to balance both organizational and professional goals (Anthony et al., 2005). Nurse managers in Iceland are accountable for the nursing services provided under their authority to the director of nursing care or to their immediate superior according to the health care facility's organization chart (Ministry of Welfare, 2007). Hence, nurse administrators in Iceland are accountable by law for all professional nursing services provided in the country.

Nurses play a critical role in providing continuous and safe patient care within a complex environment involving multidisciplinary health professionals in various health care settings. Nurses and ancillary staff constitute more than half of all health care 
providers. A majority of practicing nurses (82\%) work in the public sector (Icelandic Nurses Association [INA], 2011). The total number of practicing nurses in Iceland in 2009 was 2,686, and midwives were 250. Licensed practical nurses were 2,185 (Directorate of Health, 2010). The number of practicing nurses (and midwives) was 9.2 per 1000 population which is a $4.2 \%$ decrease from the year 2007, when there were 9.6 nurses (and midwives) per 1000 population. The average number of practicing nurses within Organization for Economic Co-Operation and Development [OECD] countries in 2008 was 9.8 nurses per 1000 population [OECD, 2010b].

The decrease in total number of nurses per 1000 population is of concern. According to a recent report from the Icelandic Nurses' Association (2007), it is estimated that the need for nurses in Iceland will increase by 2.2\% every year for the next ten years. Moreover, due to the economic crisis that hit the country in fall of 2008, hospitals and health care centers have been suffering major financial cuts. Furthermore, due to reorganization of the health care system, hospitals have been merged, units downsized, and a number of health care professionals have been laid off, including nurses. This raises concern in relation to staff morale, staffing, workload and job stress, which are empirically linked to patient safety and quality of nursing care (Kramer \& Schmalenberg, 2008). It is the Nurse manager's responsibility to create a positive work environment to enhance better patient, nurse, and institutional outcomes, yet this becomes complicated when there are severe fiscal constraints.

Information sharing within and across organizations is an essential function to achieve desired health outcomes. Successful management of data, information, and knowledge is fundamental to support managerial and clinical decisions and to provide competitive advantage in the modern health care environment. Information sharing requires the adoption of standardized terminologies and data structures. A widespread adoption of health information standards and a national framework to capture, store, and 
retrieve information in formats that are readily accessible, timely, understandable and can be shared across health systems is urgently needed (Hovenga et al., 2005).

\section{National Health Information Infrastructure (NHII)}

A national health information infrastructure (NHII) has been defined as a network which links electronic health data across different information systems, health care settings and geographic locations (Westra, Delaney, Konicek, \& Keenan, 2008) and which supports all facets of health care and public health (Bakken, Cimino \& Hripcsak, 2004), including secure access to health-related information by consumers (Westra et al., 2008). The purpose of the NHII is health knowledge management and delivery. The ultimate goal is appropriate information and knowledge sharing available to professionals, policy makers, researchers, patients, and consumers whenever needed to make the best possible health-related decisions to improve the quality of health and health care (National Committee on Vital and Health Statistics [NCVHS], 2001) around the world.

\section{The United States}

Several breakthrough efforts have helped to push for a NHII in the U.S. In 1991 Congress passed the High Performance Computing Act to promote work on technical infrastructure (NCVHS, 2001), and the Institute of Medicine [IOM, 1991] called for a national infrastructure for the development and implementation of an electronic health record [EHR] to improve the quality of health care delivery. Two years later, the President's Information Infrastructure Initiative included a Health Information and Applications Work Group, which published a breakthrough report in 1995, Making a Powerful Connection: The Health of the Public and the National Information Infrastructure. In 1998, the U.S. National Committee on Vital and Health Statistics [NCVHS], which serves as a public advisory body for the Secretary of Health and Human Services [HHS] on national health information policy, created a Workgroup on 
the NHII. The Next Generation Internet Act was passed the same year, followed by the Networking and Information Technology Research and Development Act of 2000 (NCVHS, 2001).

The IOM reports, To Err is Human Building a Safer Health System in 1999 and “Crossing the Quality Chasm” in 2001 further highlighted the need for a NHII. Both reports identified serious and extensive quality problems in the American health care system, primarily due to a lack of appropriate environment, processes and capabilities in the system to ensure safe, effective, and timely services. They recommended the use of information technology [IT] as a key to achieving safety goals. An earlier report by the IOM (1991) had recommended a widespread use of an electronic health record [EMR] to increase quality in health care.

Terrorist attacks and large-scale infectious disease emergencies further underline the need for an information infrastructure to respond in a quick and timely manner to major health-related threats. The Public Health Information Network [PHIN] sponsored by the CDC, was funded in 2004, with the aim to advance and coordinate public health information systems and to establish a consistent national network of systems preparedness (Loonsk, McGarvey, Conn, \& Johnson, 2006).

In 2004 President Bush launched an electronic health record [EHR] initiative with the establishment of the Office of the National Coordinator for Health Information Technology [ONC]. The goal was national implementation of electronic health records by the year 2014. In 2007, ONC commissioned the National Health Information Network Trial Implementations with the aim to develop content specifications to promote interoperability of health data. This included the development of a "summary patient record” for interoperable sharing of patient data (Kuperman, Blair, Frack, Devaraj, \& Low, 2010).

President Obama supported the deadline initiated by Bush, and in 2009 Congress passed a landmark legislation of the American Recovery and Reinvestment Act [ARRA] 
and its key Health Information Technology Act [HITECH]. The legislation allocates funds and incentives to health care providers who implement certified EHRs in a "meaningful way". The meaningful use criteria focuses on electronic capture of health information, the use of clinical decision support tools and clinical quality measures reporting to improve safety, efficiency, and quality of health care services in the US (Murphy, 2010).

\section{International Activities}

There are international efforts underway to establish NHIIs. The member states of the European Community [EC] have been cooperating on eHealth initiatives for several years. The concept of eHealth embraces all use of information and communication technologies in health care to meet the needs of patients, health care providers, citizens and policy makers. The Commission of the European Communities has issued several recommendations towards the common goal to contribute to maintaining sustainable health care for all. These were to improve patient safety and reduce numbers of errors in health care delivery; to support secure authorized access to relevant patient health information, anytime, anywhere; and to support mobile citizens to seek high quality health care throughout Europe. The eHealth Action Plan in 2004 was the first formal commitment initiated by the Commission followed by the i2010 policy framework for the information society and media (EC, 2008).

In 2008 the Commission presented three documents with recommendations on eHealth initiatives: application of patients' rights in cross-border health care, telemedicine, and crossborder interoperability of electronic health record systems. The recommendations provide guidance for interoperability of electronic health records, summary patient records, and emergency data sets. Interoperability has been defined as the ability of information and communication technology systems and the processes they support to exchange data and share information and knowledge (EC, 2008). 
Furthermore, under the auspices of the Commission, a three year project, Smart open services for European patients (epSOS) was initiated in 2008 to establish a European patient summary and facilitate prescribing across national borders. The overall goal is European eHealth interoperability by the end of 2015 (EC, 2008). The latest policy framework succeeding the 2010 is the Digital Agenda, where information and communication technology are key implementation targets (EC, 2010).

\section{Iceland}

The Icelandic Government has long recognized the need for a NHII and published several policies toward the aims for Iceland to become a leading nation in the utilization of information technology and electronic services to improve quality of life for all Icelanders. The latest policy on the information society Iceland the e-Nation spans the years 2008-2012, and takes note of the European Commission's policy framework i2010. The $e$-Nation policy statement emphasizes increased use of information technology for the purposes of improving public services and efficiency. Standardization, coordination, security and cooperation are key factors within an environment which fosters sharing and reuse of information for multiple purposes. The e-citizen shall have access to all personal information stored in official data bases, accessible from one online public portal, www.island.is, which calls for national implementation of electronic identification [eIDs] (Prime Minister's Office, 2008). Currently all new bank cards in Iceland have built in eIDs for on line identification and electronic signature.

In January of 2010 the Ministry of Welfare was established by merger of the Ministry of Health and the Ministry of Social Affairs. The Ministry of Welfare is responsible for administration and policy-making for health care, social affairs and social security in the country. It is also responsible for IT policy in health care and coordinates and finances projects related to IT implementation. Since 1997 the eHealth strategic plan of the Ministry of Welfare (former Ministry of Health) toward a healthier nation has supported patient-based 
seamless health care where patient data and information are shared among health care professionals within and across health care institutions and private practices. The strategy embraces implementation of a lifelong electronic health record for every citizen, accessible to authorized professionals at point of care.

In 2009 the Icelandic Congress passed the Health Records Act no.55/2009, a landmark document which provided the first legal framework for access, sharing, and connections of electronic health record [EHR] systems among health care providers. The purpose of the act was to develop rules on health records with the aim of providing the best possible health care at any time, while also safeguarding privacy and confidentiality of health data. The law allows different organizations to share the same EHR database via connected and secure network; however, the Minister of Welfare needs to acknowledge that beforehand. All information necessary with respect to the patient's treatment shall be systematically entered immediately or no longer than 24 hours from the time when the data were collected. All health data is viewed as sensitive information. Health care professionals who are involved in the treatment of a patient have authorized access to the patient's electronic health record anytime, anywhere. However, the patient can prohibit such access to healthcare professionals if he/she perceives the information to be especially sensitive health data. Nevertheless, if deemed necessary for the security of health care professionals, exceptions may be made from such access restrictions. Furthermore, the patient shall be informed that refusal to authorize necessary access to the health record may under some circumstances be equivalent to refusal of treatment. The law also addressed the patients' right to access own health record and the right to be informed on who accessed their health record, when, and why. Moreover, privacy and confidentiality are emphasized, with penalties if breached. The law also gives the first legal framework for secondary health data uses for quality improvement and research (Ministry of Welfare, 2009).

Several eHealth projects have been launched under the auspices of and funded by the former Ministry of Health, and in close partnership with Landspitalinn, the University Hospital 
in Reykjavik, and primary health care clinics. All primary health care institutions have been using the same EHR journal system for the past decade. In 2010 an admission, discharge, transfer [ADT] hospital system was implemented in every hospital in Iceland. In 2011 a fully integrated nursing documentation component was added to the system. Hence, nursing documentation of clinical patient care can be captured within an electronic health record system both in hospitals and primary health care in the country. Having the same system makes it less complicated to share information across institutions.

The country is divided into seven health districts, each with one or more hospitals and primary health care facilities. Currently, most hospitals and primary health care clinics within the same health district share a connected EHR journal system, excluding the Reykjavik area. Moreover, laboratory results in biochemistry and hematology for most of the country are shared through a connected nationwide network hosted at Landspitali, the University Hospital in Reykjavik. This is of great importance to patient safety, efficiency and costs of care. Having access to recent laboratory test results reduces duplication, can accelerate diagnosis and start of appropriate treatment, can decrease the number of needle sticks, possibly reduce the length of stay at hospital or perhaps lead to earlier admittance to the hospital. Private practices and nursing homes are yet to be connected to the laboratory network, but plans are in place to have them connected by 2012 .

A great majority of physicians have access to e-Prescriptions (very few private clinics have yet to gain access), and all pharmacies in Iceland are connected to the e-Prescriptions network. Currently, over $60 \%$ of all prescriptions in the country are electronic.

All immunization information is shared across health care institutions in real time. When a person receives an immunization in one location, another location can see the data input. Furthermore, citizens will have electronic access to their own immunization information by the end of 2011 through a shared government portal, island.is.

All Icelanders receive a unique personal identification number at birth allocated from the Icelandic Register. This used to be a paper-based application form which took days to 
apply for. This caused problems at hospital birth units as a dummy ID had to be created for newborns for data input in the EHR, resulting in missing files as the newborn had more than one electronic health record, and with different ID numbers. This process has become electronic since 2009 and is integrated into the hospital EHR system for immediate ID allocation at birth. Moreover, in 2009, real time surveillance data collection on Swine flu was established among health care providers and the Directorate of Health. This project has been expanded to include more communicable diseases reported in real time, thus offering more robust, targeted quick-response interpretation capability.

Steady progress has been made toward increased use of information and communication technologies in health care in Iceland and toward the establishment of a NHII. The current most important projects include, but are not limited to, central access to medication profiles and known allergies, both for health care professionals and patients, connecting EHR's among health districts to a common network, strategies to improve data reporting for benchmarking and, and integration of patient adverse events reporting into the EHR. Another important project is to link X-ray images and results into one common network (currently there are five) and integrate them within the EHR journal system.

\section{Electronic Health Record (EHR)}

An EHR has been defined as “ an electronic patient record that resides in a system specifically designed to support users by providing accessibility to complete and accurate data, alerts, reminders, clinical decision support systems, links to medical knowledge, and other aids” (IOM, 1991, p. 11). Furthermore, "automation of clinical, financial, and administrative transactions is essential to improve quality, prevent errors, and enhance consumer confidence in the health system” (IOM, 2001, p. 16).

The key functionalities of an EHR information system include: "1) health information and data, 2) results management, 3) order entry management, 4) decision support, 5) electronic communication and connectivity, 6) patient support, 7) 
administrative processes, and 8) reporting and population health management” (p. 5). Health information systems must support: 1) longitudinal collection of individual's electronic health information, 2) immediate electronic access to health information by authorized users, 3) knowledge and decision support, and 4) support of efficient processes for the delivery of health care (Committee on Data Standards for Patient Safety, 2003).

The development of a NHII requires interoperability among the various electronic health information systems (Hammond 2005; Kuperman et al., 2010) to communicate, manage, report, and share data, information, and knowledge (Westra et al., 2008) to support the quality of health care delivery. Interoperability requires health care data standards to be defined, agreed upon and implemented (Hammond, 2005).

\section{Health Care Data Standards}

Health care data standards are essential to the establishment of interoperability (Hammond 2005; Kuperman et al., 2010). Among the most important health care data standards for nursing practice are content, messaging, and confidentiality and security standards. Content standards define the content and structure of terms and concepts for use in practice; for example diagnoses, interventions, and outcomes. Standardized terminologies and minimum data sets are content standards that facilitate the integration of nursing data into the electronic health record. Health care data message standards support interoperability among different health information systems (Bakken, 2006; Westra et al., 2008). Message interchange standards ensure that the information structure is maintained between different information systems (Hammond, Bailey, Boucher, Spohr, \& Whitaker, 2010). Confidentiality and security standards are critical to protect patient information within an electronic health record.

Health care data standards are developed through the work of independent and voluntary organizations. The American National Standards Institute [ANSI] is a non-profit 
organization that coordinates the development of voluntary national standards in the U.S. but does not develop standards itself. The Health Care Informatics Standards Board is responsible for the coordination of health care data standards. The ANSI represents the United States in collaboration with international standards developers, such as the International Standards Organization [ISO] (Murphy, 2003). The ISO is one of the world's largest standards developers. The ISO's Technical Committee 215 is responsible for standardization in the field of health care information and communication technology. Their goal is to achieve compatibility and interoperability between independent systems, to ensure data compatibility for statistical comparative purposes, and to reduce duplication and redundancies (ISO, 2007). Among work being done by the ISO is a standard for an EHR architecture [EHRA] that supports the use, sharing, and exchange of an EHR across different health sectors and different countries [ISO TS 18308:2004]. Another standards development organization, Health Level 7 [HL-7] is an ANSI accredited not-for-profit organization. The HL-7 standard focuses on the exchange, management, and integration of electronic health care information (HL-7, 2007). LOINC develops universal codes to identify laboratory and other clinical observations (LOINC, 2010®). The first three elements of the NMMDS have recently been updated and mapped to LOINC.

In Europe, the European Standardization of Health Informatics' [CEN] technical committee 251 is responsible for voluntary health information data standards, such as vocabulary standards, imaging standards, privacy, security, and confidentiality standards (CEN, 2007). The CEN is funded by multiple national member fees and the European Union (Hammond, 2005). The Digital Imaging and Communications in Medicine [DICOM] group developed a standard to share and view medical images, and the International Health Terminology Standards Developing Organization [IHTSDO] developed and promotes the use of SNOMED-CT, a comprehensive clinical terminology. In the United States the Health Insurance Portability and Accountability Act [HIPAA] is a key federal initiative in place to ensure privacy and confidentiality of patient information within an electronic health record 
[EHR]. Coordination and a common policy framework on health care data standards are needed at a national and international level for the establishment of an interoperable NHII.

\section{Standardized Nursing Languages}

Nurses play a significant role in standards development, both at a local, national and international level. The American Nurses Association [ANA] led nursing activities toward data standardization. In 1989 the ANA established the Steering Committee on Databases Supporting Clinical Nursing Practice, now known as the Committee for Nursing Practice Information Infrastructure [CNPII] (Westra et al., 2008), with the purpose to influence national and international policy related to health information (ANA, 2010). The ANA established the Nursing Information and Data Set Evaluation Center [NIDSEC] in 1996 to develop and disseminate standards to evaluate information systems that support documentation of nursing practice within electronic health records. The standards are based on the model of the Joint Commission on Accreditation of Healthcare Organizations [The Joint Commission] and are used to evaluate four dimensions of nursing data sets. They include nomenclature, clinical content, clinical data repository (storage and retrieval of data), and general systems characteristics (ANA/NIDSEC, 2003).

In the past decade, the need for standardized vocabularies to identify, name, classify, and evaluate nursing practice has been well described (Bakken, Cashen, Mendonca, O’Brien, \& Zieniewicz, 2000; Clark, Craft-Rosenberg, \& Delaney, 2000; Coenen, Marin, Park, \& Bakken, 2001; Harris, Graves, Solbrig, Elkin, \& Chute, 2000; Henry, Warren, Lange, \& Button, 1998; Keenan, Stocker, Barkauskas, Treder, \& Heath, 2003; Keenan et al., 2003; McCormick \& Jones, 1998). Standardized nursing languages and reference terminologies for processing and managing nursing data and information are essential for interoperable electronic health records and seamless patient care. 
Currently, the ANA recognizes ten terminologies and two data sets that support the documentation of nursing care delivery within clinical information systems [CIS]. There are eight interface terminologies, two reference terminologies, and two minimum data sets: the North American Nursing Diagnosis Association [NANDA], the Nursing Interventions Classification [NIC], the Clinical Care Classification [CCC], the Omaha System, the Nursing Outcomes Classification [NOC], the PeriOperative Nursing Data Set [PNDS], the ABC Codes, SNOMED CT, the International Classification for Nursing Practice [ICNP ${ }^{\circledR}$ ], the Logical Observation Identifiers Names and Codes [LOINC®] the Nursing Minimum Data Set [NMDS], and the Nursing Management Minimum Data Set [NMMDS] (ANA/NIDSEC, 2010). With the use of recognized nursing languages in EHR systems, it should be possible to describe, explain, and predict nursing care anywhere (Lunney, Delaney, Duffy, Moorhead, \& Welton, 2005).

Since 1999, the organizing body for nursing terminology standards has been the Nursing Terminology Summit, a series of invitational conferences and ongoing collaborations related to methods of developing health care terminologies and standards. Their mission has been to promote and coordinate the development, evaluation, and use of reference terminology for nursing practice, and integration with health care applications. The first conference focused mainly on terminology standards in the U.S., but the effort then progressed into the development of global terminology standards with international participation (Ozbolt, 2003; Ozbolt \& Saba, 2008; Westra et al., 2008). A collaborative international effort where Summit participants partnered with the Nursing Special Interest Group [NI-SIG] of the International Medical Informatics Association [IMIA], and the International Standards Organization [ISO] led by the International Council of Nurses [ICN] resulted in an agreed upon international nursing reference terminology standard (ISO 18104:2003) for nursing diagnoses and interventions.

In 2007 the International Health Terminology Standards Development Organization [IHTSDO] acquired ownership of SNOMED CT and thus responsibilities 
for maintaining SNOMED CT as an international reference terminology standard. The Nursing Terminology Summit and the ISO work provided significant input to ensure representation of nursing concepts within SNOMED CT, an important contribution to integrating nursing data, information, and knowledge within international terminologies. Furthermore, the Nursing Terminology Summit contributed to nursing participation and leadership roles in other major standards developing initiatives, including the Health Information Technology Standards Panel [HITSP], the Certification Commission for Healthcare Information Technology [CCHIT], Health Level 7 International [HL7], and Logical Object Names, Identifiers, and Codes [LOINC]. The HITSP evaluates and recommends which standards the federal government should implement for interoperability of health information transactions, and the CCHIT certifies hardware and software that adhere to adopted standards (Ozbolt \& Saba, 2008). Health Level 7 International develops standards for exchanging and sharing of electronic health information (HL7, 2010), and LOINC develops universal codes to identify laboratory and other clinical observations (LOINC, 2010®). The first three elements of the NMMDS have recently been updated and mapped to LOINC. The LOINC has specifically been used to incorporate survey instruments, and the LOINC data structures are similar to the NMMDS. This is of great importance as the LOINC provides a national and international structure for the transmission of health care data in EHRs for use and reuse of data within and across information systems and health care organizations (Westra et al., 2010). Moreover, the LOINC is publicly available at no cost, and some of the LOINC elements are incorporated into the EHR journal system Saga in Iceland.

Since 2008, the attention of the Nursing Terminology Summit Conference has changed from developing standardized terminologies to reviewing and implementing standards (Ozbolt \& Saba, 2008) in order to demonstrate their usefulness in practice to support nursing documentation, interoperability and reuse of health care data (Westra et al., 2008). 
Nurses worldwide continue to make their steadfast contributions toward a NHII by harnessing technology to improve safety and quality of health care delivery through nursing informatics. Nursing informatics is dedicated to developing and implementing data standards to facilitate electronic data collection, information and knowledge sharing within all of health care.

\section{Nursing Informatics}

The nursing informatics movement started in the early 1970s and has since advanced at both national and international levels (Saba, 2001). The word informatics has its origins in the French word informatique, which includes all features of the computer milieu (Ball, Hannah, \& Douglas, 2000; Saba, 2001). The term medical informatics was widely used over 25 years ago as an overarching term to describe any informatics efforts within health care (Shortliffe \& Blois, 2001; Staggers \& Thompson, 2002). However, that term was considered to be too centered on physicians, and thus the term health informatics became popular (Shortliffe \& Blois, 2001). Within the nursing profession, nursing informatics is considered a distinct nursing specialty. Gassert (2000) described nursing informatics as a specialty within nursing and health informatics, where health informatics is the broader category of informatics within which medical, dental, and consumer informatics reside. A definition is essential to determine a specialty (Staggers \& Thompson, 2002).

In 1992 the American Nurses Association [ANA] recognized nursing informatics as a specialty within nursing practice. The ANA (2008) defined nursing informatics [NI] as a specialty that integrates nursing, computer, and information science to manage and communicate data, information, knowledge, and wisdom of nursing practice. Nurses educated in informatics use their expertise in information processes, structures, and technologies to support improved patient outcomes. Knowledge development in nursing 
was led by Werley (1987), who identified the need and initiated the development of the Nursing Minimum Data Set [NMDS] in the United States (Graves \& Corcoran, 1989).

\section{$\underline{\text { Minimum Data Sets }}$}

The purpose of minimum data sets is to support comparability of data and information across settings of care delivery by using standard data elements with uniform definitions (Delaney et al., 1994; Teslow \& Wilde, 2001). Numerous health care databases that collect standardized elements have been developed, including the Uniform Hospital Discharge Data Set [UHDDS], Uniform Ambulatory Care Data Set [UACDS], the Minimum Data Set for Long Term Care [MDS], the Minimum Data Set-Post Acute Care [MDS-PAC], and the Mental Health Minimum Data Set (Charters, 2003). The Uniform Hospital Discharge Data Set [UHDDS] identifies data that must be collected on all hospitalized patients on Medicare. However, it does not include nursing data; and hence, does not provide data to determine the effectiveness of nursing care (Coenen \& Schoneman, 1995; Ryan \& Delaney, 1995; Werley et al., 1991).

\section{Nursing Minimum Data Sets [NMDS]}

The development of the Nursing Minimum Data Set [NMDS] in 1985 was the first attempt made to standardize the collection of essential core nursing data, comparable across clinical settings and geographical areas. The NMDS was derived from the concept of a Uniform Minimum Health Data Set, which by definition, is the collection of minimum set of standardized elements concerning a specific dimension of the health care system and that meets the needs of multiple data users (Werley et al., 1991).

The NMDS is defined, as "a minimum set of items of information with uniform definitions and categories concerning the specific dimension of nursing which meets the information needs of multiple data users in the health care system” (Werley et al., 1991, p. 422). The data set includes sixteen elements that are grouped into three categories; Nursing Care, Client Demographics, and Service elements. Ten of the elements are also 
components of the UHDDS and thus articulate the two minimum data sets. The Nursing Care category of the NMDS includes nursing diagnoses, nursing interventions, nursing outcomes and intensity of nursing care (Werley et al., 1991). The NMDS collects essential data needed to support clinical decision-making in nursing (Delaney, 1996) and provides the framework for basic data collection for all patients receiving nursing care (Coenen, Weis, Schank, \& Matheus, 1999; Delaney, 1996).

Numerous other nursing minimum data sets have also been developed in other countries. Those include, but are not limited to the Nursing Minimum Data Set for the Netherlands [NMDSN] (Goossen et al., 1998), the Thai Nursing Minimum Data Set [TNMDS] (Volrathongchai, Delaney, \& Phuphaibul, 2003), the Belgian Nursing Minimum Data Set [B-NMDS] (Sermeus et al, 2005), the Australian Minimum Data Set (Butler et al., 2006), the Canadian Minimum Data Set (Anderson \& Hannah, 1993), the Irish NMDS (Butler et al., 2006), and the Icelandic Nursing Minimum Data Set.

The Icelandic Nursing Minimum Data Set is a part of the Icelandic Hospital Discharge Data Set which includes, but is not limited to, patient's demographic elements, such as ID, date of birth, sex, marital status, municipality, and nationality but does not include race or ethnicity. The service elements are the same as for the American NMDS, except for expected payer for the bill. The nursing care elements only include nursing diagnoses and nursing interventions. Hence, the Icelandic NMDS does not support the collection of key nursing data to describe nursing sensitive patient outcomes or intensity of nursing care. The nursing data are not yet disseminated systematically on a national basis.

Although internationally nurse leaders have acknowledged the importance of systematic collection of core nursing data (Clark \& Lang, 1992; Huber, 2006; Maas \& Delaney, 2004; Sermeus, Delesie, Van den Heede, Diya, \& Lesaffre, 2008; Westra et al., 2010), Belgium is still the only country with nationwide implementation of a NMDS (Sermeus et al., 2005; Sermeus et al., 2008; Van den Heede, Michiels, Thonon, \& 
Sermeus, 2009). Possible reasons for slow progress on the implementation of nursing minimum data sets include lack of resources to collect, store, and analyze nursing data (i.e. if hospital information systems do not support the NMDS elements), lack of knowledge about NMDS, and a lack of understanding the importance nursing information has on health policy decisions (Karpiuk, Delaney, \& Ryan, 1997). Currently, there are collaborative international efforts underway focused on the development of an international Nursing Minimum Data Set [i-NMDS] under the auspices of the International Council of Nurses [ICN] and the International Medical Informatics Association Nursing Informatics Special Interest Group [IMIA NI-SIG ] (Goossen, Delaney, Hovenga, Marin, \& Saba, 2005).

Several nursing specialty data sets have also been developed. Those include, but are not limited to, the Perioperative Nursing Data Set [PNDS] for operating room nurses (AORN, 2000; Beyea, 2000), the Nursing Minimum Data Set for School Nursing [NDSSN] (Fahrenkrug, 2003), the Community Nursing Minimum Data Set Australian [CNMDSA] for use in public health (Goossen et al., 1998), the Midwifery Nursing Health Data Set (Rukanuddin, 2006), and the Nursing Management Minimum Data Set [NMMDS] for nurse administrators (Delaney \& Huber, 1996; Huber et al., 1992; Huber, et al., 1997). The Nursing Minimum Data Set [NMDS] supports the collection of clinical information but does not meet the requirements of nurse administrators for data collection to support managerial decision-making. The NMMDS was developed to address the information needed for nurse administrators and managers regarding clinical and financial environments of the delivery of nursing care, such as information on staffing, staffing profile, patient mix, care delivery models, environmental turbulence, and budgeting (Delaney \& Huber, 1996).

The potential for using the NMDS is vast. Implications for practice include complete and more accurate documentation of nursing care. Implications for research areas include nursing practice description, outcomes research, quality monitoring, 
research through links with national databases (Ryan \& Delaney, 1995), and nursing diagnosis, intervention, and outcome linkage studies for quality and effectiveness research (Maas \& Delaney, 2004). Implications for health care policy include access to comparable minimum nursing data to support decisions and enhance quality of nursing care.

Nursing minimum data sets facilitate aggregation of data for comparison within and across health care organizations (Westra et al., 2008). Health care organizations need adequate information infrastructure consistent with demands for a NHII and international imperatives. Given the overwhelming nature and volume of health care data, health care organizations need standardized data sets for internal and external benchmarking. The NMDS and the NMMDS have standardized terms and definitions and support the documentation of nursing care within automated Nursing Information Systems [NIS]. Together the two ANA recognized nursing data sets enhance the documentation and management of nursing care and empower nurses with essential data needed for quality monitoring in providing safe, efficient, and cost-effective patient care (Delaney \& Huber, 1996; Huber et al., 1997).

\section{The Nursing Management Minimum Data Set [NMMDS]}

The recommended data set to capture the needs for nurse managers and administrators for complex decision-making is the Nursing Management Minimum Data Set (NMMDS) (Moorhead \& Delaney, 1998; Urden, 1996). In 1989, the co-principal investigators of the NMMDS, Delaney and Huber, formed a research team to identify and develop a framework for essential data needed by nurse administrators to capture the quality and cost of nursing care. In 1992 the National Institute for Nursing Research [NINR], formerly known as the Priority Expert Panel on Nursing Informatics of the National Center for Nursing Research [NCNR] identified the need to build databases of both clinical and management nursing information, highlighting the importance of 
Table 1. The Nursing Management Minimum Data Set Elements

\begin{tabular}{|l|l|l|}
\hline \multicolumn{1}{|c|}{ Environment } & \multicolumn{1}{c|}{$\begin{array}{c}\text { Nursing Care } \\
\text { Resources }\end{array}$} & \multicolumn{1}{c|}{$\begin{array}{c}\text { Financial } \\
\text { Resources }\end{array}$} \\
\hline -Unit/Service unique identifier & $\begin{array}{l}\text {-Management demographic } \\
\text { profile }\end{array}$ & -Payer type \\
\hline $\begin{array}{l}\text {-Type of nursing delivery } \\
\text { unit/service }\end{array}$ & -Staff demographic profile & -Reimbursement \\
\hline -Patient/client population & -Staffing & $\begin{array}{l}\text {-Nursing delivery unit/service } \\
\text { budget }\end{array}$ \\
\hline $\begin{array}{l}\text {-Volume of nursing delivery } \\
\text { unit/service }\end{array}$ & -Satisfaction & -Expenses \\
\hline $\begin{array}{l}\text {-Care delivery structure and } \\
\text { outcomes }\end{array}$ & & \\
\hline $\begin{array}{l}\text {-Patient/client accessibility } \\
\text {-Clinical Decision making } \\
\text { complexity }\end{array}$ & & \\
\hline $\begin{array}{l}\text { - Environmental Complexity } \\
\text {-Nursing delivery/unit/service }\end{array}$ & & \\
\hline $\begin{array}{l}\text {-Autonomy } \\
\text { Soureditation }\end{array}$ & & \\
\hline & & \\
\hline
\end{tabular}

Source: Delaney \& Huber (2005). ANursing Management Minimum Data Set (NMMDS): A report of an invitational conference [monograph].Chicago, IL: American Organization of Nurse Executives [AONE].

analyzing relationships among them (Delaney \& Huber, 1997; Huber \& Delaney, 1998). In 1996, an invitational workshop, co-sponsored by the American Organization of Nurse Executives [AONE], resulted in an agreed upon standardized NMMDS (Delaney \& Huber, 1996; Huber \& Delaney, 1998). The American Nurses Association [ANA] recognized the NMMDS in 1999, thus the NMMDS became the second nursing minimum data set to be recognized in the United States (ANA, 2011). 
By definition the NMMDS is a " research-based management data set that meets the nurse executive's need for a specific nursing management data capture system that will produce accurate, reliable, and useful data for decision-making” (Huber et al., 1997, p. 43). The data set elements have standardized definitions and measurements, and are applicable to all settings of health care delivery (Delaney \& Huber, 1996; Huber \& Delaney, 1998). The 2005 version of the NMMDS includes eighteen elements grouped into three categories, Environment, Nursing Care Resources, and Financial Resources (see Table 1) (Huber \& Delaney, 2005). Recently the first three elements of the NMMDS were updated and mapped to LOINC. The LOINC reference terminology is publicly available at no cost. It has specifically been used to incorporate survey instruments, and the LOINC data structures are similar to the NMMDS. This is of great importance as the LOINC provides a national and international structure for the transmission of health care data in EHRs for use and reuse of data within and across information systems and health care organizations (Westra et al., 2010).

\section{Environment}

Nurse administrators need to constantly monitor and evaluate the environment to ensure safe and quality patient care at every point of service (Heath, Johanson, \& Blake, 2004). The Environment category forms "the context of the care delivery environment that the nurse executive assesses, coordinates, leads, and manages” (Huber et al., 1997, p. 44). The Environment category of the NMMDS includes ten variables that describe the environment of nursing care delivery. They are 1) unit/service unique identifier, 2) type of nursing delivery unit/service, 3) patient/client populations served, 4) volume of nursing delivery, 5) care delivery structure and outcomes, 6) patient/client accessibility, 7) complexity of clinical decision making, 8) complexity of the environment, 9) autonomy, and 10) accreditation of nursing delivery. The unit/service unique identifier is measured by the unique name, identifier, payment, and geographic location of a health 
care organization. Type of nursing delivery unit/service is measured by identification of the type of services that most accurately describe the level of care. The element of patient/client populations served is measured by the characteristics of the patient/client population served by the nursing unit, including specialty, developmental focus, interaction focus, and population focus. Volume of nursing delivery is measured by the amount of services provided and available to the patient, family, group, and community. The care delivery structure and outcomes element is measured by the form of provided care, professional nurse outcomes, and clinical patient outcomes. Patient/client accessibility is measured by time and distance required for the care provider to reach point of care. Complexity of clinical decision-making is measured by the degree of routineness, uniformity, predictability, level of expert knowledge, and computerization involved in care delivery. Complexity of the environment is measured by amount of patient turnover, client mix, and environmental climate. Autonomy is measured by degree of freedom to act, perceived control, and opportunity to participate in organizational decision-making. Finally, accreditation of nursing delivery is measured by accreditation or certification status of the nursing unit service (Delaney \& Huber, 1996; Huber \& Delaney, 2005).

Recent studies indicate that the environment in which health care services are delivered affects patient, nurse, and institutional outcomes (Aiken et al., 2008). Attributes such as nurse-staffing levels, education (Koen Van den Heede et al., 2009), high workloads, case mix, and complexity of care, all have impact on the quality of services provided (Aiken et al., 2008; Hegney, Plank, \& Parker, 2006; Rafferty et al., 2006; Stone et al., 2007; Tourangeau, Cranley, \& Jeffs, 2006). Quality care is promoted within environments that enhance professional nursing practice and provide "healthy" work conditions. 


\section{Healthy Work Environment}

A "healthy work environment" is a "work setting in which the policies, procedures, and systems are designed so that employees are able to meet organizational objectives and achieve personal satisfaction in their work” (Disch, 2000, p. 75). Furthermore, healthy work environments have been aligned with the elements of the Magnet Recognition Program ${ }^{\circledR}$, especially the concepts of autonomy and interdisciplinary relationships (Kramer, Maguire, \& Brewer, 2011; Lewis \& Malecha, 2011). The NMMDS includes variables to measure both autonomy and interdisciplinary relationships.

Patient safety problems have been a prominent concern and a global health policy issue (Koshy, 2005; Le Duff, Daniel, Kamendjé, Beux, \& Duvauferrier, 2005; Tournageou et al., 2006) for several years. In 1998 the World Health Organization highlighted the need to promote safe and healthy work environments in relation to reducing stress in the workplace. In 1999 the Institute of Medicine [IOM] released a landmark report on medical errors and unsafe health care delivery. The IOM noted that thousands of patients die due to medical errors every year, and a large number of patients suffer due to adverse events or preventable patient injuries. In addition to the harm adverse events cause to patients and their families, they are high in costs for health care organizations and society, with estimated costs of several billion dollars annually. The actual number of adverse events occurring in hospitals is considered underreported (Bates et al., 2003).

The American Organization of Nurse Executives (AONE) (2004) identified nine elements which are believed to provide the basis for a healthy practice environment. They are: 1) collaborative practice culture, 2) communication rich culture, 3) a culture of accountability, 4) the presence of adequate numbers of qualified nurses, 5) the presence of expert, competent, credible, and visible leadership, 6) shared decision-making at all levels, 7) the encouragement of professional practice and continued growth/development, 
8) recognition of the value of nursing's contribution, and 9) recognition by nurses for their meaningful contribution to practice. The NMMDS includes variables to measure culture, collaboration, autonomy, staffing and education, satisfaction with leadership, autonomy, staff quality development, and recognition by nurses for their meaningful contribution to practice.

Aiken and colleagues (2008) found in their research that hospitals which supported healthy work environments had better nurse and patient outcomes. They randomly surveyed over ten thousand nurses in 168 Pennsylvania hospitals using the practice environment scales of the Nursing Work Index. Discharge data from over 230,000 patients, who underwent common surgical procedures, were analyzed using robust regression models that controlled for 133 variables such as nurse characteristics and patient comorbidity, age, and sex. Nurse outcomes included job satisfaction, burnout, and intent to leave current position. Their results indicated that nurses working in hospitals with poor work environments reported higher burnout levels, less job satisfaction and perceived worse quality of patient care than nurses working in hospitals with healthy work environments. Furthermore, failure to rescue was associated with nurse staffing, nurse education, and care environments, both individually and jointly. The likelihood of patients dying within 30 days of admission was 14\% lower in hospitals fostering healthy work environments. The NMMDS includes variables to measure job satisfaction and intent to leave, staffing and education.

McGillis Hall and colleagues (2008) conducted a quasi-experimental study of 16 Nurse Managers, 1,137 patients, and 296 observations from registered nurses to test interventions to improve practice environments in hospitals. The interventions were designed to improve resource availability on hospital units. Their results indicated that experience and education affected both nurse and patient outcomes. Nurses working on units with higher patient-to-nurse ratios reported higher job stress as did nurses with a baccalaureate degree, nurses on medical units and nurses in teaching hospitals reported 
higher perceptions of quality of care than did nurses on surgical units and in community hospitals. Patients in teaching hospitals also reported higher perceptions of quality care than patients in community hospitals. The NMMDS includes variables to measure staffing, education and complexity of care.

Tourangeau and colleagues (2007) investigated how structures and processes of care affected patient mortality. Their sample included all teaching and community hospitals in Ontario, Canada, a survey of 5980 nurses, and a retrospective review, over a one-year period, of all patients discharged from these hospitals who had one of four diagnoses: acute myocardial infarction, stroke, pneumonia, or septicemia. Analyses included descriptive statistics and regression models. Their findings indicated that hospitals that had higher proportions of RNs and baccalaureate prepared nurses were associated with lower risk adjusted 30-day hospital mortality rates.

Rafferty and colleagues (2006) found similar results in their study of hospital nurse staffing and patient outcomes in hospitals in the United Kingdom. They used a cross-sectional study design, combining survey data from 3,984 nurses with 118,752 surgical patient discharge data from 30 hospitals. Data analysis included descriptive statistics and logistic regression models with risk adjustments, to estimate the effects of nurse staffing on patient outcomes and nurse reporting of the quality of care and job satisfaction. Their results indicated that hospitals that had higher nurse staffing levels had significantly lower surgical mortality rates and lower rates of nurse burnout and job dissatisfaction, compared to hospitals where each nurse cared for a higher number of patients.

Other studies had different results. A study by Sasichay-Akkadechnunt and colleagues (2003) did not support the relationship between higher education and lower hospital mortality rates, and a study by Van den Heede and colleagues (2009 b) had mixed results. They found that higher nurse staffing in postoperative general hospital units was significantly linked to decreased patient mortality, but nurse staffing in 
postoperative intensive care units was not. This may be due to lack of variation in nurse staffing in intensive care units across hospitals. Furthermore, this highlights the importance of using nursing-unit-level data to study the relationship between nurse staffing and inpatient mortality (Van den Heede et al., 2009 b).

Kane and colleagues (2007) conducted a systematic review and meta-analysis of 28 studies measuring patient outcomes in relation to nurse-to-patient ratio. The study was a part of a larger research project conducted under the auspices of the Agency for Healthcare Research and Quality (AHRQ). They concluded that studies using different designs suggest that there is an association between registered nurse staffing and lower odds of adverse patient events and hospital-related mortality in surgical patients and ICUs. However, the arguments for a causal relationship are mixed. Evidence in the literature suggests that overall organizational commitment to quality care combined with effective nurse retention strategies leads to better patient and nurse outcomes. Job satisfaction and perceptions of autonomy were associated with nurse retention and better patient outcomes. Moreover, nurse-physician collegial relationships and managerial support may lead to better patient outcomes.

Organizational climate is characterized by how staff perceives being a member of the organization. Culture is characterized by internal group control based on beliefs about the survival of the group. It symbolizes customs and values and the way people think and act (Huber, 2000). Organizational structure and leadership style directly influence culture, especially in relation to staff empowerment (Rutherford, Leigh, Monk, \& Murray, 2005). When nurses are empowered with autonomous decision-making, it stimulates thinking, learning, and knowledge networking across the organization (Heath et al., 2004).

According to Kanter $(1977,1993)$ empowering work environments provide employees access to the information, equipment and supplies they need to perform their job in the best possible manner. Moreover, empowering environments provide support 
and feedback, as well as opportunities for professional growth (as cited in Patrick \& Laschinger, 2006). Decentralized decision-making and empowerment influence nurses' autonomy. Research shows that autonomy and empowerment are likely to be associated with job satisfaction (Gelsema et al., 2006; Mrayyan, 2006; O’Brien-Pallas et al., 2006). Autonomous nursing practice presumes expert knowledge, accountability, and shared decision-making (Scott, Sochalski, \& Aiken, 1999). Nurse managers play an important role in promoting autonomous decision-making by staff nurses (Mrayyan, 2006; O’BrienPallas et al., 2006). Nurses who are empowered by the structural characteristics of their organization are likely to perceive autonomy and control over their work. Empowered employees are likely to be more committed to the organization, highly motivated, less burned out, and be more satisfied with their jobs, leading to increased effectiveness and patient satisfaction (Sabiston \& Laschinger, 1995). Increased staff nurses’ participation in decision-making and perceptions of autonomy are likely to influence better patient outcomes and perceived quality of care (Laschinger, Shamian, \& Thomson, 2001; Pallas et al., 2006; Sabiston, \& Laschinger, 1995).

Nurse managers play a critical role in creating healthy work environments. Solutions to improve health care work environments include appropriate staffing levels, standards of safe, effective, collaborative care, computerized data entry, autonomy, recognition or reward system based on results, and a strong, supportive nursing leadership (Heath et al., 2004). Important manager leadership characteristics that have been found to support healthy practice environments include accessibility and visibility, support, recognition, and consultation (Duffield, Roche, Blay, \& Stasa, 2010). Strong positive organizational climate and cultures are built on effective communication, collaborative relationships, and autonomy in decision-making (Heath et al., 2004). The NMMDS measures staffing levels, collaboration, level of computerization, autonomy, skill mix and climate. 


\section{Nursing Care Resources}

The Nursing Care Resources category of the NMMDS includes four essential variables that describe the human resources aspects of nursing care delivery. They are: 1) management demographic profile, 2) staff demographic profile, 3) staffing, and 4) staff satisfaction. The management demographic profile is measured by educational background, credentials, gender, experience, unique provider number, and specific title. The direct care staff demographic profile is measured by education, certification, membership in a professional organization, mean age, number of dependent persons responsible for, number available to provide direct and indirect care, and average years of service. The staffing category is measured by quantity of available staff, turnover, and retention. Finally, satisfaction is measured by percentage of personnel who report positive or negative affects toward their current job (Delaney \& Huber, 1996; Huber \& Delaney, 2005). By collecting data and using the information available from the nursing care resources category, it is possible to plan strategies and interventions to enhance the human component of the delivery system by having ready access to the demographic profile of the nursing care personnel (Huber et al., 1997).

The lack of standardized terms for nursing personnel and staffing data for research purposes has been described in the literature. Moreover, data at the hospital unit level are usually lacking in large administrative databases (Duffield, Diers, Aisbett, \& Roche, 2009). These data are important but often overlooked.

The Institute of Medicine (1996) explored the adequacy of nurse staffing in hospitals and nursing homes in 1996. The committee reported on the unavailability of data on patient outcomes influenced by nursing care. They concluded that high priority should be given to obtaining information about the relationship of nurse staffing levels, skill mix, and the quality of patient care. They recommended the development of standardized variables on nurse staffing data and outcome measures sensitive to nursing interventions and measurable across health care institutions. The NMMDS provides a 
standardized method to collect information on nurse staffing data which can be linked to clinical data bases and nursing sensitive patient outcome measures for research purposes and quality management.

Furthermore, Junttila and colleagues (2007) reported on the lack of data to describe personnel competencies and educational needs; adverse events reporting, like patient falls, medication errors, and skin breakdown; patient satisfaction with care delivery; and staff job satisfaction. The NMMDS measures nursing care personnel characteristics, on a five point high/low Likert scale, and to what extent desirable outcomes, such as maintenance of skin integrity, have been met; and staff job satisfaction. The NMMDS does not measure patient satisfaction with care delivery because it is focused on nurses’ data.

Van den Heede and colleagues (2007) recognized the need for a comprehensive set of variables on staffing and outcomes measures. They used the Delphy approach to survey an international panel of experts from ten countries to assess key variables to be used in research on nurse staffing and patient outcomes. There was more than 85\% agreement among panelists on 32 patient outcomes variables, 29 background variables, and 10 nurse staffing variables. Among the background variables suggested were nurse characteristics such as level of education, experience, and employment status (full-time, part-time, casual) and organizational characteristics such as type of institution and technological sophistication. Organizational process variables included culture, practice environment, support, nursing leadership, nurse-physician relationships, autonomy, professional development, certification, patient turnover, nurse perception of safety culture, turnover and vacancy rates, retention, traveling employees, and job satisfaction.

The NMMDS includes all the recommended background variables on nurse characteristics and all but one of the organizational characteristics. Moreover the NMMDS collects all but 4 of the environment processes (absenteeism, nursing intensity, tasks left undone, and patient nursing care needs). The NMMDS includes 9 of 10 of the 
recommended staffing variables, such as nursing hours per patient day, full time equivalents, total nursing staff, total RN staff, and skill mix, but not nurse-to-patient ratio. Of the staffing variables, nursing hours per patient day received the highest consensus score.

\section{Staffing}

A review of the literature revealed considerable evidence for an association between nurse staffing in hospitals and patient outcomes across hospitals and in different countries (Clarke \& Aiken, 2006; Hugonnet et al., 2007; Van den Heede et al., 2007). However, results are ambiguous. The mixed results may be due to different levels of measurement (i.e. unit versus hospital), different sources of available data, and different methodology approaches (Patrician et al., 2011; Van den Heede et al., 2009a).

McGillis Hall and colleagues (2004) found that the higher the number of professional nurses providing patient care, the lower the rate of medication errors and wound infections. Other studies have found an association between nurse staffing and mortality rates following common surgical procedures, with significantly higher mortality rates where staffing levels were low ( Rafferty et al., 2006). Rafferty and colleagues reported that if all the patients in their sample had been treated in hospitals with optimum nurse staffing levels, 246 deaths could have been avoided. Years of nurse clinical experience and physician characteristics have also been found to be predictors of mortality for hospitalized patients (Tourangeau et al., 2006).

A recent Belgian study by Van den Heede and colleagues (2009 b) failed to identify a significant relationship between nurse staffing at the hospital level and ten different nursing sensitive patient outcomes, in patient populations comparable to earlier studies conducted in the U.S. (Aiken et al., 2002) and in the U.K. (Rafferty et al., 2007). The outcomes variables in the study included pressure ulcers, deep vein thrombosis, postoperative infections, urinary tract infections, failure to rescue and hospital mortality. 
The study was a cross-sectional design linking data from the Belgian nursing minimum data set and the Belgian hospital discharge data set, from all acute care hospitals in Belgium. Logistic regression models were applied for data analysis. Their results indicated substantial differences in patient outcomes across Belgian hospitals. However, the results did not measure significant differences in patient outcomes in association with either staffing levels or education. They concluded that this did not mean that nurse staffing did not have an impact on nurse sensitive patient outcomes in hospitals in Belgium. Further research would be needed in this area. Furthermore, they concluded that this might be due to the lack of variance in staffing levels across Belgian hospitals because of the strong federal influence in hospital financing. They recommended that this relationship should be studied using staffing data at the hospital unit level.

Another study by Van den Heede and colleagues (2009a) that analyzed data at the hospital unit level using logistic regression models did indicate that higher nurse staffing and educational level, in hospital units in Belgium, was significantly associated with decreased in-hospital patient mortality. The study included data from all cardiac centers in Belgium, with a total of 58 intensive care units, 75 general units, and 9,054 patients.

Patrician and colleagues (2011) studied the relationship between nurse staffing and patient outcomes such as patient falls and medication errors in thirteen military hospitals in the U.S. Analysis included logistic regression models. Their results indicated a strong relationship between total staffing, skill mix and falls with injury. Falls without injury were more likely to happen on night shifts. Similarly, a higher number of RNs was significantly associated with fewer medication errors. The NMMDS includes data elements to measure staffing, education and skill mix, which would facilitate data collection on nursing personnel that can be linked to clinical data bases for research purposes. 


\section{$\underline{\text { Job Satisfaction and Turnover }}$}

Nursing shortage and staff turnover rates represent a major problem for many health care organizations, worldwide, in terms of quality, safety, and cost of patient care. Historically, nursing has had a high turnover rate compared to other professionals of comparable education and gender. The definition of turnover presumes that people leave their job either by voluntary or involuntary (i.e. dismissal, medical disability, or death) reasons (Tai et al., 1998). Turnover creates financial implications for the organization in terms of recruitment and retention costs, including orientation costs, and increased burden on remaining staff (Currie, \& Watterson, 2007). A small international pilot study with participants from Australia, Canada, New Zealand, Scotland, and the U.S.A. in 2006, suggested that the average turnover rate for medical and surgical units was 9.49\%, with a turnover cost of $\$ 21,514$ per nurse. The highest average direct cost occurred through temporary replacements (O’Brien-Pallas et al., 2006). Despite the general lack of information about the staff nurse workforce in Iceland, there is one recent study available. A study assessing the relationship between RNs turnover, workload and sickness absence on medical and surgical inpatient units at Landspitali, University hospital in Iceland reported an average turnover rate for RNs of 10.89\% (Hálfdánardóttir, 2009).

High staff turnover rates have indicated negative impacts on staff cohesiveness and morale and an increased potential for burnout. A study by Rafferty and colleagues (2007) found that nurses working in hospitals with higher nurse staffing levels had significantly lower rates of burnout and job dissatisfaction. The most important aspects of nurses' job satisfaction have been reported to be autonomy, communication and support from supervisor and peers, feedback, recognition for outstanding performance, and monetary awards (Gelsema et al., 2006), as well as teamwork and the prospect of career advancement (Hegeney et al., 2006). 
Landspitali, the University Hospital in Reykjavik Iceland (2010), surveyed their staff recently to examine staff perceptions about the quality of the work environment, including job satisfaction. Approximately $60 \%$ of the entire staff responded. Of respondents, over $50 \%$ of staff nurses and $40 \%$ of nurse managers reported high or very high levels of work load, and almost $60 \%$ of both staff nurses and nurse managers reported either high or very high levels of work-related stress. However, a great majority of both staff nurses (>80\%) and nurse managers (100\%) reported that they either "agreed" or "strongly agreed” to being generally satisfied in their job. Only $10 \%$ of staff nurses “disagreed” or "strongly disagreed, while 30\% of physicians “disagreed" or “strongly disagreed”. Staff nurses and nurse managers also responded highly positively on nurturing culture, while a great majority of physicians (60\%) reported negatively on culture in general. However, when responding to nurturing culture within their own hospital unit, physicians also reported highly positively about nurturing culture. When asked about intent to leave within the next two years, all nurse managers intended to stay, and only approximately $4 \%$ of nurses intended to leave. Data on satisfaction with management and administration were not reported.

A pilot study using the NMMDS-ICE on four pediatric units, at Landspitali the University Hospital in Reykjavik and Akureyri Hospital, showed similar results. Both staff nurses and nurse managers on those units either "agreed” or "strongly agreed” to being satisfied with their job and rarely think of quitting. Only $2 \%$ of staff nurses “disagreed" to being satisfied with their job, and 18\% did think about quitting their job. There were $24 \%$ of staff nurses who were not satisfied with nursing management; $42 \%$ were dissatisfied with nursing administration, $10 \%$ were not satisfied with physician interaction, $2 \%$ were dissatisfied with interaction with other health care team members, and $4 \%$ were not satisfied with own level of autonomy. None of the nurse managers were dissatisfied with either nursing administration or interactions with physicians or other health care personnel (Thorlacius, 2011). 
Another study also conducted at Landspitali, the University Hospital in Reykjavik found that job satisfaction, emotional exhaustion, and nurse-rated quality of care were independently associated with perceived support from unit-level managers, adequate staffing levels, and nurse-physician relationships (Gunnarsdóttir et al., 2009). High levels of work stress, low morale, and burnout have consistently been linked to job dissatisfaction and intention to leave (Hegney, et al., 2006; Rafferty et al., 2007). Causes of stress are associated with heavy workload, lack of autonomy, poor communication, low recognition, and having insufficient resources to work with (Sveinsdóttir, Biering, \& Ramel, 2006).

Several studies have reported on the importance of nurse-physician relationships (Aiken \& Patrician, 2000; Tourangeau et al., 2006). Gunnarsdóttir and colleagues (2009) found relationships with physicians to be an important predictor of Icelandic nurses' perceived quality of patient care. A study by Kramer and colleagues (2011) on healthy work environments experienced by nurses working in Magnet hospitals further highlights the importance of a collaborative nurse-physician relationship.

An important factor in improving patient safety is to strengthen organizational structure and process dimensions that promote desirable patient outcomes (Tourangeau et al., 2007). The study of patient outcomes in nursing is not new, as Nightingale recognized patient outcomes during the Crimean War by the use of mortality and morbidity statistics. Outcomes management and quality improvement require a standardized way to collect data for analysis and knowledge management. Comprehensive standardized nursing languages, such as the NANDA, NIC, and NOC, incorporated into clinical information systems are essential to evaluate the effectiveness of health care delivery (Lunney et al., 2005). By extension, standardized management data sets incorporated into clinical information systems are essential for evidence-based management practice.

Research indicates that the size and skill mix of nursing teams are significant factors for planning and management of safe and efficient health care services (Gerdtz \& 
Nelson, 2007). Strategies aimed at maximizing the proportion of registered nurses in nursing staff, creating a culture of effective communication, and strong collaborative relationships are essential to promote quality care (Tourangeau et al., 2007).

It is crucial that nurse administrators have easy and timely access to relevant information to optimize utilization of resources and promote the delivery of safe, quality patient care. The NMMDS has standardized terms and provides a framework to collect management data on key factors that influence the quality of health care delivery, such as nursing staff personnel characteristics, for easy retrieval of nurse staffing and skill mix data, variables to measure turnover, retention, interaction with physicians, and job satisfaction. The data collected, information gathered, and knowledge available to nurse administrators through the use of the NMMDS, and especially when linked to nursing interventions and nursing-sensitive patient outcomes data, provide an evidence base to build local, national, and international strategies and policies for health care systems to improve health care services that enhance patients' safety and provide quality health outcomes.

\section{Financial Resources}

Health care systems all over the world face continuous reform strategies to improve safety and quality of service delivery while lowering the costs of patient care. According to the Organization for Economic Co-Operation and Development [OECD] (2010a), which offers comparable statistics on health and health systems across industrialized countries, health care expenditures account for the largest portion of Government spending among OECD countries: 8.3\% on average in 2008. Health care expenditures accounted for 16\% of GDP in the United States in 2008, which is the highest share within OECD countries. Iceland ranked $15^{\text {th }}$, along with Spain, with total health spending accounting for 9.1\% of GDP in 2008 (OECD, 2010a). 
Like in most other countries there is growing concern about rising health care costs in Iceland and increased emphasis on cost containment. Hospital services are the biggest chunk of total health-related services. Iceland has national health insurance coverage that provides universal access to health care services whenever needed. However, since the 1980s hospitals have been on a fixed budget instead of fee-for-service payment mechanism and are under constant pressure to cut costs. Currently, there has been a 3\%-5\% cut per year (2009-2011) in the Government's funding to hospitals and health care centers in Iceland due to the collapse of the Icelandic banking system in 2008. This causes increased concern about the quality of health care delivery, access to health services and patient safety. Quality of health care in Iceland is rated high among the OECD countries. In 2007, Iceland's mortality rates within 30 days of admission for acute myocardial infarction and ischemic stroke were the lowest of the OECD countries. Furthermore, the five-year relative survival rate for breast cancer (2002-2007) was 88.3\% in Iceland, ranking second place of the OECD countries, where the average survival rate was 81.2\% (OECD, 2009; Statistics Iceland, 2009).

The important role and increased accountability that nurse managers and nurse administrators have in financial and quality monitoring has been described thoroughly in the literature (Biron, Richer, \& Ezer, 2007; Pappas, 2007, 2008). Huber (2000) defined financial management as "a series of activities designed to allocate resources and plan for the efficient operation of an organization” (p. 398). She identified four phases of financial management as budgeting, recording, reporting, and evaluating. The financial management of health care organizations is strongly influenced by the surrounding environment. For example, the demographic profile of the population has an effect on the consumption of health care services, and payer type and number also have an impact on financial management.

The Financial Resources category of the NMMDS has four elements that describe the unit or service level of monetary resources for the institution. They are: 1) payer 
type, 2) reimbursement, 3) nursing delivery unit/service budget, and 4) expenses. Payer type is defined as "type of payer for care delivered by nursing delivery unit/service" (Delaney \& Huber, 1996, p. 4) and is measured by volume of services delivered per unit of service, such as hours, days, visits, procedures, consults, contacts, programs, classes, or enrollees (Huber \& Delaney, 2006). Reimbursement is defined as “distribution formula/payment for services within nursing delivery unit/service” (Delaney \& Huber, 1996, p. 4), and is measured by percentage distribution of payment basis, such as fee-forservice, discounted fee for service, per diem, diagnosis-related group [DRG], all payer group [APG], per visit, or per member/month (Huber \& Delaney, 2006). Nursing delivery unit/service budget is defined as “percent of organization’s total annual itemized budget represented by the nursing delivery unit/service” (Delaney \& Huber, 1996, p. 4) and is measured by costs, such as wages, salaries per year, benefits, depreciation, supplies, and other operating expenses, and revenue (Huber \& Delaney, 2005). Expenses are defined as “direct, direct material, and indirect cost per nursing delivery unit/service per year” (Delaney \& Huber, 1996, p. 4). Direct expenses are measured by sum of labor costs, direct material expenses are measured by sum of material costs including patient supplies, and indirect expenses include such costs as equipment, administration, clinical program development, and future development per year (Huber \& Delaney, 2006).

Given the growing evidence for the relationship between nursing care resources and quality outcomes, it is paramount to gain increased knowledge of the relationship between costs of patient care and the use of nursing resources. However, methods used to describe the costs of nursing services have been inconsistent and vary greatly depending on the approach used. When analyzing patient costs it is important to account for all associated costs of the entire patient care process and to realize that it is the patient care activities that drive the cost. The process of care involves resources from multiple hospital units, such as nursing, pharmacy, laboratory, and radiology (Pappas, 2007). 
The recommended model to describe costs is Activity-based Costing [ABC], which captures variations in the processes of health care delivery. However, further research is needed to develop financial evidence about patient costs sensitive to nursing practice (Pappas, 2007). Knowledge of the costs and quality outcomes related to nursing processes gives nurse managers support to justify higher nurse staffing, specific to patient and unit characteristics, to improve the quality of nursing services (Pappas, 2008).

Pappas (2008) conducted research with the aim to establish a methodology which nurse administrators could use to determine the actual costs of adverse events linked to nurse staffing, using data from hospital accounting systems, quality systems, and medical records. A convenience sample of over 2,000 patients from two acute care hospitals with specified DRGs was used. The patient outcomes variables included patient falls, pressure ulcers, medication errors, urinary tract infection, and pneumonia. Multiple and logistic regression were used for analysis to understand cost per case and predictors of clinical outcomes and costs. The results indicated a significant increase in cost per case when an adverse event was reported. The increase in cost varied from $\$ 300$ (medication error) to $\$ 2,400$ (pressure ulcer).

Too often hospitals identify nurses as the most convenient source to downsize to meet the organizational financial goals because nurses represent a majority of the hospital workforce and account for the largest labor costs. The potential negative effects in terms of increased adverse patient events and increased financial costs due to increased complications are either not recognized or overlooked (Pappas, 2007).

Nurse managers and administrators in health care need objective evidence to show their contribution to cost-effective, quality patient care. Having easy access to the unit, department, institutional, and system level of financial resources, showing both direct and indirect costs for nursing care delivery, helps nurse administrators to both justify and control costs of nursing care services for cost-effective quality decisionmaking (Huber et al., 1997; Huber \& Delaney, 1998). 
There is a clear need for data sets to measure structure, processes and outcomes within health care systems and across hospitals and countries, to guide the management of nursing services (Van den Heede et al., 2007). The NMMDS includes standardized essential administrative data elements that can easily be represented within an information system. The data set can support nurse administrators in the collection of reliable, accurate, and timely data for comparison and bench-marking to support effective decisions for resource allocation and quality improvements. Translation of the NMMDS into Icelandic could open up a window of opportunity for international information sharing and comparisons. However, the translation process needs to adhere to rigorous methodological translation methods to produce a valid and reliable translated version.

\section{Instrument Translation}

Cross-cultural and international collaborative nursing research studies are needed. There is a need for the translation of quantitative measures such as questionnaires/ instruments from one language to another (Maneesriwongul \& Dixon, 2004). Although it may seem to be a simple task to translate an instrument from one language to another it cannot be assumed that a particular concept has the same specific meaning or relevance across cultures. Jargon, colloquial phrases, word clarity, and word meanings all affect the validity of the translated instrument. A word-for-word translation is simply not adequate to account for linguistic and cultural differences (Hilton \& Skrutkowski, 2002). Instrument translation from one language to another is a complex process. Several methods for translation procedures have been described in the literature. The three methods most often used are one-way or forward only translation, translation by committee, and the back-translation technique.

Maneesriwongul and Dixon (2004) reviewed 47 articles in nursing that included translation of quantitative research instruments. They found that both the method used for translation of instruments and the quality of the translation processes varied widely. 
Of the 48 studies, 9 used forward translation (one-way translation), and 38 used the backtranslation method. They also found that standardized guidelines for instrument translation are lacking. However, the most preferred method to minimize translation errors and obtain equivalence is the back-translation technique described by Brislin (1970).

\section{One-Way Translation}

The one-way translation method utilizes one bilingual individual to translate a questionnaire/instrument from the source language into the target language. This method has been described as the least thorough translation process and neither a valid nor reliable method (Maneesriwongul \& Dixon, 2004). Even when the translator is considered a highly skilled and experienced person, this method is not considered an acceptable technique to give high quality translation results (Hilton \& Skrutkowski, 2002). Furthermore, this approach should not be used for cross-cultural comparisons as it cannot be assured that detected similarities or differences are not due to translation error (Maneesriwongul \& Dixon, 2004).

\section{Translation by Committee}

This procedure uses two or more bilingual individuals to translate the original version into the target language, either working separately or in collaboration. Although this method is less time-consuming than the back-translation technique, it has some serious limitations. These occur, for example when committee members have common cultural views, share the same backgrounds, or are under pressure to form a consensus. This might be evident when researchers use bilingual graduate students or faculty colleagues (Hilton \& Skrutkowski, 2002). 


\section{Back-Translation Technique}

The back-translation technique by Brislin (1970) is the most highly recommended translation procedure to establish equivalence in cross-cultural research. This method involves a minimum of two bilingual translators working independently. No consultation among them is permitted. One translator translates the original version into the target language checking it for grammatical errors, while the other translator takes the translated version and translates it back to the original version. The two "original” versions are then compared to identify errors. If inaccuracy is found between the original and backtranslated versions, the items of concern are re-translated as well as back-translated again by other bilingual experts. This process is repeated until conceptual meaning is achieved (Hilton \& Skrutkowski, 2002). Although this has been considered the optimal translation technique, it also has its limitations. Limitations include that the two translators may share a common cultural world view if they come from similar backgrounds, they may be so skilled that they are able to infer what the original version meant and, in order to keep the grammatical forms of the original version, the translated version may be awkwardly phrased and confusing. However, these limitations can be minimized if the researcher gives the translators specific instructions with respect to wording, phrasing, and inference. Moreover, the translators should be asked to identify all words that could be translated differently (Carlson, 2000). The back-translation methodology was used to translate the NMMDS from the source language English to the target language Icelandic, as recommended by Jones and colleagues (2001).

\section{Summary}

The need to make nursing visible within health care effectiveness and policy making has been recognized internationally by nurse leaders (Maas \& Delaney, 2004). Patient safety and quality problems in health care delivery have become global issues. A key matter in improving patient safety is to strengthen organizational structure and process 
dimensions to promote desirable patient outcomes (Tourangeu et al., 2007) and the NMMDS is a prime example.

Data standards and common policies are necessary to build a National and International Health Information Infrastructure [NHII] where data are collected, shared and reused for multiple purposes. A NHII and a widespread adoption of terminologies and data sets is needed to capture, store, and retrieve information in a format that is timely and readily accessible. Having access to timely, accurate, relevant and comparable data is essential to effective and evidence-based decision-making, at the clinical, administrative, and policy levels.

Successful management of data, information, and knowledge is essential to support clinical and managerial decision-making, improve patient safety and increase quality of health services delivery (Hovenga et al., 2005). The Nursing Management Minimum Data Set [NMMDS] includes standardized variables and definitions to facilitate the collection, retrieval, and analyses on core data needed by nurse administrators to support decisionmaking for effective management needed to improve patient safety, and to promote costeffective, high quality patient care. Moreover, national standards have been promulgated to support the collection and sharing of the NMMDS. The study methodology and data analysis will be discussed in the next chapter. 


\section{CHAPTER III \\ METHODOLOGY}

\section{Purpose of Study}

The purpose of this study was to adapt to Iceland and clinically test the Nursing Management Minimum Data Set (NMMDS@2005) in all acute adult inpatient care units in the country of Iceland. The specific aims of the study were:

1. To translate the Nursing Management Minimum Data Set (NMMDS@) from source language (English) to target language (Icelandic).

2. To validate the translated instrument.

3. To describe the environment, nursing care resources, and financial resources across acute adult inpatient care units in the country of Iceland, using the Icelandic version (NMMDS-ICEC) of the Nursing Management Minimum Data Set (NMMDS@).

\section{$\underline{\text { Research Questions }}$}

The study's research questions were:

1. Does the NMMDS-ICE demonstrate semantic equivalence and content equivalence?

2. What is the aggregate profile of the 1) environment, 2) nursing care resources, and 3) financial recourses across acute adult inpatient units in hospitals in Iceland?

3. Are there measurable differences in environmental, nursing care resources, and financial resources among hospitals in Iceland, depending on their geographic location and size?

This chapter will be divided into two sections: The first section will discuss the translation method, and the second section will discuss the NMMDS-ICE survey method. 


\section{$\underline{\text { Overview }}$}

The design of this study includes two parts. The first part is instrument translation and adaptation to Iceland of the NMMDS survey instrument. The next part is to use the translated instrument to collect data to further validate its use in practice and to collect data to describe the NMMDS management variables as they occur in Iceland.

\section{$\underline{\text { Instrument Translation and Adaptation }}$}

\section{Study Design}

Instrument development consisted of translating the Nursing Management Minimum Data Set ${ }^{\circledR}$ (NMMDS) survey from the source language, English, to the target language, Icelandic; expert validation; and psychometric testing in the country of Iceland. Brislin’s (1970) back-translation procedure was employed, as recommended by experts on cross-cultural research. Moreover, a panel of nurses who were experts in nursing administration compared the original and back-translated versions of the instrument and validated both the semantic equivalence and content validity of the translated instrument.

The ultimate goal of instrument translation is to achieve measurement equivalence. To ensure measurement equivalence between the original version and the translated version, both semantic and content equivalence need to be achieved (Brislin, 1970; Willgerodt, Kataoka-Yahiro, Kim, \& Ceria, 2005). Semantic equivalence indicates that the meaning of each variable remains the same in each culture after translation. Content equivalence means that the content of each variable of the instrument is relevant in each culture under study. A team of experts evaluated the content equivalence of each variable as recommended by Flaherty and colleagues (1988).

\section{Expert Sample}

The sample was a convenience sample that consisted of seven bilingual Icelandic nurse experts and two nurse managers $(n=9)$. For the purpose of this study, the nurse was 
considered to be an expert if he/she had more than 5 years of experience in nursing administration. The nurse experts were all educated at the Master's or PhD level in the U.S. They all had more than 5 years' of experience in administration, six of them were working in nursing administration in hospitals in Iceland, and the primary investigator was also included. The two nurse managers pilot tested the translated version in two long term care units at Landspitali, University Hospital. Both had more than 5 years’ of experience in nursing.

\section{Translation Procedure}

The translators consisted of a convenience sample of four bilingual Icelandic nurse experts. As recommended by Jones and colleagues (2001), two translators, independently and simultaneously, did the forward translation from source language English to target language Icelandic (see Figure 2). The two translators then met, compared versions, and developed one single agreed upon Icelandic version. The translated version was then given to two other bilingual experts, who had never seen the original English version, for back-translation. The bilingual experts were all given specific instructions on wording, phrasing, and inference, and to specifically identify all words that could be translated in a different manner, as recommended by Carlson (2000). After completion of the back-translation all four translators met and compared both versions to check for translation errors and resolve any inconsistencies that might be present. Then the agreed upon version was given to an expert panel of three nurse administrators for semantic and content validation prior to pilot testing. 
Figure 2. Translation Process and Adaptation of the NMMDS@2005

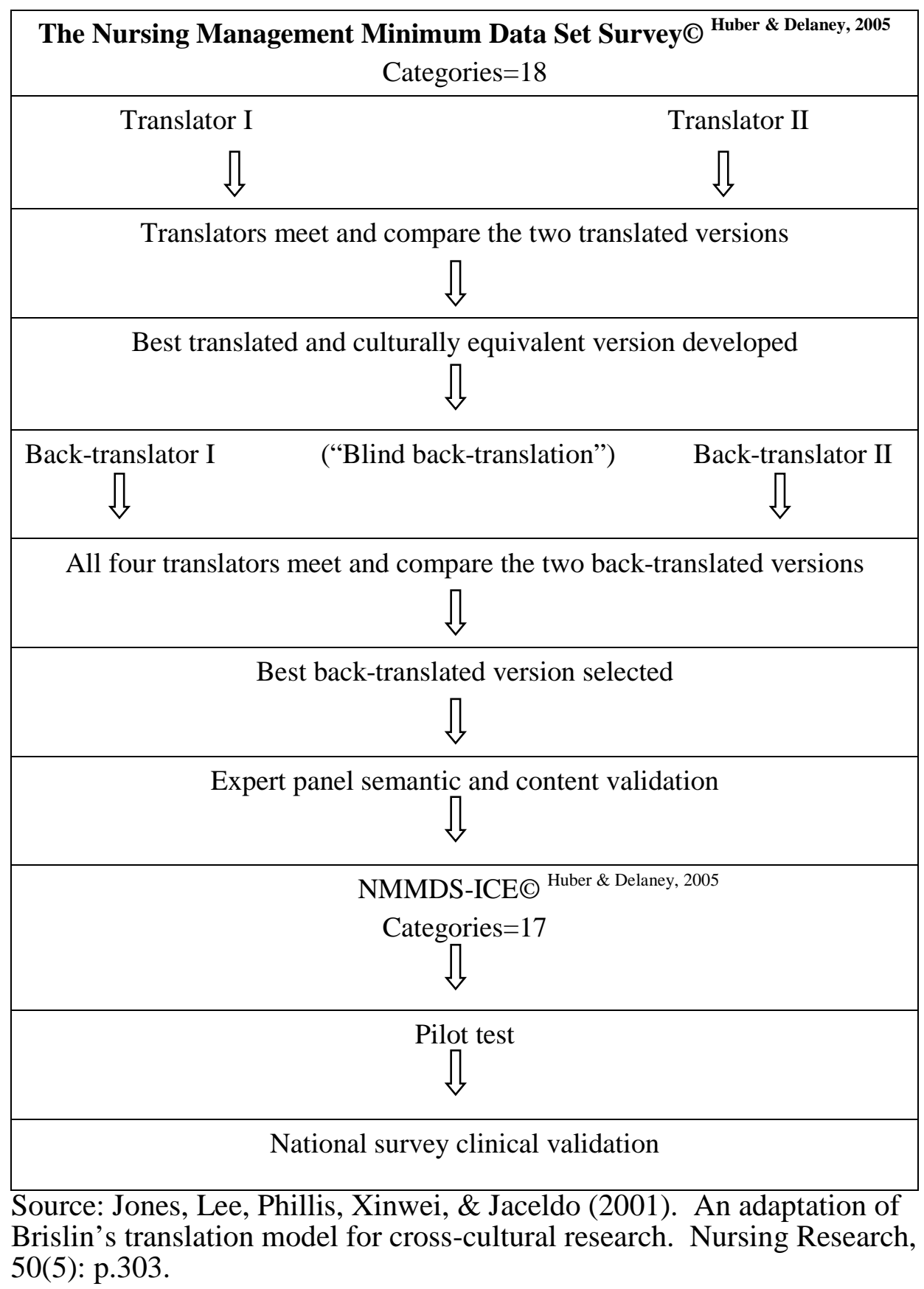

\section{Expert Validation}

The expert panel consisted of a convenience sample of three bilingual Icelandic nurse experts with in-depth knowledge in nursing administration. The expert panel nurse 
administrators did not participate in either the forward- or backward translation process. To assess if the variables of the NMMDS (see Appendix A) reflected the same meaning (semantic equivalence) between the two countries, the expert panel individually compared both the original and the back-translated version of the NMMDS rating each variable as having: "exactly the same meaning”, "almost the same meaning” or "a different meaning”.

The expert panel also addressed the content validity of the NMMDS-ICE (see Appendix B). Assessing the content validity of an instrument helps to identify elements that can be revised, eliminated, or added before it is finalized (Beck \& Gable, 2001). Content validity was established by rating each item of the NMMDS-ICE (see Appendix B) for necessity, clarity, and collectability on a five point Likert scale, where 1=strongly disagree; 2=disagree, 3=neutral; 4=agree, 5= strongly agree.

Gilmer and colleagues (1995) also recommended that the translator be familiar with both cultures to increase content equivalence. This study used Icelandic/English bilingual experts to translate the elements of the NMMDS (see Appendix A) from the original language to the target language. All translators had lived and worked in both cultures; the two translators doing the forward translation were both familiar with the NMMDS.

\section{Pilot Testing}

A convenience sample of two nurse managers representing two long-term care units at Landspitali, the University Hospital in Reykjavik, pilot tested the NNMDS-ICE (see Appendix B). The results indicated that most of the variables of the NMMDS-ICE (see Appendix B) were collectable on these units. However, both managers agreed that item \#4.1 “volume of nursing delivery unit/service” would not be easily collectable within hospital units in Iceland. This information was not easily available and "required too many calculations for the whole year”. The expert panel yielded similar results on 
collectability, but also "strongly agreed" on the necessity of collecting these data. Based on these recommendations and consultation with the authors of the NMMDS, question \# 4.1 "patient, volume of nursing delivery unit/service” was altered to include information on total inpatient beds on unit, patient admissions, and average length of stay.

Furthermore, the nurse managers agreed that the NMMDS (see Appendix A) item "patient/client accessibility” did not apply within the hospital unit environment in Iceland. Moreover, the nurse managers recommended that four variables of the Financial Resources category would be combined into two variables; variable \# 17.131 "wages” and variable \#17.132 “salaries” and variable \# 17.135 “supplies” and variable \# 17.139 “other operating expenses” for easier collection of financial data.

Both nurse managers agreed that items \#4 "volume of nursing delivery unit/service” and item \#12 "staff demographic profile” were the questions that took the most time and were the hardest to answer. The two nurse managers reported that it took 3.5 hours to complete the entire questionnaire.

\section{NMMDS Survey Method}

\section{Study Design}

The study design was a non-experimental descriptive survey. The purpose of descriptive studies is to observe, describe, and document circumstances (Polit \& Beck, 2006). This study design was chosen because descriptive studies are a way to gather more knowledge about characteristics within a certain field of study and are appropriate to verify what others in similar positions are doing (Burns \& Grove, 2009). This design is chosen when little is known about concepts and their relationships. Descriptive studies identify differences among populations but do not evaluate cause and effect relationships. Descriptive studies can contribute to an understanding of relevant concepts, help in planning resource allocation, and identify areas that need further research. 


\section{Setting of the Study}

This study was conducted in the Republic of Iceland. Iceland is a small island in Europe, located in the North Atlantic Ocean. The size of the country is $103.000 \mathrm{~km}^{2}$ (39.8 $\mathrm{mi}^{2}$ ) with a population of 318, 452 people. More than half of the population, 202, 400 people, resides in the capital city of Reykjavik and surrounding areas (Statistics Iceland, 2010). Average life expectancy in Iceland is among the highest in the world: 83 years for females and 79.6 years for males; and infant mortality is among the lowest, at 2.5 per 1000 live births (OECD, 2010 b). The population is very homogeneous both culturally and socioeconomically. The native language is Icelandic.

Health care in Iceland is nationalized, with health services primarily financed by the government, mainly through taxes. The country is divided into seven health care regions. Each region has one or more health care centers and one or more regional hospitals. Health care centers run local regional hospitals and are also responsible for primary health care, home nursing, and school nursing services. The regional hospitals provide general inand outpatient care with a certain degree of specialty services. Some of the regional hospitals are small in size, and their function is more like a nursing home than acute care hospitals. The main hospital in Iceland is Landspitali, the University Hospital in Reykjavik, providing highly specialized in and outpatient services for the whole country. Landspitali collaborates with the University of Iceland. The main hospital for the North of Iceland is Akureyri Hospital, which is defined as a teaching hospital that collaborates with the University of Akureyri. Akureyri Hospital provides specialized in and outpatient services for the whole country. Hence, there are three layers of types of hospitals in Iceland; two university hospitals, six regional hospitals, and six hospitals where the service is mostly long term care with 2-4 acute beds. The total number of hospitals in Iceland is 14. Qualified professionals provide sophisticated technical health services, and for the entire country, the entry level into professional 
nursing practice has since the closure of the Icelandic School of Nursing in 1986, solely been at the BSN level.

The setting for this study includes all adult acute care units, including medical, surgical, intensive, gynecology and maternal care (excluding psychiatry), in all 14 hospitals in Iceland. These include one University Hospital located in Reykjavik, one teaching Hospital located in Akureyri, and 12 regional hospitals outside Reykjavik. Psychiatry units were excluded to protect confidentiality as there are only two hospitals that have special psychiatry units. The total number of hospital beds within each hospital ranged from approximately 12 (the smallest regional hospitals) to 960 (Landspitali, the University Hospital in Reykjavik). The total number of hospital beds has been changing rapidly since 2008. For example at Landspitali, the University Hospital in Reykjavik, four acute care units were merged between 2009 and 2011 (now 18, were 22). The current listing of all hospitals in Iceland is available online through the Ministry of Welfare's web page in Iceland. All hospitals in Iceland were identified through this listing (velferdarraduneyti.is, 2010).

\section{Population and Sample}

The target population was all nursing units that provide in-patient adult acute care in hospitals in Iceland. The sample for this research equals the population. The nurse managers $(n=38)$ representing each adult acute inpatient unit of these hospitals were asked to complete the NMMDS-ICE survey (see Appendix B). The total number of adult

acute care units within these 14 hospitals was 38. Landspitali, the University Hospital in Reykjavik had 18 units and one nurse manager responsible for the nursing care in each unit, or 18 nurse managers. The total number of units ranged from one to four units within the other hospitals, with one manager sometimes covering more than one unit. The total number of units within all the hospitals in Iceland was 38 and the total number of nurse managers managing these units was 38, see Table 2. 
Table 2. Number of Targeted Hospital Units and Staff Nurses

\begin{tabular}{|l|l|l|}
\hline Hospital & $\begin{array}{l}\text { Number of } \\
\text { acute care units }\end{array}$ & $\begin{array}{l}\text { Number of } \\
\text { staff nurses }\end{array}$ \\
\hline Landspitali & 18 & N/A \\
\hline Akureyri Hospital & 4 & 80 \\
\hline Heilbrigdisstofnun Vesturlands & 3 & 28 \\
\hline Heilbrigdisstofnun Sudurlands & 2 & 27 \\
\hline Heilbrigdisstofnun Sudurnesja & 2 & 25 \\
\hline Heilbrigdisstofnun Austurlands & 1 & 8 \\
\hline Heilbrigdisstofnun Blönduóss & 1 & 6 \\
\hline $\begin{array}{l}\text { Heilbrigdisstofnun } \\
\text { Fjallabyggdar }\end{array}$ & 1 & 8 \\
\hline Heilbrigdisstofnun Húsavíkur & 1 & 16 \\
\hline $\begin{array}{l}\text { Heilbrigdisstofnun Sud- } \\
\text { Austurlands }\end{array}$ & 1 & 6 \\
\hline Heilbrigdisstofnun Saudarkroks & 1 & 7 \\
\hline $\begin{array}{l}\text { Heilbrigdisstofnun } \\
\text { Patreksfjardar }\end{array}$ & 1 & 4 \\
\hline Heilbrigdisstofnun Vestjarda & 1 & $\mathbf{2 3 4}$ \\
\hline $\begin{array}{l}\text { Heilbrigdisstofnun } \\
\text { Vestmannaeyja }\end{array}$ & 1 & 11 \\
\hline Total : & $\mathbf{3 8}$ & 8 \\
\hline
\end{tabular}

Furthermore, all of the staff nurses on these acute adult inpatient units were asked to complete a job satisfaction survey (Data Collection Form - Individual) distributed by the nurse manager (survey question \# 14.11 and 14.21) and returned to the PI for data entry and analysis. The total number of staff nurses on these units was 234 (see Table 2).

Access to the staff nurses for each inpatient unit was through the nurse manager. However, staff nurses working on the units at Landspitali, the University Hospital in Reykjavik were excluded from the job satisfaction survey in order to gain access to the total population of the nurse managers at Landspitali. Through personal conversation with the investigator, the nurse executive at Landspitali expressed great concerns about 
the targeted population of nurse managers and staff nurses because of the already high workload on staff nurses and nurse managers at the hospital. It was clear that a compromise had to be made with regard to the targeted population. Hence, to gain access to the total population of nurse managers in this setting, the decision was made to exclude the staff nurses on these units from the survey. The variable of job satisfaction can sometimes be difficult to collect in research studies despite its value. In some cases, this is considered to be highly sensitive organizational data, and nurse managers and staff nurses thus may not want to or be authorized to share this information. The estimated number of staff nurses on these units at Landspitali is between 400-500 staff nurses. Hence, for this one variable, the sample does not equal the population.

When selecting a sample size, one of the most important things to determine is whether the sample represents the total population under study. As the sampling in this study included all hospitals and all acute care units within each hospital (excluding psychiatry), the sample equals the population for all but the variable job satisfaction. Because sample size is a crucial factor in controlling for type II errors, the larger the sample the more likely it is that results reflect reality rather than variation in sampling (Minium, King, \& Bear, 1993). As this study included all nurse managers representing each adult inpatient unit of all hospitals in Iceland, the sample size equals the total population under study, for all but one variable; staff nurses' job satisfaction. The return rate in this study was 74\%, however usable data was 53\%.

\section{Instrument}

The NMMDS survey® 2005 was developed in 1998 by Huber and Delaney and has been tested for reliability and validity in several settings and sites across the United States of America (Delaney \& Huber, 1996; Hardardottir, 2002). Various research methods were used to identify, define and validate the elements of the NMMDS, including inductive methods, invitational working conference, expert panel validation, a 
state-level pilot survey, national Delphi surveys, and validation across multiple nursing care settings, including acute care, long term care, ambulatory care, and community care (Huber et. al., 1997). Moreover, it has been pilot tested at an international level in pediatric units in Iceland (Thorlacius, 2011).

The NMMDS was recognized by the American Nurses Association [ANA] in 1998, and the first three elements of the data set have recently been mapped to the Logical Object Names, Identifiers, and Codes [LOINC] terminology. The LOINC is publicly available at no cost and can easily be incorporated in EHR systems. The contents of the NMMDS have been reviewed regularly by the authors to refine the instrument to reflect modern health care.

The NMMDS (2005) questionnaire (see Appendix A) consists of eighteen elements (17 variables and one unique identifier) clustered into three categories: Environment (items \#01-10), Nursing Care Resources (items \#11-14), and Financial Resources (items \# 15-18) (see Appendix A). A list of the instrument's items and subscales of the Environment variable are presented in Table 5, Nursing Care Resources is in Table 6 and Financial Resources is in Table 7. The 2005 version of the NMMDS survey was translated from the source language English to the target language Icelandic, using the back translation procedure to maximize equivalence (Maneesriwongul \& Dixon, 2004; Wang et al., 2006). The translated version of the NMMDS, the NMMDSICE, was used in this survey (see Appendices A-B for English and Icelandic versions of the instrument). The authors granted permission to translate and use the instrument for this study.

Several sub-variables were excluded from the Icelandic version of the NMMDS. These included 14 variables within the Environment category, one variable within the Nursing Care Resources category, and 21 variables within the Financial Resources category (see Table 3). The sub-variables are: “Medicare payment category”, “community /outreach“, “custodial”, “nursing home intermediate care”, "nursing home 
Table 3. NMMDS Variables Excluded from the NMMDS-ICE version

\begin{tabular}{|c|c|c|}
\hline Variable Number & Variable Name & Category \\
\hline 01.06 & Medicare payment category & Environment \\
\hline 02.01 & Community/outreach & Environment \\
\hline 02.03 & Custodial & Environment \\
\hline 02.08 & $\begin{array}{l}\text { Nursing home intermediate } \\
\text { care }\end{array}$ & Environment \\
\hline 02.11 & Nursing home sub-acute care & Environment \\
\hline 02.12 & $\begin{array}{l}\text { Free-standing nurse managed } \\
\text { clinic }\end{array}$ & Environment \\
\hline 02.20 & Transitional care & Environment \\
\hline 02.26 & Hospital based skilled care & Environment \\
\hline 02.30 & $\begin{array}{l}\text { Hospital based sub-acute } \\
\text { inpatient }\end{array}$ & Environment \\
\hline 03.113 & Developmental ability & Environment \\
\hline 03.45 & Population, state & Environment \\
\hline 03.49 & Population, aerospace & Environment \\
\hline 05.07 & Managed care & Environment \\
\hline 10 & $\begin{array}{l}\text { Nursing delivery unit/service } \\
\text { accreditation }\end{array}$ & Environment \\
\hline 11.101 & Associate degree & Nursing Care Resources \\
\hline 15.1101 & Medicare & Financial Resources \\
\hline 15.1102 & Medicaid & Financial Resources \\
\hline 15.1103 & Public health service (PHS) & Financial Resources \\
\hline 15.1104 & PHS-Indian & Financial Resources \\
\hline 15.1105 & Military health system & Financial Resources \\
\hline 15.1106 & Dept. of justice & Financial Resources \\
\hline 15.1107 & state employer, & Financial Resources \\
\hline 15.1108 & State health service & Financial Resources \\
\hline 15.1201 & $\begin{array}{l}\text { Health Maintenance } \\
\text { Organization (HMO) }\end{array}$ & Financial Resources \\
\hline 15.202 & $\begin{array}{l}\text { Preferred provider } \\
\text { organization (PPO), }\end{array}$ & Financial Resources \\
\hline 15.203 & Discount fee-for-service & Financial Resources \\
\hline 15.1204 & Commercial insurance & Financial Resources \\
\hline 15.1205 & Workers' compensation & Financial Resources \\
\hline
\end{tabular}


Table 3. Continued

\begin{tabular}{|l|l|l|}
\hline 15.1206 & Industrial & Financial Resources \\
\hline 15.1207 & Trust accounts, & Financial Resources \\
\hline 15.1209 & Indigent & Financial Resources \\
\hline 15.1210 & Charity & Financial Resources \\
\hline 15.1213 & Multy-method & Financial Resources \\
\hline 15.1214 & $\begin{array}{l}\text { Non-patient revenue } \\
\text { generation }\end{array}$ & Financial Resources \\
\hline 16.15 & All payer group (APG) & Financial Resources \\
\hline 16.17 & Per member/month & Financial Resources \\
\hline
\end{tabular}

sub-acute care”, "free-standing nurse managed clinic”, "transitional care”, "hospitalbased skilled care”, “hospital-based sub-acute inpatient”, “developmental ability”, "population, state”, “population, aerospace”, "managed care”, and "nursing delivery unit/service accreditation”, which are all variables within the Environment category of the NMMDS. The one sub-variable within the Nursing Care Resources that was excluded was "associate degree” which is a degree that does not exist within nursing education in Iceland. The Financial Resources category had the most sub-variables excluded from the Icelandic version. They were: "Medicare”, "Medicaid”, "public health service (PHS)”, “PHS-Indian”, “military health system”, “dept. of justice”, "state employer”, "state health service”, "health maintenance organization (HMO)”, "preferred provider organization (PPO)”, “discount fee-for-service”, "commercial insurance”, “workers' compensation”, “industrial”, “trust accounts”, “indigent”, “trust accounts”, “charity”, “multy-method”, “non-patient revenue generation”, "all payer group (APG)”, and finally “per member/month”. Furthermore, variable 06 patient/client accessibility was not collected for the purposes of this study as it was concluded to be applicable in primary health care, but not the hospital environment in Iceland, although it is a part of the NMMDS-ICE. Two sub-variables were not collected in this study; sub-variable \# 17.134 depreciation of the Financial Resources category and the sub-variable \#12.1113 
Table 4. Additional Variables Included in the NMMDS-ICE

\begin{tabular}{|l|l|l|}
\hline Variable Number & Variable Name & Category \\
\hline 03.140 & Geriatrics & Environment \\
\hline 03.141 & Gynecology & Environment \\
\hline 04.110 & Pt. admissions & Environment \\
\hline 04.111 & Average LOS & Environment \\
\hline 04.112 & Number of beds per unit & Environment \\
\hline 11.109 & University degree diploma & Nursing Care Resources \\
\hline 15.45 & Self-pay without insurance & Financial Resources \\
\hline 16.47 & Other reimbursement & Financial Resources \\
\hline
\end{tabular}

number of dependent persons responsible for of the Nursing Care Resources category. Some variables were added to the NMMDS-ICE (Table 4). The sub-variables \# 03.140 geriatrics and \# 03.141 gynecology were added to variable \# 03 patient/client population; the sub-variables \# 04.110 “pt. admissions”, \#04.111 “average LOS and \# 04.112 ”number of beds per unit” were added to variable \# 04 volume of nursing delivery unit/service to try to capture patient volume within the hospital unit. This was done in accordance with the results of the expert panel and discussion with the authors of the instrument. One variable was added to the Nursing Care resources category to capture nursing education in Iceland, variable \# 11.109 "university degree diploma“. Furthermore, two variables were added to the Financial Resources category; "payer type”, variable \# 15.45 “self-pay without insurance”, and reimbursement variable \# 16.47 “other reimbursement“. Moreover, four variables of the Financial Resources category were combined into two variables: variable \# 17.131 “wages” and variable \#17.132 “salaries” were combined into one variable, and variable \# 17.135 “supplies” and variable \# 17.139 “other operating expenses” were combined into one variable based on recommendations from the pilot study. 


\section{The Environment}

The items, subscales and measurement of the Environment category of the NMMDS are presented in Table 5. The items collected in this study included eight out of the ten environmental elements. They are \#1 unit/service unique identifier, \#2 type of nursing delivery unit/service, \#3 patient/client populations served, \#4 volume of nursing delivery, \#5 care delivery structure and outcomes, \#7 clinical decision making complexity, \#8 environmental complexity, and \#9 autonomy. The elements that were excluded from data collection in this study were element \# 6) patient/client accessibility and element \# 10) accreditation of nursing delivery. These two variables were excluded after analysis of the NMMDS (see Appendix A) for feasibility and applicability within the hospital environment in Iceland. One sub-variable, \#1.06 Medicare payment category of variable \#1 unit/service unique identifier, was also excluded. The decision to exclude element \# 10) accreditation of nursing delivery from the data collection in this study was based on the recommendations by the expert panel. Accreditation of nursing services does not apply in Iceland. Variable \# 01.06 Medicare payment category was excluded from the Icelandic version of the NMMDS, as this form of payment for health care services does not exist within the nationalized health care system in Iceland.

The NMMDS-ICE (see Appendix B) was pilot tested in two long-term care units at Landspitali, University Hospital. The decision to exclude variable \# 6, patient/client accessibility, from the study was based on the results from the pilot study. The patient/client accessibility was considered not to be applicable within the hospital environment in Iceland. However, it does apply in home care nursing, which is provided by nurses in primary health care, and thus this element is included in the Icelandic 
Table 5. The NMMDS Instrument, Items, Subscales and Measurement of the Environment Category

\begin{tabular}{|c|c|c|c|}
\hline Environment & $\begin{array}{l}\text { Item \# } \\
01-10\end{array}$ & Subscales & Measurement \\
\hline $\begin{array}{l}\text { 1. Unit/Service Unique } \\
\text { Identifier }\end{array}$ & $\begin{array}{l}\text { \# 01.01- } \\
01.09\end{array}$ & N/A & $\begin{array}{l}\text { Unique name, identifier, } \\
\text { payment, and geographic } \\
\text { location }\end{array}$ \\
\hline $\begin{array}{l}\text { 2. Type of Nursing Delivery } \\
\text { Unit/Service }\end{array}$ & $\begin{array}{l}\text { \# 02.01- } \\
02.37\end{array}$ & N/A & $\begin{array}{l}\text { Type of nursing services } \\
\text { (\%) }\end{array}$ \\
\hline 3. Patient/Client Population & $\begin{array}{l}\# 03.1- \\
03.4\end{array}$ & $\begin{array}{l}\text { Specialty (\# 03.101-03.139) } \\
\text { Developmental Focus (\#03.20 } \\
\text { 1-03.211) } \\
\text { Interaction Focus (\#03.31- } \\
\text { 03.34) } \\
\text { Population Focus (\#03.41- } \\
\text { 03.49) }\end{array}$ & $\begin{array}{l}\text { Population characteristics } \\
\text { (\%) }\end{array}$ \\
\hline $\begin{array}{l}\text { 4. Volume of Nursing } \\
\text { Delivery Unit/ Service }\end{array}$ & $\begin{array}{l}\text { \# 04.1- } \\
04.4\end{array}$ & $\begin{array}{l}\text { Patient (\# 04.101-04.109) } \\
\text { Family (\# 04.201-04.209) } \\
\text { Group (\# 04.301-04.309 } \\
\text { Community/Population } \\
\text { (\# 04.4-04.409) }\end{array}$ & $\begin{array}{l}\text { Amount of services } \\
\text { provided and available }\end{array}$ \\
\hline $\begin{array}{l}\text { 5. Care Delivery Structure } \\
\text { and Outcomes }\end{array}$ & $\begin{array}{l}\# 05.1- \\
05.3\end{array}$ & $\begin{array}{l}\text { Structure (\#05.01-05.08) } \\
\text { Outcomes-Professional } \\
(\# 05.21-05.24) \\
\text { Outcomes-Clinical } \\
(\# 05.31-0.36)\end{array}$ & $\begin{array}{l}\text { Form of provided care (\%) } \\
\text { A 5-point Likert scale } \\
\text { (1=lowest; 5= highest) } \\
\text { A 5-point Likert scale } \\
\text { (1=lowest; 5= highest) }\end{array}$ \\
\hline 6. Patient/Client Accessibility & $\begin{array}{l}\text { \# 06.01- } \\
06.06\end{array}$ & N/A & $\begin{array}{l}\% \text { of typical access } \\
\text { Not collected in this study }\end{array}$ \\
\hline $\begin{array}{l}\text { 7. Clinical Decision Making } \\
\text { Complexity }\end{array}$ & $\begin{array}{l}\# 07.1- \\
07.2\end{array}$ & $\begin{array}{l}\text { Patient/Client Care } \\
\text { (\# 07.11-07.14) } \\
\text { Computerization } \\
\text { (\# 07.201-07.212) }\end{array}$ & $\begin{array}{l}\text { A 5-point Likert scale } \\
\text { (1=lowest; 5= highest) } \\
\text { A 5-point Likert scale } \\
\text { (1=lowest; 5= highest) }\end{array}$ \\
\hline 8. Environmental Complexity & $\begin{array}{l}\text { \# 08.01- } \\
08.03\end{array}$ & N/A & $\begin{array}{l}\text { A 5-point Likert scale } \\
\text { (1=stable ; } 5=\text { shifting) } \\
\text { (1=alike ; } 5=\text { =diverse) } \\
\text { (1=stable ; } 5=\text { =turbulent) }\end{array}$ \\
\hline 9. Autonomy & $\begin{array}{l}\text { \# 09.01- } \\
09.04\end{array}$ & N/A & $\begin{array}{l}\text { A 5-point Likert scale } \\
\text { (1=never; } 2=\text { seldom, } \\
\text { 3=sometimes; 4=often, } \\
\text { 5= always) }\end{array}$ \\
\hline
\end{tabular}


Table 5. Continued

\begin{tabular}{|l|l|l|l|}
\hline $\begin{array}{l}\text { 10. Nursing delivery } \\
\text { Unit/Service Accreditation }\end{array}$ & $\begin{array}{l}\# 10.01- \\
10.15\end{array}$ & N/A & $\begin{array}{l}\text { Check certification status } \\
\text { Not collected in this study }\end{array}$ \\
\hline
\end{tabular}

Source: Delaney \& Huber, 1996. Nursing Management Minimum Data Set (NMMDS): A report of an invitational conference [monograph]. Chicago, IL: American Organization of Nurse Executives [AONE].

version of the NMMDS, although not collected in this study.

Furthermore, the pilot test indicated that information on number of hours of care and encounters of variable \# 4.1 would be difficult to obtain. This was in accordance with the results of the expert panel. Hospitals in Iceland do not have patient acuity systems implemented, except for Landspitali, the University Hospital in Reykjavik. Therefore, these data are not readily available to nurse managers in Iceland. Moreover, at the time of the data collection for this study, Landspitali was in the phase of implementing a new patient acuity system. Based on these results plus recommendations from one of the authors of the instrument, additional sub-variables were added to variable \# 4.1 "patient" to include information on total inpatient beds on unit, patient admissions, and average LOS.

The unit/service unique identifier is measured by the unique name, identifier, and geographic location of a health care organization. The type of delivery unit/service is measured by identification of the type of services that most accurately describe the level of care. The element of patient/client populations served is measured by the characteristics of the patient/client population served by the nursing unit, including specialty, developmental focus, interaction focus, and population focus. Volume of nursing delivery is measured by the amount of services provided and available to the patient, family, group, and community. The care delivery structure and outcomes element is measured by the form of provided care, professional nurse outcomes, and clinical patient outcomes. Complexity of clinical decision-making is measured by the 
degree of routine, uniformity, predictability, level of expert knowledge, and computerization involved in care delivery. Complexity of the environment is measured by amount of patient turnover, client mix, and environmental climate. Finally, autonomy is measured by degree of freedom to act, perceived control, and opportunity to participate in organizational decision-making (Delaney \& Huber, 1996; Huber \& Delaney, 2005).

\section{Nursing Care Resources}

The items, subscales and measurement of the Nursing Care Resources category of the NMMDS are presented in Table 6. The elements of the Nursing Care Resources collected in this study included all four nursing care resources elements. They are: \#1 management demographic profile, \#2 staff demographic profile, \#3 staffing, and \#4 staff satisfaction.

The management demographic profile is measured by educational background, credentials, gender, experience, unique provider number, and specific title. The direct care staff demographic profile is measured by education, certification, membership in a professional organization, mean age, number of dependent persons responsible for, number of staff available to provide direct and indirect care, and average years of service.

The staffing category is measured by quantity of available staff, turnover, and retention. Finally, satisfaction is measured by the percentage of personnel who report positive or negative affects toward their current job using a five point Likert scale (Delaney \& Huber, 1996; Huber \& Delaney, 2005).

Based on the results of the expert panel one variable, "associate degree”, was excluded from the NMMDS-ICE (see Appendix B) as this education level for nurses does not exist in Iceland. Moreover, one variable was added, \# 11.109 "university degree diploma", to capture all educational levels of Icelandic nurses. The university degree diploma is further education after a Bachelor's degree in nursing, however does not fulfill a master’s degree requirements. Variable \#14, related to job satisfaction, is where data 
Table 6. The NMMDS Instrument, Items, Subscales and Measurement of the Nursing Care Resources Category

\begin{tabular}{|c|c|c|c|}
\hline $\begin{array}{l}\text { Nursing Care } \\
\text { Resources }\end{array}$ & $\begin{array}{l}\text { Item \# } \\
11-14\end{array}$ & Subscales & Measurement \\
\hline $\begin{array}{l}\text { 11. Management } \\
\text { Demographic Profile }\end{array}$ & $\begin{array}{l}\text { \# 11.1- } \\
11.25\end{array}$ & N/A & $\begin{array}{l}\text { Demographic } \\
\text { measurement: } \\
\text { Level of education } \\
\text { (7 items) } \\
\text { Credentials, gender, } \\
\text { work experience, } \\
\text { unique provider } \\
\text { number, title }\end{array}$ \\
\hline $\begin{array}{l}\text { 12. Staff Demographic } \\
\text { Profile }\end{array}$ & $\begin{array}{l}\# 12.11- \\
12.2513\end{array}$ & $\begin{array}{l}\text { Direct Care Staff (\# 12.111- } \\
\text { 12.142) } \\
\text { Management, Administrative, } \\
\text { Support Staff (\# 12.21-12.2513) }\end{array}$ & $\begin{array}{l}\text { Demographic } \\
\text { measurement: } \\
\text { Level of education } \\
\text { ( } 7 \text { items) } \\
\text { certification, } \\
\text { member of prof. } \\
\text { organization, } \\
\text { mean age, number of } \\
\text { dependent persons, } \\
\text { total number, total } \\
\text { FTE, average years } \\
\text { of service }\end{array}$ \\
\hline 13. Staffing & $\begin{array}{l}\text { \# 13.10- } \\
13.316\end{array}$ & $\begin{array}{l}\text { Quantity (\# 13.10-13.116) } \\
\text { Turnover (\#13.20-13.216) } \\
\text { Retention (\#13.30-13.316) }\end{array}$ & $\begin{array}{l}\text { Number of staff/skill } \\
\text { mix, FTEs, super- } \\
\text { vised, budgeted, } \\
\text { average daily } \\
\text { productive staff, } \\
\text { turnover rate, } \\
\text { retention rate }\end{array}$ \\
\hline 14. Satisfaction & $\begin{array}{l}\# 14.11- \\
14.225\end{array}$ & $\begin{array}{l}\text { Position Direct Care Staff } \\
\text { (\# 14.1-14.115) } \\
\text { Position Management, } \\
\text { Administrative and Support Staff } \\
\text { (\# 14.12-14.125) } \\
\text { Context Direct Care Staff } \\
\text { (\# 14.21-14.215) } \\
\text { Context Administrative and } \\
\text { Support Staff (\# 14.22-14.225) }\end{array}$ & $\begin{array}{l}\text { A 5-point Likert } \\
\text { scale (1=strongly } \\
\text { disagree;2=disagree, } \\
\text { 3=neutral; 4=agree, } \\
\text { 5= strongly agree) }\end{array}$ \\
\hline
\end{tabular}

Source: Delaney \& Huber, 1996. A Nursing Management Minimum Data Set (NMMDS): A report of an invitational conference [monograph]. Chicago, IL: American Organization of Nurse Executives [AONE]. 
from the Landspitali, the University Hospital in Reykjavik, were not able to be obtained from the staff nurses.

\section{Financial Resources}

The items, subscales and measurement of the Financial Resources category of the NMMDS are presented in Table 7. The elements collected in this study included all four elements that describe the unit or service level of monetary resources for the institution. They are: 1) payer type, 2) reimbursement, 3) nursing delivery unit/service budget, and 4) expenses. Payer type is measured by volume of services delivered per unit of service, such as hours, days, visits, procedures, consults, contacts, programs, classes, or enrollees (Huber \& Delaney, 2006). Reimbursement is measured by percentage distribution of payment basis, such as fee-for-service, discounted fee for service, per diem, diagnosisrelated group [DRG], all payer group [APG], per visit, or per member/month (Huber \& Delaney, 2006). Nursing delivery unit/service is measured by costs, such as wages, salaries per year, benefits, depreciation, supplies, and other operating expenses, and revenue (Huber \& Delaney, 2005). Expenses are defined as “direct, direct material, and indirect cost per nursing delivery unit/service per year” (Delaney \& Huber, 1996, p. 4). Direct expenses are measured by sum of labor costs, direct material expenses are measured by sum of material costs including patient supplies, and indirect expenses include such costs as equipment, administration, clinical program development, and future development per year (Huber \& Delaney, 2006).

The payer type of the Icelandic version of the NMMDS had to be modified to be applicable within the Icelandic health care system. The Icelandic version of this category only includes three types of payer type; 1) government, 2) self-pay with insurance, and 3) self-pay without insurance. One variable was added to the reimbursement category, variable \# 16.47 “other reimbursement”. Furthermore, the sub-variables of variable \# 16 reimbursement; “all payer group (APG)” and “per member/month” are not applicable in 
Table 7. The NMMDS Instrument, Items, Subscales and Measurement of the Financial Resources Category

\begin{tabular}{|c|c|c|c|}
\hline Financial Resources & $\begin{array}{l}\text { Item \# } \\
15-18\end{array}$ & Subscales & Measurement \\
\hline 15. Payer Type & $\begin{array}{l}\# 15.11- \\
15.44\end{array}$ & $\begin{array}{l}\text { Total Health System (if applicable) } \\
\text { Total Organization (\# 15.21-15.24) } \\
\text { Total Nursing Department (\# 15.31- } \\
\text { 15.34) } \\
\text { Nursing Delivery Unit/Service (\# } \\
\text { 15.41-15.44) }\end{array}$ & $\begin{array}{l}\text { \% of total service } \\
\text { effort by payer } \\
\text { type }\end{array}$ \\
\hline 16. Reimbursement & $\begin{array}{l}\text { \# 16.11- } \\
16.47\end{array}$ & $\begin{array}{l}\text { Total Health System (\# 16.11-16.17) } \\
\text { Total Organization (\# 16.21-16.27) } \\
\text { Total Nursing Department (\#16.31- } \\
\text { 16.37) } \\
\text { Total Nursing Delivery Unit/Service } \\
\text { (\#16.41-16.47) }\end{array}$ & $\begin{array}{l}\text { \% distribution of } \\
\text { reimbursement } \\
\text { by payment basis }\end{array}$ \\
\hline $\begin{array}{l}\text { 17. Nursing Delivery } \\
\text { Unit/Service Budget }\end{array}$ & $\begin{array}{l}\# 17.111- \\
17.139\end{array}$ & $\begin{array}{l}\text { Costs (\# 17.111-17.139) } \\
\text { Organization/Nursing } \\
\text { Department/Unit } \\
\text { (\#17.121-17.129) } \\
\text { Revenues } \\
\text { Organization/Nursing } \\
\text { Department/Unit } \\
(17.21-17.231)\end{array}$ & $\begin{array}{l}\text { \% of planned and } \\
\text { actual annual } \\
\text { budget } \% \text { of } \\
\text { planned and } \\
\text { actual revenues }\end{array}$ \\
\hline 18. Expenses & $\begin{array}{l}\# 18.11- \\
18.33\end{array}$ & $\begin{array}{l}\text { Organization (\# 18.11-18.13) } \\
\text { Nursing Department (\# 18.21-18.23) } \\
\text { Nursing Delivery Unit/Service (\# } \\
\text { 18.31-18.33) }\end{array}$ & $\begin{array}{l}\% \text { of total nursing } \\
\text { department } \\
\text { expenses for the } \\
\text { reporting year }\end{array}$ \\
\hline
\end{tabular}

Source: Delaney \& Huber, 1996. A Nursing Management Minimum Data Set (NMMDS): A report of an invitational conference [monograph]. Chicago, IL: American Organization of Nurse Executives [AONE].

Iceland and therefore were excluded from the Icelandic version of the NMMDS, as recommended by the expert panel. Data collection was aimed at the hospital unit level, and therefore data were not collected at the total health system or total organization level in this study.

Although DRGs are not used for reimbursement by the government in Iceland, some of the hospitals are collecting data on DRGs within their hospital. DRGs are the 
payment basis for hospital services provided in Iceland to foreigners. Furthermore, salaries and wages were combined into one variable as were supplies and other operating expenses, as recommended by the nurse managers that participated in the pilot study.

\section{$\underline{\text { Reliability }}$}

Reliability of an instrument refers to measurement consistency so that repeated measures applied at different times to similar elements reveal similar results. Reliability testing is usually indicated as a form of correlation coefficient where a 1.00 indicates a perfect reliability and a reliability of 0.70 is considered the lowest acceptable measure for a well-developed instrument (Burns \& Grove, 2009; Polit \& Beck, 2006). The reliability of the NMMDS survey has been tested through extensive research, including a three round National Delphi to test the necessity, clarity, and collectability of the instrument (Delaney \& Huber, 1996; Huber \& Delaney, 2005).

\section{Validity}

Instrument validity refers to the extent to which the instrument actually reflects the abstract construct being examined (Burns \& Grove, 2009), that is, whether the instrument is measuring what it is supposed to measure. The validity of an instrument is supported by collection of evidence and is an ongoing process (Polit \& Beck, 2006). Construct validity and content validity will be addressed.

Construct validity determines whether the measure captures the major dimensions of the concept under study, or in other words, whether it is measuring exactly what it should be measuring. For instance, when measuring quality of care, each dimension of quality (structure, process, and outcome) needs to be addressed. Expert knowledge via the judgment of a panel of experts and a literature review were the methods used to detect whether there exists an agreed upon criteria to measure certain concepts (Shi, 1997). The NMMDS builds on The Iowa Model for Nursing Administration (Johnson et al., 1991), the Nursing Minimum Data Set (Werley et al., 1991), and Donabedian’s (1980) 
components for quality measurement. It includes all three dimensions to measure quality: structure, process, and outcome. Moreover, the NMMDS was developed through expert panels and extensive literature review, as well as field testing.

Content validity refers to whether the concepts of an instrument really cover everything the researcher needs to know. Expert knowledge and literature review are methods that are used to ensure content coverage adequacy of an instrument (Polit \& Beck, 2006). The NMMDS was developed through expert review panels, focus groups, national surveys, extensive review of the literature, and a national consensus conference to ensure its construct and content validity, as well as necessity, clarity and collectability. These include a working conference in partnership with the American Organization of Nurse Executives (AONE), a 3-round national Delphi study of nurse executives, and a national clinical pilot test in 11 different states in the U.S. (Delaney \& Huber, 1996).

\section{Protection of Human Rights}

This study was approved by the Institutional Review Board (IRB) at The University of Iowa and the Icelandic Data Protection Authority under the criteria for exempt human subjects' research, as there was minimal risk to the participants in this study. Participants were adult nurse professionals, and no patients or persons from vulnerable populations were included. Permission was also obtained from the Landspitali Institutional Review Board, Akureyri Hospital Institutional Review Board and the directors of nursing services from all fourteen hospitals in Iceland. Completing the questionnaire signified consent to participate in the study.

\section{Survey Procedure}

The nurse managers $(\mathrm{N}=38)$ representing each adult acute care inpatient unit were contacted by telephone by the researcher to obtain preliminary agreement to participate in the study. The study and the consent process were discussed over the phone with all the nurse manager participants, using a phone script (Appendix D script 
used in phone call). The phone script was based on the IRB exempt information sheet to minimize the possibility of coercion and make sure that potential subjects understood the consent process.

The questionnaire was numbered (1-38) for the purposes of being able to answer research question number 3, whether there are measurable differences in environmental, nursing care resources, and financial resources among nursing units in hospitals in Iceland, depending on their geographic location and size. All 38 nurse managers agreed to participate and received the mailed survey. A self-addressed, stamped envelope and the exempt information sheet were mailed with the survey. In addition to being asked to complete the survey, 20 of the 38 nurse managers (excluding the 18 nurse managers at Landspitali, the University Hospital in Reykjavik), were asked to distribute a study packet with the consent information, the individual satisfaction data collection form, and plain return envelope to each of the staff nurses on their units.

The staff nurses who were willing to participate in the study were asked to complete the satisfaction data collection form (Data Collection Form-Individual) and seal it in the envelope. The Nurse managers were asked to provide a closed paper box and place it within the nursing station for three days for the nurses to return the satisfaction data collection form. The nurse managers were asked to collect the sealed envelopes and return them to the researcher for data entry and analysis, in the envelope with the NMMDS form completed by the nurse manager, so that the satisfaction data collection form could be linked to the NMMDS forms. The nurse managers had access to the researcher's phone number and were welcome to call if they needed to ask questions about the survey.

The code numbers (1-38) for each participating inpatient unit were kept in a password protected computer file. The computer was located at the researcher's study and was also password protected. The hard copies were destroyed and the password protected computer file was deleted after entering the data into SPSS for data analyses. 
The passwords were known only to the researcher. Data collection occurred over a threeweek period in the month of March, 2011.

\section{Data Analysis}

For the purposes of this study, sixteen of the eighteen elements of the NMMDS were collected and analyzed. One item of the English version, “nursing delivery unit/service accreditation” was excluded from the Icelandic version as it does not apply in the Icelandic health care environment. Moreover, the NMMDS item "patient/client accessibility” was omitted from this data collection as it does not apply within hospital units in Iceland. The data were entered into PASW statistics software, version 18.0 (SPSS Inc., 2009) for statistical analysis. Descriptive analysis (see Table C1, Appendix C) using frequency tables, mean, median and standard deviations were used to illustrate demographic characteristics. Due to the small sample size, non-parametric statistics (Mann-Whitney U test) was used to test for significant differences (see Table C2, Appendix C) among two independent groups, and Spearman rank-order (see Table C3, Appendix C) was calculated to determine correlation among variables (Burns \& Grove, 2009). Percent of agreement was used to evaluate interrater reliability among the expert panel members, and coefficient alpha was calculated (see Table C4, Appendix C) to assess internal consistency reliability for the NMMDS sub-scales (Polit \& Beck, 2010).

\section{Research Question Number One}

Does the NMMDS-ICE demonstrate semantic and content equivalence?

A panel of experts in nursing administration validated both the semantic (linguistic) equivalence (Flaherty et al., 1988; Tang \& Dixon, 2002; Yu et al., 2004) and content validity of the translated instrument (Chao, Wang, Chang, Wang, \& See, 2009; Maneesriwongul \& Dixon, 2004). Semantic equivalence was established by comparing the original version of the NMMDS with the back-translated Icelandic version for 
accuracy, looking for errors and rating each variable as having: "exactly the same meaning”, “almost the same meaning” or "a different meaning”. Content validity was established by rating each item of the NMMDS-ICE for necessity, clarity, and collectability on a five point Likert scale, where 1=strongly disagree; 2 =disagree, 3=neutral; 4=agree, 5= strongly agree. The experts were also asked to propose additional items for the Icelandic version of the NMMDS, if needed. An index of agreement was calculated for every item as recommended by Nóbrega and Gutierrez (2000). Moreover, Cronbach's Alpha was calculated to assess internal consistency reliability for the NMMDS sub-scales of “care delivery structure and outcomes”, “clinical decision making complexity”, “environmental complexity”, “autonomy, and “satisfaction” (see Table C4) (Polit \& Beck, 2010).

\section{Research Question Number Two}

What is the aggregate profile of the 1) environment, 2) nursing care resources, and 3) financial resources across acute adult inpatient units in hospitals in Iceland?

Descriptive statistics were used to synthesize and describe data by calculating percentage, means, medians, standard deviations, and frequency distributions for all the questions of the instrument (Polit \& Beck, 2010).

\section{Research Question Number Three}

Are there measurable differences in environmental, nursing care resources, and financial resources among hospitals in Iceland, depending on their geographic location and size?

Table 8 displays the research questions, variables analyzed, and corresponding statistical techniques used in this study. The Mann-Whitney U statistical test was used to 
Table 8. Research Questions and Statistical Analysis

\begin{tabular}{|c|c|c|}
\hline Research Questions & Variables & Statistical Analysis \\
\hline $\begin{array}{l}\text { 1. Does the NMMDS-ICE } \\
\text { demonstrate semantic } \\
\text { equivalence and content } \\
\text { equivalence? }\end{array}$ & $\begin{array}{l}\text { Item } 1-18 \text { of the } \\
\text { NMMDS-ICE }\end{array}$ & $\begin{array}{l}\text { Descriptive statistics } \\
\text { Percentage of agreement } \\
\text { Cronbach’s Alpha }\end{array}$ \\
\hline $\begin{array}{l}\text { 2. What is the aggregate profile } \\
\text { of the environment, nursing } \\
\text { care resources, financial } \\
\text { resources across adult } \\
\text { inpatient health care settings } \\
\text { in hospitals in Iceland? }\end{array}$ & $\begin{array}{l}\text { Items } 1-18 \text { of the } \\
\text { NMMDS-ICE }\end{array}$ & $\begin{array}{l}\text { Descriptive statistics } \\
\text { percentage, means, medians, } \\
\text { standard deviations, and } \\
\text { frequency distributions } \\
\text { Spearman rank correlation } \\
\text { coefficient }\end{array}$ \\
\hline $\begin{array}{l}\text { 3. Are there measurable } \\
\text { differences in environmental, } \\
\text { nursing care resources, and } \\
\text { financial resources among } \\
\text { hospitals in Iceland, } \\
\text { depending on their } \\
\text { geographic location and size? }\end{array}$ & $\begin{array}{l}\text { Items } 1-18 \text { of the } \\
\text { NMMDS-ICE }\end{array}$ & $\begin{array}{l}\text { Descriptive statistics, } \\
\text { Mann-Whitney U test } \\
(\alpha=0.05)\end{array}$ \\
\hline
\end{tabular}

determine if there were significant differences in environmental and nursing care resources, among hospitals in Iceland depending on their location and size. Due to missing data and variations in nurse managers' display of financial data, statistical tests could not be run for the financial resources category of the NMMDS. Spearman rank correlation coefficient was used to assess correlation between the variables of autonomy and satisfaction. A significance level of 0.05 was used in this study (Polit \& Beck, 2006).

\section{Summary}

The design chosen for this study was descriptive methodology. Instrument development consisted of translating the Nursing Management Minimum Data Set (NMMDS $^{\odot}$ ) from the source language, English, to the target language, Icelandic, by method of back-translation, expert validation, and psychometric testing, with permission from the authors. 
The target population was inpatient adult acute care units (excluding psychiatry) and the nurse managers representing each unit. The sample included the entire population under study, and hence, represents the target population. The whole population was selected for this study because it was feasible and desirable to do so. Furthermore, the staff nurses on these acute adult inpatient units at the nurse manager's hospital, excluding the staff nurses at Landspitali, were asked to complete a job satisfaction survey. For this one variable of the NMMDS-ICE the sample does not equal the whole population under study.

The NMMDS-ICE, a paper-and-pencil survey, was mailed to the nurse managers who agreed to participate in the clinical validation of the instrument. Data were collected in 14 hospitals in Iceland in March 2011.

The PASW software for statistical analysis, version 18.0 (SPSS Inc., 2009) was used for data analysis. In the next chapter, the results of this study are displayed and discussed. 


\section{CHAPTER IV}

\section{RESULTS}

The purpose of this study was to adapt to Iceland and clinically test the Nursing Management Minimum Data Set (NMMDS@ 2005) in all adult inpatient care units in the country of Iceland (excluding psychiatry). The study design was a non-experimental descriptive survey. The specific aims of the study were:

1. To translate the Nursing Management Minimum Data Set (NMMDS®) from source language (English) to target language (Icelandic).

2. To validate the translated instrument.

3. To describe the environment, nursing care resources, and financial resources across acute adult inpatient care units in the country of Iceland, using the Icelandic version (NMMDS-ICE@) of the Nursing Management Minimum Data Set (NMMDS@2005).

In this chapter the results of each research question are displayed. Demographic characteristics of the nurse managers and staff nurses are displayed under research question two, nursing care resources. The PASW statistical software package, version 18.0 (SPSS Inc., 2009) was used for statistical analysis.

\section{$\underline{\text { Research Questions }}$}

The study's research questions were:

1. Does the NMMDS-ICE demonstrate semantic equivalence and content equivalence?

2. What is the aggregate profile of the 1) environment, 2) nursing care resources, and 3) financial recourses across acute adult inpatient units in hospitals in Iceland? 
3. Are there measurable differences in environmental, nursing care resources, and financial resources among hospitals in Iceland, depending on their geographic location and size?

\section{$\underline{\text { Return Rate }}$}

As presented in Chapter III, the sample included all adult acute care units, including medical, surgical, intensive, gynecology and maternal care (excluding psychiatry), in all 14 hospitals in Iceland, and the nurse managers $(n=38)$ representing those adult acute inpatient units. Furthermore, the sample included all the staff nurses $(n=234)$ on these units, who were asked to complete a job satisfaction survey, excluding staff nurses working on the units at Landspitali, the University Hospital, due to the nurse executive's condition of participation. Of the 38 nurse managers, 28 returned the survey for a return rate of 74\%; however, because 8 surveys were returned blank, including some with a note that the time commitment was too burdensome, the usable return rate was 53\%. These eight were considered returned but with missing data. Of the 8 blank surveys, 6 nurse managers included the message that they did not have time to complete the survey; it would be too time consuming. As the access to the staff nurses was through the nurse manager, the staff nurses on these units did not receive the satisfaction survey. For staff nurses who received the survey $(n=181)$ on 20 units, due to nonparticipation of nurse managers, and restrictions to access to staff nurses at Ladspitali the return rate was 71\%. The units included $80 \%$ medical/surgical units, 15\% gynecology and maternal care, and 5\% intensive care. The restrictions were due to heavy workload on nurses, as explained by the nurse executive at Landspitali.

\section{Research Question Number One}

Does the NMMDS-ICE demonstrate semantic equivalence and content equivalence? 
Instrument development consisted of translating the Nursing Management Minimum Data Set $\left(\mathrm{NMMDS}^{\odot}\right.$ ) survey from the source language, English, to the target language, Icelandic, expert validation, and psychometric testing in the country of Iceland. Brislin's (1970) back-translation procedure was employed, as recommended by experts on cross-cultural research. Furthermore, both translation and content equivalence were assessed by a panel of experts in nursing administration who were fluent in both languages. To assess if the variables of the NMMDS (see Appendix A) reflected the same meaning (semantic equivalence) between the two countries, the expert panel individually compared both the original and the back-translated version of the NMMDS, rating each variable as having: "exactly the same meaning”, "almost the same meaning" or "a different meaning". The nurse experts were in great agreement on the ratings: of 281 items rated, different ratings only occurred on 24 words. The interrater reliability was $91.5 \%$, measured as percent of agreement among the expert panel raters.

No variable was rated as having a different meaning. The expert panel met and discussed all the items that had received different ratings. Minor revisions on wording were made based on consensus from the panel.

Content validity was established by rating each item of the NMMDS-ICE (see Appendix B) for necessity, clarity, and collectability on a five point Likert scale, where 1=strongly disagree; $2=$ disagree, $3=$ neutral; $4=$ =agree, $5=$ strongly agree (see Table 9 ). The nurse panel experts all rated independently and at different locations. There was 99.7\% agreement among the expert panel on the necessity of collecting the NMMDS data. Only variable \# 18:33 “expenses indirect” was rated differently by one voter $(\mathrm{M}=4.33 ; \mathrm{SD}=1.15)$.

All experts agreed 100\% that 14 NMMDS variables within the Environment category were not applicable within the Icelandic health care system (see Table 3). The variables are: \#01.06 “Medicare payment category”, \# 02.01 “community/outreach”, \# 02.03 “custodial” \#02.08 “nursing home intermediate care”, \# 02.11 "nursing home sub- 
Table 9. Expert Panel Ratings

\begin{tabular}{|c|c|c|c|c|}
\hline $\begin{array}{l}\text { Variab. } \\
\text { number }\end{array}$ & Variable name & $\begin{array}{l}\text { Necessity } \\
\text { Mean }\end{array}$ & $\begin{array}{l}\text { Clarity } \\
\text { Mean }\end{array}$ & $\begin{array}{l}\text { Collectability } \\
\text { Mean }\end{array}$ \\
\hline 01 & Unit/Service Unique Identifier & 5 & 5 & 5 \\
\hline 02 & $\begin{array}{l}\text { Type of Nursing Delivery } \\
\text { Unit/Service }\end{array}$ & 5 & 5 & $4.66(\mathrm{SD}=0.57)$ \\
\hline 03 & $\begin{array}{l}\text { Patient/Client Pop. Specialty } \\
\text { Patient/Client Pop.Dev.Focus } \\
\text { Patient/Client Pop.Intera.Focus } \\
\text { Patient/Client Pop.Focus }\end{array}$ & $\begin{array}{l}5 \\
5 \\
5 \\
5\end{array}$ & $\begin{array}{l}5 \\
5 \\
5 \\
5\end{array}$ & $\begin{array}{l}4.66(\mathrm{SD}=0.57) \\
5 \\
5 \\
4.66(\mathrm{SD}=0.57)\end{array}$ \\
\hline 04 & Volume of Nursing Delivery & 5 & $2.66(\mathrm{SD}=0.57)$ & $2.66(\mathrm{SD}=0.57)$ \\
\hline 05 & $\begin{array}{l}\text { Care Delivery Structure } \\
\text { Outcomes Professional } \\
\text { Outcomes Clinical }\end{array}$ & $\begin{array}{l}5 \\
5 \\
5\end{array}$ & $\begin{array}{l}5 \\
5 \\
5\end{array}$ & $\begin{array}{l}3.66(\mathrm{SD}=0.57) \\
5 \\
4(\mathrm{SD}=1.00)\end{array}$ \\
\hline 06 & Patient/Client Accessibility & 5 & 5 & $3.66(\mathrm{SD}=1.15)$ \\
\hline 07 & $\begin{array}{l}\text { Cl. Decision Making Complx. } \\
\text { Patient/Client Care } \\
\text { Computerization }\end{array}$ & $\begin{array}{l}5 \\
5\end{array}$ & $\begin{array}{l}5 \\
5\end{array}$ & $\begin{array}{l}5 \\
4.33(0.57) \\
5\end{array}$ \\
\hline 08 & Environmental Complexity & 5 & 5 & $3.66(\mathrm{SD}=0.57)$ \\
\hline 09 & Autonomy & 5 & 5 & $4.33(\mathrm{SD}=1.15)$ \\
\hline 10 & $\begin{array}{l}\text { Nursing Delivery Unit/Service } \\
\text { Accreditation }\end{array}$ & 1 & 5 & 1 \\
\hline 11 & $\begin{array}{l}\text { Management Demographic } \\
\text { Profile }\end{array}$ & 5 & 5 & 5 \\
\hline 12 & Staff Demographic Profile & 5 & 5 & 5 \\
\hline 13 & $\begin{array}{l}\text { Staffing/Quantity } \\
\text { Staffing/Turnover } \\
\text { Staffing/Retention }\end{array}$ & $\begin{array}{l}5 \\
5 \\
5\end{array}$ & $\begin{array}{l}5 \\
5 \\
5\end{array}$ & $\begin{array}{l}5 \\
4.66(\mathrm{SD}=0.57) \\
4.66(\mathrm{SD}=0.57) \\
\end{array}$ \\
\hline 14 & Satisfaction & 5 & 5 & 5 \\
\hline 15 & $\begin{array}{l}\text { Payer Type } \\
\text { Government } \\
\text { Self-Pay } \\
\text { Self-Pay Uninsured }\end{array}$ & $\begin{array}{l}5 \\
5 \\
5\end{array}$ & $\begin{array}{l}5 \\
5 \\
5\end{array}$ & $\begin{array}{l}5 \\
5 \\
5\end{array}$ \\
\hline 16 & $\begin{array}{l}\text { Reimbursement } \\
\text { Per Diem } \\
\text { DRGs } \\
\text { Per Visit } \\
\text { Other }\end{array}$ & $\begin{array}{l}5 \\
5 \\
5 \\
5\end{array}$ & $\begin{array}{l}5 \\
5 \\
5 \\
5\end{array}$ & $\begin{array}{l}4.33(\mathrm{SD}=0.57) \\
4.33(\mathrm{SD}=0.57) \\
4.33(\mathrm{SD}=0.57) \\
4.33(\mathrm{SD}=0.57)\end{array}$ \\
\hline 17 & $\begin{array}{l}\text { Nsg Delivery Unit/Serv.Budget } \\
\text { Costs } \\
\text { Revenue }\end{array}$ & $\begin{array}{l}5 \\
5\end{array}$ & $\begin{array}{l}5 \\
5\end{array}$ & $\begin{array}{l}5 \\
3.66(\mathrm{SD}=1.15)\end{array}$ \\
\hline 18 & $\begin{array}{l}\text { Expenses Direct } \\
\text { Expenses Direct Material } \\
\text { Expenses Indirect }\end{array}$ & $\begin{array}{l}5 \\
5 \\
4.33(\mathrm{SD}= \\
1.15)\end{array}$ & $\begin{array}{l}5 \\
5 \\
4.33(\mathrm{SD}=1.15)\end{array}$ & $\begin{array}{l}4.33(\mathrm{SD}=1.15) \\
4.33(\mathrm{SD}=1.15) \\
4.33(\mathrm{SD}=1.15)\end{array}$ \\
\hline
\end{tabular}


acute care”, \#02.12 “free-standing nurse managed clinic”, \# 02.20 “transitional care”, 02.26 “hospital based skilled care”, \# 02.30 “hospital based sub-acute inpatient”, \# 03.13 “developmental ability”, \# 03.45 “ population, aerospace”, \#05.07 “Managed care”, and \# 10 "nursing delivery unit/service accreditation”. Furthermore, it was recommended to add five variables within the Environment category, variable \#03.140 “geriatrics”, \# 03.141 “gynecology”, \#04.110 “average LOS”, \# 04.111 “patient admissions”, and \# 04.112 "number of beds on the unit".

There was 99.3\% agreement among the expert panel members on the clarity of the items of the NMMDS. Only two items were rated differently, variable \# 04 "volume of nursing delivery” (M=2.66; SD=0.57), and variable \# 18.33 “expenses indirect” $(M=4.33$; $\mathrm{SD}=1.15)$.

The expert panel varied more in opinion on the collectability of the NMMDS variables. However, the interrater reliability was 93\%, measured as percent of agreement among the expert panel raters. Of the variables that were rated as necessary, variable \# 4 "volume of nursing delivery" was the only variable that was rated below neutral (M= 2.66; $\mathrm{SD}=0.57)$, i.e. although necessary, it could be difficult to collect the data. The variables “care delivery structure”, and “environmental complexity” received an average score of 3.66 ( $\mathrm{SD}=0.57)$, and "patient/client accessibility", and "revenue" had an average score of 3.66 ( $\mathrm{SD}=1.15)$. All the other ratings were on average 4 (agree) and above (strongly agree) (see Table 9).

Furthermore, there was 100\% agreement among the expert panel to exclude variable \# 11.101 “associate degree” in the Nursing care resources category, and to add the variable “\# 11.109 “ university degree diploma”. There was also 100\% agreement among panel experts to exclude item \# 16.41 "fee for service”, item \# 16.42 “discount fee for service”, item \# 16.45 “all payer group (APG)”, and item \# 16.47 “per member /month” which are all variables of the Financial category. Moreover, the panel 
recommended adding variables \# 15.45 “self-pay without insurance” and variable \# 16.47 "other reimbursement" in order to be specific and appropriate to Iceland.

The NMMDS-ICE (see Appendix B) was pilot tested in two long term care units at Landspitali, the University Hospital in Reykjavik, before the national survey. The results indicated that most of the variables of the NMMDS-ICE (see Appendix B) were collectable on these units. However, both managers agreed that item \#4.1 "volume of nursing delivery unit/service” would not be easily collectable in Iceland. Minor revisions were therefore made, and the "patient, volume of nursing delivery unit/service" was altered to include information on total inpatient beds on unit, patient admissions, and average length of stay. It took the two nurse managers on average 3.5 hours to complete the entire questionnaire. If the data were captured in an electronic information system and collected on a regular basis, this survey would not take such a long time to complete. The estimated time to complete the staff nurse satisfactinon survey was 5 minutes.

Furthermore, the instrument's reliability was tested for internal consistency, that is, how closely the items are related as a group, by summing each item of the sub-scales of the questions (Lee et al, 2005; Maneesriwongul \& Dixon, 2004; Wang et al, 2011). Cronbach's alpha coefficient was used to test for internal consistency. For this analysis, higher reliability coefficient indicates more accurate instrument measures. A coefficient of 0.70 or higher is considered acceptable (Polit \& Beck, 2006).

The variables tested were: 1) satisfaction/position, 2) autonomy, 3) clinical decision making complexity, 4) satisfaction/ context, 5) care delivery/outcomes professional, 6) environmental complexity, and 7) care delivery/outcomes - clinical.

In this study five of the seven variables received Cronbach's alpha coefficient of higher than 0.70 for the overall sub-scales (see Table 10). Both satisfaction/position and autonomy had a moderately high internal consistency (coefficient $\alpha=0.83$ ). Clinical decision making complexity/computerization (coefficient $\alpha=0.74$ ), satisfaction/context (coefficient $\alpha=0.71$ ), and care delivery/outcomes - professional (coefficient $\alpha=0.71$ ), 
all had coefficient alpha values greater than 0.70 , which is acceptable. There were two variables that had lower alpha coefficient values than 0.70 for the sub-scales; environmental complexity (coefficient $\alpha=0.23$ ), and care delivery/outcomes professional (coefficient $\alpha=0.013$ ). Due to the very low alpha score on care delivery/outcomes - professional, the scores of mortality rate, LOS, adverse reactions, and complications were re-coded. This was done because some nurse managers were confused on how to rate this item and reversed the scale, due to lack of clarity about how to rate. Scores were re-coded in such way that a score of 1 was replaced by a score of 5 , and a score of 2 was replaced by a score of 4 . The reliability test was then re-run and the alpha score for the sub-scales increased to $\alpha=0.56$ (see Table 10). Furthermore, the statistical analysis indicated, that the alpha score would further increase to $\alpha=0.61$ if the item LOS would be deleted from the sub-scale.

Table 10. Internal Consistency Testing/Cronbach’s alpha

\begin{tabular}{|l|l|l|}
\hline $\begin{array}{l}\text { Sub-variable } \\
\text { number }\end{array}$ & Variable name & Cronbach alpha \\
\hline $14.111-14.115$ & Satisfaction/Position & 0.83 \\
\hline $09.01-09.04$ & Autonomy & 0.83 \\
\hline $07.201-07.212$ & $\begin{array}{l}\text { Clinical Decision Making } \\
\text { Complexity/Computerization }\end{array}$ & 0.74 \\
\hline $14.211-14.215$ & Satisfaction/Context & 0.71 \\
\hline $05.21-05.24$ & Care Delivery/Outcomes - Professional & 0.71 \\
\hline $08.01-08.03$ & Environmental Complexity & 0.23 \\
\hline $05.31-05.36$ & Care Delivery/Outcomes - Clinical & 0.013 (0.56 re-run) \\
\hline
\end{tabular}

\section{$\underline{\text { Research Question Number Two }}$}

What is the aggregate profile of the 1) environment, 2) nursing care resources, and 3) financial recourses across acute adult inpatient units in hospitals in Iceland? 


\section{Environment}

\section{Type of Nursing Delivery Unit/Service}

This element describes the type of services provided at the unit level, identified in percentages of each category (Delaney \& Huber, 1996; Huber \& Delaney, 2005). This information was provided by all 20 nurse managers. This analysis shows great variability in data, due to the fact that the size and services that these 14 hospitals in Iceland provide vastly differ. There are three types of hospitals in Iceland: two university hospitals, six regional hospitals, and six hospitals where the service is mostly long term care with 2-4 acute beds. No attempt was made to calculate means for this category due to the wide range in frequencies and percentage reported by the nurse managers. The median was the preferred index to describe the central tendency for these sub-variables due to the highly skewed distribution.

Table 11. Type of Nursing Delivery Unit/Service

\begin{tabular}{|l|l|l|l|l|l|}
\hline $\begin{array}{l}\text { Sub- } \\
\text { variable } \\
\text { number }\end{array}$ & Sub-variable name & $\begin{array}{c}\mathbf{N = 2 0} \\
\mathbf{n}\end{array}$ & Median & $\begin{array}{c}\text { Minimum } \\
\mathbf{( \% )}\end{array}$ & $\begin{array}{c}\text { Maximum } \\
\mathbf{( \% )}\end{array}$ \\
\hline 02.25 & Hospital acute inpatient & 18 & 100 & 13 & 100 \\
\hline 02.28 & Hospital-based nursing center & 6 & 37.5 & 2 & 80 \\
\hline 02.29 & Hospital-based outpatient clinic & 4 & 17.5 & 2 & 30 \\
\hline 02.18 & Respite care & 4 & 5 & 4 & 6 \\
\hline 02.27 & Hospital-based critical care inpatient & 1 & 100 & 100 & 100 \\
\hline 02.09 & Nursing home skilled care & 1 & 80 & 80 & 80 \\
\hline 02.21 & Rehabilitation center & 1 & 12.5 & 12.5 & 12.5 \\
\hline 02.23 & Emergency service & 1 & 12 & 12 & 12 \\
\hline 02.31 & Hospital-based home care & 1 & 3 & 3 & 3 \\
\hline
\end{tabular}

The services most often reported by the nurse managers was hospital acute inpatient care (see Table 11), or 18 units (Median=100). Of those 18 units, 10 were described as $100 \%$ acute inpatient, 2 units were described as 90\%-98\% acute inpatient, 4 
units were described as $40 \%$ - $80 \%$ acute inpatient, and 2 units were described as $13 \%$ 20\% acute inpatient. Furthermore, 6 units were described as 2\% - 80\% hospital-based nursing center (Median=37.5). Of those 6 units, 2 were described as $80 \%$ hospital-based nursing center, 2 units were described as 25\% - 50\% hospital-based nursing center, and 2 units were described as 2\% - 15\% hospital-based nursing center. Hospital-based outpatient clinic were described as $2 \%$ - 30\% of the services of 4 units (Median=17.5). Of those 4 units, 2 were described as $2 \%$ - 15\% hospital-based outpatient clinics, and 2 units were described as $20 \%$ - 30\% hospital-based outpatient clinics. Respite care was reported as being 4\% - 6\% of the services provided by 4 units (Median=5). One unit was described as $100 \%$ hospital critical care, one unit was described as $80 \%$ nursing home skilled care, and one unit was described as providing 12.5\% rehabilitation. Finally, one unit was described as providing 12\% emergency services and one unit delivered 3\% of their services to hospital-based home care.

\section{Patient/Client Population}

This element describes the characteristics, including specialty, developmental-, interaction-, and population focus of the patient/client population served by the nursing unit (Delaney \& Huber, 1996). This information was provided by all 20 nurse managers. Again, this analysis shows great variability in data, due to the fact that the size and services these 14 hospitals in Iceland provide differ vastly in terms of bed size and level of services provided. No attempt was made to calculate means for this category due to the wide range in frequencies and percentage reported by the nurse managers. The median was the preferred index to describe the central tendency for these sub-variables due to the highly skewed distribution.

\section{Specialty Services}

This information was provided by all 20 nurse managers. However, 4 nurse managers commented that it was difficult to provide this information. Once again, this 
analysis shows great variability in data, due to the fact that the size and services these 14 hospitals in Iceland provide differ vastly in terms of bed size and level of services provided. No attempt was made to calculate means for this category due to the wide range in frequencies and percentage reported by the nurse managers. The median was the preferred index to describe the central tendency for these sub-variables due to the highly skewed distribution.

The specialty services most often reported by the nurse managers (see Table 12) were, medical (Median=58.5), surgical (Median=65), birthing (Median=75), and geriatrics (Median=60). Five nurse managers reported gynecology (Median=2) as being part of their services, and 3 described emergency/trauma (Median=25) as part of the units’ specialty services. Maternal services (Median=19.5), and rehabilitation (Median=11.5) were reported by 2 nurse managers. Seven other specialty services were

Table 12. Specialty

\begin{tabular}{|c|l|c|c|c|c|}
\hline $\begin{array}{c}\text { Sub-variable } \\
\text { number }\end{array}$ & Sub-variable name & $\begin{array}{c}\mathbf{N = 2 0} \\
\mathbf{n}\end{array}$ & Median & $\begin{array}{c}\text { Minimum } \\
\mathbf{( \% )}\end{array}$ & $\begin{array}{c}\text { Maximum } \\
\mathbf{( \% )}\end{array}$ \\
\hline 03.122 & Medical & 10 & 58.5 & 5 & 100 \\
\hline 03.135 & Surgical & 7 & 65 & 20 & 100 \\
\hline 03.102 & Birthing & 6 & 75 & 3 & 100 \\
\hline 03.140 & Geriatrics & 6 & 60 & 6 & 90 \\
\hline 03.141 & Gynecology & 5 & 2 & 0.5 & 10 \\
\hline 03.116 & Emergency/trauma & 3 & 25 & 10 & 35 \\
\hline 03.120 & Maternal & 2 & 19.5 & 9 & 30 \\
\hline 03.131 & Rehabilitation & 2 & 11.5 & 10 & 13 \\
\hline 03.103 & Cardiology & 1 & 1 & 1 & 1 \\
\hline 03.104 & Communicable disease & 1 & 1 & 1 & 1 \\
\hline 03.106 & Critical care, medical & 1 & 22 & 22 & 22 \\
\hline 03.108 & Critical care, surgical & 1 & 73 & 73 & 73 \\
\hline 03.110 & Critical care, pediatric & 1 & 2 & 2 & 2 \\
\hline 03.118 & Hematology & 1 & 100 & 100 & 100 \\
\hline 03.121 & Child/Pediatric & 1 & 1.5 & 1.5 & 1.5 \\
\hline
\end{tabular}


reported. They are: cardiology (Median=1), communicable disease (Median=1), critical care, medical (Median=22), critical care surgical (Median=73), critical care, pediatric (Median=2), hematology (Median=100), and child/pediatric (Median=1.5).

\section{Developmental Focus}

All 20 nurse managers provided information on this variable. The patient population most often reported by the nurse managers (see Table 13) was middle adult [41 - 64 years] (Median=24.5), young adult [19 -40 years] (Median=17.5), and late adult [age $>64$ years] (Median=63). Six nurse managers noted patient population of mixed or all ages (Median=100), 5 noted adolescents [13 -18 years] (Median=3), 4

Table 13. Developmental Focus

\begin{tabular}{|l|l|l|l|l|l|}
\hline $\begin{array}{l}\text { Sub- } \\
\text { variable } \\
\text { number }\end{array}$ & Sub-variable name & $\begin{array}{l}\mathbf{N = 2 0} \\
\mathbf{n}\end{array}$ & Median & $\begin{array}{l}\text { Minimum } \\
(\mathbf{\%})\end{array}$ & $\begin{array}{l}\text { Maximum } \\
\mathbf{( \% )}\end{array}$ \\
\hline 03.208 & Middle adult (age 41-64 years) & 10 & 24.5 & 2 & 97 \\
\hline 03.207 & Young adult (age 19-40 years) & 10 & 17.5 & 2 & 85 \\
\hline 03.209 & Late adult (age greater than 64 years) & 9 & 63 & 5 & 94 \\
\hline 03.211 & Mixed (all ages) & 6 & 100 & 10 & 100 \\
\hline 03.206 & Adolescent (age 13-18 years) & 5 & 3 & 2 & 20 \\
\hline 03.210 & End of life & 4 & 3.5 & 1 & 10 \\
\hline 03.202 & Infant (age 0-12 months) & 3 & 30 & 2 & 35 \\
\hline 03.205 & Elementary/middle sch (age 7-12 years) & 1 & 5 & 5 & 5 \\
\hline 03.204 & Early childhood (age 2-6 years) & 1 & 3 & 3 & 3 \\
\hline 03.201 & Fetal & 1 & 1 & 1 & 1 \\
\hline
\end{tabular}

provided information on end of life (Median=3.5), and 3 units provide some services to infants [age 0-12 months] (Median=30). The age groups of Elementary/middle school [age 7-12 years] (Median=5), early childhood [age 2-6 years] (Median=3), and fetal (Median=1), where noted by 1 nurse manager. The age group for toddlers [13 - 23 months] was not mentioned by any of the nurse managers. 
Table 14. Interaction Focus

\begin{tabular}{|l|l|l|l|l|l|}
\hline $\begin{array}{l}\text { Sub-variable } \\
\text { number }\end{array}$ & Sub-variable name & $\begin{array}{l}\mathbf{N = 2 0} \\
\mathbf{n}\end{array}$ & Median & $\begin{array}{l}\text { Minimum } \\
\mathbf{( \% )}\end{array}$ & $\begin{array}{c}\text { Maximum } \\
\mathbf{( \% )}\end{array}$ \\
\hline 03.31 & Individual & 17 & 70 & 50 & 100 \\
\hline 03.32 & Family & 18 & 35 & 10 & 100 \\
\hline
\end{tabular}

Interaction Focus

Eighteen nurse managers provided information on this variable. A majority ( $\mathrm{n}=16)$ noted an interaction focus of both individual (Median=70) and family (Median=35) (Table 14). Two units reported 100\% family, and one unit reported 100\% individual interaction focus. None of the units included group or community/population as an interaction focus.

Population Focus

Seventeen nurse managers provided information on this variable (see Table 15). A majority of nurse managers $(n=10)$ described the population served by their units as

Table 15. Population Focus

\begin{tabular}{|l|l|l|l|l|l|}
\hline $\begin{array}{l}\text { Sub-variable } \\
\text { number }\end{array}$ & Sub-variable name & $\begin{array}{l}\mathbf{N = 2 0} \\
\mathbf{n}\end{array}$ & Median & Minimum (\%) & Maximum (\%) \\
\hline 03.46 & Population, region & 10 & 46.5 & 10 & 99 \\
\hline 03.47 & Population, nation & 10 & 9.5 & 1 & 100 \\
\hline 03.44 & Population, province & 5 & 90 & 70 & 100 \\
\hline 03.41 & Population, city/town & 4 & 70 & 15 & 100 \\
\hline 03.48 & Population, international & 4 & 1 & 1 & 5 \\
\hline 03.43 & Population, county/parish & 2 & 87.5 & 85 & 90 \\
\hline
\end{tabular}

population region (Median=46.5) or population nation (Median=9.5). Five nurse managers described their population focus as province (Median=90), and 4 of the 17 
nurse managers described their population as either city/town (Median=70) or international (Median=1). Two nurse managers noted the population to be county/parish (Median=87.5). Population district was not mentioned by any of the nurse managers.

\section{Volume of Nursing Delivery Unit/Service}

This category of the NMMDS describes the amount of available or provided services to an individual, family, group, population or community by the unit (Delaney \& Huber, 1996). For each nursing delivery unit/service the NMMDS survey asks respondents to identify the type of encounter, number of hours of care designated for each encounter, the average number of encounters delivered per 24 hours for the reporting year, and the maximum number of encounters that could be provided during a 24 hour period. Given the recommendations by the expert panel and results from the pilot test, this category was altered to also include information on total inpatient beds on unit, patient admissions, and average length of stay (LOS). This analysis shows great variability in data, due to the fact that the size and services these 14 hospitals in Iceland provide differ vastly in terms of bed size and level of services provided. No attempt was made to calculate means for this category due to the wide range in frequencies and percentage reported by the nurse managers. The median was the preferred index to describe the central tendency for these sub-variables due to the highly skewed distribution.

Table 16. Volume of Nursing Delivery Unit/Service

\begin{tabular}{|l|l|c|c|c|c|}
\hline $\begin{array}{l}\text { Sub-variable } \\
\text { number }\end{array}$ & Sub-variable name & $\begin{array}{c}\text { N=20 } \\
\mathbf{n}\end{array}$ & Median & Minimum & Maximum \\
\hline 04.110 & Number of inpatient beds per unit & 20 & 19 & 5 & 39 \\
\hline 04.111 & Patient admissions & 14 & 670 & 140 & 3,637 \\
\hline 04.102 & Bed occupancy & 12 & 5,273 & 993 & 9,988 \\
\hline 04.112 & Average LOS & 12 & 4.8 & 1.8 & 37 \\
\hline 04.113 & Outpatient encounters & 4 & 419 & 58 & 1,936 \\
\hline
\end{tabular}


All 20 nurse managers provided data on total inpatient beds on the unit (see Table 16), which ranged from a minimum of 5 beds to a maximum of 39 beds (Median=19). Only 14 nurse managers provided information on total number of patient admissions, which ranged from 140 - 3,637 (Median=670) admissions for the reporting year (2010); and only 12 nurse managers provided information on bed occupancy, which ranged from 993 - 9,988 (Median=5,273) patient days. Similarly, only 12 nurse managers provided information on average LOS, which ranged from 1.8 - 37 days (Median=4.8).

All 4 nurse managers who reported hospital-based outpatient services in the category of type of nursing delivery provided data on total number of encounters for the reporting year (2010). Outpatient services ranged from a minimum of 58 encounters to a maximum of 1,936 encounters (Median=419). None of the nurse managers provided any information on visits, procedures, consults, contacts, programs, classes or enrollees.

\section{$\underline{\text { Care Delivery Structure and Outcomes }}$}

This category includes three elements; care delivery structure, outcomes professional, and outcomes - clinical.

\section{Care Delivery Structure}

The care delivery structure is measured by the form of provided care (Delaney \& Huber, 1996; Huber \& Delaney, 2005). All 20 nurse managers provided information on

Table 17. Care Delivery Structure

\begin{tabular}{|l|l|c|c|c|c|}
\hline $\begin{array}{l}\text { Sub-variable } \\
\text { number }\end{array}$ & Sub-variable name & $\begin{array}{c}\text { N=20 } \\
\mathbf{n}\end{array}$ & Median & $\begin{array}{c}\text { Minimum } \\
\mathbf{( \% )}\end{array}$ & $\begin{array}{c}\text { Maximum } \\
\mathbf{( \% )}\end{array}$ \\
\hline 05.03 & Team & 9 & 100 & 30 & 100 \\
\hline 05.04 & Total patient care & 8 & 60 & 30 & 100 \\
\hline 05.05 & Primary nursing & 7 & 70 & 30 & 100 \\
\hline 05.02 & Functional & 2 & 100 & 100 & 100 \\
\hline
\end{tabular}


the structure of care delivery provided on the unit. Team nursing was the care delivery most often reported by the nurse managers (see Table 17) (Median=100). Total patient care was reported by eight nurse managers (Median=60), seven reported primary nursing (Median=70), and 2 reported 100\% functional nursing.

\section{Outcomes - Professional}

The professional nurse outcomes category includes four variables rated on a five point Likert scale ( $1=$ lowest; 5 = highest) regarding to what extent the outcomes have been met. The variables are: 1) reward and pay for performance, 2) career mobility and expansion, 3) recognition by nurses for meaningful contribution to practice, and 4) nursing care personnel injury rate. The results are presented in Table 18. A great majority of the twenty nurse managers rated reward and pay for performance low. No one rated this item higher than 3; the mean score was $2.15(\mathrm{SD}=0.67)$. The mean score for career mobility and expansion was similar, or 2.85 ( $\mathrm{SD}=0.87)$. Most of the nurse managers seemed to perceive recognition by other nurses for their contribution to the practice of nursing, average rating $3.68(\mathrm{SD}=1.00)$, and the injury rate among nursing personnel seems to be low (mean $4.75, \mathrm{SD}=0.44$ ). Data were missing on one unit for the item "recognition by nurses for meaningful contribution to practice".

Table. 18 Outcomes - Professional

\begin{tabular}{|c|c|c|c|c|c|c|}
\hline $\begin{array}{l}\text { Sub- } \\
\text { variable } \\
\text { number }\end{array}$ & Sub-variable name & $\begin{array}{l}\mathbf{N}=\mathbf{2 0} \\
\mathrm{n}\end{array}$ & Mean & SD & Min. & Max \\
\hline 05.21 & Reward and pay for performance & 20 & 2.15 & 0.67 & 1 & 3 \\
\hline 05.22 & Career mobility and expansion & 20 & 2.85 & 0.87 & 1 & 4 \\
\hline 05.23 & $\begin{array}{l}\text { Recognition. by nurses for meaningful } \\
\text { contribution to practice }\end{array}$ & 19 & 3.68 & 1.00 & 2 & 5 \\
\hline 05.24 & Nursing care personnel injury rate & 20 & 4.75 & 0.44 & 4 & 5 \\
\hline
\end{tabular}




\section{Outcomes - Clinical}

The clinical patient outcomes category includes six variables rated on a five point Likert scale (1=lowest; $5=$ highest), regarding to what extent the outcomes have been met. The variables are: 1) mortality rate, 2) length of stay, 3) adverse reactions 4) complications, 5) pain management level achieved, and 6) maintenance of skin integrity. Overall, nurse managers rated mortality rate as low, or on average $1.47(\mathrm{SD}=0.77)$ (see Table 19). Data were missing from one unit. The average rating for length of stay was $2.56(\mathrm{SD}=1.09)$. Data were missing from two units. Adverse reactions were reported with a mean of $2.58(\mathrm{SD}=1.07)$, and complications were similar, with a mean of 2.37 $(S D=1.16)$. Data were missing from one unit. Pain management level seemed to be achieved in most cases; the mean was $4.11(\mathrm{SD}=0.58)$. Data on this variable were missing from two units. Maintenance of skin integrity was also rated high, with a mean of $4.56(\mathrm{SD}=0.70)$. Data were missing from two units. Three nurse managers commented that it was confusing to determine how to rate some of the variables. It was not clear whether a low mortality rate should be given a high score of five or a low score of one. Moreover, a suggestion was made to add to this variable "avoidable mortality rate”. Furthermore, how one should measure length of stay was confusing. For example, would high LOS be worse, although it is sometimes safer for the patient? This nurse

Table19. Outcomes - Clinical

\begin{tabular}{|l|l|l|l|l|l|l|}
\hline $\begin{array}{l}\text { Sub-variable } \\
\text { number }\end{array}$ & Sub-variable name & $\mathbf{N = 2 0}$ & & & & \\
\hline 05.31 & Mortality rate & $\mathbf{n}$ & Mean & SD & Min. & Max \\
\hline 05.32 & Length of stay (LOS) & 19 & 1.47 & 0.77 & 1 & 3 \\
\hline 05.33 & Adverse reactions & 18 & 2.56 & 1.09 & 1 & 5 \\
\hline 05.34 & Complications & 19 & 2.58 & 1.07 & 1 & 4 \\
\hline 05.35 & Pain management level achieved & 18 & 4.11 & 0.58 & 3 & 5 \\
\hline 05.36 & Maintenance of skin integrity & 18 & 4.56 & 0.70 & 3 & 5 \\
\hline
\end{tabular}


manager commented that due to long travel distances between the patient's home and the hospital out in the country, patients might be discharged later than in the capital area. Results mirror some confusion on the measurement for mortality rate, LOS, adverse reactions and complications. Table 19 shows raw data before the data on mortality rate, LOS, adverse reactions and complications were re-coded. Due to low Cronbach's alpha levels, these data were re-coded in such way that a score of 1 was replaced by a score of 5 , and a score of 2 was replaced by a score of 4 . The reliability test was then re-run and the alpha score for the sub-scales increased to $\alpha=0.56$.

\section{Clinical Decision Making Complexity}

The complexity of care is measured by the perceived degree of routineness, consistency, predictability, and level of expert knowledge, which impact the delivery of care (Delaney \& Huber, 1996). This category includes two elements; patient/client care and computerization. Complexity is measured on a five point Likert scale (1=lowest; $5=$ highest).

\section{Patient/client care}

For the category of patient/client care, perceived professional judgment, experience and intuition received the highest score (see Table 20). The mean for this variable was $4.32(\mathrm{SD}=0.47)$ and minimum score was rated 4 . Data were missing from one unit. Expert knowledge was also rated high by a majority of the nurse managers, with a mean of $3.74(\mathrm{SD}=0.99)$. Data were missing from one unit. Standardized procedures of care received an average rating of 3.53 (SD=0.90). Missing data included one unit. Variability or exceptions was most often rated neutral, the average was 3.12 $(S D=0.78)$. Data were missing from three units. 
Table 20. Patient/Client Care

\begin{tabular}{|c|c|c|c|c|c|c|}
\hline $\begin{array}{l}\text { Sub-variable } \\
\text { number }\end{array}$ & Sub-variable name & $\begin{array}{l}\mathrm{N}=\mathbf{2 0} \\
\mathrm{n}\end{array}$ & Mean & SD & Min. & Max \\
\hline 07.11 & Standardized procedures/care & 19 & 3.53 & 0.90 & 1 & 5 \\
\hline 07.12 & Variability or exceptions & 17 & 3.12 & 0.78 & 2 & 4 \\
\hline 07.13 & $\begin{array}{l}\text { Perceived professional judgment } \\
\text { experience and intuition }\end{array}$ & 19 & 4.32 & 0.47 & 4 & 5 \\
\hline 07.14 & Expert knowledge & 19 & 3.74 & 0.99 & 1 & 5 \\
\hline
\end{tabular}

\section{Computerization}

For the category computerization, respondents were asked to estimate the extent of computerization on their unit (see Table 21). Overall, the extent of computerization seems to be low on the units. All 20 nurse managers scored history/assessment, with an average score of $3.50(\mathrm{SD}=1.05)$. Ratings for documentation were somewhat similar to history/assessment, mean ratings were $3.32(\mathrm{SD}=1.37)$. Data were missing on one unit. The mean on discharge planning was $3.05(\mathrm{SD}=1.50)$. Data were missing on one unit. Ratings on care plan revealed an average score of $3.74(\mathrm{SD}=1.68)$. Missing data included two units. The average rating on graphics was 2.59 ( $\mathrm{SD}=1.46)$. All nurse managers provided information on this item. Medication was on average rated 3.16 ( $\mathrm{SD}=1.74)$; data were missing for one unit. Physiological monitoring does not seem to be very accessible on computers. Three nurse managers did not rate this item; the mean score was 2.59 ( $\mathrm{SD}=1.46)$. Only 15 nurse managers provided data on data repository and management data. Data repository received an average score of 2.67 (SD=1.63), and management data had an average score of 2.69 ( $\mathrm{SD}=1.49)$. Decision support did not get 
Table 21. Computerization

\begin{tabular}{|l|l|l|l|l|l|l|}
\hline $\begin{array}{l}\text { Sub-variable } \\
\text { number }\end{array}$ & Sub-variable name & $\mathbf{N = 2 0}$ & & & & \\
\hline 07.201 & History/assessment & 20 & 3.50 & 1.05 & 1 & 5 \\
\hline 07.202 & Documentation & 19 & 3.32 & 1.37 & 1 & 5 \\
\hline 07.203 & Discharge planning & 19 & 2.83 & 1.50 & 1 & 5 \\
\hline 07.204 & Care plan & 18 & 3.74 & 1.68 & 1 & 5 \\
\hline 07.205 & Graphics & 20 & 2.85 & 1.49 & 1 & 5 \\
\hline 07.206 & Medication & 19 & 3.16 & 1.74 & 1 & 5 \\
\hline 07.207 & Physiological monitoring & 17 & 2.59 & 1.46 & 1 & 5 \\
\hline 07.208 & Data repository & 15 & 2.67 & 1.63 & 1 & 5 \\
\hline 07.209 & Management data & 15 & 2.69 & 1.49 & 1 & 5 \\
\hline 07.210 & Decision support & 17 & 3.00 & 1.22 & 1 & 5 \\
\hline 07.211 & Acuity/workload & 18 & 1.94 & 1.30 & 1 & 5 \\
\hline 07.212 & Standardized nursing languages & 16 & 2.00 & 1.36 & 1 & 5 \\
\hline
\end{tabular}

high ratings either, with a mean score of $3(S D=1.22)$. Acuity/workload and standardized nursing languages received the lowest scores: acuity on average was rated 1.94 $(\mathrm{SD}=1.30)$, and standardized nursing languages was on average rated $2.0(\mathrm{SD}=1.36)$.

Environmental Complexity

The complexity of the environment measures the perceived amount of patient turnover, heterogeneity and stability of the unit climate (Huber \& Delaney, 2005). Environmental complexity is measured on a five point Likert scale (1=lowest; 5= highest).

All 20 nurse managers rated each of the items. Patient turnover was most often rated as shifting, with a mean rating of $3.65(\mathrm{SD}=1.26)$. The patient population seems to be rather diverse (mean 3.80; $\mathrm{SD}=1.15$ ). However, the climate on the units was most often rated stable (mean 2.40; SD=1.04). Data are displayed in Table 22.

\section{Autonomy}

Autonomy is measured by degree of freedom to act, perceived control, and 
Table 22. Environmental Complexity

\begin{tabular}{|l|l|l|l|l|l|l|}
\hline $\begin{array}{l}\text { Sub-variable } \\
\text { number }\end{array}$ & Sub-variable name & N=20n & Mean & SD & Min. & Max \\
\hline 08.01 & Patient/Client turnover & 20 & 3.65 & 1.26 & 1 & 5 \\
\hline 08.02 & Heterogeneity of Patient/Client Mix & 20 & 3.80 & 1.15 & 2 & 5 \\
\hline 08.03 & Environmental Climate & 20 & 2.40 & 1.04 & 1 & 5 \\
\hline
\end{tabular}

opportunity to participate in organizational decision-making (Delaney \& Huber, 1996;

Huber \& Delaney, 2005). Autonomy is measured on a five point Likert scale (1=never; $5=$ always).

Overall, nurse managers seem to perceive having autonomy and good control on their units (see Table 23). Clinical autonomy was rated on average 4.53 (SD=0.51) by 19 nurse managers, and professional autonomy received an average score of $4.58(\mathrm{SD}=0.60)$. Control over nursing practice received the highest average score, 4.72 ( $\mathrm{SD}=0.57)$ rated by 18 nurse managers. Freedom to act on what you know was on average rated 4.44 ( $S D=0.61)$, and accountability and authority in decision making had a mean score of 4.00 $(\mathrm{SD}=0.76)$. Only 16 nurse managers provided data on freedom from bureaucratic constraints, which received the lowest score, an average of 3.38 (SD=0.88).

Table 23. Autonomy/Unit/Service Manager

\begin{tabular}{|c|c|c|c|c|c|c|}
\hline $\begin{array}{l}\text { Sub- } \\
\text { variable } \\
\text { number }\end{array}$ & Sub-variable name & $\begin{array}{l}\mathrm{N}=\mathbf{2 0} \\
\mathrm{n}\end{array}$ & Mean & SD & Min. & $\operatorname{Max}$ \\
\hline 09.01 & Clinical autonomy & 19 & 4.53 & 0.51 & 4 & 5 \\
\hline 09.01 & Professional autonomy & 19 & 4.58 & 0.60 & 3 & 5 \\
\hline 09.01 & Control over nursing practice & 18 & 4.72 & 0.57 & 3 & 5 \\
\hline 09.01 & Freedom to act on what you know & 18 & 4.44 & 0.61 & 3 & 5 \\
\hline 09.01 & Freedom from bureaucratic constraints & 16 & 3.38 & 0.88 & 2 & 5 \\
\hline 09.01 & $\begin{array}{l}\text { Allows for accountability and authority in } \\
\text { decision making }\end{array}$ & 18 & 4.00 & 0.76 & 3 & 5 \\
\hline
\end{tabular}


Table 24. Autonomy/Department of Nursing

\begin{tabular}{|c|c|c|c|c|c|c|}
\hline $\begin{array}{l}\text { Sub- } \\
\text { variable } \\
\text { number }\end{array}$ & Sub-variable name & $\begin{array}{l}\mathrm{N}=\mathbf{2 0} \\
\mathrm{n}\end{array}$ & Mean & SD & Min. & Max \\
\hline 09.02 & Clinical autonomy & 4 & 4.25 & 0.95 & 3 & 5 \\
\hline 09.02 & Professional autonomy & 4 & 5.00 & 0.00 & 5 & 5 \\
\hline 09.02 & Control over nursing practice & 4 & 5.00 & 0.00 & 5 & 5 \\
\hline 09.02 & Freedom to act on what you know & 4 & 4.75 & 0.50 & 4 & 5 \\
\hline 09.02 & Freedom from bureaucratic constraints & 4 & 4.25 & 0.50 & 4 & 5 \\
\hline 09.02 & $\begin{array}{l}\text { Allows for accountability and authority in } \\
\text { decision making }\end{array}$ & 4 & 4.25 & 0.95 & 3 & 5 \\
\hline
\end{tabular}

Only 4 of the 20 nurse managers provided information on autonomy for the department of nursing (see Table 24). Responses indicate that nurse managers seem to perceive control of the department of nursing. Clinical autonomy was rated on average 4.25 ( $\mathrm{SD}=0.95)$. The nurse managers were all in complete agreement when rating professional autonomy and control over nursing practice, which both received an average score of $5.00(\mathrm{SD}=0.00)$. Freedom to act on what you know was on average rated 4.75 $(\mathrm{SD}=0.50)$, freedom from bureaucratic constraints had a mean of $4.25(\mathrm{SD}=0.50)$ and accountability and authority in decision making had also a mean score of $4.25(\mathrm{SD}=0.95)$.

Table 25. Autonomy/Organization e.g. Chief Nurse Executive

\begin{tabular}{|c|c|c|c|c|c|c|}
\hline $\begin{array}{l}\text { Sub- } \\
\text { variable } \\
\text { number }\end{array}$ & Sub-variable name & $\begin{array}{l}\mathbf{N}=\mathbf{2 0} \\
\mathrm{n}\end{array}$ & Mean & SD & Min. & Max \\
\hline 09.03 & Clinical autonomy & 9 & 4.33 & 0.70 & 3 & 5 \\
\hline 09.03 & Professional autonomy & 10 & 4.60 & 0.69 & 3 & 5 \\
\hline 09.03 & Control over nursing practice & 10 & 4.80 & 0.42 & 4 & 5 \\
\hline 09.03 & Freedom to act on what you know & 10 & 4.30 & 0.67 & 3 & 5 \\
\hline 09.03 & Freedom from bureaucratic constraints & 10 & 2.90 & 0.99 & 2 & 5 \\
\hline 09.03 & $\begin{array}{l}\text { Allows for accountability and authority in } \\
\text { decision making }\end{array}$ & 10 & 4.20 & 0.78 & 3 & 5 \\
\hline
\end{tabular}


Ten of the 20 nurse managers provided information on autonomy for the chief nurse executive (see Table 25). Clinical autonomy was rated on average 4.33 (SD=0.70), professional autonomy 4.60 (SD=0.69), and control over nursing practice 4.80 $(\mathrm{SD}=0.42)$. Freedom to act on what you know was on average rated $4.30(\mathrm{SD}=0.67)$, freedom from bureaucratic constraints had a mean of $2.90(\mathrm{SD}=0.99)$, and accountability and authority in decision making had also a mean score of 4.20 (SD=0.78).

\section{Nursing Care Resources}

What is the aggregate profile of nursing care resources across acute adult inpatient units in hospitals in Iceland?

\section{Management Demographic Profile}

A majority of the 20 nurse managers, or 14 (70\%), had a BSN degree in nursing; the other 5 nurse managers (25\%) had an Associate nursing degree from the Icelandic State School of Nursing (see Figure 3). Furthermore, 12 (60\%) had a diploma degree, which is continuing education in a nursing specialty offered at the university level in Iceland, but without an official master's degree, and 1 (5\%) had a master's degree. One nurse manager (5\%) was male. Years of experience as a nurse manager (see Table 26) varied from 1.5 to 26 years, or on average $13.47(\mathrm{SD}=7.79)$ years. Experience in nursing varied from 13 to 38 years, and average experience was $25.29(\mathrm{SD}=7.91)$ years. The age of the nurse managers ranged from 34 to 60 years, with a mean age of $49.26(\mathrm{SD}=6.76)$.

Eight units presented data on an assistant nurse manager (nurse manager 2). They were all but one educated at the BSN level, and 5 had further nursing education at the UI diploma level. All were female. The number of years in current position varied from 1 to 10 years, on average this was $3.57(\mathrm{SD}=2.96)$ years. Experience in nursing ranged from 6 to 28 years, with an average of $15.66(S D=7.71)$ years working as a nurse. 
Figure 3. Management Demographic Profile/Education

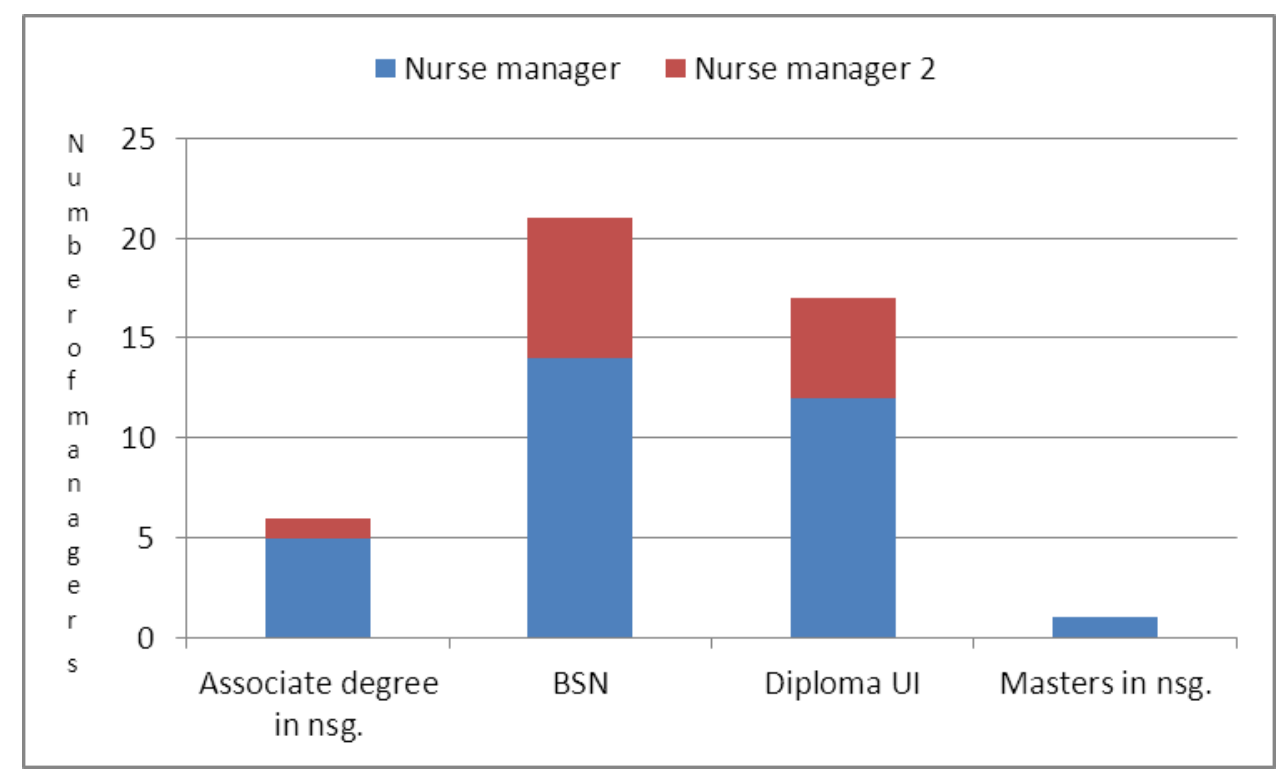

\section{$\underline{\text { Staff Demographic Profile }}$}

A great majority of the reported staff nurses had a BSN degree in nursing, or $81 \%$ $(n=147)$; and 16\% $(n=29)$ had an Associate nursing degree from the Icelandic State School of Nursing (see Figure 3). Midwives were 18\% ( $n=31)$ of the reported staff. Furthermore, $15 \%(n=27)$ of the staff nurses had a continuing education at the University diploma level, but without an official Master’s degree, and 4\% (n=7) had a Master’s degree. The average age of the staff nurses/midwives was 41.08 (SD=9.53). The number of years in current position varied from zero to eighteen years, or on average 5.48 $(\mathrm{SD}=4.80)$ years.

\section{$\underline{\text { Staffing }}$}

This category includes three sub-classes. They are 1) quantity, 2) turnover, and 3) retention. All the nurse managers provided some information on staffing. Staffing on the hospital units included RNs/midwives, LPNs, nurse aids, nursing students, and unit 
Table 26. Management Demographic Profile/Experience

\begin{tabular}{|l|l|l|l|l|l|l|}
\hline $\begin{array}{l}\text { Sub-variable } \\
\text { number }\end{array}$ & Sub-variable name & $\mathbf{N = 2 0}$ & & & & \\
\hline 11.131 & Years of experience as a manager & 20 & 13.47 & 7.79 & 1.5 & 26 \\
\hline 11.132 & Years of experience in nursing & 20 & 25.29 & 7.91 & 13 & 38 \\
\hline 11.231 & Years of experience as a manager 2 & 8 & 3.57 & 2.96 & 1 & 10 \\
\hline 11.232 & Years of experience in nursing & 8 & 15.66 & 7.71 & 6 & 28 \\
\hline
\end{tabular}

clerks. One nurse manager made a comment that she/he was also the quality improvement staff and educator. Independent contractors or agency/travelers were not part of unit staffing.

\section{Quantity}

The number of budgeted staff was variable (see Table 27), or varied from 2 nurses/midwifes to 39 nurses/midwifes working per unit. The average number of nurses/midwifes was 15.40 (SD=8.97). This information was provided by all 20 nurse managers. Nurses/midwifes working full time (FTEs) varied from a minimum of 1.6 to a maximum of 24.7; on average this was 10.90 ( $\mathrm{SD}=5.59)$. Nineteen nurse managers provided this information. Average daily RN staffing was close to eight nurses/midwifes or mean=7.59 (SD=3.21). The minimum daily staffing included 4 nurses/midwifes and the maximum was 15 nurses/midwifes. Data on this variable was provided by 17 units.

LPNs in Iceland are supervised by nurses. Two units did not employ LPNs. The number of LPNs varied from a minimum of 1 to a maximum of 24, or on average 12 ( $S D=5.66)$ per unit. Full time LPNs were on average 8.13 (SD = 3.71), and varied from a minimum of 0.6 to a maximum of 14 per unit. Average daily staffing of LPNs was 7.14 ( $S D=3.07)$, with a minimum daily staffing of 2 LPNs and a maximum of 12 LPNs.

Nurse aides or equivalent were part of budgeted staff on 11 units. The number of nurse aides varied from 1 to 18 per unit, on average this was 8.09 (SD=6.60). Budgeted 
Table 27. Staffing/Quantity

\begin{tabular}{|l|l|l|l|l|l|l|}
\hline $\begin{array}{l}\text { Sub-variable } \\
\text { number }\end{array}$ & Sub-variable name & $\mathbf{N = 2 0}$ & & & & \\
\hline 13.102 & Budgeted number of RNs/midw & 20 & 15.40 & 8.97 & 2 & 39 \\
\hline 13.102 & Budgeted RNs/midw FTEs & 19 & 10.90 & 5.59 & 1.6 & 24.7 \\
\hline 13.102 & Average daily productive staff & 17 & 7.59 & 3.21 & 4 & 15 \\
\hline 13.103 & Budgeted number of LPNs & 18 & 12.00 & 5.66 & 1 & 24 \\
\hline 13.103 & Budgeted LPN FTEs & 18 & 8.13 & 3.71 & 0.6 & 14 \\
\hline 13.103 & Average daily productive staff & 15 & 7.14 & 3.07 & 2 & 12 \\
\hline 13.104 & Budgeted number of Aides or eq. & 11 & 8.09 & 6.60 & 1 & 18 \\
\hline 13.104 & Budgeted Aides or eq. & 11 & 5.45 & 4.48 & 1 & 12.3 \\
\hline 13.104 & Average daily productive staff & 5 & 4.01 & 3.26 & 1 & 8.9 \\
\hline
\end{tabular}

FTEs for nurse aides ranged from 1 to 12.3 , or on average 5.45 (SD=4.48). The daily average number of nurse aides was $4.01(\mathrm{SD}=3.26)$, where minimum staffing included 1 staff member and the maximum of 8.9 nurse aides. Only 5 nurse managers provided data on this variable.

Nursing students were on average $3.5(\mathrm{SD}=2.12)$, mentioned as part of supervised staff by two nurse managers. Four nurse managers included nursing students as part of their budgeted staff. The number of nursing students ranged from 1 to 4 , or on average 2.5 (SD=1.29) nursing students. Nursing students were included in FTEs on two units, and varied from 0.4 to 0.8; on average this was 0.60 (SD=0.28) FTEs. Nursing students were not mentioned as being part of average daily staffing on those units.

\section{Turnover}

One nurse manager reported on voluntary turnover for 1 midwife, and 5 nurse managers reported on the number of budgeted positions filled (see Table 28), which ranged from 4-23.7 positions, on average 8.6 (SD=8.08). Eight nurse managers provided data on voluntary turnover of nurses. The range was from 1 to 4 nurses, with an average turnover rate of $7 \%$. A comment was made by 3 nurse managers that there was 
Table 28. Staffing/Turnover

\begin{tabular}{|l|l|l|l|l|l|l|}
\hline $\begin{array}{l}\text { Sub- } \\
\text { variable } \\
\text { number }\end{array}$ & Sub-variable name & $\mathbf{N = 2 0}$ & & & & \\
\hline 13.201 & Midwifes voluntary turnover & $\mathbf{n}$ & Mean & SD & Min. & Max \\
\hline 13.201 & Midwifes \#of budgeted positions filled & 1 & 1 & & 1 & 1 \\
\hline 13.202 & RNs voluntary turnover & 8 & 10.17 & 8.01 & 4 & 23.7 \\
\hline 13.202 & RNs \#of budgeted positions filled & 12 & 1.75 & 1.16 & 1 & 4 \\
\hline 13.203 & LPNs voluntary turnover & 2 & 2 & 4.03 & 4 & 16.1 \\
\hline 13.203 & LPNs\#of budgeted positions filled & 12 & 7.94 & 4.21 & 1 & 3 \\
\hline 13.204 & Nurse Aides voluntary turnover & 3 & 2 & 1.73 & 1 & 4 \\
\hline 13.204 & Nurse Aides \#of budgeted positions filled & 7 & 5.62 & 4.75 & 1 & 12.3 \\
\hline 13.205 & Nsg. students involuntary turnover & 1 & 1 & & 1 & 1 \\
\hline 13.205 & Nsg. students\#of budgeted positions filled & 1 & 0.6 & & 0.6 & 0.6 \\
\hline 13.212 & Nrs. manager \#of budgeted positions filled & 17 & 1 & 0.35 & 1 & 2 \\
\hline 13.216 & Sup. staff/unit clerks \# of positions filled & 7 & 0.98 & 0.56 & 0.25 & 2.10 \\
\hline
\end{tabular}

no turnover for the reporting year. The number of budgeted RN positions filled was provided by 12 nurse managers. The range was 4-16.1 positions, which on average was $10.32(\mathrm{SD}=4.03)$.

Two nurse managers reported voluntary turnover of LPNs. The range was from 1 to 3 LPNs, with an average turnover of $2(S D=1.41)$. The number of budgeted positions filled by LPNs was provided by 12 nurse managers. The range was from 0.6 to 14 LPNs, on average $7.94(\mathrm{SD}=4.21)$.

Voluntary turnover of nurse aids was reported by 3 nurse managers. The range was from 1 to 4 nurse aides, with an average turnover of $2(\mathrm{SD}=1.73)$. The number of budgeted positions filled by nurse aides was provided by 7 nurse managers. The range was from 1 to $12.3 \mathrm{LPNs}$, on average $5.62(\mathrm{SD}=4.75)$.

Involuntary turnover was reported by 1 nurse manager for a nursing student. One manager also reported on an average 0.6 budgeted position for nursing students.

Seventeen nurse managers reported on the number of budgeted positions filled for nurse managers, which was the same for the majority of units. However one unit 
reported 2 positions filled (Mean=1; $\mathrm{SD}=0.35$ ). Data were provided by 7 nurse managers on the number of budgeted positions filled by unit clerks. The range was from 0.25 to 2.10, on average this was 0.98 ( $\mathrm{SD}=0.56$ ). Information on average turnover and average vacancy was missing on all units.

Table 29. Staffing/Retention

\begin{tabular}{|l|l|l|l|l|l|l|}
\hline $\begin{array}{l}\text { Sub-variable } \\
\text { number }\end{array}$ & & $\mathbf{N = 2 0}$ & & & & \\
& Sub-variable name & n & Mean & SD & Min. & Max \\
\hline 13.301 & Midwives stability rate & 4 & 100 & 0.00 & 100 & 100 \\
\hline 13.302 & RNs accession rate & 3 & 100 & 0.00 & 100 & 100 \\
\hline 13.302 & RNs stability rate & 11 & 90 & 8.60 & 75 & 100 \\
\hline 13.302 & RNs instability rate & 8 & 13.58 & 6.92 & 3 & 25 \\
\hline 13.302 & RNs separation rate & 6 & 14.45 & 7.94 & 3 & 25 \\
\hline 13.302 & RNs survival rate & 2 & 100 & 0.00 & 100 & 100 \\
\hline 13.302 & RNs wastage rate & 1 & 10 & 0.00 & 10 & 10 \\
\hline 13.303 & LPNs accession rate & 3 & 100 & 0.00 & 100 & 100 \\
\hline 13.303 & LPNs stability rate & 9 & 96.88 & 6.25 & 84 & 100 \\
\hline 13.303 & LPNs instability rate & 2 & 13.5 & 3.53 & 11 & 16 \\
\hline 13.303 & LPNs separation rate & 1 & 11 & 0.00 & 11 & 11 \\
\hline 13.303 & LPNs survival rate & 2 & 100 & 0.00 & 100 & 100 \\
\hline 13.304 & Nurse Aides stability rate & 4 & $93.5(\mathrm{Md}=99)$ & 12.34 & 75 & 100 \\
\hline 13.304 & Nurse Aides instability rate & 3 & $42(\mathrm{Md}=25)$ & 51.6 & 1 & 100 \\
\hline 13.304 & Nurse Aides separation rate & 3 & $42(\mathrm{Md}=25)$ & 51.6 & 1 & 100 \\
\hline 13.304 & Nurse Aides survival rate & 2 & 100 & 0.00 & 100 & 100 \\
\hline 13.305 & Nsg.stud. stability rate & 1 & 100 & 0.00 & 100 & 100 \\
\hline 13.305 & Nsg.stud. instability rate & 1 & 100 & 0.00 & 100 & 100 \\
\hline 13.312 & Nrs. manager stability rate & 20 & 100 & 0.00 & 100 & 100 \\
\hline 13.316 & Sup.st/unit clerks stability rate & 7 & 100 & 0.00 & 100 & 100 \\
\hline
\end{tabular}

\section{Retention}

Four nurse managers provided information on the stability rate of midwifes, but did not provide information on other retention variables. The stability rate of midwifes was $100 \%$ on all units (see Table 29). Three nurse managers reported on RNs accession 
rate, which was $100 \%$ on all three units. Information on RNs stability rate was provided by 11 nurse managers. The range was from $75 \%-100 \%$, an average rate of $90 \%$ $(\mathrm{SD}=8.60)$. RNs instability rate was provided by 8 nurse managers, and ranged from $3 \%-25 \%$, or on average $13.58 \%(S D=6.92)$. RNs separation rate was on average $14.45 \%$ ( $\mathrm{SD}=7.94)$, ranging from 3\%-25\%, as reported by 6 nurse managers. RNs survival rate was reported by 2 nurse managers; both rated 100\%. One nurse manager provided data on RNs wastage rate, which was $10 \%$.

LPNs accession rate was provided by 3 nurse managers, who all rated $100 \%$. LPNs stability rate was given by 9 nurse managers. The range was from $84 \%-100 \%$, an average rate of 97\% (SD=6.25). Two nurse managers rated on LPNs instability rate, which ranged from 11\%-16\%, on average 13.5\% (SD=3.53). LPNs separation rate was presented by 1 nurse manager, and was 11\%. Two nurse managers provided information on LPNs survival rate, which was rated $100 \%$ by both managers. No information was provided on LPNs wastage rate.

Nurse aides' stability rate was provided by 4 nurse managers. The range was from 75\%-100\%, an average rate of 93.5\% (SD=12.34; $\mathrm{Md}=99)$. The instability rate and separation rate for nurse aides was provided by 3 nurse managers, and varied greatly among units. The instability and the separation rate ranged from 1\%-100\%, an average rate of $42 \%(\mathrm{SD}=51.64 ; \mathrm{Md}=42)$. Two nurse managers rated on the survival rate of nurse aides; which was rated $100 \%$ by both managers. No information was provided on nurse aides accession- or wastage rate.

The stability rate of nursing students was provided by 1 nurse manager, who rated this item at $100 \%$. One nurse manager rated on the instability rate of nursing students, which was $100 \%$ for the unit. No information was provided on accession-, separation-, survival- or wastage rate by any of the nurse managers. 
All 20 nurse managers provided information on the stability rate of nurse managers, which was $100 \%$ on all units. Seven nurse managers provided data on the stability rate of unit clerks, which was rated $100 \%$ by all 7 managers.

\section{$\underline{\text { Satisfaction }}$}

Satisfaction has two sub-categories, one for position and the other for context. This category describes the percentage of employees reporting positive or negative affects toward their work (Delaney \& Huber, 1996; Huber \& Delaney, 2005). This is measured by a 5 point Likert scale, where 1 equals “strongly disagree” , 2 equals “disagree”, 3 equals “neutral”, 4 equals “agree” and 5 equals “strongly agree”.

Overall, both nurse managers and staff nurses seem to be rather satisfied with their job as seen in the aggregate scores on the satisfaction survey (Tables 30-31). A great majority of both nurse managers $(n=19)$ and staff nurses $(n=134)$ were either satisfied or very satisfied with their job. An average score for nurse managers on this item was $4.05(\mathrm{SD}=0.70)$ and $4.38(\mathrm{SD}=0.76)$ for staff nurses. The score range was 3-5 for nurse managers, and 1-5 for staff nurses. However, nurse managers $(n=20)$ seem to think more often about quitting their job $(45 \%$; $n=9)$ than staff nurses $(n=134)$ do $(12 \%$; $\mathrm{n}=16)$. An average score for nurse managers on this item was $3.15(\mathrm{SD}=1.26)$ and 4.08 $(\mathrm{SD}=1.10)$ for staff nurses. The score range was 2-5 for nurse managers, and 1-5 for staff nurses. For responses to the question "I am generally satisfied with the kind of work I do in this job” both nurse managers $(n=20)$, and staff nurses $(n=134)$ either agreed or strongly agreed. An average score for nurse managers on this item was 4.10 ( $S D=0.55)$ and $4.24(\mathrm{SD}=0.69)$ for staff nurses. The score range was 3-5 for nurse managers, and 15 for staff nurses. A majority of the nurse managers $(n=20)$ were neutral about whether other nursing staff were satisfied. An average score for nurse managers on this item was $3.35(\mathrm{SD}=0.87)$, and scores ranged from 2-5. However, most of the staff nurses $(\mathrm{n}=132)$ agreed or strongly agreed to this statement. An average score for staff nurses on this item 
Table 30. Satisfaction/Position Nurse Managers

\begin{tabular}{|l|l|l|l|l|l|l|}
\hline $\begin{array}{l}\text { Sub-variable } \\
\text { number }\end{array}$ & Sub-variable name & $\mathbf{N = 2 0}$ & & & & \\
\hline 14.121 & $\begin{array}{l}\text { Generally speaking, I am very } \\
\text { satisfied with this job }\end{array}$ & 19 & 4.05 & 0.70 & 3 & 5 \\
\hline 14.122 & I rarely think of quitting this job & 20 & 3.15 & 1.26 & 2 & 5 \\
\hline 14.123 & $\begin{array}{l}\text { I am generally satisfied with the } \\
\text { kind of work I do in this job }\end{array}$ & 20 & 4.10 & 0.55 & 3 & 5 \\
\hline 14.124 & $\begin{array}{l}\text { Most nursing staff on this job are } \\
\text { very satisfied with the job }\end{array}$ & 20 & 3.35 & 0.87 & 2 & 5 \\
\hline 14.125 & $\begin{array}{l}\text { Nursing staff on this job rarely } \\
\text { think of quitting }\end{array}$ & 20 & 3.15 & 0.87 & 1 & 5 \\
\hline
\end{tabular}

Table 31. Satisfaction/Position Staff Nurses

\begin{tabular}{|l|l|l|l|l|l|l|}
\hline $\begin{array}{l}\text { Sub-variable } \\
\text { number }\end{array}$ & Sub-variable name & $\mathbf{N = 1 3 4}$ & & & & \\
\hline 14.111 & $\begin{array}{l}\text { Generally speaking, I am very } \\
\text { satisfied with this job }\end{array}$ & 134 & 4.38 & 0.76 & 1 & 5 \\
\hline 14.112 & I rarely think of quitting this job & 134 & 4.08 & 1.10 & 1 & 5 \\
\hline 14.113 & $\begin{array}{l}\text { I am generally satisfied with the } \\
\text { kind of work I do in this job }\end{array}$ & 134 & 4.24 & 0.69 & 1 & 5 \\
\hline 14.114 & $\begin{array}{l}\text { Most nursing staff on this job are } \\
\text { very satisfied with the job }\end{array}$ & 132 & 3.70 & 0.79 & 1 & 5 \\
\hline 14.115 & $\begin{array}{l}\text { Nursing staff on this job rarely } \\
\text { think of quitting }\end{array}$ & 132 & 3.44 & 0.87 & 1 & 5 \\
\hline
\end{tabular}

was 3.70 ( $\mathrm{SD}=0.79)$, and scores ranged from $1-5$. Both nurse managers $(n=20)$ and staff nurses ( $n=132)$ are rather neutral about whether nursing staff on this job think about quitting. An average score for nurse managers on this item was $3.15(\mathrm{SD}=0.87)$ and 3.44 $(\mathrm{SD}=0.87)$ for staff nurses. The score range was $1-5$ for both nurse managers and staff nurses.

Both nurse managers $(n=18)$ and staff nurses $(n=134)$ in this study either agreed or strongly agreed to being very satisfied with nursing management (see Tables 32-33). 
Table 32. Satisfaction/Context Nurse Managers

\begin{tabular}{|l|l|l|l|l|l|l|}
\hline $\begin{array}{l}\text { Sub-variable } \\
\text { number }\end{array}$ & \multicolumn{1}{|l|}{$\begin{array}{l}\text { N=20 } \\
\text { Sub-variable name }\end{array}$} & $\mathbf{n}$ & Mean & SD & Min. & Max \\
\hline 14.221 & $\begin{array}{l}\text { Generally speaking, I am very satisfied } \\
\text { with nursing management }\end{array}$ & 18 & 3.94 & 0.63 & 3 & 5 \\
\hline 14.222 & $\begin{array}{l}\text { Generally speaking, I am very satisfied } \\
\text { With nursing administration }\end{array}$ & 19 & 3.42 & 0.96 & 2 & 5 \\
\hline 14.223 & $\begin{array}{l}\text { Generally speaking, I am very satisfied } \\
\text { with interactions with physicians }\end{array}$ & 20 & 3.85 & 1.04 & 2 & 5 \\
\hline 14.224 & $\begin{array}{l}\text { Generally speaking, I am very satisfied } \\
\text { with interactions with non-physician } \\
\text { health care team members }\end{array}$ & 20 & 4.40 & 0.59 & 3 & 5 \\
\hline 14.225 & $\begin{array}{l}\text { Generally speaking, I am very satisfied } \\
\text { With my own level of autonomy }\end{array}$ & 20 & 4.15 & 0.98 & 2 & 5 \\
\hline
\end{tabular}

Table 33. Satisfaction/Context Staff Nurses

\begin{tabular}{|c|c|c|c|c|c|c|}
\hline $\begin{array}{l}\text { Sub-variable } \\
\text { number }\end{array}$ & Sub-variable name & $\mathrm{N}=134$ & Mean & SD & Min. & Max \\
\hline 14.211 & $\begin{array}{l}\text { Generally speaking, I am very satisfied } \\
\text { with nursing management }\end{array}$ & 134 & 4.04 & 1.03 & 1 & 5 \\
\hline 14.212 & $\begin{array}{l}\text { Generally speaking, I am very satisfied } \\
\text { With nursing administration }\end{array}$ & 132 & 3.43 & 1.02 & 1 & 5 \\
\hline 14.213 & $\begin{array}{l}\text { Generally speaking, I am very satisfied } \\
\text { with interactions with physicians }\end{array}$ & 134 & 3.53 & 1.07 & 1 & 5 \\
\hline 14.214 & $\begin{array}{l}\text { Generally speaking, I am very satisfied } \\
\text { with interactions with non-physician } \\
\text { health care team members }\end{array}$ & 132 & 3.81 & 0.95 & 1 & 5 \\
\hline 14.215 & $\begin{array}{l}\text { Generally speaking, I am very satisfied } \\
\text { With my own level of autonomy }\end{array}$ & 132 & 4.17 & 0.72 & 1 & 5 \\
\hline
\end{tabular}

albeit responses from staff nurses varied more. An average score for nurse managers on this item was $3.94(\mathrm{SD}=0.63)$ and $4.04(\mathrm{SD}=1.03)$ for staff nurses. The score range was 3-5 for nurse managers and 1-5 for staff nurses.

The responses on satisfaction with nursing administration received the lowest scores of all the variables, both from nurse managers $(n=19)$ and staff nurses $(n=132)$. 
Twenty percent of nurse managers $(n=4)$ were either neutral or disagreed on this item, with similar scores from almost 50\% $(n=67)$ of staff nurses. An average score for nurse managers on this item was $3.42(\mathrm{SD}=0.96)$ and $3.43(\mathrm{SD}=1.02)$ for staff nurses. The score range was 2-5 for nurse managers and 1-5 for staff nurses.

The results of this study suggest that nurse managers $(n=20)$ and staff nurses $(n=134)$ are overall satisfied with interactions with physicians. An average score for nurse managers on this item was $3.85(\mathrm{SD}=1.04)$ and $3.53(\mathrm{SD}=1.07)$ for staff nurses. The score range was 2-5 for nurse managers and 1-5 for staff nurses. However, $16 \%$ $(n=21)$ of staff nurses in this study either disagreed or strongly disagreed to this statement, as did $15 \%(n=3)$ of nurse managers.

Nurse managers $(n=20)$ seem to be satisfied with interactions with non-physician health care team members. This was the variable that received the highest score by nurse managers on average $4.40(\mathrm{SD}=0.59)$ and ranging from 3-5. Staff nurses $(n=132)$ also seem to be happier with the interaction with non-physician health care team members. An average score for staff nurses on this item was $3.81(\mathrm{SD}=0.95)$ ranging from 1-5. A majority of both nurse managers $(n=20)$ and staff nurses $(n=132)$ agreed or strongly agreed to being very satisfied with their own level of autonomy. An average score for nurse managers on this item was $4.15(\mathrm{SD}=0.98)$ and $4.17(\mathrm{SD}=0.72)$ for staff nurses. The score range was 2-5 for nurse managers and 1-5 for staff nurses. Furthermore, for nurse managers, a Spearman correlation was computed to assess the relationship between the variables of autonomy and satisfaction. This statistical test was chosen as the data are ordinal-level. The results of this study indicated a positive correlation (see Table 34) between autonomy and satisfaction with nursing management, nursing administration, and satisfaction with own level of autonomy. Other variables of satisfaction were not significantly correlated to autonomy, which may be affected by the small sample size. 
Table 34. Spearman's rho Correlations between Autonomy and Satisfaction of Nurse Managers

\begin{tabular}{|l|l|l|}
\hline $\begin{array}{l}\text { Sub-variable } \\
\text { number }\end{array}$ & Satisfaction - Sub-variable name & $\begin{array}{l}\text { Autonomy } \\
\text { correlation }\end{array}$ \\
\hline 14.211 & $\begin{array}{l}\text { Generally speaking, I am very satisfied } \\
\text { with nursing management }\end{array}$ & $0.658^{*}$ \\
\hline 14.212 & $\begin{array}{l}\text { Generally speaking, I am very satisfied } \\
\text { With nursing administration }\end{array}$ & $0.738^{* *}$ \\
\hline 14.215 & $\begin{array}{l}\text { Generally speaking, I am very satisfied } \\
\text { With my own level of autonomy }\end{array}$ & $0.812^{* *}$ \\
\hline
\end{tabular}

*Correlation is significant at the 0.05 level (2-tailed)

** Correlation is significant at the 0.01 level (2-tailed)

\section{Financial Resources}

What is the aggregate profile of financial resources across acute adult inpatient units in hospitals in Iceland?

This describes the type of payer for the health care delivered by the nursing unit (Delaney \& Huber, 1996). This category has four sub-categories. They are: 1) payer type, 2) reimbursement, 3) nursing delivery unit/service budget, and 4) budget.

\section{$\underline{\text { Payer type }}$}

The response rate on this variable was low. Twelve of the 20 nurse managers (60\%) returned this blank. Three commented that this was not easily available information to them and would take too long to collect. Three nurse managers included the comment that all three payer types were applicable, however not easily accessible to the nurse manager. The payer type “Government” was 100\% on 8 units.

\section{$\underline{\text { Reimbursement }}$}

This variable describes the payment for services within the nursing unit (Delaney \& Huber, 1996). All the nurse managers left this blank, and six commented that this was not applicable to their unit. 


\section{Nursing Delivery Unit/Service Budget}

This describes the percent of total planned and actual annual budget of the nursing unit/service, and has two sub-groups: costs and revenue (Delaney \& Huber, 1996; Huber \& Delaney 2005). Salaries and benefits were collected together in the Icelandic version of the NMMDS as this is typical within health care organizations in Iceland. Moreover, it was strongly recommended by the nurse managers who participated in the pilot study.

Seven of the 20 nurse managers (35\%) left this blank. Six included the comment that it would take too much time to collect this information, which was not readily accessible to them; and one nurse manager included the comment that she/he had not yet received this information, despite asking for it. Furthermore, during the data collection phase the PI received an e-mail from the CEO of one of the hospitals saying that one of her/his unit managers was asking for financial information for this study. The CEO wrote in a friendly manner that of course he would provide the information, however, she/he commented: "Why on earth is a nurse collecting financial information".

Only 1 nurse manager (5\%) provided data in percentage on both planned and actual costs for all variables. One nurse manager provided percentage on actual costs, but left planned costs blank, and another nurse manager provided percentage on planned costs but left the actual costs blank. Ten nurse managers provided actual monetary values. Four of the 20 nurse managers (20\%) provided actual monetary values on both planned and actual costs for all variables. One nurse manager provided information for planned costs for wages and salaries together and other operating costs, but left actual costs blank; two nurse managers provided information for actual wages, salaries and other operating costs, but left planned costs blank. Three nurse managers provided both actual and planned costs, but did not separate wages, salaries and benefits. Furthermore, one nurse manager included the comment that physician salaries were included in the total budget on the unit. On average wages, salaries and benefits were greater than $60 \%$ of both planned and actual unit costs, and ranged from 60\%-72\%. All units reported 
some change between planned and actual budget, on average $2.5 \%(\mathrm{SD}=1.71)$ increase in actual budget. One agency reported actual budget being slightly lower than anticipated in the planned budget.

\section{$\underline{\text { Revenues }}$}

Four nurse managers provided financial information on both planned and actual revenue, but the data were provided in actual figures not percentages. These were small amounts that are collected on an outpatient basis. One nurse manager provided a zero for this variable, and 1 commented on this information not being available. Furthermore, 1 nurse manager commented that this was applicable for the unit, but information not available to the nurse manager. Four nurse managers commented that this was not applicable on their units and the other 9 nurse managers left this variable blank and without comments.

\section{Expenses}

Eight of the 20 nurse managers provided this information in percentage, 3 nurse managers provided monetary values on these variables, and 9 nurse managers left this blank. One of them commented that it was too time consuming to collect this information, other two commented on this information not being readily available for them, and one commented on having asked for this information but had not yet received any. One of the nurse managers who provided this information in actual monetary values showed the difference between labor costs for nurses as compared to labor costs attributable to other staff at the organizational level. Furthermore, one nurse manager left the comment that she/he now realized how inaccessible and difficult it really was to gain access to financial information for nurse managers. Thus it was possible to obtain this information despite being difficult to do so.

Direct labor costs ranged from 9.6\%-85\% (Md=61.7\%). Direct material and indirect material costs were not separated, and ranged from 7.9\%-44\% (Md=31.8\%). 


\section{$\underline{\text { Research Question Number Three }}$}

Are there measurable differences in environmental, nursing care resources, and financial resources among hospitals in Iceland, depending on their geographic location and size?

Due to the small sample size $(\mathrm{N}=20)$ the hospital units were grouped into two groups to answer this question. One group contained the two larger hospitals, Landspitali, and Akureyri Hospital ( $\mathrm{n}=9$ ), and the second group included all the other hospitals ( $\mathrm{n}=11)$. Landspitali, the University Hospital is located in Reykjavik, and Akureyri Hospital is located in the North of Iceland. For the other hospital group the hospitals are all located outside Reykjavik. As the sample size was small, non-parametric statistics (the Mann-Whitney U Test; $\mathrm{p}=0.05$ ) were used to interpret research findings (Burns \& Grove, 2009).

\section{Environment}

To test for differences in type of nursing delivery (variable \#2), patient/client population (variable \# 3), volume of nursing services (variable \#4), care delivery structure and outcomes (variable \# 5), clinical decision making complexity (variable \#7),

Table 35. Mann-Whitney U Test Summary of Significance for Environment

\begin{tabular}{|l|l|l|}
\hline $\begin{array}{l}\text { Sub- } \\
\text { variable } \\
\text { number }\end{array}$ & Variable name & Sub-variable name \\
\hline 02.25 & Type of Nursing Delivery/ Hospital Acute Inpatient & value \\
\hline 03.32 & Pt/client Population/ Family Interaction Focus & $0.021^{*}$ \\
\hline 04.111 & Volume of Nsg Delivery Unit/Service - Patient admissions & $0.027^{*}$ \\
\hline 05.22 & Care Delivery/Outcomes -Professional Career Mobility and Expansion & $0.014^{*}$ \\
\hline 07.206 & Medication & $0.025^{*}$ \\
\hline 07.212 & Standardized Nursing Languages & $0.017^{*}$ \\
\hline${ }^{*} \mathrm{p}=0.05$ & & \\
\hline
\end{tabular}


environmental complexity (variable \# 8), and autonomy (variable \# 9), the MannWhitney U test for independent samples was used (Burns \& Grove, 2009).

When comparing the type of nursing delivery, the results suggested that there is a statistically significant difference between the two groups on sub-variable \#02.25 "hospital acute inpatient” ( $p=0.021$ ) (see Table 35). Other sub-variables of type of services were not significant.

No significant differences were found between the groups when comparing the variables of patient/client population either for specialty services, developmental- or population focus. However, there was a statistically significant difference between the groups on sub-variable \# 03.32 "family" interaction focus ( $\mathrm{p}=0.027$ ).

When comparing the variable "volume of nursing services", a statistical difference was detected on one variable; sub-variable \#04.111 "patient admissions". Other sub-variables on volume of nursing services did not indicate a significant difference.

When testing for differences in care delivery structure and outcomes, no statistical differences were found in the structure of care delivery. However, one sub-variable was found to be statistically significant when comparing the outcomes: professional category, sub-variable 05.22 “career mobility and expansion” $(\mathrm{p}=0.025)$. No statistical differences were found on the sub-variables within the category outcomes - clinical.

Significant statistical differences between the two groups were detected on two sub-variables in the clinical decision making complexity. Those were sub-variables of computerization, variables \#07.206 “Medication” ( $\mathrm{p}=0.023$ ) and \#07.212 "Standardized nursing languages” $(p=0.017)$. Environmental complexity and autonomy seem to be similar between the groups; statistical tests did not detect significant differences between the two groups on any of the items within these categories. 


\section{Nursing Care Resources}

To test for differences $(\mathrm{p} \leq 0.05)$ in "management demographic profile" (variable \#11), “staff demographic profile” (variable \#12), “staffing” (variable \#13), and “satisfaction” (variable \# 14), The Mann-Whitney U test for independent samples was used (Burns \& Grove, 2009).

The results of this study indicated statistical differences for 3 variables within the nursing care resources category between the groups. Staffing differences were significantly very high for RNs/midwives on three sub-variables (see Table 36); subvariable \#13.102 “number of budgeted staff” ( $\mathrm{p}=0.001)$, sub-variable \#13.102 "Budgeted FTEs” ( $p=0.001)$, and sub-variable 13.102 “Average daily productive staff” ( $p=0.008)$, but not significant for other staff or other variables within this category.

Table 36. Mann-Whitney U Test Summary of Significance for Nursing Care Resources

\begin{tabular}{|l|l|l|}
\hline $\begin{array}{l}\text { Sub-variable } \\
\text { number }\end{array}$ & Variable name & \multicolumn{1}{c|}{ Sub-variable name } \\
\hline 13.102 & Staffing/Quantity/RNs/midw. Number of Budgeted Staff & $0.001^{*}$ \\
\hline 13.102 & Staffing/Quantity/RNs/midw. Budgeted FTEs & $0.001^{*}$ \\
\hline 13.102 & Staffing/Quantity/RNs/midw. Average Daily Productive Staff & $0.008^{*}$ \\
\hline${ }^{*} \mathrm{p}=0.05$ &
\end{tabular}

Financial Resources

Due to the high rate of missing data and considerable variations in representation (percentage vs. monetary value) of financial data, it was not possible to test for any significant differences between the hospitals.

\section{Summary}

This chapter presented the results of the data collection and analyses. The NMMDS was translated and pilot tested for both validity and reliability. The level of 
Interrater reliability among raters, measured as an index of agreement, was over 91\% both on semantic equivalence and content equivalence. Five of seven subscales of the instrument received Cronbach's alpha score of higher than $0.70(\alpha=0.71-0.83)$, which is considered acceptable.

Clinical validation within 20 acute adult care units in hospitals in Iceland indicated that it was feasible to collect the NMMDS-ICE, although there was an issue with the time commitment to do so. Significant differences of the environment were identified between hospitals on the type of nursing delivery, family interaction focus, patient admissions, professional career mobility and expansion, and computerization of medication and standardized nursing languages. Moreover, significant differences of nursing care resources were identified regarding RN staffing. Due to missing data and variations in representation of financial resources, it was not possible to test for any significant differences between hospitals.

Results on both nurse managers’ and staff nurses' satisfaction survey suggested that overall both nurse managers and staff nurses are satisfied with their job. However, $20 \%(n=4)$ of nurse managers and almost $50 \%(n=67)$ of staff nurses were either neutral or disagreed on being satisfied with nursing administration.

In the next chapter, these results will be discussed and the limitations of this study will be identified. Recommendations for future research and application to nursing administration practice are discussed. 


\section{CHAPTER V \\ DISCUSSION}

The purpose of this study was to adapt to Iceland and clinically test the Nursing Management Minimum Data Set (NMMDS@ 2005) in all adult inpatient care units in the country of Iceland (excluding psychiatry). The study's three research questions were:

1. Does the NMMDS-ICE demonstrate semantic equivalence and content equivalence?

2. What is the aggregate profile of the 1) environment, 2) nursing care resources, and 3) financial recourses across acute adult inpatient units in hospitals in Iceland?

3. Are there measurable differences in environmental, nursing care resources, and financial resources among hospitals in Iceland, depending on their geographic location and size?

\section{Research Question Number One}

Does the NMMDS-ICE demonstrate semantic equivalence and content equivalence?

A standardized method to collect and analyze administrative nursing data in health care in Iceland has been lacking. The NMMDS was developed primarily to support nurse administrators in their decision-making for effective and safe health care delivery. Moreover, the NMMDS data set supports representation of administrative nursing data within the electronic health record (Delaney \& Huber, 1996). Therefore, the NMMDS was translated from source language English into the target language Icelandic, and the NMMDS-ICE instrument was developed.

Semantic equivalence of the NMMDS-ICE was established in three phases: 1) forward translation; 2) backward translation; and 3) expert panel ratings (Nóbrega \& Guiterres, 2000; Tang \& Dixon, 2002; Yu et al., 2004). 
Evidence of content equivalence was obtained in three phases: 1) expert panel ratings on necessity, clarity, and collectability; 2) a pilot study; and 3) a national survey of nurse managers, including a satisfaction survey of staff nurses on the nurse managers' units, excluding staff nurses at Landspitali, the University Hospital (Beck \& Gable, 2001).

A measurement of internal consistency reliability (Cronbach's $\alpha$ ) was computed for the instrument's subscales of the environment category and satisfaction in the nursing care resources category (Lee et al, 2005; Maneesriwongul \& Dixon, 2004; Wang et al., 2011). Cronbach's $\alpha$ for the sub-scales indicated good reliability ( $\alpha=0.71-0.83)$ (Polit $\&$ Beck, 2006), except on the two variables of environmental complexity ( $\alpha=0.23)$ and clinical outcomes $(\alpha=0.013)$. The reasons for low Cronbach's alpha could be due to the fact that inter-correlation of sub-scale items is little, or the numbers of items in the scale are too few. Hence, adding items to measure the environmental complexity might increase Cronbach’s alpha. Furthermore, the alpha scores for the sub-scales of clinical outcomes included negative alphas for some of the items. A negative alpha score indicates either inconsistent coding or a mixture of items measuring different dimensions. The results of this study indicated that there was some confusion on how to rate the items within this category, where a majority of respondents rated mortality rate, LOS, adverse reactions, and complications as low; and achievement of pain management and skin integrity maintenance as high. After re-coding of items the alpha score increased to a score of 0.56 . The results of this study suggest that it is necessary to revise the coding of these items to reflect the same direction of measurement of all these items. This is further addressed at the end of this chapter under recommendations. Additional studies are needed to focus on improoving this low reliability for this one variable of the NMMDS-ICE. 


\section{Research Question Number Two}

What is the aggregate profile of the 1) environment, 2) nursing care resources, and 3) financial recourses across acute adult inpatient units in hospitals in Iceland?

\section{Environment}

The findings of this study indicate that variables of the Environmental category of the NMMDS are collectable within hospital units in Iceland. Of the nine categories, eight were collected at a response rate of $85 \%-100 \%$. However, item number four, volume of nursing delivery, seems to be the most difficult information to collect, even though changes had been made to add some variables to the instrument, as recommended by the nurse managers that pilot tested the NMMDS-ICE. These findings support results of former studies that also indicated a low response on the volume of nursing services of the NMMDS (Hardardottir, 2002; Thorlacius, 2011). This was also the variable that received the lowest scores on both clarity and collectability by the expert nurse panel (see Table 9). It is of concern that even information on total number of patient admissions was not readily available to $30 \%(n=6)$ of the nurse managers, and length of stay was not readily available to $40 \%(n=8)$ of the nurse managers. It is likely that access to computerized informatics systems that capture such vital management data would assist nurse managers to better manage nursing services.

The results on the type of nursing services most often reported, being hospital acute inpatient and hospital-based nursing center, were to be expected. The participants in this study were nurse managers on acute, adult inpatient units, and many of the hospitals outside Reykjavik have mixed units of acute and long term care. However, comments were made by 4 nurse managers that it was difficult to provide this information, and data were missing from 2 units (10\%). Similar comments were made by nurse managers in community health services in the U.S., in a former study of clinical validation of the NMMDS (Hardardottir, 2002). 
The results of this study indicate that nurse managers in Iceland do not perceive that they receive much reward and pay for performance. A majority of the twenty nurse managers rated reward and pay for performance as either low (55\%) or very low (15\%), and the remaining were neutral (30\%). Furthermore, they do not seem to perceive that they have much opportunity for career mobility and expansion (see Table 21). Thorlacius (2011) also reported that reward and pay for performance was the NMMDS-ICE item that received the lowest scores $(M=3.3)$ on professional outcomes, followed closely by career mobility and expansion (M=3.7). Moreover, Sveinsdóttir and colleagues (2006) found in their study on occupational stress, job satisfaction, and working environment of Icelandic nurses, that inadequate feedback on performance was one of the individual items on the Source of Occupational Stress Scale that had the highest mean scores (three other items scored higher). Likewise, opportunity for promotion was one of the items that received the lowest satisfactory score. Other studies also indicate that rewards and recognition for performance (Gelsema et al., 2006; Sorensen, Seebeck, Scherb, Specht, \& Loes, 2009), teamwork and opportunities for professional growth (Hegeney et al., 2006: Sorensen, et al., 2009) are important aspects of job satisfaction.

A great majority of respondents rated recognition by nurses for meaningful contributions to practice as high or very high (70\%). Similar results were reported when surveying nurse managers on pediatric units in Iceland (Thorlacius, 2011). Recognition by nurses on the value of nursing's contribution to practice is one of the elements considered to provide a healthy practice environment (ANOE, 2004).

Overall, nurse managers seem to perceive that clinical outcomes are being met. However, some confusion was evident about how to measure those items, resulting in negative and unsatisfactory alpha values on the reliability test. Furthermore, this is data that is not readily available to nurse managers in hospital information systems. One nurse manager commented that this measurement was mostly based on subjective 
information. This variable of the NMMDS needs more clarity and some amendments to increase measurement reliability.

The findings of this study suggest that nurse managers in hospitals in Iceland perceive professional judgment, experience, intuition and expert knowledge to be high. Thorlacius (2011) reported similar results for pediatric units in hospitals in Iceland. Furthermore, Gunnarsdóttir and colleagues (2009) assessed the perceived quality of patient care by nurses at a University Hospital in Iceland. Their results indicated that a majority of respondents rated the perceived quality of care either as good (68.7\%) or excellent (26.4\%).

Results about the low level of computerization within hospitals in Iceland were not surprising to someone working within the hospital environment; however, due to the high level of technology use in Iceland, where over $90 \%$ of the people use the Internet on a daily basis, those results might come as a surprise. It is only recently that a fully integrated nursing documentation system was added to a hospital electronic health system in every hospital in Iceland. Acuity/workload, standardized nursing languages, physiological monitoring, data repository, and management data were the items that received the lowest scores. Similar results were reported by Thorlacius (2011); with the exception that acuity/workload was reported at a high level of computerization. A possible reason for this difference is that only one hospital in Iceland has a patient acuity system implemented, and only two hospitals have specialized pediatric units, which was the targeted population in her study. Clearly, efforts to accelerate the implementation of a fully integrated nursing documentation system are important and highly recommended.

The findings of this study suggest that patient turnover within hospital units in Iceland is most often shifting, and the patient population is mostly diverse. These findings were expected as this study was limited to acute, adult inpatient units within hospitals in Iceland. Furthermore, only one hospital, Landspitali, the University Hospital in Reykjavik has highly specialized medical/surgical units (e.g. cardiology, pulmonology) where as other hospitals have mixed specialization within units. 
The results of this study suggest that nurse managers of acute, adult inpatient units in

hospitals in Iceland generally perceive themselves as independent, accountable, with authority in decision-making, freedom to act on what they know, and good control over nursing practice. Similar results were reported by Thorlacius (2011), for nurse managers on pediatric units, although mean scores were somewhat lower. Autonomy, accountability and control over practice are considered elements of healthy work environments and have been linked to increased job satisfaction and nurse retention (Sorensen, et al., 2009; Weston, 2010). Autonomous work environments have been associated with increased staff performance and better patient outcomes. Furthermore, autonomous work environments have been linked to Magnet hospital characteristics (Kramer et al, 2011; Lewis \& Malecha, 2011). Supporting such work environment factors is encouraged.

\section{Nursing Care Resources}

The findings of this study indicate that all the variables included in the Nursing Care Resources category of the NMMDS are collectable within hospital units in Iceland.

This study indicates that nurse managers within acute adult inpatient units in hospitals in Iceland generally have baccalaureate degree (70\%; $n=14)$, and a majority (65\%; $n=13$ ) have some further education, albeit only 1 of the 20 managers had completed a Master's degree. Likewise, a majority (81\%; n=147) of staff nurses working on those units had a BSN degree, and 4\% had a Master's degree. As the entry level into nursing practice has solely been at the baccalaureate level since 1986, this was to be expected. Furthermore, this is congruent with national averages reported in 2009, where $70 \%$ of the Icelandic nursing workforce had a BSN degree (Directorate of Health, 2009). The nurse managers in Thorlacius (2011) pilot study were all educated at the BSN level; half of them had continuous education at the University diploma degree level, and 25\% had a master's degree. Furthermore, the staff nurses were all educated at the BSN level, and $10 \%$ had a Master's degree. A national sample survey of RNs conducted by the 
Health Resources and Services Administration (HRSA) (2008) showed that $50 \%$ of the nursing workforce in the U.S. held a baccalaureate or graduate degree. The number of baccalaureate-prepared RNs has been linked with lower in-hospital mortality and failure to rescue rates (Aiken et al., 2008; Van den Heede et al., 2009a).

It was not surprising that the number of staff and staff mix varied among the units, given that a number of units were described by nurse managers as partly being hospitalbased nursing centers. However, the low average turnover rate (7\%) of nursing staff reported within 12 acute care hospital units in Iceland, in this study, came as a surprise. A study assessing the relationship between RN turnover, workload and sickness absence on medical/surgical inpatient units at Landspitali, University hospital over the year 2008, reported an average turnover rate for RNs of 10.89\% (Hálfdánardóttir, 2009). This is supported by international studies which have suggested an average turnover rate for medical and surgical units of 9.49\% with high turnover costs per nurse (O’Brien-Pallas et al., 2006). A possible explanation for the lower turnover rate found in this study may be due to the financial crisis that hit Iceland in fall of 2008, possibly resulting in fewer people leaving their jobs and less opportunity to choose other positions. Both job satisfaction and autonomy have been associated with nurse retention (Kane et al., 2007), and nurses in Iceland appear to perceive high levels of autonomy and generally are satisfied with their jobs.

The results of this study indicate that overall both nurse managers and staff nurses are satisfied with their jobs. Previous studies have shown high levels of job satisfaction among Icelandic nurses (Biering \& Flygenring, 2000; Biering \& Sveinsdóttir, 2001; Gunnarsdóttir et al., 2009; Thorlacius, 2011) and low levels of burnout (Gunnarsdóttir et al., 2009). However, $45 \%(n=9)$ of nurse managers think about leaving their job, while a majority of staff nurses $(62 \%$; $n=83)$ rarely think of quitting. This is contrary to results reported by Landspitali, the University Hospital in Reykjavik, when surveying their staff on satisfaction in 2010. Their results indicated that all nurse managers participating in 
the study intended to stay, when asked about intent to leave within the next two years, whereas approximately $4 \%$ of staff nurses intended to leave. It is also of interest that satisfaction with nursing management was generally high (70\% for nurse managers and 77.6\% for staff nurses), but satisfaction with nursing administration was either rated neutral or low by $45 \%$ of nurse managers and $50 \%$ of staff nurses. Support from unitlevel managers, adequate staffing levels, and nurse-physician relationships have been found to be important predictors of satisfaction (Gunnarsdóttir et al., 2007). Likewise rewards and recognition for performance (Gelsema et al., 2006), and professional growth (Hegeney et al., 2006: Sorensen, et al., 2009) are important aspects of job satisfaction. A possible explanation for the finding that nurse managers are thinking about quitting their job, albeit overall satisfied, may be that they do not perceive that they get enough support by superior management or reward and recognition for all their contribution to practice and the institution. When nurse managers perceive organizational support, they are more likely to feel valued, rewarded and satisfied in their job (Patrick \& Laschinger, 2006). Furthermore, due to the financial crisis in Iceland, cut-backs in the Government's financing to health care institutions may have some influence on these responses.

\section{Financial Resources}

All the variables of this category were collectable; however, although this category passed expert review, this was the category of the NMMDS that was most difficult to collect and had the most variations in presentation of the data. The reasons for this may be explained in part by the fact that nurse managers do not have this information readily available, the sophistication of the informatics systems for nurses is low, and they feel it is too time consuming to gather such detailed information, especially in paper-and-pencil format. Some even reported not being provided with this information by superiors, even though it was asked for. It is difficult for nurse managers to be cost conscious without access to any data for decision-making. Furthermore, nurse managers 
may not be used to this way of gathering financial data. As was found in the research in the U.S. using the NMMDS instrument in research flushes out the reality of the difficulty that nurses have in extracting nursing-specific data for evidence-based management practice, as called for by the Institute of Medicine (2004). However, it appears that by simply asking for financial data, a dialogue begins which can lead to greater focus on informatics systems to capture nurses’ data.

Expenses is the category that most of the respondents provided in percentage rather than in monetary values. The reason for the differences in the range of both labor, and material costs of the units in relation to costs for the nursing department, is due to the fact that the smaller hospitals only have one unit, while the bigger hospitals have many.

\section{$\underline{\text { Research Question Number Three }}$}

Are there measurable differences in environmental, nursing care resources, and financial resources among hospitals in Iceland, depending on their geographic location and size?

There are three layers of types of hospitals in Iceland: two university hospitals, six regional hospitals, and six hospitals where the service is mostly long term care with 2-4 acute beds. Moreover, there is a huge difference in the number of acute care units among these 14 hospitals. Landspitali, the university hospital in Reykjavik, has 18 acute care units, Akureyri hospital has 4, three of the regional hospitals have 2-3 units and the remaining nine hospitals only have 1 unit each. In smaller hospitals only some of the beds are acute care, and most of their services are provided to long-term care. Due to the small sample size and to maintain confidentiality, a decision was made to aggregate the data and to compare two groups of hospitals rather than compare the hospitals based on size and geographical location. Landspitali and Akureyri hospital were in one group; all the other hospitals were in the other group. One group was composed of 9 units, the other group of 11 units. Hence, when comparing resources of the environment between 
the two groups of hospitals it was not, surprising that statistical differences were found in the type of services provided, volume of services provided and computerization level. However, it was surprising that only two variables, measuring level of computerization, medication and standardized nursing languages, were significantly different. It was expected that more variables, especially “data repository” would be different at Landspitali. The University Hospital in Reykjavik operates the most comprehensive information technology services and is the only hospital that has a data warehouse implemented. A possible explanation may be that either nurse managers did not understand the concept of data repository or that management data is not readily available within data warehouses for nurse managers to access. This can form the beginning point for the transformation into the use of nursing-specific electronic databases for nursing management.

Within the nursing care resources category, RN staffing was the only variable that was statistically different between the hospital groups. This was expected given the difference in the type of services between these two groups of hospitals. Financial information was not available for comparison, due to variations in representation among the hospitals. The lack of access thatnurse managers have to financial data is of concern. Nurse managers are accountable for the nursing services provided on their units, and they need to have state of the art data and information at their fingertips to be able to provide the best quality and most cost effective services available at any given time. This includes all elements of the NMMDS, which is an evidence-based data set specific to nursing care management. Because this information traditionally has not been available to nurses, some question why a nurse would need it. The NMMDS developers also faced the same questions and lack of access to data. Perhaps this research will lend further validity to the argument for nurses to have the data that they need to manage well. 


\section{$\underline{\text { Limitations }}$}

This study has some limitations that should be identified. Lack of familiarity with the collection of management data in Iceland is one limitation. The NMMDS-ICE data set is new to nurse managers in Iceland, and length of time to complete the survey was mentioned by six of eight nurse managers who returned the survey blank. The amount of time it takes to complete a paper survey was an outcome of this study. The time could be dramatically reduced if a computerized system was in place. Another limitation was due to restrictions on access to staff nurses at Landspitali, the University Hospital in Reykjavik, where approximately 50\% of all registered nurses work (INA, 2011), regarding the job satisfaction survey. The restrictions were due to heavy workload on RNs within the hospital. An additional limitation is that financial data were not available for statistical analysis due to variance in data presentation by nurse managers. However, it did give valuable information on nurse managers' access to financial data.

The return rate for the nurse managers in this study was $74 \%$, with $53 \%$ as the usable rate. It was $71 \%$ for staff nurses who received the survey. The sample of nurse managers includes the entire population under study. However, due to the 53\% usable surveys for analysis, the generalizability of the sample to Iceland should be taken with some caution. The sample of staff nurses does not equal the total population under study. The length of the study is a burden identified by nurse manager refusals and may need to be addressed by informatics sytems programming to reduce the time burden. In addition, as was found by the NMMDS developers, asking staff nurses about job satisfaction may be an issue causing nurse managers to refuse to participate. As job satisfaction is just one variable of 16 collected in this study, the threat to the study's integrity is not harmed.

Thus the results on this single variable need to be interpreted with caution due to convenience sampling. 


\section{$\underline{\text { Implications for Practice and Future Research }}$}

The Icelandic Government has ambitions for Iceland to become a leading nation in the utilization of information technology and electronic services to improve quality of life for all Icelanders (Prime Minister's Office, 2008). This requires an implementation of a National Health Information Infrastructure [NHII]. The ultimate goal of an NHII is appropriate information and knowledge sharing available to professionals, policy makers, researchers, patients, and consumers whenever needed to make the best possible healthrelated decisions to improve the quality of health and health care (National Committee on Vital and Health Statistics [NCVHS], 2001).

The overall goal in Europe is European eHealth interoperability by the end of 2015, shared across geographical and international boundaries (EC, 2008). The development of a NHII requires interoperability among the various electronic health information systems (Hammond 2005; Kuperman et al., 2010) to communicate, manage, report, and share data, information, and knowledge (Westra et al., 2008) at all levels of health care; clinical, administrative, policy, and consumers' to be used in practice, research, education and policy making.

The results of this study provide valuable information to nursing administration practice. According to Pitkäaho and colleagues (2010), information in hospital information systems is ever increasing; albeit, very little is being used in nursing management and leadership. Nurse managers in Iceland are accountable for providing healthy work environments for staff, and safe and efficient patient care. Yet they lack resources and access to data and information they need at their fingertips to make optimal decisions to enhance patient-, nurse-, and institutional outcomes. To enhance desirable outcomes hospitals and health care institutions need to have adequate systems in place that foster healthy work environments. The results from this study further highlight the need for a standardized, accessible system to collect management data in Iceland at the unit and institutional level on a regular basis for benchmarking. Effective nursing 
leadership is needed to include nursing administrative data within electronic health information systems and data warehouses that can be accessed and easily used by nurse managers on a regular basis for effective decision making and quality improvements (Westra et al., 2010).

Interoperability requires health care data standards to be defined, agreed upon and implemented (Hammond, 2005). The NMMDS-ICE (see Appendix B) could, if incorporated into current hospital EHR systems in Iceland, provide nurse managers and administrators with valuable information they need to support effective decision-making on a daily basis. Furthermore, this study indicates that the NMMDS-ICE is in general, a valid and reliable tool to collect administrative nursing minimum data within acute adult inpatient units in hospitals in Iceland. The validity of an instrument is supported by collection of evidence and is an ongoing process (Polit \& Beck, 2006). To further validate the results of this study, and to identify effective strategies and policies for promoting adoption of the NMMDS-ICE within health care in Iceland, future research needs to include a replication of this study including psychiatry units, long term-, and rehabilitation care, operation theaters, primary health care, and outpatient units. Due to the great variability in the size and services the14 hospitals in Iceland provide, future studies should include measurements calculated in quartiles to better describe and display the variability.

Moreover, studies to evaluate nurse managers' use of information technology are needed. Furthermore, future studies using descriptive, correlative and regression analyses are needed to examine the relationships between nurses work environment and nurse, patient, and institutional outcomes to improve safety and quality of health care services.

\section{$\underline{\text { Recommendations on NMMDS }}$}

The following recommendations are based on the results of this study. 
1. Modification on variable \#5.3 outcomes clinical is needed. This could be done by replacing the items of adverse events and complications with for example patient falls, medication errors, post surgical infection rate, urinary tract infection, hospital acquired pneumonia, unexpected death and failure to rescue. Adding items to the scale could improve alpha levels. It might also be considered to include percentage of these events on the unit rather than rate to what extent these outcomes have been met. It is unclear as it is today how one should judge what would be a rate of high Likert score of 5 vs. score of 4 or a low score of 2, and how these can be compared, because people will perceive this differently.

2. It is highly recommendated that the two items of variable \#5.3; pain management level and maintenance of skin integrity be in a separate category from the other items in that category, as those two variables tend to have a positive meaning while the other items on the scale would tend to have a negative meaning, resulting in confusion on the measurement. By separating these items measurement reliability could be increased.

3. Add the variables of geriatrics and gynecology to variable \#3 patient/client population.

4. Consider designing the NMMDS in such a way as having different parts of the NMMDS depending on services provided e.g. acute care units, longterm care units, outpatient services, and primary health care.

5. Consider ways to reduce the amount of time the survey takes for nurse managers. This includes programming informatics systems to capture all data and show basic analyses. 


\section{$\underline{\text { Summary }}$}

Semantic, and content equivalence of the NMMDS-ICE was established. Study findings indicate that all of the variables of the NMMDS-ICE are collectable within acute adult inpatient hospital units in Iceland. The specialty services that best described the patient population served by the units was medical-, surgical services, birthing, and geriatrics. Results suggest that overall, nurse managers seem to perceive good control on their units, and both nurse managers and staff nurses are satisfied with their job. A positive correlation was found between autonomy and satisfaction with nursing management, nursing administration, and satisfaction with own level of autonomy.

Statistical differences were identified in environmental and staffing resources between two hospital groups, where one group consisted of the two largest hospitals in Iceland, Landspitali located in Reykjavik and Akureyri Hospital located in Akureyri, and the other group included all the other hospitals. It was not possible to test for statistical differences in financial resources due to diverse data representation and number of missing data. However, the strength of this study being conducted in Iceland is that was feasible to collect data on the entire target population of nurse managers and nurses. Iceland generally has very good general population health outcomes and has sophisticated informatics usage outside of hospital care. The impact of the global financial crisis, as well as the one in Iceland, bears watching and monitoring for the effects on the delivery of health care and argues for sophisticated informatics systems that will enhance health care quality and safety and will better serve the nursing workforce.

Study results indicate that some important management data and information is not readily available to nurse managers in hospitals in Iceland, to make optimal decisions to enhance patient-, nurses-, and institutional outcomes. Further studies are needed to validate the instrument in other health care settings, and to identify effective strategies and policies for promoting the use of the NMMDS-ICE within health care settings in 
Iceland. Clearly, sophisticated informatics systems are a critical health care infrastructure component towards building a National Health Information Infrastructure [NHII]. Successful management of data, information, knowledge and wisdom is essential in complex health care systems to receive optimal health care outcomes and efficient care. 


\section{REFERENCES}

Aiken, L.H., Clarke, S.P., Sloane, D.M., Lake, E.T., \& Cheney, T. (2008). Effects of hospital care environment on patient mortality and nurse outcomes. Journal of Nursing Administration, 38(5), 223-229.

American Nurses Association [ANA]/NIDSEC. (2002). Retrieved February 2, 2002, from:from http://www.nursingworld.org/nidsec/

American Nurses Association [ANA]. (2003). Nursing Information \& Data Set Evaluation Center [NIDSEC]. Standards and Scoring Guidelines. Washington, DC: American Nurses Publishing.

American Nurses Association [ANA]. (2008). Nursing Informatics: Scope and Standards of Practice. Silverspring, MD: Nursesbooks.org.

American Nurses Association 「ANA] (2010). About the committee for nursing practice information infrastructure (CNPII). Retrieved from http:// www.nursingworld.org/npii/committee.htm.

American Nurses Association [ANA] (2011). ANA recognized terminologies that support nursing practice. Retrieved from http://www.nursingworld.org/MainMenuCategories/ThePracticeofProfessionalNursin g/NursingStandards/Recognized-Nursing-Practice-Terminologies.aspx

American Organization of Nurse Executives[ANOE]. (2004). Principles and elements of a healthful practice/work environment. Retrieved from http://www.aone.org/aone/resource/home.html

Association of PeriOperative Registered Nurses. [AORN]. PNDS Resources. (2007). Retrieved from http://www.aorn.org/PracticeResources/PNDS/PNDSResources/

Anthony, M. K., Standing, T. S., Glick, J.A., Duffy, M., Paschall, F., Sauer, M. R., Sweeney, D. K., Modic, M. B., \& Dumpe, M.L. (2005). Leadership and nurse retention. The pivotal role of nurse managers. Journal of Nursing Administration, 35(3), 146-155.

Bakken, S., Cashen, M. S, Mendonca, E. A, O’Brien, A., \& Zieniewicz, J. (2000). Representing nursing activities within a concept-oriented terminological system: Evaluation of a type definition. Journal of the American Medical Informatics Association, 7(1), 81-90.

Bakken, S. (2006). Informatics for patient safety: A nursing research perspective. Annual Review for Nursing Research, 24, 219-254.

Bakken, S., Cimino, J.J., \& Hripcsak, G. (2004). Promoting Patient Safety and Enabling Evidence-Based Practice Through Informatics. Medical Care, suppl. 42(2), 49-56.

Ball, M.J., Hannah, K.J., \& Douglas, J.V. (2000). Nursing and Informatics. In M.J. Ball, K.J. Hannah, S.K. Newbold, \& J.V. Douglas (Eds.), Nursing Informatics Where Caring and Technology Meet ( $3^{\text {rd }}$ ed.) (pp.6-14). NY:Springer. 
Bates, D.W., Evans, R.S., Murff, H., Stetson, P.D., Pizziferri, L., \& Hripcsak, G. (2003). Detecting Adverse Events Using Information Technology. Journal of the American Medical Informatics Association, 10(2), 115-128.

Beck, T.C., \& Gable, R. K. (2001). Ensuring Content Validity: An Illustration of the Process. Journal of Nursing Measurement, 9(2), 201-215.

Beyea, S. C. (2000). Perioperative data elements: interventions and outcomes. AORN Journal, 71(2), 344-352.

Biering, P., \& Flygenring, B. (2000). Könnun á vinnuálagi og starfsáncegju hjúkrunarfrceðinga [Study of stress and job satisfaction in Icelandic Nurses]. Reykjavik: University of Iceland.

Biering, P., \& Sveinsdóttir, H. (2001). National survey on occupational stress and job satisfaction among Icelandic Nurses. The Icelandic Journal of Nursing, 77(5), 321327).

Biron, A.D., Richer, M.C., \& Ezer, H. (2007). A conceptual framework contributing to nursing administration and research. Journal of Nursing Management, 15, 188-196.

Blum, B. L. (1986). Clinical Information Systems: NewYork: Springer-Verlag.

Boston Consulting Group (2011). Health care system reform and short term savings opportunities. Iceland health care system project. Retrieved November 29, 2011 from http//www.velferdarraduneyti.is/media/ritogskyrslur2011/Iceland_HCS-Final_report_long_version.pdf.

Brislin, R.W. (1970). Back-translation for cross-cultural research. Journal of CrossCultural Psychology, 1(3), 185-216.

Burns, N. \& Grove, S. (Eds.). (2009). The Practice of Nursing Research (6 ${ }^{\text {th }}$ ed). St. Louis MI: Saunders Elsevier.

Butler, M., Treacy, M., Scott, A., Hyde, A., Neela, P.M., Irving, K., Byrne, A., \& Drennan, J. (2006). Towards a nursing minimum data set for Ireland: making Irish nursing visible. Journal of Advanced Nursing, 55(3), 364-375.

Biron, A.D., Richer, M.C., \& Ezer, H. (2007). A conceptual framework contributing to nursing administration and research. Journal of Nursing Management, 15, 188-196.

Carlson, E.D. (2000). A case study in translation methodology using the healthpromotion lifestyle profile II. Public Health Nursing 17(1), 61-70.

Clarke, S.P., \& Aiken, L.H. (2006). More nursing, fewer deaths. Quality and Safety in Healthcare, 15, 2-3

CEN. (2007). European Committee for Standardization. Standards and drafts. Retrieved March 2 2007, from http://www.cen.eu/cenorm/homepage.htm

Chao, K., Y., Wang, H., S., Chang, H., L., Wang, Y., W., \& See, L., C. (2009). Establishment of the reliability and validity of the stress index for children or adolescents with tourette syndrome (SICATS). Journal of Clinical Nursing, 19, 332340 doi: 10.1111/j.1365-2702.2009.03061.x 
Charters, K., G. (2003). Nursing informatics, outcomes and quality improvement. Advanced Critical Care, 14(3), 282-294.

Clark, J., \& Lang, N. (1992). Nursing's next advance: an internal classification for nursing practice. International Nursing Review, 39(4), 109-112 138.

Clark, J., Craft-Rosenberg, M., \& Delaney C. (2000). An international methodology to describe clinical nursing phenomena: a team approach. International Journal of Nursing Studies, 37, 541-553.

Coenen, A., \& Schoneman, D. (1995). The Nursing Minimum Data Set: Use in the quality process. Journal of Nursing Care Quality, 10(1), 9-15.

Coenen, A., Weis, D.M., Schank, M.J., \& Matheus, R. (1999). Describing parish nurse practice using the Nursing Minimum Data Set. Public Health Nursing, 16(6), 412416.

Coenen, A., Marin, H. F, Park, H. A, \& Bakken, S. (2001). Collaborative efforts for representing nursing concepts in computer-based systems: International perspectives. Journal of American Medical Informatics Association, 8(3), 202-211.

Committee on Data Standards for Patient Safety (2003). Key capabilities of an electronic health record system: Letter Report. Board on Health Care Services [HCS]. Institute of Medicine [IOM]. The National Academic Press: Washington D.C.

Currie, L., \& Watterson, L. (2007). Challenges in delivering safe patient care: a commentary on a quality improvement initiative. Journal of Nursing Management, 15, 162-168.

Delaney, C., Gardner Huber, D., Mehmert, M., Crossley, J., \& Ellerbe, S. (1994). A Nursing Management Minimum Data Set. Nursing Informatics: An International overview for Nursing in a Technological Era. Proceedings of the Fifth IMIA International Conference on Nursing Use of Computers and Information Science. San Antonio, Texas: Elsevier Science B. V.

Delaney, C. (1996). Significance of the Nursing Minimum Dataset for decision support in acute care. In M.E. Mills, C.A. Romano, \& B.R. Heller (Eds.), Information management in nursing and health care (p. 32-38). PA: Springhouse Corporation.

Delaney, C., \& Huber, D. (1996). A Nursing Management Minimum Data Set (NMMDS): A report of an invitational conference [Monograph]. Chicago, IL: American Organization of Nurse Executives [AONE].

Delaney, C., \& Huber, D. (1997). Clinical Testing of a National Standardized Minimum Data Set Designed To Capture the Management Context of Health Care Delivery. American Medical Informatics Association, Fall Symposium.

Directorate of Health (2009a). Yearly report 2009. Retrieved November 29, 2010 from http://landlaeknir.is/pageid=1398.

Directorate of Health (2009b, 2010). Statistics on health care personnel. Retrieved from http://landlaeknir.is/pages/1175. 
Disch, J. (2000). Healthy work environments for all nurses. Journal of Professional Nursing, 16(2), 75.

Donabedian, A. (1966). Evaluating the quality of medical care. Milbank Memorial Fund Quarterly. 44(3 Suppl.), 166-206.

Donabedian, A. (1980). Methods for deriving criteria for assessing the quality of medical care. Medical Care Review. 37(7), 653-698.

Donabedian, A. (1988). The quality of care. How can it be assessed? Journal of the American Medical Association, 260(12), 1743-1748.

Duffield, C., Roche, M. A., Blay, N., \& Stasa, H. (2010). Nursing unit managers, staff retention and the work environment. Journal of Clinical Nursing, 20, 23-33. doi: 10.1111/j. 1365-2702.2010.03478.x.

European Commission (2008). EU: Commission recommendation on cross-border interoperability of electronic health record systems. Retrieved from http://www.epractice.eu/en/library/281617.

European Commission (2010). i2010 A European information society for growth and employment. Retrieved from http://ec.europa.eu/information_society/eeurope/i2010/index_en.htm.

Fahrenkrug, M.A. (2003). Development of a nursing data set for school nursing. Journal of School Nursing, 19(4), 238-248.

Flaherty, J.A., Gavira, F.M., Pathak, D., Mitchell, T., Wintrob, R., Richman, J.A., \& Bitz, S. (1988). Developing instruments for cross-cultural psychiatric research. Journal of Nervous and Mental Disease, 176(5), 257-263.

Gassert, C.A. (2000). Academic Preparation in Nursing Informatics. In M.J. Ball, K.J. Hannah, S.K. Newbold, \& J.V. Douglas (Eds.), Nursing Informatics Where Caring and Technology Meet ( $3^{\text {rd }}$ ed.) (pp.15-32). NY: Springer.

Gelsema, T.I., Van Der Doef, M., Maes, S., Janssen, M., Akerboom, S., \& Verhoeven, C. (2006). A longitudinal study of job stress in the nursing profession: causes and consequences. Journal of Nursing Management, 14, 289-299.

Gerdtz, M.F., \& Nelson, S. (2007). 5-20: a model of minimum nurse-to-patient ratios in Victoria, Australia. Journal of Nursing Management, 15, 64-71.

Gilmer, J.S, Tripp-Reimer, T., Buckwalter, K.C., Andrews, P.H., Morris, W.W., Rios, H., Lindencrona, C., \& Evers, G. (1995). Technical notes: Translation and validation issues for a multidimensional elderly self-assessment instrument. Western Journal of Nursing Research, 17(2), 220-226.

Goossen, W.T.F., Epping, P.J.M.M., Feuth, T., Dassen, T.W.N., Hasman, A., \& van den Heuvel, W.J.A. (1998). A comparison of nursing minimal data sets. Journal of the American Medical Informatics Association, 5(2), 152-163. 
Goossen, W.T.F, Delaney, C., Hovenga, E., Marin, H., \& Saba, V. (2005). Lessons learned from the international nursing minimum data set (i-NMDS). In W. Sermeus \& $\mathrm{M}$ Enhfors (Eds.). Proceedings of the 5th biennial European Conference of ACENDIO. (p. 31-34). Bern: Verlag Hans Huber.

Graves, J. R., \& Corcoran, S. (1989). An overview of nursing informatics. Image: Journal of Nursing Scholarship, 21, 227-231.

Gunnarsdóttir, S., Clarke, S.P., Rafferty, A.M., \& Nutbeam, D. (2009). Front-line management, staffing and nurse-doctor relationships as predictors of nurse and patient outcomes. A survey of Icelandic hospital nurses. International Journal of Nursing Studies, 46, 920-927.

Halamka J., Overhage, J.M., Ricciardi, L., Rishel, W., Shirky, C., \& Diamond, C. (2005). Exchanging health information: local distribution, national coordination. As more communities develop information-sharing networks, a coordinated approach is essential for linking these networks. Health Affairs. 24(5), 1170-1179.

Hálfdánardóttir, H. (2009). Starfsmannavelta hjúkrunarfræðinga, hjúkrunarpyngd og veikindafjarvistir [RNs turnover rate, workload, and sickness absence]. Unpublished MS thesis_University of Iceland, Reykjavík, Iceland.

Hammond, W. E. (2005). The making and adoption of health data standards. Health Affairs, 24(5), 1205-1213. doi: 101377/hlthaff.24.5.1205.

Hammond, W. E., Bailey, C., Boucher, P., Spohr, M., \& Whitaker, P. (2010). Connecting information to improve health. Health Affairs, 29(2), 284-288.

Hardardottir, G., A. (2002) Clinical validation of the nursing management minimum data set (NMMDS) in community and publis health care settings. Unpublished MS thesis, the University of Iowa, Iowa, U.S.A.

Harris, M. R, Graves, J. R, Solbrig, H. R, Elkin, P. L, \& Chute, C. G (2000). Embedded structures and representation of nursing knowledge. Journal of the American Medical Informatics Association, 7(6), 539-549.

Health Level Seven [HL7]. What is HI7? Retrieved from http://www.hl7.org/

Health Resources and Services Administration [HRSA] (2008). Sample Survey of Registered Nurses. Retrieved from

hpr.hrsa.gov/healthworkforce/rnsurveys/rnsurveyfinal.pdf

Heath, J., Johanson, W., \& Blake, N. (2004). Healthy work environments. A validation of the literature. Journal of Nursing Administration, 34(11), 524-530.

Hegney, D., Plank, A., \& Parker, V. (2006). Extrinsic and intrinsic work values: their impact on job satisfaction in nursing. Journal of Nursing Management, 14, 271-281.

Henry, S. B, Warren, J. J, Lange, L., \& Button, P. (1998). A review of major nursing vocabularies and the extent to which they have the characteristics required for implementation in computer-based systems. Journal of the American Medical Informatics Association, 5(4), 321-428. 
Hilton, A. and Skrutkowski, M. (2002). Translating Instruments into other languages: Development and testing processes. Cancer Nursing 25(1), 1-7.

Hovenga, E., Garde, S., \& Heard, S. (2005). Nursing constraint models for electronic health records: A vision for domain knowledge governance. International Journal of Medical Informatics. 74, 886-898.

Huber, D. (2000). Leadership and Nursing Care Management. Philadelphia, PA: W.B.Saunders Company.

Huber, D. (2006). Leadership and Nursing Care Management. Philadelphia, PA: W.B.Saunders Company.

Huber, D., \& Delaney, C. (1997). Capturing the context of health care reform: Clinical testing of the Nursing Management Minimum Data Set (NMMDS). The Seventh National Conference on Nursing Administration Research. Kansas City, MI: University of Kansas School of Nursing.

Huber, D., \& Delaney, C. (1998). Nursing management data for nursing information systems. In S. Moorhead, \& C. Delaney (Eds.), Information systems innovations for nursing: New visions and ventures (pp 15-29). CA: Sage Publications.

Huber, D., Schumacher, S., \& Delaney, C. (1997). Nursing Management Minimum Data Set (NMMDS). Journal of Nursing Administration, 27(4), 42-48.

Huber, G.D., Delaney, C., Crossley, J., Mehmert, M., \& Ellerby, S. (1992). A Nursing Management Minimum Data Set. Significance and development. Journal of Nursing Administration, 22(7/8), 35-40.

Hugonnet, S., Chevrolet, J.C., \& Pittet, D. (2007). The effect of workload on infection risk in critically ill patients. Critical Care Medicine, 35(1),76-81.

Icelandic Nurses’ Association [INA]. (2007). Nursing Shortage (Mannekla í hjúkrunSkýrsla Félags íslenskra hjúkrunarfræðinga). Reykjavík: Nón

Icelandic Nurses Association [INA] (2011). Nursing in Iceland. Retrieved from http://www.hjukrun.is/English-Information/Nursing-in-Iceland

Institute of Medicine [IOM]. (1991). The Computer-Based Patient Record: An Essential Technology for Health Care. R.S., Dick, and E.B. Steen (Eds.). Washington, DC: National Academies Press.

Institute of Medicine [IOM]. (1996). Nurse staffing in hospitals and nursing homes. Is it adequate? Wunderlich,G. S., Sloan, F. A., \& Davis, C. K. (Eds.). DC: National Academies Press.

Institute of Medicine [IOM]. (1999). To Err is Human: Building a Safer Health System. Kohn, L.T., Corrigan, J.M., \& Donaldson, M.S. (Eds.). Washington, DC: National Academies Press.

Institute of Medicine [IOM]. (2001). Committee on quality of health care in America Crossing the Quality Chasm. A New Health System for the $21^{\text {st }}$ Century. Washington, DC: National Academies Press. 
Institute of Medicine [IOM]. (2004a). Committee on Data Standards for Patient Safety, Board on Health Care Services. Patient Safety: Achieving a New Standard for Care. (P.Aspen et al. Eds.). Washington, DC: National Academies Press.

Institute of Medicine [IOM]. (2004b). Keeping patients safe: Transforming the work environment of nurses. Washington, DC: National Academies Press.

Institute of Medicine [IOM]. (2010). The future of nursing: Leading change, advancing health. Washington, DC: National Academies Press.

International Council of Nurses [ICN]. (2006). The global nursing shortage: priority areas for intervention. Retrieved November 29, 2011 from:

http//www.icn.ch/images/stories/documents/publications/GNRI/The_Global_Nursing _Shortage-Priority_Areas_for_Intervention.pdf.

International Organization for Standardization [ISO]. About ISO. Retrieved March 4, 2007, from http://www.iso.org/iso/about/discover-isomeet-iso.htm.

Johnson, M., Gardner, D., Kelly, K., Maas, M., \& McCloskey, J.C. (1991). The Iowa model: a proposed model for nursing administration. Nursing Economics, 9(4),25562.

Jones, Lee, Phillis, Xinwei, \& Jaceldo (2001). An adaptation of Brislin's translation model for cross-cultural research. Nursing Research, 50(5), 300-304.

Junger, A., Berthou, A., \& Delaney, C. (2004). Modeling, the essential step to consolidate and integrate a national NMDS. Medinfo 11(Pt.1), 521-524.

Junttila, K., Meretoja, R., Seppälä, A., Tolppanen, E., Ala-Nikkola, T., \& Silvennoinen, L. (2007). Data warehouse approach to nursing management. Journal of Nursing Management, 15, 155-161.

Kane, R.L., Shamliyan, T.A., Mueller, C., Duval, S., \& Wilt, T.J. (2007). T he association of registered nurse staffing levels and patient outcomes. Medical Care, 45(12), 1195-1204.

Karipuk, K.L., Delaney, C.W., \& Ryan, P. (1997). South Dakota statewide nursing minimum data set project. Journal of Professional Nursing, 13(2), 76-83.

Keenan, G., Barkauskas, V., Stocker, J., Johnson, M., Maas, M., Moorhead, S., \& Reed, D. (2003). Establishing the Validity, Reliability, and Sensitivity of NOC in an Adult Care Nurse Practitioner Setting. Outcomes Management, 7(2),74-83.

Keenan, G., Stocker, J., Barkauskas, V., Treder, M., \& Heath, C. (2003). Toward integrating a common nursing data set in home care to facilitate monitoring outcomes across settings. Journal of Nursing Measurement, 11(2), 157-169.

Koshy, R. (2005). Navigating the information technology highway: computer solutions to reduce errors and enhance patient safety. Transfusion, suppl. 189-191.

Kramer, M., \& Schmalenberg, C. (2008). Confirmation of a healthy work environment. Critical Care Nurse, 28(2), 56-63. 
Kramer, M., Maguire, P., \& Brewer, B. B. (2011). Clinical nurses in Magnet hospitals confirm productive, healthy unit work environments. Journal of Nursing management, 19(1), 5-17. doi: 10.1111/j.1365-2834.2010.01211.x

Kuperman, G. J., Blair,J. S., Franck,R. A., Devaraj, S., \& Low, A. F. H. (2010). Developing data content specifications for the nationwide health information network trial implementations. Journal of the American Medical Informatics Association, 17, 6-2. doi:10.1197/jamia.M3282

Laiho, A. (2010). Academisation of nursing education in the Nordic Countries. Higher Education, 60(6), 641-656. Doi: 10.1007/s10734-010-9321-y.

Landspitali (2010). Könnun á starfsumhverfi starfsmanna Landspítala [Landspitali employee work environment survey]. Reykjavík: Landspítali. Retrieved from www.lsh.is/lisalib/getfile.aspx?itemid=27354.

Laschinger, H.K., Shamian, J., \& Thomson, D. (2001). Impact of magnet hospital characteristics on nurses' perceptions of trust, burnout, quality of care, and work satisfaction. Nursing Economics, 19(5), 202-219.

Le Duff, F., Daniel, S., Kamendjé, B., Le Beux, P., \& Duvauferrier, R. (2005). Monitoring incident report in the healthcare process to improve quality in hospitals. International Journal of Medical Informatics, 74, 111-117.

Lewis, P. S., \& Malecha, A. (2011). The impact of workplace incivility on the work environment, manager skill, and productivity. Journal of Nursing Administration, 41(1), 41-47.

Loonsk, J.W., McGarvey, S.R., Conn, L.A., Johnson, J. (2006). The Public Health Information Network (PHIN) Preparedness Initiative. Journal of the American Medical Informatics Association, 13(1), 1-4.

Lunney, M., Delaney, C., Duffy, M., Moorhead, S., Welton, J. (2005). Advocating for standardized nursing languages in electronic health records. Journal of Nursing Administration, 35(1), 1-3.

Maas, M.L., \& Delaney, C. (2004). Nursing process outcome linkage research issues, current status, and health policy implications. Medical Care, 42(2 Suppl):II40-48.

Maneesriwongul, W., \& Dixon, J.K. (2004). Instrument translation process: a methods review. Journal of Advanced Nursing, 48(2), 175-186.

Marek, K.D. (1997). Measuring the effectiveness of nursing care. Outcomes Management for Nursing Practice, 1(1), 8-12.

McCormick, K. A, \& Jones, C. B. (1998). Is one taxonomy needed for health care vocabularies and classifications? Online Journal of Issues in Nursing. Retrieved March 4, 2002, from: http://nursingworld.org/ojin/tpc7/tpc7_2.htm

McGillis Hall, L., Dorna, D., \& Pink, G.H. (2004). Nurse staffing models, nursing hours and patient safety outcomes. Journal of Nursing Administration, 34(1), 41-45. 
McGillis Hall, L., Doran, D., \& Pink, L.(2008). Outcomes of interventions to improve hospital nursing work environments. Journal of_Nursing Administration, 38(1), 4046.

Ministry of Welfare (2007). Health Service Act No.40/2007. Retrieved from http://eng.velferdarraduneyti.is/acts-of-Parliament/nr/20098

Ministry of Welfare (2009). Health records act no.55/2009. Retrieved from http://eng.velferdarraduneyti.is/acts-of-Parliament/nr/20194

Ministry of Welfare (2010). Hospitals and health care centers in Iceland. Retrieved from http://eng.velferdarraduneyti.is/agencies/nr/20311.

Minium, E.W., King, B.M., \& Bear, G. (Eds.) (1993). Statistical Reasoning in Psychology and Education, (3rd.ed.). New York: John Wiley.

Moorhead, S., \& Delaney, C. (1998). Mapping nursing intervention data into the Nursing Interventions Classification (NIC): process and rules. Nursing Diagnosis. 8(4),137144.

Mrayyan, M.T. (2006). A unit-based protocol to enhance Jordanian nurses autonomous decision making. Journal of Nursing Management, 14, 391-396.

Murphy, J. (2010). The journey to meaningful use of electronic health records. Nursing Economics, 28(4), 283-286.

National Committee on Vital and Health Statistics [NCVHS]. (2001). Information for Health. A Strategy for Building the National Health Information Infrastructure. Retrieved from http://www.ncvhs.hhs.gov/nhiilayo.pdf

Nelson, R. \& Joos, I. (1989, Fall). On language in nursing: From data to wisdom. Pennsylvania League for Nursing, PLN Vision (p. 6).

Nelson, R. (2002). Major theories supporting health care informatics. In S. Englebart, \& R. Nelson (Eds.). Health care informatics: An interdisciplinary approach (pp.3-27). St.Louis, MO: Mosby-Year Book.

Nóbrega, M.M., \& Guiterres, M.G. (2000). Semantic equivalence of the Nursing Phenomena Classification of ICNP: Alpha Version in Brazilian Portuguese. Intermational Nursing Review, 47(1), 19-27.

O’Brien-Pallas, L., Duffield, C., \& Hayes, L. (2006). Do we really understand how to retain nurses? Journal of Nursing Management, 14, 262-270.

O’Brien-Pallas, L., Griffin, P., Shamian, J., Buchan, J., Duffield, C., Hughes, F., Laschinger, H. K. S., North, N., \& Stone, P. W. (2006). The impact of nurse turnover on patient, nurse, and system outcomes: A pilot study and focus for a multicenter international study. Policy, Politics, \& Nursing Practice, 7(3), 169-179. doi: 10.1177/1527154406291936.

Organization for Economic Co-Operation and Development [OECD]. (2009). Health at a glance 2009. Retrieved from http://www.oecd.org/document/11/0,3343,en_2649_33929_16502667_1_1_1_37407, 00.html. 
Organization for Economic Co-Operation and Development [OECD]. (2010a). Growing health spending puts pressure on government budgets, according to OECD Health Data 2010- . Retrieved from http://www.oecd.org/document/11/0,3343,en_21571361_44315115_45549771_1_1_1 _1,00.html.

Organization for Economic Co-Operation and Development [OECD]. (2010b). Health at a glance: Europe 2010. Retrieved from http://www.oecd-ilibrary.org/social-issuesmigration-health/health-at-a-glance-europe-2010_health_glance-2010-en.

Ozbolt, J. G. (2003). The Nursing Terminology Summit Conferences: a case study of successful collaboration for change. Journal of Biomedical Informatics, 36(4/5), 362374.

Ozbolt, J. G.,\& Saba, V. (2008). A brief history of nursing informatics in the United States of America. Nursing Outlook, 56(5), 199-205. doi: 10.1016/j.outlook.2008.06.008.

Pappas, S., H. (2007). Describing costs related to nursing. The Journal of Nursing Administration, 37(1), 32-40.

Pappas, S., H. (2008). The cost of nurse-sensitive adverse events. The Journal of Nursing Administration, 38(5), 230-236.

Patrician, P. A., Loan, L., McCarthy, M., Fridman, M., Donaldson, N., Bingham, M., \& Brosch, L. R. (2011). The association of shift-level nurse staffing with adverse patient events. Journal of Nursing Administration, 41(2), 64-70. doi: 10.1097/NNA.0b013e31820594bf.

Patrick, A., \& Laschinger, H. K. S. (2006). The effect of structural empowerment and perceived organizational support on middle level nurse managers' role satisfaction. Journal of Nursing Management, 14,13-22.

Peters, M. \& Passchier J. (2006). Translating instruments for cross-cultural studies in headache research. Headache. 46(1), 82-91.

Pitkäaho, T., Ryynänen, O.- P., Partanen, P., \& Vehviläinen- Julkunen, K. (2010). Databased nurse staffing indicators with Bayesian networks explain nurse job satisfaction: a pilot study. Journal of Advanced Nursing, 67(5), 1053-1066.

Polit, D. F., \& Beck, C. T. (2006). Essentials of nursing research (6 ${ }^{\text {th }}$ ed.). Philadelphia, PA: Lippincott Williams \& Wilkins.

Polit, D. F., \& Beck, C. T. (2010). Essentials of nursing research ( $7^{\text {th }}$ ed.). Philadelphia, PA: Lippincott Williams \& Wilkins.

Prime Minister's Office (2008). Iceland the e-Nation. Icelandic Government policy on the information society 2008-2012. Retrieved from http//www.eng.forsaetisraduneyti.is/media/utgefidefni/Iceland_the_eNation.pdf

Rafferty, A.M., Clarke, S.P., Coles, J., Ball, J., James, P., McKee, M., \& Aiken, L.H. (2006). Outcomes of variation in hospital nurse staffing in English hospitals: Crosssectional analysis of survey data and discharge records. International Journal of Nursing Studies, 44, 175-182. 
Rafferty, A. M., Clarke, S. P., Coles, J., Ball, J., James, P., McKee, M., \& Aiken, L. H. (2007). Outcomes of variation in hospital nurse staffing in English hospitals:

Crosssectional analysis of survey data and discharge records. International Journal of Nursing Studies, 44 (2), 175-182.

Rukanuddin, R.J. (2006). Development of standardized Midwifery Nursing Reproductive Health Data Set (MN-RHDs) for Pakistan. Studies in health technology and Informatics.122, 461-464.

Rutherford, J., Leigh, J., Monk, J., \& Murray, C. (2005). Creating an organizational infrastructure to develop and support new nursing roles - a framework for debate. Journal of Nursing Management, 13, 97-105.

Ryan, P., \& Delaney, C. (1995). Nursing Minimum Data Set. Annual Review of Nursing Research, 13, 169-194.

Saba, V. K. (2001). Nursing informatics: Yesterday, today and tomorrow. International Nursing Review, 48, 177-187.

Sabiston, J. A., \& Laschinger, H. K. S. (1995). Staff nurse work empowerment and perceived autonomy. Testing Kanter's theory of structural power in organizations. Journal of Nursing Administration, 25(9), 42-50.

Sasichay-Akkadechnunt T., Scalzi C.C., \& Jawad A.F. (2003). The relationship between nurse staffing and patient outcomes. The Journal of Nursing Administration 33, 478485.

Scott, J. G., Sochalski, J., \& Aiken, L. (1999). Review of magnet hospital research. Findings and implications for professional nursing practice. Journal of Nursing Administration, 29(1), 9-19.

Seki, Y., \& Yamazaki, Y. (2006). Effects of working conditions on intravenous medication errors in a Japanese hospital. Journal of Nursing Management, 14,128139.

Sermeus, W., Van den Heede, K., Michiels, D., Delesie, L., Thonon, O., Van Boven, C., Codognotto, J., \& Gillet, P. (2005). Revising the Belgian Nursing Minimum Data Set: From concept to implementation. International Journal of Medical Informatics, 74, 946-951.

Sermeusa, W., Delesiea, L., Van den Heede, K, ,Diya, L., \& Lesaffre, E. (2008). Measuring the intensity of nursing care: Making use of the Belgian nursing minimum data set. International journal of Nursing Studies,45(7), 1011-1021. doi: 10.1016/j.ijnurstu.2007.05.006

Shi, L. (1997). Health services research methods. Measurements in Health Services Research. (p.250-253.). Albany: Delmar Publishers.

Shortliffe, E. H., \& Barnett, G.O. (2001). Medical Data: Their Acquisition, Storage, and Use. In E.H. Shortliffe, L.E. Perreault, G. Wiederhold, \& L.M. Fagan (Eds.). Medical Informatics. Computer Applications in Health Care and Biomedicine (2nd ed.). New York: Springer. 
Shortliffe, E. H., \& Blois, M.S. (2001). The Computer Meets Medicine and Biology: Emergence of a Discipline. In E.H. Shortliffe, L.E. Perreault, G. Wiederhold, \& L.M. Fagan (Eds.). Medical Informatics. Computer Applications in Health Care and Biomedicine (2nd ed.). New York: Springer.

Snæbjörnsdóttir, S. (1989). Nursing Administration in Iceland. In B Henry, R. Heyden \& B. Richardson (Eds.), International Administration of Nursing Services (pp. 39-47). Philadelphia, PA: The Charles Press.

Sorensen, E., E., Seebeck, E., D., Scherb, C., A., Specht, J., P., \& Loes, J., L. (2009). The relationship between RN job satisfaction and accountability. Western Journal of Nursing Research, 31(7), 872-888.

Staggers, N., \& Thompson, C.B. (2002). The evolution of definitions for nursing informatics: a critical analysis and revised definition. Journal of the American Medical Informatics Association, 9(3), 306-307.

Statistics Iceland (2009). Iceland compared with other OECD countries. Retrieved from http://www.statice.is/Pages/444?NewsID=5071.

Statistics Iceland (2010). Population development 2010. Retrieved from http://www.statice.is/?PageID=452\&itemid=367e9f6e-7e2e-422a-8caf-14ff76a6d3b9

Stone, P.W., Kane, C.M., Larson, E.L., Horan, T., Glance, L.G., Zwanziger, J., \& Dick, A.W. (2007). "Nurse working conditions and patient safety outcomes," Medical Care, 45(6): 571-578.

Sveinsdóttir, H., Biering, P., \& Ramel, A. (2006). Occupational stress, job satisfaction, and working environment among Icelandic nurses: A cross-sectional questionnaire survey. International Journal of Nursing Studies, 43, 875-889.

Tai, T.W., Bame, S.I., \& Robinson, C.D. (1998). Review of nursing turnover research, 1977-1996. Social Science \& Medicine, 47(12),1905-1924.

Tang, S.T., \& Dixon, J. (2002). Instrument translation and evaluation of equivalence and psychometric properties: the Chinese Sense of Coherence Scale. Journal of Nursing Measurement, 10(1), 59-76.

Teslow, M.S., \& Wilde, D.J. (2001). Data Collection Standards. In M. Abdelhak, S. Grostick, M.A. Hanken, and E. Jacobs (Eds. $2^{\text {nd }}$ ed.). Health Information: Management of a Strategic Resource. (pp. 374-424). PA: W.B. Saunders.

Thorlacius, M. (2011). Using the nursing management minimum data set- Icelandic survey (NMMDS-ICE survey) to describe the characteristics of pediatric units in Icelandic hospitals. Unpublished MS thesis, University of Iceland, Reykjavík, Iceland.

Toussaint, P.J., \& Coiera, E. (2005). Supporting communication in health care[Editorial]. International Journal of Medical Informatics, 74, 779-781.

Tourangeau, A.E., Cranley, L.A., \& Jeffs, L. (2006). Impact of nursing on hospital patient mortality:a focused review and related policy implications. Quaity and Safety in Health Care, 15(1), 4-8 
Tourangeau, A.E., Doran, D.M., McGillis Hall, L., O’Brien Pallas, L., Pringle, D., Tu, J.V., \& Cranley, L.A. (2007). Impact of hospital nursing care on 30-day mortality for acute medical patients. Journal of Advanced Nursing, 57(1), 32-44.

Unruh, L. (2008). Nurse staffing and patient, nurse, and financial outcomes. American Journal of Nursing, 108(1), 62-71.

Urden, L. D. (1996). Development of a nurse executive decision support database. A model for outcomes evaluation. Journal of Nursing Administration, 26(10), 15-21.

Van den Heede, K., Clarke, S. P., Sermeus, W., Vleugels, A., \& Aiken, L. H. (2007). International expert's perspectives on the state of the nurse staffing and patient outcomes literature. Journal of Nursing Scholarship, 39(4), 290-297.

Van den Heede, K., Lesaffre, E., Diya, L., Vleugels, A., Clarke, S.P., Aiken, L.H., \& Sermeus, W. (2009a). The relationship between inpatient cardiac surgery mortality and nurse numbers and educational level: analysis of administrative data. International Journal of Nursing Studies, 46(6), 796-803.

Van den Heede, K., Sermeus, W., Diya, L., Clarke, S.P., Lesaffre, E., Vleugels, A.,\& Aiken, L.H. (2009b). Nurse staffing and patient outcomes in Belgian acute hospitals: Cross-sectional analysis of administrative data. International Journal of Nursing Studies, 46(6), 928-939.

Van den Heede, K., Michiels, D., Thonon, O., \& Sermeus, W. (2009). Using nursing interventions classification as a framework to revise the Belgian nursing minimum data set. International Journal of Nursing Terminologies and Classifications, 20(3), 122-131. doi: 10.1111/j.1744-618X.2009.01124.x

Volrathongchai, K., Delaney, C.W., \& Phuphaibul, R. (2003). Nursing Minimum Data Set development and implementation in Thailand. Journal of Advanced Nursing, 43(6), 588-594.

Wang, W., L., Lee, H., L., \& Fetzer, S., J. (2006). Challenges and strategies of instrument translation. Western Journal of Nursing Research, 28(3), 310-321.

Werley, H. H., Devine, E. C., Zorn, C. R., Ryan, P., \& Westra, B. L. (1991). The Nursing Minimum Data Set: Abstraction tool for standardized, comparable, essential data. American Journal of Public Health, 81(4), 421-426.

Weston, M., J. (2010). Strategies for enhancing autonomy and control over nursing practice. The Online Journal of Issues in Nursing, 15(1), Manuscript 2. doi: 10.3912/OJIN.Vol15No01Man02.

Westra, B.L., Delaney, C.W., Konicek, D., \& Keenan, G. (2008). Nursing standards to support the electronic health record. Nursing Outlook, 56(5), 258-266.

Westra, B.L., Subramanian, A., Hart, C.M., Matney, S.A., Wilson, P.S., Huff, S.M., Huber, D.L., \& Delaney, C.W. (2010). Achieving "meaningful use” of electronic health records through the integration of the Nursing Management Minimum Data Set. Journal of Nursing Administration, 40(7-8), 336-343. 
Willgerodt, M.A., Kataoka-Yahiro, M., Kim, E., \& Ceria, C. (2005). Issues of instrument translation in research on Asian immigrant populations. Journal of Professional Nursing, 21(4), 231-239.

World Health Organization[WHO]. (2006). Formulating national health workforce strategies. Retrieved November 29, 2011 from: http//who.int/whr/2006/chapter6/en/index.html.

Yu, D.F., Lee, D.T., \& Woo, J. (2004). Issues and challenges of instrument translation. Western Journal of Nursing Research, 26, 307-320. 
APPENDIX A INSTRUMENT: THE NURSING MANAGEMENT MINIMUM DATA SET (NMMDS) SURVEY ${ }^{\odot}$ DHUBER \& CDELANEY, 2005 
THE NURSING MANAGEMENT MINIMUM DATA SET

SURVEY ${ }^{\circledR}$ DHuber \& CDelaney2005

\section{ENVIRONMENT}

\section{Unit/Service Unique Identifier}

Identify the unique name, identifier, payment and geographic data for a center of excellence, service program, cluster by level of care, service/product line, or service/area where the majority of patient/client care is delivered; this is the first level of data aggregation beyond the patient/client care provider.

$01.01 \quad$ Unique facility identifier

01.02 Unique service identifier

01.03 Unique service name

01.04 Unique unit identifier

01.05 Unique unit name

01.06 Medicare payment category

01.061 Urban

01.062 Rural

01.063 Rural access

01.064 Critical access

01.07 Geographic location (state, province, canton)

01.08 Postal location (mailing code, zip code)

01.09 Country code 


\section{Type of Nursing Delivery Unit/Service}

Identify the percentage of each category that most accurately describes the service or type of organization and level of care.

02.01 Community/outreach

02.02 Community/public health

02.03 Custodial

02.04 Day care

02.05 Residential care

02.06 Retirement living

02.07 Assisted living care

02.08 Nursing home intermediate care

$02.09 \quad$ Nursing home skilled care

02.10 Nursing home special care unit

02.11 Nursing home sub-acute inpatient

02.12 Free-standing nurse-managed clinic/center/service

$02.13 \quad$ Free-standing outpatient clinic

02.14 Primary care clinic

02.15 Health promotion/well care/ fitness service

02.16 Home care

$02.17 \quad$ Hospice care/end of life

02.18 Respite care/compassionate care

02.19 Ambulatory/surgery/procedural/outpatient recovery area

02.20 Transitional care

02.21 Rehabilitation center

02.22 Telephone triage

$02.23 \quad$ Emergency service

02.24 Observation

02.25 Hospital acute inpatient

$02.26 \quad$ Hospital based skilled care

02.27 Hospital based critical care inpatient

$02.28 \quad H o s p i t a l$ based nursing center

02.29 Hospital based outpatient clinic

02.30 Hospital based sub-acute inpatient

02.31 Hospital based home care

02.32 Laboratory/screening/diagnostic

02.33 Operating room/surgical suite

02.34 School health service

02.35 Sports medicine service

$02.36 \quad$ Occupational health service

02.37 Volunteer 


\section{Patient/Client Population}

Identify the percentage of each category that best describes the patient/client population served by the nursing delivery unit/service.

\subsection{Specialty}

03.101

03.102

03.103

03.104

03.105

03.106

03.107

03.108

03.109

03.110

03.111

03.112

03.113

03.114

03.115

03.116

03.117

03.118

03.119

03.120

03.121

03.122

03.123

03.124

03.125

03.126

03.127

03.128

03.129

03.130

03.131

03.132

03.133

03.134

03.135

03.136

03.137

03.138

03.139
AIDS/HIV

Birthing

Cardiology

Communicable disease

Critical care, cardiac

Critical care, medical

Critical care, medical/psychiatric

Critical care, surgical

Critical care, neonatal

Critical care, pediatric

Critical care, surgical

Dental

Developmental ability

Diabetes

Dialysis

Emergency/trauma

Wellness

Hematology

Immunization

Maternal

Child/Pediatric

Medical

Medical/psychiatric

Neurology

Nutrition

Oncology

Pain

Post anesthesia care

Psychiatry/psychology

Pulmonary

Rehabilitation

Rheumatology

Sexually transmitted diseases

Substance abuse

Surgical

Transplant

Violence/injury

Fertility (reproductive)

Genetic Counseling 


\subsection{Developmental Focus}

03.201

03.202

03.203

03.204

03.205

03.206

03.207

03.208

03.209

03.210

03.211
Fetal

Infant (age 0-12 months)

Toddler (age 13-23 months)

Early childhood (age 2-6 years)

Elementary/middle school (age 7-12 years)

Adolescent (age 13-18 years)

Young Adult (age 19-40 years)

Middle Adult (age 41-64 years)

Late adult (age greater than 64)

End of life

Mixed (all ages)

\subsection{Interaction Focus}

03.31

03.32

03.33

Individual

Group

03.34 Community/Population

\subsection{Population Focus}

03.41

03.42

03.43

03.44

03.45

03.46

03.47

03.48

03.49

Population, city/town

Population, district

Population, county/parish

Population, province

Population, state

Population, region

Population, nation

Population, international

Population, aerospace 


\section{Volume of Nursing Delivery Unit/Service}

Identify the type of encounter(s)* (volume measure of unit of service $\{\mathrm{UOS}\}$ ) that are used on this unit/service, the number of hours of care designated for each type of encounter, the average number of encounters delivered per 24 hours for the reporting year, and the maximum number of encounters that could be provided available during a 24-hour period.

\subsection{Patient}

\begin{tabular}{|l|l|l|l|}
\hline $\begin{array}{l}\text { Type of } \\
\text { Encounter* }\end{array}$ & $\begin{array}{l}\text { \# of Hours of Care } \\
\text { Designated per } \\
\text { Encounter }\end{array}$ & $\begin{array}{l}\text { Average \# of } \\
\text { Encounters per 24 } \\
\text { Hours }\end{array}$ & $\begin{array}{l}\text { Maximum \# of } \\
\text { Encounters That } \\
\text { Could Be } \\
\text { Provided During } \\
\text { a 24 Hour Period }\end{array}$ \\
\hline $\begin{array}{l}\text { Hours } \\
04.101\end{array}$ & & & \\
\hline $\begin{array}{l}\text { Days } \\
04.102\end{array}$ & & & \\
\hline Visits & & & \\
04.103 & & & \\
\hline $\begin{array}{l}\text { Procedures } \\
04.104\end{array}$ & & & \\
\hline Consults & & \\
04.105 & & & \\
\hline Contacts & & & \\
\hline $\begin{array}{l}\text { Programs } \\
04.107\end{array}$ & & & \\
\hline $\begin{array}{l}\text { Classes } \\
04.108\end{array}$ & & & \\
\hline Enrollees \\
04.109
\end{tabular}

* An encounter is the direct provision of health care service(s) through a provider's interaction. 


\subsection{Family}

\begin{tabular}{|l|l|l|l|}
\hline $\begin{array}{l}\text { Type of } \\
\text { Encounter* }\end{array}$ & $\begin{array}{l}\text { \# of Hours of Care } \\
\text { Designated per } \\
\text { Encounter }\end{array}$ & $\begin{array}{l}\text { Average \# of } \\
\text { Encounters per 24 } \\
\text { Hours }\end{array}$ & $\begin{array}{l}\text { Maximum \# of } \\
\text { Encounters That } \\
\text { Could Be } \\
\text { Provided During } \\
\text { a 24 Hour Period }\end{array}$ \\
\hline $\begin{array}{l}\text { Hours } \\
04.201\end{array}$ & & & \\
\hline Days & & & \\
04.202 & & & \\
Visits & & & \\
\hline $\begin{array}{l}\text { Procedures } \\
04.204\end{array}$ & & & \\
\hline Consults & & & \\
04.205 & & & \\
\hline Contacts & & & \\
\hline $\begin{array}{l}\text { Programs } \\
04.206\end{array}$ & & & \\
\hline Classes & & & \\
04.208 & & & \\
\hline Enrollees & & & \\
04.209 & & & \\
\hline
\end{tabular}

* An encounter is the direct provision of health care service(s) through a provider's interaction. 


\subsection{Group}

\begin{tabular}{|l|l|l|l|}
\hline $\begin{array}{l}\text { Type of } \\
\text { Encounter* }\end{array}$ & $\begin{array}{l}\text { \# of Hours of Care } \\
\text { Designated per } \\
\text { Encounter }\end{array}$ & $\begin{array}{l}\text { Average \# of } \\
\text { Encounters per 24 } \\
\text { Hours }\end{array}$ & $\begin{array}{l}\text { Maximum \# of } \\
\text { Encounters That } \\
\text { Could Be } \\
\text { Provided During } \\
\text { a 24 Hour Period }\end{array}$ \\
\hline $\begin{array}{l}\text { Hours } \\
04.301\end{array}$ & & & \\
\hline Days & & \\
04.302 & & & \\
\hline Visits & & & \\
\hline $\begin{array}{l}\text { Procedures } \\
04.304\end{array}$ & & & \\
\hline $\begin{array}{l}\text { Consults } \\
04.305\end{array}$ & & & \\
\hline $\begin{array}{l}\text { Contacts } \\
04.306\end{array}$ & & & \\
\hline $\begin{array}{l}\text { Programs } \\
04.307\end{array}$ & & & \\
\hline Classes & & & \\
04.308 & & & \\
\hline Enrollees \\
04.309
\end{tabular}

* An encounter is the direct provision of health care service(s) through a provider's interaction. 


\subsection{Community/Population}

\begin{tabular}{|l|l|l|l|}
\hline $\begin{array}{l}\text { Type of } \\
\text { Encounter* }\end{array}$ & $\begin{array}{l}\text { \# of Hours of Care } \\
\text { Designated per } \\
\text { Encounter }\end{array}$ & $\begin{array}{l}\text { Average \# of } \\
\text { Encounters per 24- } \\
\text { Hours }\end{array}$ & $\begin{array}{l}\text { Maximum \# of } \\
\text { Encounters That } \\
\text { Could Be } \\
\text { Provided During } \\
\text { a 24 Hour Period }\end{array}$ \\
\hline $\begin{array}{l}\text { Hours } \\
04.401\end{array}$ & & & \\
\hline Days & & \\
04.402 & & & \\
\hline Visits & & & \\
\hline $\begin{array}{l}\text { Procedures } \\
04.404\end{array}$ & & & \\
\hline $\begin{array}{l}\text { Consults } \\
04.405\end{array}$ & & & \\
\hline $\begin{array}{l}\text { Contacts } \\
04.406\end{array}$ & & & \\
\hline $\begin{array}{l}\text { Programs } \\
04.407\end{array}$ & & & \\
\hline Classes & & & \\
04.408 & & & \\
\hline Enrollees \\
04.409
\end{tabular}

* An encounter is the direct provision of health care service(s) through a provider's interaction. 


\section{Care Delivery Structure and Outcomes}

Identify the percentage of each of the following care delivery methods or forms of organizing the work that most accurately describes care delivery structure of the nursing delivery unit/service. Total distribution should equal 100\%.

\subsection{Structure}

$05.01 \quad$ Private Duty:

RN employed by the patient/client and accountable for planning, coordinating, delivering, and evaluating nursing care to the patient/client.

$05.02 \quad$ Functional:

RN employed by organization and accountable for specific tasks and technical aspects of care to a group of patients/clients.

05.03 Team:

RN employed by organization and accountable for planning, coordinating, and evaluating nursing care for a group of patients/clients and for directing a team of professional and non-professional providers and assistants

$05.04 \quad$ Total Patient Care:

RN employed by organization and accountable for planning, coordinating, delivering, and evaluating nursing care for one or more patients/clients for a work shift.

$05.05 \quad$ Primary Nursing:

RN employed by organization and accountable for planning, coordinating, delivering, and evaluating nursing care over a 24-hour period with or without assistive staff.

05.06 Case Management:

RN employed by client or organization and accountable for planning, coordinating, monitoring, and evaluating the health care provided by an interdisciplinary team across the continuum of health care over a 24-hour period with or without assistive staff.

05.07 Managed Care:

RN employed by organization and accountable for coordinating clinical and financial care aspects for covered lives.

05.08 Community and Home Health Care:

RN employed by organization and accountable for planning, coordinating, delivering, and evaluating nursing care for a case load or identified population in the community and/or home. 


\subsection{Outcomes - Professional}

Rate the extent to which each of these outcomes has been met:

Scale: 1(lowest), 5 (highest).

\begin{tabular}{|c|c|c|}
\hline Category & Rating & \\
\hline $\begin{array}{l}\text { Reward and pay for performance } \\
05.21\end{array}$ & $\begin{array}{cc}1 & 2 \\
\text { Low }\end{array}$ & High \\
\hline $\begin{array}{l}\text { Career mobility and expansion } \\
05.22\end{array}$ & $\begin{array}{ccc}1 & 2 & 3 \\
\text { Low } & & \\
\end{array}$ & High \\
\hline $\begin{array}{l}\text { Recognition by nurses for meaningful } \\
\text { contribution to practice } \\
05.23\end{array}$ & $\begin{array}{ccc}1 & 2 & 3 \\
\text { Low } & \end{array}$ & High \\
\hline $\begin{array}{l}\text { Nursing care personnel injury rate } \\
05.24\end{array}$ & $\begin{array}{ccc}1 & 2 \\
\text { Low } & 3\end{array}$ & High \\
\hline
\end{tabular}

\subsection{Outcomes - Clinical}

Rate the extent to which each of these outcomes has been met:

Scale: 1(lowest), 5 (highest).

\begin{tabular}{|c|c|}
\hline Category & Rating \\
\hline $\begin{array}{l}\text { Mortality rate } \\
05.31\end{array}$ & $\begin{array}{rrrrr}1 & 2 & 3 & 4 & 5 \\
\text { Low } & & & & \text { High }\end{array}$ \\
\hline $\begin{array}{l}\text { Length of stay } \\
05.32\end{array}$ & $\begin{array}{rrrrr}1 & 2 & 3 & 4 & 5 \\
\text { Low } & & & & \text { High } \\
\end{array}$ \\
\hline $\begin{array}{l}\text { Adverse reactions } \\
05.33\end{array}$ & $\begin{array}{rrrrr}1 & 2 & 3 & 4 & 5 \\
\text { Low } & & & & \text { High } \\
\end{array}$ \\
\hline $\begin{array}{l}\text { Complications } \\
05.34\end{array}$ & $\begin{array}{rrrrr}1 & 2 & 3 & 4 & 5 \\
\text { Low } & & & & \text { High } \\
\end{array}$ \\
\hline $\begin{array}{l}\text { Pain management level achieved } \\
05.35\end{array}$ & $\begin{array}{rrrrr}1 & 2 & 3 & 4 & 5 \\
\text { Low } & & & & \text { High }\end{array}$ \\
\hline $\begin{array}{l}\text { Maintenance of skin integrity } \\
05.36\end{array}$ & $\begin{array}{rrrrr}1 & 2 & 3 & 4 & 5 \\
\text { Low } & & & & \text { High }\end{array}$ \\
\hline
\end{tabular}




\section{Patient/Client Accessibility}

From the following time and distance factors associated with the point of care, identify the percentage of each factor that most clearly characterizes the care provider(s)' access to patients/clients for the purpose of care delivery.

\begin{tabular}{|l|l|}
\hline Factor & $\begin{array}{l}\text { Percentage of Typical } \\
\text { Access For This Factor }\end{array}$ \\
\hline $\begin{array}{l}\text { Self-contained unit/service; little walking or distance to } \\
\text { client }\end{array}$ & \\
06.01 & \\
\hline Spread out self-contained unit/service; clinic; same & \\
facility; same neighborhood & \\
06.02 & \\
\hline Geographic assignment/normal caseload 30-60 & \\
minutes of travel time; having responsibility in more & \\
than one facility & \\
06.03 & \\
\hline Frontier/rural caseload; provider travel time $\geq$ one (1) & \\
Hour & \\
06.04 & \\
\hline Internet/WWW(asynchronous) & \\
06.05 & \\
\hline Telecommunications/telehealth care (synchronous) & \\
06.06 & \\
\hline
\end{tabular}

\section{Clinical Decision Making Complexity}

\subsection{Patient/Client Care}

Estimate the extent to which patient/client care in the nursing delivery unit/service would be classified in each of the following categories.

\begin{tabular}{|c|c|}
\hline Category & Rating \\
\hline $\begin{array}{l}\text { Standardized Procedures/Care } \\
07.11\end{array}$ & $\begin{array}{rrrrr}1 & 2 & 3 & 4 & 5 \\
\text { Low } & & & & \text { High }\end{array}$ \\
\hline $\begin{array}{l}\text { Variability or Exceptions } \\
07.12\end{array}$ & $\begin{array}{rrrrr}1 & 2 & 3 & 4 & 5 \\
\text { Low } & & & & \text { High }\end{array}$ \\
\hline $\begin{array}{l}\text { Professional Judgment, Experience, Intuition } \\
07.13\end{array}$ & $\begin{array}{rrrrr}1 & 2 & 3 & 4 & 5 \\
\text { Low } & & & & \text { High }\end{array}$ \\
\hline $\begin{array}{l}\text { Level of Expert Knowledge } \\
07.14\end{array}$ & $\begin{array}{rrrrr}1 & 2 & 3 & 4 & 5 \\
\text { Low } & & & & \text { High }\end{array}$ \\
\hline
\end{tabular}




\subsection{Computerization}

Estimate the extent of computerization in the nursing delivery unit/service.

\begin{tabular}{|c|c|}
\hline Application/Solution & Rating \\
\hline $\begin{array}{l}\text { History/Assessment } \\
07.201\end{array}$ & $\begin{array}{rrrrr}1 & 2 & 3 & 4 & 5 \\
\text { Low } & & & & \text { High }\end{array}$ \\
\hline $\begin{array}{l}\text { Documentation } \\
07.202\end{array}$ & $\begin{array}{rrrrr}1 & 2 & 3 & 4 & 5 \\
\text { Low } & & & & \text { High }\end{array}$ \\
\hline $\begin{array}{l}\text { Discharge Planning } \\
07.203\end{array}$ & $\begin{array}{rrrrr}1 & 2 & 3 & 4 & 5 \\
\text { Low } & & & & \text { High }\end{array}$ \\
\hline $\begin{array}{l}\text { Care Plan } \\
07.204\end{array}$ & $\begin{array}{rrrrr}1 & 2 & 3 & 4 & 5 \\
\text { Low } & & & & \text { High } \\
\end{array}$ \\
\hline $\begin{array}{l}\text { Graphics } \\
07.205\end{array}$ & $\begin{array}{rrrrr}1 & 2 & 3 & 4 & 5 \\
\text { Low } & & & & \text { High }\end{array}$ \\
\hline $\begin{array}{l}\text { Medication } \\
07.206\end{array}$ & $\begin{array}{rrrrr}1 & 2 & 3 & 4 & 5 \\
\text { Low } & & & & \text { High }\end{array}$ \\
\hline $\begin{array}{l}\text { Physiological Monitoring } \\
07.207\end{array}$ & $\begin{array}{rrrrr}1 & 2 & 3 & 4 & 5 \\
\text { Low } & & & & \text { High }\end{array}$ \\
\hline $\begin{array}{l}\text { Data Repository } \\
07.208\end{array}$ & $\begin{array}{rrrrr}1 & 2 & 3 & 4 & 5 \\
\text { Low } & & & & \text { High }\end{array}$ \\
\hline $\begin{array}{l}\text { Management (contextual) Data } \\
07.209\end{array}$ & $\begin{array}{rrrrr}1 & 2 & 3 & 4 & 5 \\
\text { Low } & & & & \text { High }\end{array}$ \\
\hline $\begin{array}{l}\text { Decision Support } \\
07.210\end{array}$ & $\begin{array}{rrrrr}1 & 2 & 3 & 4 & 5 \\
\text { Low } & & & & \text { High }\end{array}$ \\
\hline $\begin{array}{l}\text { Acuity/Workload } \\
07.211\end{array}$ & $\begin{array}{rrrrr}1 & 2 & 3 & 4 & 5 \\
\text { Low } & & & & \text { High }\end{array}$ \\
\hline $\begin{array}{l}\text { Standardized Nursing Languages } \\
07.212\end{array}$ & $\begin{array}{rrrrr}1 & 2 & 3 & 4 & 5 \\
\text { Low } & & & & \text { High } \\
\end{array}$ \\
\hline
\end{tabular}




\section{Environmental Complexity}

Rate the perceived amount of turnover, heterogeneity, and stability of the environmental climate within the nursing delivery unit/service.

\begin{tabular}{|l|ccccc|}
\hline Patient/Client Turnover & \multicolumn{1}{|c}{$1-$} & $2-$ & $3-$ & $4-$ & 5 \\
08.01 & Stable & & & & Shifting \\
\hline Heterogeneity of Patient/Client Mix & $1-$ & $2-$ & $3-$ & $4-$ & 5 \\
08.02 & Alike & & & & Diverse \\
\hline $\begin{array}{l}\text { Environmental Climate } \\
08.03\end{array}$ & $\begin{array}{l}\mid c \\
\text { Stable }\end{array}$ & & $3-$ & $4-$ & 5 \\
& & & Turbulent \\
\hline
\end{tabular}

\section{$\underline{09}$ Autonomy}

In the left column list each position beginning with the nursing delivery unit/service manager and progressing to the facility/organization chief nurse executive/ administrator (sample categories are listed below). For each line position, rate the extent of participation in organizational decision making in each area.

Scale: 1 =never; 2=seldom; 3=sometimes; 4=often; 5=always

\begin{tabular}{|c|c|c|c|c|c|c|}
\hline $\begin{array}{l}\text { Level of } \\
\text { Decision } \\
\text { Maker }\end{array}$ & $\begin{array}{l}\text { Clinical } \\
\text { autonomy }\end{array}$ & $\begin{array}{l}\text { Professional } \\
\text { autonomy }\end{array}$ & $\begin{array}{l}\text { Control over } \\
\text { nursing } \\
\text { practice }\end{array}$ & $\begin{array}{l}\text { Freedom to } \\
\text { act on } \\
\text { what you } \\
\text { know }\end{array}$ & $\begin{array}{l}\text { Freedom } \\
\text { from } \\
\text { bureau- } \\
\text { cratic } \\
\text { constraints }\end{array}$ & $\begin{array}{l}\text { Allows for } \\
\text { account- } \\
\text { ability and } \\
\text { authority in } \\
\text { decision } \\
\text { making }\end{array}$ \\
\hline $\begin{array}{l}\text { Unit/Service } \\
\text { Manager } \\
09.01\end{array}$ & & & & & & \\
\hline $\begin{array}{l}\text { Department of } \\
\text { Nursing } \\
09.02\end{array}$ & & & & & & \\
\hline $\begin{array}{l}\text { Organization } \\
\text { (e.g. Chief } \\
\text { Nurse } \\
\text { Executive/ } \\
\text { Administrator) } \\
09.03\end{array}$ & & & & & & \\
\hline $\begin{array}{l}\text { System } \\
09.04\end{array}$ & & & & & & \\
\hline
\end{tabular}




\section{Nursing Delivery Unit/Service Accreditation}

Indicate accreditation(s) or certification(s) status of the nursing delivery unit/service.

Check all that apply.

\begin{tabular}{|l|l|l|l|l|}
\hline Accreditation Agency & $\begin{array}{l}\text { Not } \\
\text { available }\end{array}$ & $\begin{array}{l}\text { Available, } \\
\text { not sought }\end{array}$ & $\begin{array}{l}\text { Sought, } \\
\text { Not } \\
\text { granted }\end{array}$ & Granted \\
\hline $\begin{array}{l}\text { American College of Osteopathic } \\
\text { Surgeons (ACOS) }\end{array}$ & & & & \\
\hline American Diabetes Association (ADA) & & & & \\
10.02 & & & & \\
\hline American College of Surgeons & & & \\
10.03 & & & \\
\hline American Nurses Association (ANA) & & & \\
Magnet Status & & & \\
10.04 & & & \\
\hline Burn Center (any level) & & & \\
10.05 & Clinical Laboratory Improvement & & & \\
Amendment (CLIA) & & & \\
10.06 & & & \\
\hline Education & & & \\
10.07 & Joint Commission on Accreditation & & & \\
of Healthcare Organizations & & & \\
(JCAHO) & & & \\
\hline Medicaid & & & \\
10.09 & & & & \\
\hline Medicare & & & \\
10.10 & & & & \\
\hline National Committee on Quality & & & \\
Assurance & & & \\
(NCQA) & & & \\
10.11 & & & \\
\hline State & & & \\
10.12 & & & \\
\hline Trauma Center (any level) & & & \\
10.13 & & & \\
\hline Utilization Review Accreditation & & & \\
Commission (URAC) & & & \\
\hline Veterans Administration(VA) & & & \\
10.15 & & & \\
\hline
\end{tabular}




\section{NURSING CARE RESOURCES}

\section{Management Demographic Profile}

Complete this profile for the nursing delivery unit/service manager/head nurse: that is, the person (by whatever title) designated as the nurse manager with 24 hour accountability for the nursing delivery unit/service. If there is more than one manager, complete the profile for each.

\subsection{Manager 1}

11.10 Educational background:

11.101 Associate degree

11.102 Diploma

11.103 BSN

11.104 Bachelor, non-nursing

11.105 Masters in Nursing

11.106 Masters, non-nursing

11.107 Doctorate, nursing

11.108 Doctorate, non-nursing

11.11 Credentials, specify

11.12 Gender

11.13 Experience

11.121 Male

11.122 Female

11.131 Years of experience as a manager

11.132 Years of experience in nursing

11.14 Unique provider number

11.15 Title, specify

\subsection{Manager 2}

11.20 Educational background:

11.201 Associate degree

11.202 Diploma

11.203 BSN

11.204 Bachelor, non-nursing

11.205 Masters in Nursing

11.206 Masters, non-nursing

11.207 Doctorate, nursing

11.208 Doctorate, non-nursing

11.21 Credentials, specify

11.22 Gender

11.23 Experience

$$
\text { 11.221 Male }
$$

11.222 Female

11.231 Years of experience as a manager

11.232 Years of experience in nursing

11.24 Unique provider number

11.25 Title, specify 


\section{Staff Demographic Profile}

Complete this profile for the nursing staff and personnel in the nursing delivery unit/service.

\subsection{Direct Care Staff}

\begin{tabular}{|c|c|c|c|c|c|}
\hline Role & & & Average & Years & Service \\
\hline $\begin{array}{l}\text { Advanced } \\
\text { Practice } \\
\text { Nurses } \\
12.11\end{array}$ & $\begin{array}{l}\text { Total } \\
\text { Number }\end{array}$ & $\begin{array}{l}\text { Total } \\
\text { FTE }\end{array}$ & $\begin{array}{l}\text { Present } \\
\text { Institution }\end{array}$ & $\begin{array}{l}\text { Present } \\
\text { Position }\end{array}$ & $\begin{array}{l}\text { In } \\
\text { Profession }\end{array}$ \\
\hline $\begin{array}{l}\text { Education: } \\
12.111\end{array}$ & & & & & \\
\hline $\begin{array}{l}\text { Associate } \\
12.112 \\
\end{array}$ & & & & & \\
\hline $\begin{array}{l}\text { Diploma } \\
12.113\end{array}$ & & & & & \\
\hline $\begin{array}{l}\text { Bachelors, } \\
\text { Nursing } \\
12.114\end{array}$ & & & & & \\
\hline $\begin{array}{l}\text { Bachelors, } \\
\text { non-nursing } \\
12.115\end{array}$ & & & & & \\
\hline $\begin{array}{l}\text { Masters, } \\
\text { nursing } \\
12.116 \\
\end{array}$ & & & & & \\
\hline $\begin{array}{l}\text { Masters, non- } \\
\text { nursing } \\
12.117\end{array}$ & & & & & \\
\hline $\begin{array}{l}\text { Doctorate } \\
12.118\end{array}$ & & & & & \\
\hline $\begin{array}{l}\text { Doctorate, } \\
\text { non-nursing } \\
12.119\end{array}$ & & & & & \\
\hline $\begin{array}{l}\text { Certification, } \\
\text { specify } \\
12.1110\end{array}$ & & & & & \\
\hline $\begin{array}{l}\text { Member } \\
\text { nursing } \\
\text { professional/ } \\
\text { specialty } \\
\text { organization } \\
12.1111\end{array}$ & & & & & \\
\hline $\begin{array}{l}\text { Mean age } \\
12.1112\end{array}$ & & & & & \\
\hline $\begin{array}{l}\text { Number of } \\
\text { dependent } \\
\text { persons } \\
\text { responsible } \\
\text { for } \\
12.1113\end{array}$ & & & & & \\
\hline
\end{tabular}




\begin{tabular}{|c|c|c|c|c|c|}
\hline Role & & & Average & Years & Service \\
\hline $\begin{array}{l}\text { Registered } \\
\text { Nurses (RN) } \\
12.12\end{array}$ & $\begin{array}{l}\text { Total } \\
\text { Number }\end{array}$ & $\begin{array}{l}\text { Total } \\
\text { FTE }\end{array}$ & $\begin{array}{l}\text { Present } \\
\text { Institution }\end{array}$ & $\begin{array}{l}\text { Present } \\
\text { Position }\end{array}$ & $\begin{array}{l}\text { In } \\
\text { Profession }\end{array}$ \\
\hline \multicolumn{6}{|l|}{$\begin{array}{l}\text { Education: } \\
12.121\end{array}$} \\
\hline \multicolumn{6}{|l|}{$\begin{array}{l}\text { Associate } \\
12.122\end{array}$} \\
\hline \multicolumn{6}{|l|}{$\begin{array}{l}\text { Diploma } \\
12.12 \\
\end{array}$} \\
\hline \multicolumn{6}{|l|}{$\begin{array}{l}\text { Bachelors, } \\
\text { Nursing } \\
12.124\end{array}$} \\
\hline \multicolumn{6}{|l|}{$\begin{array}{l}\text { Bachelors, } \\
\text { non-nursing } \\
12.125 \\
\end{array}$} \\
\hline \multicolumn{6}{|l|}{$\begin{array}{l}\text { Masters, } \\
\text { nursing } \\
12.126\end{array}$} \\
\hline \multicolumn{6}{|l|}{$\begin{array}{l}\text { Masters, non- } \\
\text { nursing } \\
12.127\end{array}$} \\
\hline \multicolumn{6}{|l|}{$\begin{array}{l}\text { Doctorate } \\
12.128 \\
\end{array}$} \\
\hline \multicolumn{6}{|l|}{$\begin{array}{l}\text { Doctorate, } \\
\text { non-nursing } \\
12.129 \\
\end{array}$} \\
\hline \multicolumn{6}{|l|}{$\begin{array}{l}\text { Certification, } \\
\text { specify } \\
12.1210\end{array}$} \\
\hline \multicolumn{6}{|l|}{$\begin{array}{l}\text { Member } \\
\text { Nursing } \\
\text { Professional/ } \\
\text { Specialty } \\
\text { organization } \\
12.1211 \\
\end{array}$} \\
\hline \multicolumn{6}{|l|}{$\begin{array}{l}\text { Mean age } \\
12.1212\end{array}$} \\
\hline $\begin{array}{l}\text { Number of } \\
\text { dependent } \\
\text { persons } \\
\text { responsible } \\
\text { for } \\
12.1213\end{array}$ & & & & & \\
\hline
\end{tabular}




\begin{tabular}{|l|l|l|l|l|}
\hline Role & Total & Total & Average Years & of Service \\
\hline Licensed & Number & FTE & Present & $\begin{array}{l}\text { Present } \\
\text { position }\end{array}$ \\
Nurses/ & institution & & \\
Licensed & Vocational & & & \\
Nurses & & & & \\
$\mathbf{( L P N / L V N ) ~}$ & & & & \\
$\mathbf{1 2 . 1 3}$ & & & & \\
\hline $\begin{array}{l}\text { Mean age } \\
12.131\end{array}$ & & & & \\
\hline $\begin{array}{l}\text { Number of } \\
\text { dependent } \\
\text { persons }\end{array}$ & & & & \\
responsible & & & & \\
for & & & & \\
12.132 & & & & \\
\hline
\end{tabular}

\begin{tabular}{|l|l|l|l|l|}
\hline Role & Total & Total & \multicolumn{1}{|l|}{ Average Years } & of Service \\
\hline $\begin{array}{l}\text { Non- } \\
\text { professionals } \\
\text { (Aides, etc) } \\
\mathbf{1 2 . 1 4}\end{array}$ & Number & FTE & $\begin{array}{l}\text { Present } \\
\text { institution }\end{array}$ & $\begin{array}{l}\text { Present } \\
\text { position }\end{array}$ \\
\hline $\begin{array}{l}\text { Mean age } \\
12.141\end{array}$ & & & & \\
\hline $\begin{array}{l}\text { Number of } \\
\text { dependent } \\
\text { persons } \\
\text { responsible } \\
\text { for } \\
12.142\end{array}$ & & & & \\
\hline
\end{tabular}


12.2 Management, Administrative, Support Staff

\begin{tabular}{|c|c|c|c|c|c|}
\hline Role & & & Average & $\begin{array}{l}\text { Years } \\
\text { of }\end{array}$ & Service \\
\hline $\begin{array}{l}\text { Case Managers } \\
12.21\end{array}$ & $\begin{array}{l}\text { Total } \\
\text { Number }\end{array}$ & Total FTE & $\begin{array}{l}\text { Present } \\
\text { Institution }\end{array}$ & $\begin{array}{l}\text { Present } \\
\text { Position }\end{array}$ & $\begin{array}{l}\text { In } \\
\text { Profession }\end{array}$ \\
\hline $\begin{array}{l}\text { Education: } \\
12.211\end{array}$ & & & & & \\
\hline $\begin{array}{l}\text { Associate } \\
12.212\end{array}$ & & & & & \\
\hline $\begin{array}{l}\text { Diploma } \\
12.213\end{array}$ & & & & & \\
\hline $\begin{array}{l}\text { Bachelors, } \\
\text { Nursing } \\
12.214\end{array}$ & & & & & \\
\hline $\begin{array}{l}\text { Bachelors, non- } \\
\text { nursing } \\
12.215\end{array}$ & & & & & \\
\hline $\begin{array}{l}\text { Masters, } \\
\text { nursing } \\
12.216 \\
\end{array}$ & & & & & \\
\hline $\begin{array}{l}\text { Masters, non- } \\
\text { nursing } \\
12.217\end{array}$ & & & & & \\
\hline $\begin{array}{l}\text { Doctorate } \\
12.218\end{array}$ & & & & & \\
\hline $\begin{array}{l}\text { Doctorate, non- } \\
\text { nursing } \\
12.219\end{array}$ & & & & & \\
\hline $\begin{array}{l}\text { Certification, } \\
\text { specify } \\
12.2110\end{array}$ & & & & & \\
\hline $\begin{array}{l}\text { Member } \\
\text { nursing } \\
\text { professional/ } \\
\text { specialty } \\
\text { organization } \\
12.2111\end{array}$ & & & & & \\
\hline $\begin{array}{l}\text { Mean age } \\
12.2112\end{array}$ & & & & & \\
\hline $\begin{array}{l}\text { Number of } \\
\text { dependent } \\
\text { persons } \\
\text { responsible for } \\
12.2113\end{array}$ & & & & & \\
\hline
\end{tabular}




\begin{tabular}{|c|c|c|c|c|c|}
\hline Role & & & Average & Years of & Service \\
\hline $\begin{array}{l}\text { Nurse } \\
\text { Managers } \\
12.22\end{array}$ & $\begin{array}{l}\text { Total } \\
\text { Number }\end{array}$ & Total FTE & $\begin{array}{l}\text { Present } \\
\text { Institution }\end{array}$ & $\begin{array}{l}\text { Present } \\
\text { Position }\end{array}$ & $\begin{array}{l}\text { In } \\
\text { Profession }\end{array}$ \\
\hline $\begin{array}{l}\text { Education: } \\
12.221\end{array}$ & & & & & \\
\hline $\begin{array}{l}\text { Associate } \\
12.222\end{array}$ & & & & & \\
\hline $\begin{array}{l}\text { Diploma } \\
12.223\end{array}$ & & & & & \\
\hline $\begin{array}{l}\text { Bachelors, } \\
\text { Nursing } \\
12.224\end{array}$ & & & & & \\
\hline $\begin{array}{l}\text { Bachelors, non- } \\
\text { nursing } \\
12.225\end{array}$ & & & & & \\
\hline $\begin{array}{l}\text { Masters, } \\
\text { nursing } \\
12.226\end{array}$ & & & & & \\
\hline $\begin{array}{l}\text { Masters, non- } \\
\text { nursing } \\
12.227\end{array}$ & & & & & \\
\hline $\begin{array}{l}\text { Doctorate } \\
12.228\end{array}$ & & & & & \\
\hline $\begin{array}{l}\text { Doctorate, non- } \\
\text { nursing } \\
12.229\end{array}$ & & & & & \\
\hline $\begin{array}{l}\text { Certification, } \\
\text { specify } \\
12.2210\end{array}$ & & & & & \\
\hline $\begin{array}{l}\text { Member } \\
\text { nursing } \\
\text { professional/ } \\
\text { specialty } \\
\text { organization } \\
12.2211\end{array}$ & & & & & \\
\hline $\begin{array}{l}\text { Mean age } \\
12.2212\end{array}$ & & & & & \\
\hline $\begin{array}{l}\text { Number of } \\
\text { dependent } \\
\text { persons } \\
\text { responsible for } \\
12.2213\end{array}$ & & & & & \\
\hline
\end{tabular}




\begin{tabular}{|c|c|c|c|c|c|}
\hline Role & & & Average & Years of & $\begin{array}{l}\text { Service } \\
\end{array}$ \\
\hline $\begin{array}{l}\text { Staff } \\
\text { Development } \\
\text { Educators } \\
12.23\end{array}$ & $\begin{array}{l}\text { Total } \\
\text { Number }\end{array}$ & Total FTE & $\begin{array}{l}\text { Present } \\
\text { Institution }\end{array}$ & $\begin{array}{l}\text { Present } \\
\text { Position }\end{array}$ & $\begin{array}{l}\text { In } \\
\text { Profession }\end{array}$ \\
\hline \multicolumn{6}{|l|}{$\begin{array}{l}\text { Education: } \\
12.231\end{array}$} \\
\hline \multicolumn{6}{|l|}{$\begin{array}{l}\text { Associate } \\
12.232\end{array}$} \\
\hline \multicolumn{6}{|l|}{$\begin{array}{l}\text { Diploma } \\
12.233\end{array}$} \\
\hline \multicolumn{6}{|l|}{$\begin{array}{l}\text { Bachelors, } \\
\text { Nursing } \\
12.234 \\
\end{array}$} \\
\hline \multicolumn{6}{|l|}{$\begin{array}{l}\text { Bachelors, non- } \\
\text { nursing } \\
12.235\end{array}$} \\
\hline \multicolumn{6}{|l|}{$\begin{array}{l}\text { Masters, } \\
\text { nursing } \\
12.236\end{array}$} \\
\hline \multicolumn{6}{|l|}{$\begin{array}{l}\text { Masters, non- } \\
\text { nursing } \\
12.237\end{array}$} \\
\hline \multicolumn{6}{|l|}{$\begin{array}{l}\text { Doctorate } \\
12.238\end{array}$} \\
\hline \multicolumn{6}{|l|}{$\begin{array}{l}\text { Doctorate, non- } \\
\text { nursing } \\
12.239\end{array}$} \\
\hline \multicolumn{6}{|l|}{$\begin{array}{l}\text { Certification, } \\
\text { specify } \\
12.2310\end{array}$} \\
\hline \multicolumn{6}{|l|}{$\begin{array}{l}\text { Member } \\
\text { nursing } \\
\text { professional/ } \\
\text { specialty } \\
\text { organization } \\
12.2311\end{array}$} \\
\hline \multicolumn{6}{|l|}{$\begin{array}{l}\text { Mean age } \\
12.2312\end{array}$} \\
\hline $\begin{array}{l}\text { Number of } \\
\text { dependent } \\
\text { persons } \\
\text { responsible for } \\
12.2313\end{array}$ & & & & & \\
\hline
\end{tabular}




\begin{tabular}{|c|c|c|c|c|c|}
\hline Role & & & Average & Years of & Service \\
\hline $\begin{array}{l}\text { Researchers } \\
12.24\end{array}$ & $\begin{array}{l}\text { Total } \\
\text { Number }\end{array}$ & Total FTE & $\begin{array}{l}\text { Present } \\
\text { Institution }\end{array}$ & $\begin{array}{l}\text { Present } \\
\text { Position }\end{array}$ & $\begin{array}{l}\text { In } \\
\text { Profession }\end{array}$ \\
\hline \multicolumn{6}{|l|}{$\begin{array}{l}\text { Education: } \\
12.241\end{array}$} \\
\hline \multicolumn{6}{|l|}{$\begin{array}{l}\text { Associate } \\
12.242\end{array}$} \\
\hline \multicolumn{6}{|l|}{$\begin{array}{l}\text { Diploma } \\
12.243\end{array}$} \\
\hline \multicolumn{6}{|l|}{$\begin{array}{l}\text { Bachelors, } \\
\text { Nursing } \\
12.244 \\
\end{array}$} \\
\hline \multicolumn{6}{|l|}{$\begin{array}{l}\text { Bachelors, non- } \\
\text { Nursing } \\
12.245 \\
\end{array}$} \\
\hline \multicolumn{6}{|l|}{$\begin{array}{l}\text { Masters, } \\
\text { nursing } \\
12.246 \\
\end{array}$} \\
\hline \multicolumn{6}{|l|}{$\begin{array}{l}\text { Masters, non- } \\
\text { nursing } \\
12.247\end{array}$} \\
\hline \multicolumn{6}{|l|}{$\begin{array}{l}\text { Doctorate } \\
12.248\end{array}$} \\
\hline \multicolumn{6}{|l|}{$\begin{array}{l}\text { Doctorate, non- } \\
\text { nursing } \\
12.249\end{array}$} \\
\hline \multicolumn{6}{|l|}{$\begin{array}{l}\text { Certification, } \\
\text { specify } \\
12.2410 \\
\end{array}$} \\
\hline \multicolumn{6}{|l|}{$\begin{array}{l}\text { Member } \\
\text { nursing } \\
\text { professional/ } \\
\text { specialty } \\
\text { organization } \\
12.2411 \\
\end{array}$} \\
\hline \multicolumn{6}{|l|}{$\begin{array}{l}\text { Mean age } \\
12.2412\end{array}$} \\
\hline $\begin{array}{l}\text { Number of } \\
\text { dependent } \\
\text { persons } \\
\text { responsible for } \\
12.2413\end{array}$ & & & & & \\
\hline
\end{tabular}




\begin{tabular}{|c|c|c|c|c|c|}
\hline Role & & & Average & Years of & $\begin{array}{l}\text { Service } \\
\end{array}$ \\
\hline $\begin{array}{l}\text { Quality } \\
\text { Improvement } \\
\text { (QI) Staff } \\
12.25\end{array}$ & $\begin{array}{l}\text { Total } \\
\text { Number }\end{array}$ & Total FTE & $\begin{array}{l}\text { Present } \\
\text { Institution }\end{array}$ & $\begin{array}{l}\text { Present } \\
\text { Position }\end{array}$ & $\begin{array}{l}\text { In } \\
\text { Profession }\end{array}$ \\
\hline $\begin{array}{l}\text { Education: } \\
12.251\end{array}$ & & & & & \\
\hline $\begin{array}{l}\text { Associate } \\
12.252\end{array}$ & & & & & \\
\hline $\begin{array}{l}\text { Diploma } \\
12.253\end{array}$ & & & & & \\
\hline $\begin{array}{l}\text { Bachelors, } \\
\text { Nursing } \\
12.254 \\
\end{array}$ & & & & & \\
\hline $\begin{array}{l}\text { Bachelors, non- } \\
\text { nursing } \\
12.255 \\
\end{array}$ & & & & & \\
\hline $\begin{array}{l}\text { Masters, } \\
\text { nursing } \\
12.256\end{array}$ & & & & & \\
\hline $\begin{array}{l}\text { Masters, non- } \\
\text { nursing } \\
12.257\end{array}$ & & & & & \\
\hline $\begin{array}{l}\text { Doctorate } \\
12.258\end{array}$ & & & & & \\
\hline $\begin{array}{l}\text { Doctorate, non- } \\
\text { nursing } \\
12.259\end{array}$ & & & & & \\
\hline $\begin{array}{l}\text { Certification, } \\
\text { specify } \\
12.2510\end{array}$ & & & & & \\
\hline $\begin{array}{l}\text { Member } \\
\text { nursing } \\
\text { professional/ } \\
\text { specialty } \\
\text { organization } \\
12.2511 \\
\end{array}$ & & & & & \\
\hline $\begin{array}{l}\text { Mean age } \\
12.2512\end{array}$ & & & & & \\
\hline $\begin{array}{l}\text { Number of } \\
\text { dependent } \\
\text { persons } \\
\text { responsible for } \\
12.2513\end{array}$ & & & & & \\
\hline
\end{tabular}




\section{Staffing}

Complete the data requested for each job classification reporting to the designated nursing delivery unit/service manager and based on the reporting year.

\subsection{Quantity}

\begin{tabular}{|c|c|c|c|c|c|}
\hline \multirow[t]{2}{*}{ Job Classification Category } & \multicolumn{2}{|c|}{ Supervised Staff } & \multicolumn{2}{|c|}{ Budgeted Staff } & \multirow{2}{*}{$\begin{array}{l}\text { Average } \\
\text { Daily } \\
\text { Productive }^{2} \\
\text { Staff } \\
\text { FTEs }^{1} \\
\end{array}$} \\
\hline & Number & FTEs $^{1}$ & Number & FTEs $^{1}$ & \\
\hline $\begin{array}{l}\text { Direct Care Staff } \\
13.10\end{array}$ & & & & & \\
\hline $\begin{array}{l}\text { Advanced Practice Nurses }{ }^{3} \\
13.101\end{array}$ & & & & & \\
\hline $\begin{array}{l}\text { Registered Nurses Reporting to } \\
\text { Department of Nursing } \\
13.102\end{array}$ & & & & & \\
\hline $\begin{array}{l}\text { Licensed Practical } \\
\text { Nurses/Licensed Vocational } \\
\text { Nurses Reporting to Departme } \\
\text { Nursing } \\
13.103\end{array}$ & & & & & \\
\hline $\begin{array}{l}\text { Nurse Aides or Equivalent } \\
\text { Extenders } \\
13.104\end{array}$ & & & & & \\
\hline $\begin{array}{l}\text { Nursing Students } \\
13.105\end{array}$ & & & & & \\
\hline $\begin{array}{l}\text { Agency/Travelers Staff } \\
13.106\end{array}$ & & & & & \\
\hline $\begin{array}{l}\text { Independent Contractors/Sub- } \\
\text { contractors } \\
13.107\end{array}$ & & & & & \\
\hline $\begin{array}{l}\text { Management, Administrativ } \\
\text { Support Staff } \\
\text { 13.11 }\end{array}$ & & & & & \\
\hline $\begin{array}{l}\text { Case Manager } \\
13.111\end{array}$ & & & & & \\
\hline $\begin{array}{l}\text { Nurse Manager } \\
13.112\end{array}$ & & & & & \\
\hline $\begin{array}{l}\text { Staff Development/Educators } \\
13.113\end{array}$ & & & & & \\
\hline $\begin{array}{l}\text { Researchers } \\
13.114 \\
\end{array}$ & & & & & \\
\hline $\begin{array}{l}\text { Nursing Quality Improvement } \\
\text { (QI) Staff } \\
\text { 13.115 }\end{array}$ & & & & & \\
\hline $\begin{array}{l}\text { Support Staff (e.g. unit clerks, } \\
\text { environmental aides, techs) } \\
13.116\end{array}$ & & & & & \\
\hline
\end{tabular}


${ }^{1}$ FTE $=2080$ hours per year

${ }^{2}$ Productive $=$ all persons available for care/service provision, excluding e.g.: vacation, disability, or any other type of paid time off

${ }^{3}$ Advanced Practice Nurse includes Clinical Nurse Specialist (CNS), Certified Registered Nurse Anesthetist (CRNA), Nurse Practitioner (NP), and Nurse Midwife 


\subsection{Turnover}

\begin{tabular}{|c|c|c|c|c|c|}
\hline $\begin{array}{l}\text { Job Classification/ } \\
\text { Category }\end{array}$ & $\begin{array}{l}\text { Voluntary } \\
\text { Turnover }\end{array}$ & $\begin{array}{l}\text { Involuntary } \\
\text { Turnover }^{2}\end{array}$ & $\begin{array}{l}\text { Average } \\
\text { Turnover }^{3}\end{array}$ & $\begin{array}{l}\text { Average } \\
\text { Vacancy }^{4}\end{array}$ & $\begin{array}{l}\text { Number } \\
\text { of } \\
\text { Budgeted } \\
\text { Positions } \\
\text { Filled }\end{array}$ \\
\hline \multicolumn{6}{|l|}{$\begin{array}{l}\text { Direct Care Staff } \\
13.20\end{array}$} \\
\hline \multicolumn{6}{|l|}{$\begin{array}{l}\text { Advanced Practice Nurses } \\
13.201\end{array}$} \\
\hline \multicolumn{6}{|l|}{$\begin{array}{l}\text { Registered Nurses } \\
\text { Reporting to Department of } \\
\text { Nursing } \\
13.202 \\
\end{array}$} \\
\hline \multicolumn{6}{|l|}{$\begin{array}{l}\text { Licensed Practical } \\
\text { Nurses/Licensed Vocational } \\
\text { Nurses Reporting to } \\
\text { Department of Nursing } \\
13.203\end{array}$} \\
\hline \multicolumn{6}{|l|}{$\begin{array}{l}\text { Nurse Aides or Equivalent } \\
\text { Extenders } \\
13.204\end{array}$} \\
\hline \multicolumn{6}{|l|}{$\begin{array}{l}\text { Nursing Students } \\
13.205\end{array}$} \\
\hline \multicolumn{6}{|l|}{$\begin{array}{l}\text { Agency/Travelers Staff } \\
13.206\end{array}$} \\
\hline \multicolumn{6}{|l|}{$\begin{array}{l}\text { Independent } \\
\text { Contractors/ } \\
\text { Sub-contractors } \\
13.207\end{array}$} \\
\hline \multicolumn{6}{|l|}{$\begin{array}{l}\text { Management, } \\
\text { Administrative, Support } \\
\text { Staff } \\
13.21\end{array}$} \\
\hline \multicolumn{6}{|l|}{$\begin{array}{l}\text { Case Manager } \\
13.211\end{array}$} \\
\hline \multicolumn{6}{|l|}{$\begin{array}{l}\text { Nurse Manager } \\
13.212\end{array}$} \\
\hline \multicolumn{6}{|l|}{$\begin{array}{l}\text { Staff Development/ } \\
\text { Educators } \\
13.213 \\
\end{array}$} \\
\hline \multicolumn{6}{|l|}{$\begin{array}{l}\text { Researchers } \\
13.214 \\
\end{array}$} \\
\hline \multicolumn{6}{|l|}{$\begin{array}{l}\text { Nursing Quality } \\
\text { Improvement (QI) Staff } \\
13.215 \\
\end{array}$} \\
\hline $\begin{array}{l}\text { Support Staff } \\
\text { (e.g. unit clerks, } \\
\text { environmental aides, techs) } \\
13.216\end{array}$ & & & & & \\
\hline
\end{tabular}


${ }^{1}$ Voluntary Turnover - employee terminates

${ }^{2}$ Involuntary Turnover - termination of employee by the organization

${ }^{3}$ Average Turnover - percent (\%) of staff leaving a position

${ }^{4}$ Average Vacancy - percent (\%) of staff positions that are unfilled 


\subsection{Retention}

\begin{tabular}{|c|c|c|c|c|c|c|}
\hline Job Classification & $\begin{array}{l}\text { Accession } \\
\text { Rate }^{1}\end{array}$ & $\begin{array}{l}\text { Stability } \\
\text { Rate }^{2}\end{array}$ & $\begin{array}{l}\text { Instability }^{\text {Rate }^{3}} \\
\end{array}$ & $\begin{array}{l}\text { Separation } \\
\text { Rate }^{4}\end{array}$ & $\begin{array}{l}\text { Survival } \\
\text { Rate }^{5}\end{array}$ & $\begin{array}{l}\text { Wastage } \\
\text { Rate }^{6}\end{array}$ \\
\hline \multicolumn{7}{|l|}{$\begin{array}{l}\text { Direct Care Staff } \\
13.30\end{array}$} \\
\hline \multicolumn{7}{|l|}{$\begin{array}{l}\text { Advanced Practice } \\
\text { Nurses } \\
13.301\end{array}$} \\
\hline \multicolumn{7}{|l|}{$\begin{array}{l}\text { Registered Nurses } \\
\text { Reporting to } \\
\text { Department of Nsg. } \\
13.302\end{array}$} \\
\hline \multicolumn{7}{|l|}{$\begin{array}{l}\text { Licensed Practical } \\
\text { Nurses/Licensed } \\
\text { Vocational Nurses } \\
\text { Reporting to } \\
\text { Department of Nsg. } \\
13.303 \\
\end{array}$} \\
\hline \multicolumn{7}{|l|}{$\begin{array}{l}\text { Nurse Aides or } \\
\text { Equivalent Extend. } \\
13.304\end{array}$} \\
\hline \multicolumn{7}{|l|}{$\begin{array}{l}\text { Nursing Students } \\
13.305\end{array}$} \\
\hline \multicolumn{7}{|l|}{$\begin{array}{l}\text { Agency/Trav. Staff } \\
13.306\end{array}$} \\
\hline \multicolumn{7}{|l|}{$\begin{array}{l}\text { Independent } \\
\text { Contractors/ } \\
\text { Sub-contractors } \\
13.307\end{array}$} \\
\hline \multicolumn{7}{|l|}{$\begin{array}{l}\text { Management, } \\
\text { Administrative } \\
\text { Support Staff } \\
13.31 \\
\end{array}$} \\
\hline \multicolumn{7}{|l|}{$\begin{array}{l}\text { Case Manager } \\
13.311\end{array}$} \\
\hline \multicolumn{7}{|l|}{$\begin{array}{l}\text { Nurse Manager } \\
13.312\end{array}$} \\
\hline \multicolumn{7}{|l|}{$\begin{array}{l}\text { Staff Development/ } \\
\text { Educators } \\
13.313\end{array}$} \\
\hline \multicolumn{7}{|l|}{$\begin{array}{l}\text { Researchers } \\
13.314\end{array}$} \\
\hline \multicolumn{7}{|l|}{$\begin{array}{l}\text { Nursing Quality } \\
\text { Improvement (QI) } \\
\text { Staff } \\
13.315 \\
\end{array}$} \\
\hline $\begin{array}{l}\text { Support Staff } \\
\text { (e.g. unit clerks, } \\
\text { environmental } \\
\text { aides, techs) } \\
13.316\end{array}$ & & & & & & \\
\hline
\end{tabular}


${ }^{1}$ Accession Rate - percent (\%) of new nurses who stayed during a specified period of time

${ }^{2}$ Stability Rate - percent (\%) of nurses employed at the beginning of the period and who still stayed at the end of the period

${ }^{3}$ Instability Rate - percent (\%) of nurses employed at the beginning of the period but who left at the end of the period of time

${ }^{4}$ Separation Rate - percent (\%) of nurses who left at a specified period of time

${ }^{5}$ Survival Rate - percent (\%) of newly hired nurses who stayed during a specified period of time

${ }^{6}$ Wastage Rate - percent (\%) of newly hired nurses who left during a specified period of time

* Source: P. B. Hofmann. (1981). Accurate measurement of nursing turnover: The first step in its reduction. Journal of Nursing Administration, 11(11/12), 37-39. 


\section{Satisfaction*}

\subsection{Position}

\subsection{Direct Care Staff}

Complete this data table for the direct care staff in the nursing delivery unit/service. The items will be aggregated separately for each of the job classes. Report the total number answering each ranking number (1-5) and the total number of responses for that job class.

Scale: 1 =strongly disagree; $2=$ disagree; $3=$ neutral; 4=agree; $5=$ strongly agree

\begin{tabular}{|l|l|l|l|l|l|}
\hline \multicolumn{1}{|c|}{ Item } & $\mathbf{1}$ & $\mathbf{2}$ & $\mathbf{3}$ & $\mathbf{4}$ & $\mathbf{5}$ \\
\hline $\begin{array}{l}\text { Generally speaking, I am very satisfied with this job. } \\
14.111\end{array}$ & & & & & \\
\hline $\begin{array}{l}\text { I rarely think of quitting this job. } \\
14.112\end{array}$ & & & & & \\
\hline $\begin{array}{l}\text { I am generally satisfied with the kind of work I do in this job. } \\
14.113\end{array}$ & & & & & \\
\hline $\begin{array}{l}\text { Most nursing staff on this job are very satisfied with the job. } \\
14.114\end{array}$ & & & & & \\
\hline $\begin{array}{l}\text { Nursing staff on this job rarely think of quitting. } \\
14.115\end{array}$ & & & & & \\
\hline
\end{tabular}

*Satisfaction items adapted from Hackman and Oldham's (1975; 1980) General Job Satisfaction measure from the Job Diagnostic Survey (JDS). References are to the Journal of Applied Psychology, 60:159-170 and Work Redesign published by Addison-Wesley, respectively.

\subsection{Management, Administrative, and Support Staff}

Complete this data table for the management, administrative, and support staff in the nursing delivery unit/service. The items will be aggregated separately for each of the job classes. Report the total number answering each ranking number (1-5) and the total number of responses for that job class.

Scale: 1=strongly disagree; $2=$ disagree; $3=$ neutral; 4=agree; $5=$ strongly agree

\begin{tabular}{|l|l|l|l|l|l|}
\hline \multicolumn{1}{|c|}{ Item } & $\mathbf{1}$ & $\mathbf{2}$ & $\mathbf{3}$ & $\mathbf{4}$ & $\mathbf{5}$ \\
\hline Generally speaking, I am very satisfied with this job. & & & & & \\
14.121 & & & & & \\
\hline $\begin{array}{l}\text { I rarely think of quitting this job. } \\
14.122\end{array}$ & & & & & \\
\hline $\begin{array}{l}\text { I am generally satisfied with the kind } \\
\text { of work I do in this job. } \\
14.123\end{array}$ & & & & \\
\hline $\begin{array}{l}\text { Most nursing staff on this job are very satisfied with the job. } \\
14.124\end{array}$ & & & & & \\
\hline $\begin{array}{l}\text { Nursing staff on this job rarely think of quitting. } \\
14.125\end{array}$ & & & & & \\
\hline
\end{tabular}




\subsection{Context}

\subsection{Direct Care Staff}

Complete this data table for the direct care staff in the nursing delivery unit/service. The items will be aggregated separately for each of the job classes. Report the total number answering each ranking number (1-5) and the total number of responses for that job class.

Scale: 1 =strongly disagree; $2=$ disagree; $3=$ neutral; $4=$ agree; $5=$ =strongly agree

\begin{tabular}{|l|l|l|l|l|l|}
\hline \multicolumn{1}{|c|}{ Item } & $\mathbf{1}$ & $\mathbf{2}$ & $\mathbf{3}$ & $\mathbf{4}$ & $\mathbf{5}$ \\
\hline $\begin{array}{l}\text { Generally speaking, I am very satisfied with nursing } \\
\text { management. } \\
14.211\end{array}$ & & & & & \\
\hline $\begin{array}{l}\text { Generally speaking, I am very satisfied with nursing } \\
\text { administration. } \\
14.212\end{array}$ & & & & & \\
\hline $\begin{array}{l}\text { Generally speaking, I am very satisfied with interactions } \\
\text { with physicians. } \\
14.213\end{array}$ & & & & & \\
\hline $\begin{array}{l}\text { Generally speaking, I am very satisfied } \\
\text { with interactions with non-physician health care team member } \\
14.214\end{array}$ & & & & & \\
\hline $\begin{array}{l}\text { Generally speaking, I am very satisfied with my own } \\
\text { level of autonomy. } \\
14.215\end{array}$ & & & & & \\
\hline
\end{tabular}

\subsection{Management, Administrative and Support Staff}

Complete this data table for the management, administrative, and support staff in the nursing delivery unit/service. The items will be aggregated separately for each of the job classes. Report the total number answering each ranking number (1-5) and the total number of responses for that job class.

Scale: $1=$ =strongly disagree; $2=$ disagree; $3=$ =neutral; $4=$ agree; $5=$ strongly agree

\begin{tabular}{|l|l|l|l|l|l|}
\hline \multicolumn{1}{|c|}{ Item } & $\mathbf{1}$ & $\mathbf{2}$ & $\mathbf{3}$ & $\mathbf{4}$ & $\mathbf{5}$ \\
\hline $\begin{array}{l}\text { Generally speaking, I am very satisfied with nursing } \\
\text { management. } \\
14.221\end{array}$ & & & & & \\
\hline $\begin{array}{l}\text { Generally speaking, I am very satisfied with nursing } \\
\text { administration. } \\
14.222\end{array}$ & & & & & \\
\hline $\begin{array}{l}\text { Generally speaking, I am very satisfied with interactions with } \\
\text { physicians. } \\
14.223\end{array}$ & & & & & \\
\hline $\begin{array}{l}\text { Generally speaking, I am very satisfied with interactions with } \\
\text { non-physician health care team members. } \\
14.224\end{array}$ & & & & & \\
\hline $\begin{array}{l}\text { Generally speaking, I am very satisfied } \\
\text { with my own level of autonomy. } \\
14.225\end{array}$ & & & & & \\
\hline
\end{tabular}




\section{FINANCIAL RESOURCES}

\section{Payer Type}

\subsection{Total Health System (if applicable)}

Refer to "Volume of Nursing Delivery Unit/Service" (Item 03). Calculate the percentage of total service effort By each of the following payer types for each encounter type identified for the total health system.

\begin{tabular}{|c|c|c|c|c|c|c|c|c|c|}
\hline Payer Type & Hours & Days & Visits & Procedures & Consults & Contacts & Program & Classes & Enroll \\
\hline $\begin{array}{l}\text { Government } \\
15.11\end{array}$ & & & & & & & & & \\
\hline $\begin{array}{l}\text { Medicare } \\
15.1101\end{array}$ & & & & & & & & & \\
\hline $\begin{array}{l}\text { Medicaid } \\
15.1102\end{array}$ & & & & & & & & & \\
\hline $\begin{array}{l}\text { Public Health Service } \\
\text { (PHS) } \\
15.1103\end{array}$ & & & & & & & & & \\
\hline $\begin{array}{l}\text { PHS-Indian } \\
15.1104\end{array}$ & & & & & & & & & \\
\hline $\begin{array}{l}\text { Military Health System } \\
\text { (TRICARE) } \\
15.1105\end{array}$ & & & & & & & & & \\
\hline $\begin{array}{l}\text { Dept. of Justice } \\
15.1106\end{array}$ & & & & & & & & & \\
\hline $\begin{array}{l}\text { State Employer } \\
15.1107\end{array}$ & & & & & & & & & \\
\hline $\begin{array}{l}\text { State Health Service } \\
15.1108\end{array}$ & & & & & & & & & \\
\hline $\begin{array}{l}\text { Non-government } \\
15.12\end{array}$ & & & & & & & & & \\
\hline $\begin{array}{l}\text { Health Maintenance } \\
\text { Organization (HMO) } \\
15.1201\end{array}$ & & & & & & & & & \\
\hline $\begin{array}{l}\text { Preferred Provider } \\
\text { Organization } \\
\begin{array}{ll}(\mathrm{PPO}) & 15.1202\end{array}\end{array}$ & & & & & & & & & \\
\hline $\begin{array}{l}\text { Discount Fee-for-Servid } \\
15.1203\end{array}$ & & & & & & & & & \\
\hline $\begin{array}{l}\text { Commercial Insurance } \\
15.1204\end{array}$ & & & & & & & & & \\
\hline $\begin{array}{l}\text { Workers' Compensation } \\
15.1205\end{array}$ & & & & & & & & & \\
\hline 15.1206 & & & & & & & & & \\
\hline Trust Accounts 15.1207 & & & & & & & & & \\
\hline Self-Pay & & & & & & & & & \\
\hline 15.1209 & & & & & & & & & \\
\hline 15.1210 & & & & & & & & & \\
\hline Multi-Method 15.13 & & & & & & & & & \\
\hline $\begin{array}{lr}\text { Non-patient Revenue } \\
\text { Generation } & 15.14\end{array}$ & & & & & & & & & \\
\hline
\end{tabular}




\subsection{Total Organization}

Refer to "Volume of Nursing Delivery Unit/Service” (Item 03). Calculate the percentage of total service effort by each of the following payer types for each encounter type identified for the total organization.

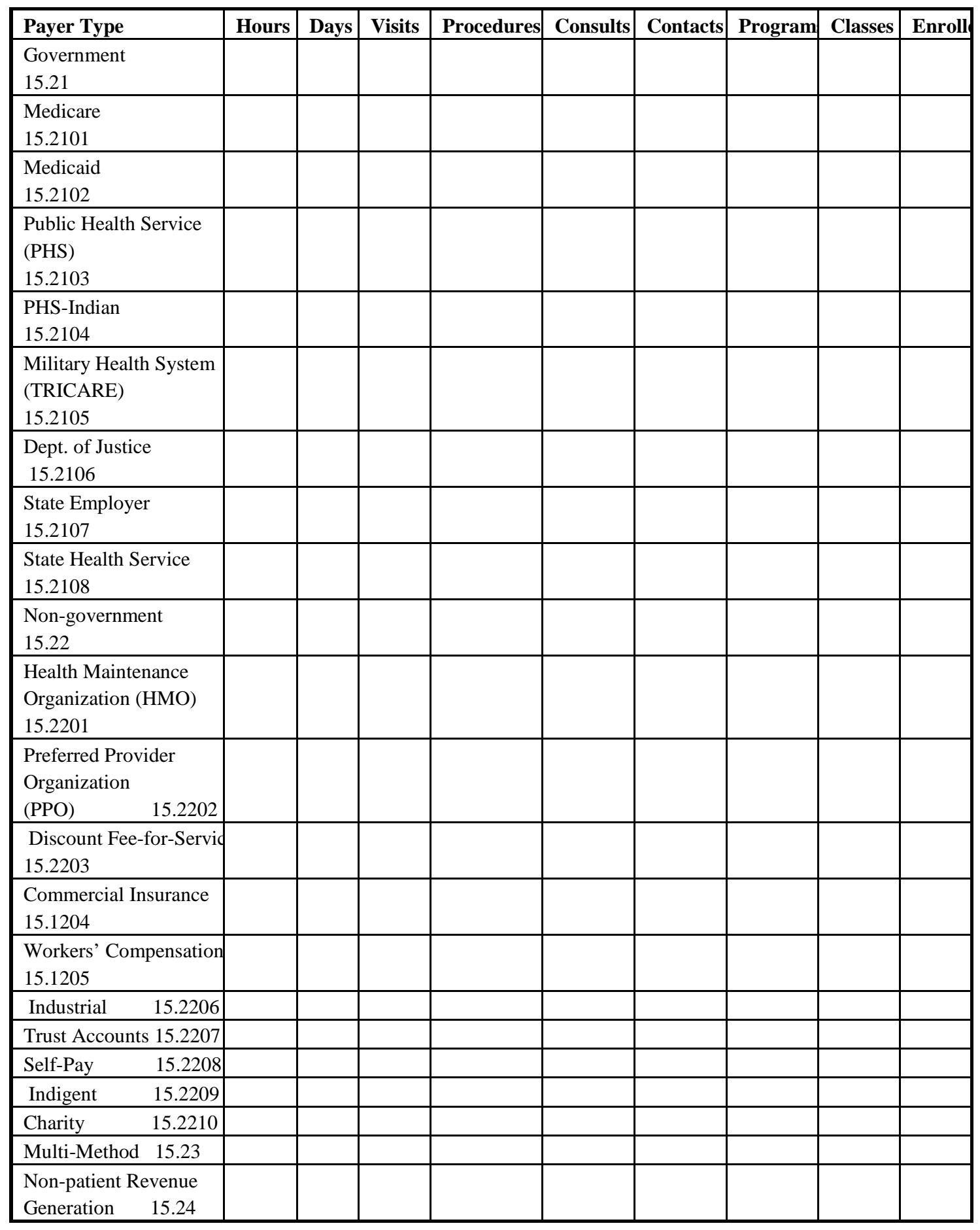




\subsection{Total Nursing Department}

Refer to "Volume of Nursing Delivery Unit/Service" (Item 03). Calculate the percentage of total service effort by each of the following payer types for each encounter type identified for the total nursing department.

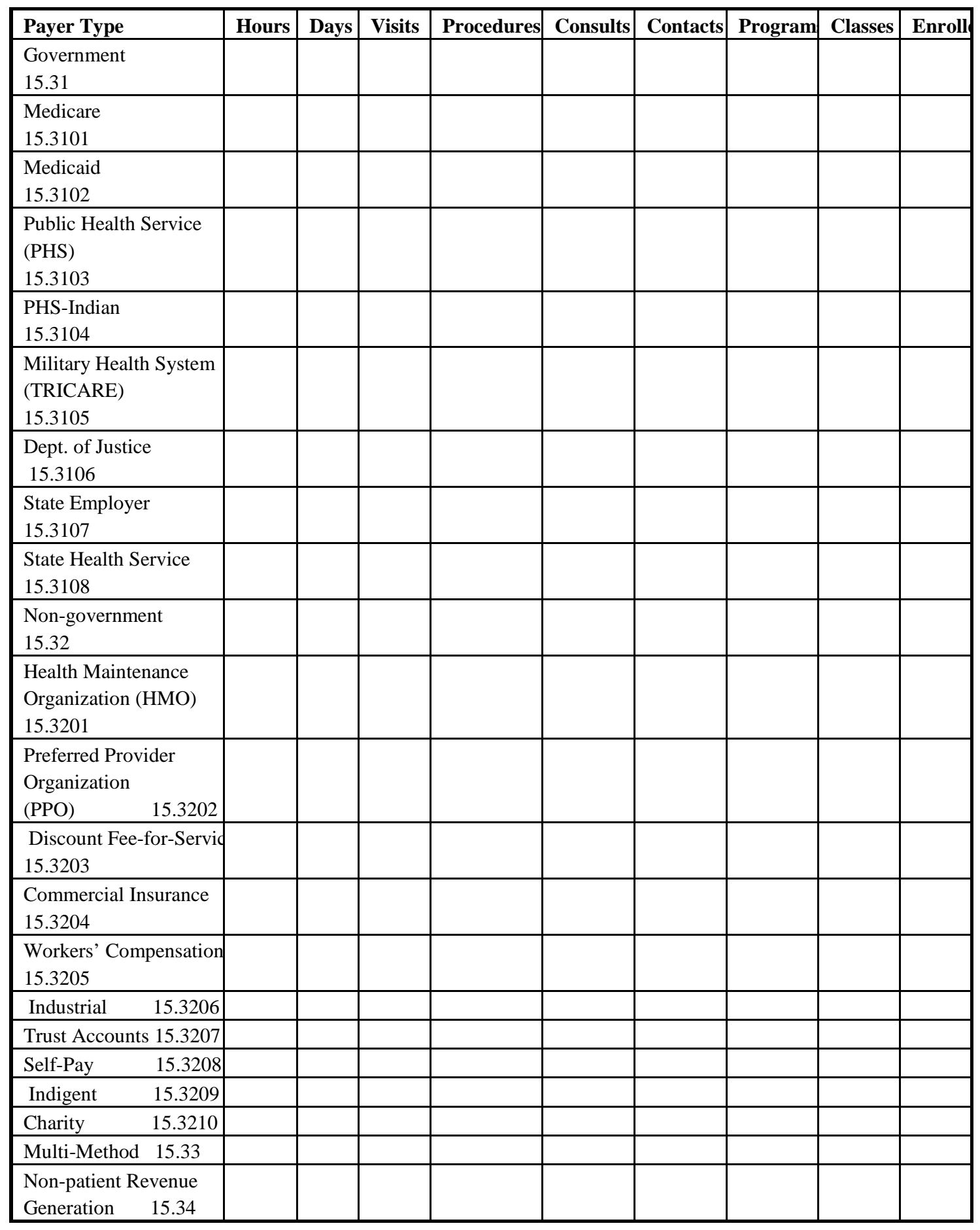




\subsection{Nursing Delivery Unit/Service}

Refer to "Volume of Nursing Delivery Unit/Service" (Item 03). Calculate the percentage of total service effort by each of the following payer types for each encounter type identified for the nursing delivery unit/service.

\begin{tabular}{|c|c|c|c|c|c|c|c|c|c|}
\hline \multirow{2}{*}{\multicolumn{10}{|c|}{$\begin{array}{l}\text { Payer Type } \\
\text { Government } \\
15.41\end{array}$}} \\
\hline & & & & & & & & & \\
\hline $\begin{array}{l}\text { Medicare } \\
15.4101 \\
\end{array}$ & & & & & & & & & \\
\hline $\begin{array}{l}\text { Medicaid } \\
15.4102\end{array}$ & & & & & & & & & \\
\hline $\begin{array}{l}\text { Public Health Service } \\
\text { (PHS) } \\
15.4103\end{array}$ & & & & & & & & & \\
\hline $\begin{array}{l}\text { PHS-Indian } \\
15.4104\end{array}$ & & & & & & & & & \\
\hline $\begin{array}{l}\text { Military Health System } \\
\text { (TRICARE) } \\
15.4105\end{array}$ & & & & & & & & & \\
\hline $\begin{array}{l}\text { Dept. of Justice } \\
15.4106\end{array}$ & & & & & & & & & \\
\hline $\begin{array}{l}\text { State Employer } \\
15.4107\end{array}$ & & & & & & & & & \\
\hline $\begin{array}{l}\text { State Health Service } \\
15.4108\end{array}$ & & & & & & & & & \\
\hline $\begin{array}{l}\text { Non-government } \\
15.42\end{array}$ & & & & & & & & & \\
\hline $\begin{array}{l}\text { Health Maintenance } \\
\text { Organization (HMO) } \\
15.4201\end{array}$ & & & & & & & & & \\
\hline $\begin{array}{l}\text { Preferred Provider } \\
\text { Organization } \\
\text { (PPO) } \quad 15.4202\end{array}$ & & & & & & & & & \\
\hline $\begin{array}{l}\text { Discount Fee-for-Servi } \\
15.4203\end{array}$ & & & & & & & & & \\
\hline $\begin{array}{l}\text { Commercial Insurance } \\
15.4204\end{array}$ & & & & & & & & & \\
\hline $\begin{array}{l}\text { Workers' Compensation } \\
15.4205\end{array}$ & & & & & & & & & \\
\hline Industrial $\quad 15.4206$ & & & & & & & & & \\
\hline Trust Accounts 15.4207 & & & & & & & & & \\
\hline $\begin{array}{ll}\text { Self-Pay } \quad 15.4208 \\
\end{array}$ & & & & & & & & & \\
\hline Indigent & & & & & & & & & \\
\hline $\begin{array}{ll}\text { Charity } & 15.4210 \\
\end{array}$ & & & & & & & & & \\
\hline Multi-Method 15.43 & & & & & & & & & \\
\hline $\begin{array}{lr}\text { Non-patient Revenue } \\
\text { Generation } \quad 15.44\end{array}$ & & & & & & & & & \\
\hline
\end{tabular}




\section{Reimbursement}

\subsection{Total Health System (if applicable)}

Identify the percentage distribution of reimbursement received for the total health system.

\begin{tabular}{|l|l|l|}
\hline \multicolumn{1}{|c|}{ Payment Basis } & \% Services Delivered & \% Revenue \\
\hline Fee for service & & \\
16.11 & & \\
\hline Discounted fee for service & & \\
16.12 & & \\
Per diem & & \\
\hline Diagnosis Related Group (DRG) & & \\
16.14 & & \\
\hline All Payer Group (APG) & & \\
16.15 & & \\
\hline Per visit & & \\
16.16 & & \\
\hline Per member/month & & \\
16.17 & & \\
\hline
\end{tabular}

\subsection{Total Organization}

Identify the percentage distribution of reimbursement received for the total organization.

\begin{tabular}{|l|l|l|}
\hline Payment Basis & \% Services Delivered & \% Revenue \\
\hline Fee for service & & \\
16.21 & & \\
\hline Discounted fee for service & & \\
16.22 & & \\
\hline Per diem & & \\
\hline Diagnosis Related Group (DRG) & & \\
16.24 & & \\
\hline All Payer Group (APG) & & \\
16.25 & & \\
\hline Per visit & & \\
16.26 & & \\
\hline Per member/month & & \\
\hline
\end{tabular}




\subsection{Total Nursing Department}

Identify the percentage distribution of reimbursement received for the total nursing department.

\begin{tabular}{|l|l|l|}
\hline Payment Basis & \% Services Delivered & \% Revenue \\
\hline Fee for service & & \\
16.31 & & \\
\hline Discounted fee for service & & \\
16.32 & & \\
\hline Per diem & & \\
16.33 & & \\
\hline Diagnosis Related Group (DRG) & & \\
\hline All Payer Group (APG) & & \\
16.35 & & \\
\hline Per visit & & \\
16.36 & & \\
\hline Per member/month & \\
16.37 & & \\
\hline
\end{tabular}

\subsection{Nursing Delivery Unit/Service}

Identify the percentage distribution of reimbursement received for the nursing delivery unit/service.

\begin{tabular}{|l|l|l|}
\hline Payment Basis & \% Services Delivered & \% Revenue \\
\hline Fee for service & & \\
16.41 & & \\
\hline Discounted fee for service & & \\
16.42 & & \\
\hline Per diem & & \\
\hline Diagnosis Related Group (DRG) & & \\
16.44 & & \\
\hline All Payer Group (APG) & & \\
16.45 & & \\
\hline Per visit & & \\
16.46 & & \\
\hline Per member/month & & \\
16.47 & & \\
\hline
\end{tabular}




\section{Nursing Delivery Unit/Service Budget}

\subsection{Costs}

17.11 Organization - Health System (if applicable)

Identify the planned and actual organizational budget figures as a percentage of the health system's annual itemized budget.

\begin{tabular}{|l|l|l|}
\hline $\begin{array}{l}\text { Organization } \\
\text { Costs }\end{array}$ & $\begin{array}{l}\text { System's } \\
\text { Planned Budget }\end{array}$ & $\begin{array}{l}\text { System's } \\
\text { Actual Budget }\end{array}$ \\
\hline Wages (hours) & & \\
17.111 & & \\
\hline Salaries per year & & \\
17.112 & & \\
\hline Benefits & & \\
17.113 & & \\
\hline Depreciation & & \\
17.114 & & \\
\hline Supplies & & \\
17.115 & & \\
\hline Other operating expenses & & \\
17.119 & & \\
\hline
\end{tabular}

\subsection{Nursing Department - Organization}

Identify the planned and actual nursing department budget figures as a percentage of the organization's annual itemized budget.

\begin{tabular}{|l|l|l|}
\hline $\begin{array}{l}\text { Nursing Department } \\
\text { Costs }\end{array}$ & $\begin{array}{l}\text { Organization's } \\
\text { Planned Budget }\end{array}$ & $\begin{array}{l}\text { Organization's } \\
\text { Actual Budget }\end{array}$ \\
\hline Wages (hours) & & \\
17.121 & & \\
\hline Salaries per year & & \\
17.122 & & \\
\hline Benefits & & \\
17.123 & & \\
\hline Depreciation & & \\
17.124 & & \\
\hline Supplies & & \\
\hline Other operating expenses & & \\
17.129 & & \\
\hline
\end{tabular}




\subsection{Nursing Delivery Unit/Service - Nursing Department}

Identify the planned and actual nursing delivery unit/service budget figures as a percentage of the nursing department's annual itemized budget.

\begin{tabular}{|l|l|l|}
\hline $\begin{array}{l}\text { Nursing Delivery } \\
\text { Unit/Service Costs }\end{array}$ & $\begin{array}{l}\text { Nursing Department's } \\
\text { Planned Budget }\end{array}$ & $\begin{array}{l}\text { Nursing Departmen } \\
\text { Actual Budget }\end{array}$ \\
\hline Wages & & \\
17.131 & & \\
\hline Salaries & & \\
17.132 & & \\
\hline Benefits & & \\
17.133 & & \\
\hline Depreciation & & \\
17.134 & Supplies & \\
17.135 & & \\
\hline $\begin{array}{l}\text { Other operating } \\
\text { expenses }\end{array}$ & & \\
17.139 & & \\
\hline
\end{tabular}




\subsection{Revenues}

\subsection{Organization - Health System (if applicable)}

Identify the planned and actual organizational revenue as a percentage of the health system's annual revenues.

\begin{tabular}{|l|l|l|}
\hline Organization Revenue & System's Planned Budget & System's Actual Budget \\
\hline Revenue & & \\
17.211 & & \\
\hline
\end{tabular}

\subsection{Nursing Department - Organization}

Identify the planned and actual nursing department revenue as a percentage of the organization's annual revenues.

\begin{tabular}{|l|l|l|}
\hline $\begin{array}{l}\text { Nursing Department } \\
\text { Revenue }\end{array}$ & $\begin{array}{l}\text { Organization's } \\
\text { Planned Budget }\end{array}$ & $\begin{array}{l}\text { Organization's } \\
\text { Actual Budget }\end{array}$ \\
\hline $\begin{array}{l}\text { Revenue } \\
17.221\end{array}$ & & \\
\hline
\end{tabular}

\subsection{Nursing Delivery Unit/Service - Nursing Department}

Identify the planned and actual nursing delivery unit/service revenue as a percentage of the nursing department's annual revenues.

\begin{tabular}{|l|l|l|}
\hline $\begin{array}{l}\text { Nursing Delivery } \\
\text { Unit/Service Revenue }\end{array}$ & $\begin{array}{l}\text { Nursing Department's } \\
\text { Planned Budget }\end{array}$ & $\begin{array}{l}\text { Nursing Department's } \\
\text { Actual Budget }\end{array}$ \\
\hline $\begin{array}{l}\text { Revenue } \\
17.231\end{array}$ & & \\
\hline
\end{tabular}




\section{Expenses}

\subsection{Organization - Health System (if applicable)}

Identify the following expenses of the total organization as a percentage of the health system's total expenses for the reporting year.

\begin{tabular}{|c|c|}
\hline Measures & $\begin{array}{l}\text { Percent of total } \\
\text { expenses }\end{array}$ \\
\hline $\begin{array}{l}\text { Direct: } \\
\text { Sum of labor costs directly attributable to a unit of service } \\
\text { including wages, benefits, travel, recruitment, education } \\
\text { per year. } \\
18.11\end{array}$ & \\
\hline $\begin{array}{l}\text { Direct material: } \\
\text { Sum of material costs, including patient/client supplies } \\
\text { used to provide the unit of service per year. } \\
18.12\end{array}$ & \\
\hline $\begin{array}{l}\text { Indirect: } \\
\text { Capital; equipment; an expense depreciated over time; } \\
\text { administration; labor expenses shared by more than } \\
\text { one nursing unit/service; clinical program development; } \\
\text { expenses for future development per year. } \\
18.13\end{array}$ & \\
\hline
\end{tabular}

\subsection{Nursing Department - Organization}

Identify the following expenses of the total nursing department as a percentage of the organization's total expenses for the reporting year.

\begin{tabular}{|l|l|}
\hline Measures & $\begin{array}{l}\text { Percent of total } \\
\text { expenses }\end{array}$ \\
\hline $\begin{array}{l}\text { Direct: } \\
\text { Sum of labor costs directly attributable to a unit of service } \\
\text { per year. }\end{array}$ & \\
18.21 & \\
\hline Direct material: & \\
Sum of material costs, including patient/client supplies & \\
used to provide the unit of service per year. & \\
18.22 & \\
\hline Indirect: & \\
Capital; equipment; an expense depreciated over time; & \\
administration; labor expenses shared by more than one & \\
nursing unit/service; clinical program development; & \\
expenses for future development per year. & \\
18.23 & \\
\hline
\end{tabular}




\subsection{Nursing Delivery Unit/Service - Nursing Department}

Identify the following expenses of the nursing delivery unit/service as a percentage of the nursing department's total expenses for the reporting year.

\begin{tabular}{|l|l|}
\hline Measures & $\begin{array}{l}\text { Percent of total } \\
\text { expenses }\end{array}$ \\
\hline $\begin{array}{l}\text { Direct: } \\
\text { Sum of labor costs directly attributable to a unit of service } \\
\text { including wages, benefits, travel, recruitment, education } \\
\text { per year. }\end{array}$ & \\
18.31 & \\
\hline $\begin{array}{l}\text { Direct material: } \\
\text { Sum of material costs, including patient/client supplies } \\
\text { used to provide the unit of service per year. } \\
18.32\end{array}$ & \\
\hline $\left.\begin{array}{l}\text { Indirect: } \\
\text { Capital; equipment; an expense depreciated over time; } \\
\text { administration; labor expenses shared by more than one } \\
\text { nursing unit/service; clinical program development; } \\
\text { expenses for future development per year. } \\
18.33\end{array}\right)$ \\
\hline
\end{tabular}




\section{Data Collection Forms - Individual}

NMMDS Variable \#14: Satisfaction

\subsection{Satisfaction: Position}

\subsection{Direct Care Staff}

*Scale: 1=strongly disagree; 2=disagree; 3=neutral; 4=agree; 5=strongly agree

\begin{tabular}{|l|l|l|l|l|l|}
\hline Question - Satisfaction Item & $\mathbf{1}$ & $\mathbf{2}$ & $\mathbf{3}$ & $\mathbf{4}$ & $\mathbf{5}$ \\
\hline Generally speaking, I am very satisfied with this job. & & & & & \\
\hline I rarely think of quitting this job. & & & & & \\
\hline $\begin{array}{l}\text { I am generally satisfied with the kind of work I do } \\
\text { in this job. }\end{array}$ & & & & & \\
\hline $\begin{array}{l}\text { Most nursing staff on this job are very satisfied with } \\
\text { the job. }\end{array}$ & & & & & \\
\hline Nursing staff on this job rarely think of quitting & & & & & \\
\hline
\end{tabular}

\subsection{Satisfaction: Context}

\subsection{Direct Care Staff}

*Scale: 1=strongly disagree; $2=$ disagree; 3=neutral; 4=agree; 5=strongly agree

\begin{tabular}{|l|l|l|l|l|l|}
\hline Question - Context Item & $\mathbf{1}$ & $\mathbf{2}$ & $\mathbf{3}$ & $\mathbf{4}$ & $\mathbf{5}$ \\
\hline $\begin{array}{l}\text { Generally speaking, I am very satisfied with nursing } \\
\text { management. }\end{array}$ & & & & & \\
\hline $\begin{array}{l}\text { Generally speaking, I am very satisfied with nursing } \\
\text { administration. }\end{array}$ & & & & & \\
\hline $\begin{array}{l}\text { Generally speaking, I am very satisfied with } \\
\text { interactions with physicians. }\end{array}$ & & & & & \\
\hline $\begin{array}{l}\text { Generally speaking, I am very satisfied with } \\
\text { interactions with non-physician health care team members. }\end{array}$ & & & & & \\
\hline $\begin{array}{l}\text { Generally speaking, I am very satisfied with my own } \\
\text { level of autonomy. }\end{array}$ & & & & & \\
\hline
\end{tabular}


APPENDIX B INSTRUMENT: THE NURSING MANAGEMENT MINIMUM DATA SET-ICE (NMMDS-ICE) SURVEY ${ }^{\circledR}$ DHUBER \& CDELANEY, 2005. TRANSLATED BY GAHARDARDOTTIR, 2011 
THE NURSING MANAGEMENT MINIMUM DATASET-ICE SURVEY ${ }^{\odot}$ DHuber, CDelaney, 2005 TRANSLATED BY GAHardardottir, 2011

ÍSLENSK ÚTGÁFA NMMDS-ICE Upplýsingasafn stjórnenda í húkrun

\section{UMHVERFI}

\section{Auðkenni bjónustu/starfseiningar}

Tilgreinið nafn stofnunar/deildar, auðkenni og staðsetningu par sem mestur hluti pjónustu við sjúklinga/skjólstæðinga fer fram; petta er forstig gagnasöfnunar fyrir ofan umönnunaraðila.

01.01 Auðkenni (kennitala) stofnunar

01.02 Flokkur heilbrigðispjónustu (sbr. Lög um heilbrigðispjónustu nr. 40/2007)

$\square$ Starfsstofur heilbrigðisstarfsmanna

Umdæmissjúkrahús

Sérhæfðar heilbrigðisstofnanir

$\square$ Hjúkrunarheimili og hjúkrunarrými

Sérhæfð sjúkrahúspjónusta

Heilsugæslustöðvar

01.03 Heiti stofnunar

01.04 Auðkenni (viðfang) deildar/starfseiningar

01.05 Nafn deildar/deildarheiti

01.07 Heimilisfang

01.08 Póstfang

01.09 Landsnúmer 


\section{Tegund hjúkrunar biónustu á deild/starfseiningu}

Tilgreinið hlutfall (\%) hvers eftirfarandi flokka sem lýsa best bjónustunni, tegund stofnunar og bjónustustigi

Dæmi: Bráðalegudeild á sjúkrahúsi 100\% eða skipta \% ef starfsemi er breytileg

\begin{tabular}{|l|l|l|}
\hline $\mathbf{0 2}$ & Pjónustutegund & Hlutfall (\%) \\
\hline 2.02 & Lýðheilsa & \\
\hline 2.04 & Dagvist/dagdvöl & \\
\hline 2.05 & Dvalarheimili aldraðra & \\
\hline 2.06 & bjónustuíbúðir aldraðra & \\
\hline 2.07 & Sambýli & \\
\hline 2.09 & Hjúkrunarheimili & \\
\hline 2.10 & Hjúkrunarheimili, sérhæfð pjónustueining & \\
\hline 2.13 & Einkarekin göngudeildarpjónusta & \\
\hline 2.14 & Heilsugæslustöð & \\
\hline 2.15 & Heilsuefling & \\
\hline 2.16 & Heimahjúkrun & \\
\hline 2.17 & Heimahlynning/líknandi meðferð & \\
\hline 2.18 & Hvíldarinnlagnir & \\
\hline 2.19 & Göngudeild/skurðbjónusta & \\
\hline 2.21 & Endurhæfing & \\
\hline 2.22 & Bráðaflokkun í gegnum síma & \\
\hline 2.23 & Bráðabjónusta & \\
\hline 2.24 & Gæsludeild/gæslueining (obs. deild) & \\
\hline 2.25 & Sjúkrahús/bráðalegudeildir & \\
\hline 2.27 & Sjúkrahús/gjörgæsla & \\
\hline 2.28 & Sjúkrahús hjúkrunardeild & \\
\hline 2.29 & Sjúkrahús/göngudeild/ & \\
\hline 2.31 & Sjúkrahústengd heimajjónusta & \\
\hline 2.32 & Rannsóknarstofa/skimun/greiningar & \\
\hline 2.33 & Skurðstofa & \\
\hline 2.34 & Skólaheilsugæsla & \\
\hline 2.35 & Ípróttalækningar & \\
\hline 2.36 & Vinnuvernd & \\
\hline 2.37 & Sjálfboðaliðar & \\
\hline & Hlutfall samtals & \\
\hline
\end{tabular}




\section{Sjúklingahópur}

Tilgreinið hlutfall (\%) hvers eftirfarandi flokka sem best lýsir sjúklingahópnum sem deildin/ bjónustueiningin sinnir

\begin{tabular}{|c|c|c|}
\hline 03.1 & Sérgrein & Hlutfall (\%) \\
\hline 03.101 & Alnæmi/HIV & \\
\hline 03.102 & Fæðingar & \\
\hline 03.103 & Hjartalækningar & \\
\hline 03.104 & Smitsjúkdómar & \\
\hline 03.105 & Hjartagjörgæsla & \\
\hline 03.106 & Lyflækningagjörgæsla & \\
\hline 03.107 & Bráðamóttaka geðsjúkra & \\
\hline 03.108 & Skurðlækningagjörgæsla & \\
\hline 03.109 & Vökudeild/Nýburagjörgæsla & \\
\hline 03.110 & Barnagjörgæsla & \\
\hline 03.112 & Tannlækningar & \\
\hline 03.114 & Sykursýki & \\
\hline 03.115 & Skilun & \\
\hline 03.116 & Slysa- og bráðapjónusta & \\
\hline 03.117 & Heilsuefling (wellness) & \\
\hline 03.118 & Blóðlækningar & \\
\hline 03.119 & Ónæmisaðgerðir/bólusetningar & \\
\hline 03.120 & Mæðravernd & \\
\hline 03.121 & Barnalækningar & \\
\hline 03.122 & Lyflækningar & \\
\hline 03.123 & Geðlækningar & \\
\hline 03.124 & Taugalækningar & \\
\hline 03.125 & Næring & \\
\hline 03.126 & Krabbameinslækningar & \\
\hline 03.127 & Verkir & \\
\hline 03.128 & Vöknun & \\
\hline 03.129 & Geðlækningar/sálfræði & \\
\hline 03.130 & Lungnalækningar & \\
\hline 03.131 & Endurhæfing & \\
\hline 03.132 & Gigtarlækningar & \\
\hline 03.133 & Kynsjúkdómar & \\
\hline 03.134 & Ávana- og fíkni meðferð & \\
\hline 03.135 & Skurðlækningar & \\
\hline
\end{tabular}




\begin{tabular}{|l|l|l|}
\hline 03.136 & Ígræðslur & \\
\hline 03.137 & Ofbeldi/áverkar & \\
\hline 03.138 & Frjósemi & \\
\hline 03.139 & Erfða ráðgjöf & \\
\hline 03.140 & Öldrunarlækningar & \\
\hline 03.141 & Kvenlækningar & \\
\hline & Hlutfall samtals & 100 \\
\hline
\end{tabular}

\begin{tabular}{|l|l|l|}
\hline $\mathbf{0 3 . 2}$ & Droski & $\begin{array}{l}\text { Hlutfall } \\
\mathbf{( \% )}\end{array}$ \\
\hline 03.201 & Fóstur & \\
\hline 03.202 & Ungbarn/kornabarn (aldur 0 -12 mánaða) & \\
\hline 03.203 & Smábarn (aldur 13 - 23 mánaða) & \\
\hline 03.204 & Leikskólaaldur (2 - 5 ára) & \\
\hline 03.205 & Barnaskólaaldur (aldur 6 - 12 ára) & \\
\hline 03.206 & Unglingsár (aldur 13 - 18 ára) & \\
\hline 03.207 & Ungir fullorðnir (aldur 19 - 40 ára) & \\
\hline 03.208 & Fullorðinsár (aldur 41 - 64 ára) & \\
\hline 03.209 & Seinni fullorðinsár (eldri en 64 ára) & \\
\hline 03.210 & Lífslok & 100 \\
\hline 03.211 & Blandaður (allir aldursflokkar) \\
\hline & Hlutfall samtals & \\
\hline
\end{tabular}

\begin{tabular}{|l|l|l|}
\hline $\mathbf{0 3 . 3}$ & Á samskipti við: & $\begin{array}{l}\text { Hlutfall } \\
\mathbf{( \% )}\end{array}$ \\
\hline 03.31 & Einstakling & \\
\hline 03.32 & Fjölskyldu & \\
\hline 03.33 & Hóp & \\
\hline 03.34 & Samfélag/íbúa & 100 \\
\hline & Hlutfall samtals \\
\hline
\end{tabular}




\begin{tabular}{|l|l|l|}
\hline $\mathbf{0 3 . 4}$ & Djónustuhópur & $\begin{array}{l}\text { Hlutfall } \\
\mathbf{( \% )}\end{array}$ \\
\hline 03.41 & pjónustuhópur, borg/bær & \\
\hline 03.42 & pjónustuhópur, hverfi & \\
\hline 03.43 & Djónustuhópur, sýsla & \\
\hline 03.44 & pjónustuhópur, umdæmi & \\
\hline 03.46 & pjónustuhópur, landshluti & \\
\hline 03.47 & pjónustuhópur, pjóðin & \\
\hline 03.48 & pjónustuhópur, alpjóðlegur & \\
\hline & Hlutfall samtals & 100 \\
\hline
\end{tabular}




\section{Magn hjúkrunarbiónustu á viðkomandi deild/starfseiningu}

Tilgreinið rúmafjölda, fjölda innlagna, fjölda legudaga og meðallegutíma á deild fyrir árið 2010. Upplýsingar má væntanlega finna í starfssemistölum deildarinnar. Ef farið er í vitjanir, pá tilgreinið fjölda vitjana. Ef hópmeðferð eða námskeið, tilgreinið pá fjölda og tegund.

04.1 Sjúklingur

\begin{tabular}{|c|c|c|c|c|}
\hline Tegund & $\begin{array}{l}\begin{array}{l}\text { Fjöldi } \\
\text { innlagna/lega }\end{array} \\
04.110 \\
\end{array}$ & $\begin{array}{l}\text { Fjöldi } \\
\text { legudaga } \\
04.102 \\
\end{array}$ & $\begin{array}{l}\text { Meðallega } \\
\text { á deild } \\
04.111\end{array}$ & $\begin{array}{l}\text { Fjöldi rúma } \\
\text { á deild } \\
04.112 \\
\end{array}$ \\
\hline \multicolumn{5}{|l|}{ Legudeild } \\
\hline & & $\begin{array}{l}\text { Fjöldi } \\
\text { hjúkrunar } \\
\text { klst. sem } \\
\text { áætlaður er } \\
\text { við hver } \\
\text { samskipti }\end{array}$ & $\begin{array}{l}\text { Meðalfjöldi } \\
\text { samskipta á } \\
24 \text { klst }\end{array}$ & $\begin{array}{l}\text { Hámarks- } \\
\text { fjöldi } \\
\text { samskipta } \\
\text { sem hægt } \\
\text { væri að } \\
\text { veita á } \\
\text { sólarhring }\end{array}$ \\
\hline \multicolumn{5}{|l|}{$\begin{array}{l}\text { Göngudeild/ } \\
\text { dagdeild komur } \\
04.101\end{array}$} \\
\hline \multicolumn{5}{|l|}{$\begin{array}{l}\text { Vitjanir } \\
04.103 \\
\end{array}$} \\
\hline \multicolumn{5}{|l|}{$\begin{array}{l}\text { Hópmeðferð (t.d. } \\
\text { hjartaendurhæfing) } \\
04.107\end{array}$} \\
\hline $\begin{array}{l}\text { Námskeið (t.d. um } \\
\text { brjóstagjöf, } \\
\text { foreldranámskeið, } \\
\text { sykursýki o.s.frv.) } \\
04.108\end{array}$ & & & & \\
\hline
\end{tabular}


Tilgreinið aðkomu að samskiptum við fjölskyldu (mæling á magni samskipta) sem notuð eru á deildinni/starfseiningunni, fjölda hjúkrunarklukkustunda. sem ætlaðar eru fyrir hverja tegund samskipta, meðalfjölda samskipta á sólarhring fyrir síðastliðið ár og hámarksfjölda samskipta sem hægt væri að veita á einum sólarhring.

\subsection{Fjölskylda ef við á}

\begin{tabular}{|l|l|l|l|}
\hline Aðkoma samskipta * & $\begin{array}{l}\text { Fjöldi hjúkrunar } \\
\text { klst. sem áætlaður } \\
\text { er við hver } \\
\text { samskipti }\end{array}$ & $\begin{array}{l}\text { Meðalfjöldi } \\
\text { samskipta á 24 klst }\end{array}$ & $\begin{array}{l}\text { Hámarksfjöldi } \\
\text { samskipta sem } \\
\text { hægt væri að } \\
\text { veita á } \\
\text { sólarhring }\end{array}$ \\
\hline $\begin{array}{l}\text { Komur } \\
04.201\end{array}$ & & & \\
\hline $\begin{array}{l}\text { Vitjanir } \\
04.203\end{array}$ & & & \\
\hline $\begin{array}{l}\text { Aðgerðir/meðferðir } \\
04.204\end{array}$ & & & \\
\hline $\begin{array}{l}\text { Ráðgjöf/samráð } \\
04.205\end{array}$ & & & \\
\hline $\begin{array}{l}\text { Önnur samskipti (t.d. } \\
\text { símtal, tölvupóstur) } \\
04.206\end{array}$ & & & \\
\hline $\begin{array}{l}\text { Hópmeðferð (t.d. } \\
\text { hjartaendurhæfing) } \\
04.207\end{array}$ & & & \\
\hline $\begin{array}{l}\text { Námskeið } \\
04.208\end{array}$ & & & \\
\hline
\end{tabular}

*Með samskiptum er átt við pá pjónustu sem heilbrigðisstarfsmaður veitir. 


\section{Skipulag hjúkrunar og árangur}

Tilgreinið hlutfall (\%) sérhvers af eftirfarandi skipulagsformum sem best lýsa pví skipulagsformi hjúkrunar sem er notað á deildinni/starfseiningunni.

Heildarhlutfall (samtala) nái 100\%

\begin{tabular}{|c|c|}
\hline 05.1 Skipulag & Hlutfall (\%) \\
\hline $\begin{array}{l}05.01 \text { Einkahjúkrun: } \\
\text { Hjúkrunarfræðingur er ráðinn af sjúklingnum/skjólstæðingnum } \\
\text { og er ábyrgur fyrir skipulagningu, samhæfingu, umönnun, og } \\
\text { mati á hjúkrunarmeðferð sem veitt er } \\
\text { sjúklingum/skjólstæðingum. }\end{array}$ & \\
\hline $\begin{array}{l}05.02 \text { Verkhæfð hjúkrun: } \\
\text { Hjúkrunarfræðingur er ráðinn af stofnuninni og er ábyrgur fyrir } \\
\text { ákveðnum verkum og tæknilegum páttum hjúkrunar fyrir } \\
\text { ákveðinn hóp sjúklinga/skjólstæðinga. }\end{array}$ & \\
\hline $\begin{array}{l}05.03 \text { Hóphjúkrun: } \\
\text { Hjúkrunarfræðingur er ráðinn af stofnuninni og er ábyrgur fyrir } \\
\text { skipulagningu, samhæfingu, og mati á hjúkrunarmeðferð fyrir } \\
\text { hóp sjúklinga/skjólstæðinga og fyrir að stýra hópi faglærðra sem } \\
\text { og ófaglærðra starfsmanna. }\end{array}$ & \\
\hline $\begin{array}{l}\text { 05.04 Alhliða hjúkrun: } \\
\text { Hjúkrunarfræðingur er ráðinn af stofnuninni og er ábyrgur fyrir } \\
\text { skipulagningu, samhæfingu, umönnun og mati á } \\
\text { hjúkrunarmeðferð fyrir einn eða fleiri sjúklinga/skjólstæðinga á } \\
\text { hverri vakt. }\end{array}$ & \\
\hline $\begin{array}{l}05.05 \text { Einstaklingshæfð hjúkrun: } \\
\text { Hjúkrunarfræðingur er ráðinn af stofnuninni og er ábyrgur fyrir } \\
\text { skipulagningu, samhæfingu, umönnun og mati á } \\
\text { hjúkrunarmeðferð } 24 \text { klst. á sólarhring, allan pann tíma sem } \\
\text { sjúklingur liggur inni á deildinni, með eða án aðstoðarfólks. }\end{array}$ & \\
\hline $\begin{array}{l}05.06 \text { Kjarnahjúkrun } \\
\text { Hjúkrunarfræðingur er ráðinn af skjólstæðingi eða stofnuninni } \\
\text { og er ábyrgur fyrir skipulagningu, samhæfingu umönnun og mati } \\
\text { á hjúkrunarmeðferð sem veitt er fjölda sjúklinga eða ákveðnum } \\
\text { sjúklingahópum i samfélaginu og/eða á heimili einstaklings. }\end{array}$ & \\
\hline $\begin{array}{l}05.08 \text { Heilsugæslu- og heimahjúkrun: } \\
\text { Hjúkrunarfræðingur er ráðinn af stofnuninni og er ábyrgur fyrir } \\
\text { skipulagningu, samhæfingu, umönnun og mati á } \\
\text { hjúkrunarpjónustumeðferð sem veitt er fjölda sjúklinga eða } \\
\text { ákveðnum sjúklingahópum í samfélaginu og/eða á heimili } \\
\text { einstaklings. }\end{array}$ & \\
\hline Samtals hlutfall & $100 \%$ \\
\hline
\end{tabular}




\section{2 Árangur - Fagfólk}

Veldu að hve miklu leyti hverju pessara viðmiða hefur verið náð

Vinsamlegast setjið hring utan um viðeigandi tölustaf í töflunni hér fyrir neðan. Mælikvarði: 1 (lágt), 5 (hátt)

\begin{tabular}{|c|c|c|c|c|}
\hline Flokkur & \multicolumn{4}{|c|}{ Stigagjöf } \\
\hline $\begin{array}{l}\text { Umbun og laun fyrir frammistöðu } \\
05.21\end{array}$ & $\begin{array}{r}1 \\
\text { Lágt }\end{array}$ & 2 & 3 & Hátt \\
\hline $\begin{array}{l}\text { Möguleikar á starfspróun } \\
05.22\end{array}$ & $\begin{array}{r}1 \\
\text { Lágt }\end{array}$ & 2 & 3 & Hátt \\
\hline $\begin{array}{l}\text { Viðurkenning annarra hjúkrunarfræðinga á } \\
\text { mikilvægu framlagi til hjúkrunarstarfsins } \\
05.23\end{array}$ & $\begin{array}{l}1 \\
\text { Lágt }\end{array}$ & 2 & & Hátt \\
\hline $\begin{array}{l}\text { Tíðni meiðsla starfsmanna hjúkrunar } \\
05.24\end{array}$ & $\begin{array}{r}1 \\
\text { Lágt }\end{array}$ & 2 & & Hátt \\
\hline
\end{tabular}

\section{3 Árangur - Klínískur}

Veldu að hve miklu leyti hverju pessara viðmiða hefur verið náð

Vinsamlegast setjið hring utan um viðeigandi tölustaf í töflunni hér fyrir neðan. Mælikvarði: 1 (lágt), 5 (hátt)

\begin{tabular}{|c|c|c|c|c|}
\hline Flokkur & Stige & & & \\
\hline $\begin{array}{l}\text { Dánartíðni } \\
05.31\end{array}$ & Lágt & 2 & ? & $\begin{array}{l}5 \\
\text { Hátt } \\
\end{array}$ \\
\hline $\begin{array}{l}\text { Legutími } \\
05.32\end{array}$ & Lágt & 2 & 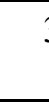 & $\begin{array}{ll}5 \\
\text { Hátt } \\
\end{array}$ \\
\hline $\begin{array}{l}\text { Atvik } \\
05.33 \\
\end{array}$ & Lágt & 2 & ; & $\begin{array}{ll}5 \\
\text { Hátt } \\
\end{array}$ \\
\hline $\begin{array}{l}\text { Fylgikvillar } \\
05.34\end{array}$ & Lágt & 2 & & $\begin{array}{ll}5 \\
\text { Hátt } \\
\end{array}$ \\
\hline $\begin{array}{l}\text { Meðhöndlun verkja, markmiðum náð } \\
05.35\end{array}$ & Lágt & 2 & & $\begin{array}{l}5 \\
\text { Hátt } \\
\end{array}$ \\
\hline $\begin{array}{l}\text { Viðhald á heilbrigði húðar } \\
05.36\end{array}$ & & 2 & & $\begin{array}{l}5 \\
\text { Hátt } \\
\end{array}$ \\
\hline
\end{tabular}




\section{Aðgengi að sjúklingi/ skjólstæðingi}

Tilgreinið hlutfall (\%) hvers eftirfarandi páttar sem best lýsir aðgengi heilbrigðisstarfsmanns (manna) að sjúklingum/skjólstæðingum í peim tilgangi að veita heilbrigðisbjónustu, út frá eftirfarandi tíma og fjarlægðarpáttum sem tengjast meðferðarstað.

\begin{tabular}{|l|l|}
\hline Páttur & $\begin{array}{l}\text { Hlutfall (\%) } \\
\text { fyrir dæmigert } \\
\text { aðgengi }\end{array}$ \\
\hline $\begin{array}{l}\text { Starfseining/bjónusta; í göngufæri eða nálægt sjúklingi } \\
06.01\end{array}$ & \\
\hline $\begin{array}{l}\text { Dreifð pjónusta starfseiningar; deild/stöð, sama stofnun, sama } \\
\text { hverfi } \\
06.02\end{array}$ & \\
\hline $\begin{array}{l}\text { Úthlutun verkefna eftir svæðum/ venjulegt tilvik 30-60 mínútna } \\
\text { ferðatími; með ábyrgð á fleiri en einni deild/stöð } \\
06.03\end{array}$ & \\
\hline $\begin{array}{l}\text { Óbyggðir/dreifbýli; heilbrigðisstarfsmaður parf að ferðast } \\
\geq \text { eina (1) klukkustund til að veita sjúklingi bjónustu } \\
06.04\end{array}$ & \\
\hline $\begin{array}{l}\text { Veraldarvefur/Internet } \\
06.05\end{array}$ & \\
\hline Fjarheilbrigðisbjónusta & \\
06.06 & \\
\hline Samtals hlutfall & \\
\hline
\end{tabular}

\section{Margbreytileiki klínískrar ákvarðanatöku}

\subsection{Umönnun sjúklings/skjólstæðings}

Áætlið að hve miklu leyti hjúkrunarbjónustan við sjúklinginn/skjólstæðinginn á deildinni/ starfseiningunni myndi flokkast í eftirfarandi flokka

Vinsamlegast setjið hring utan um viðeigandi tölustaf í töflunni hér fyrir neðan. Mælikvarði: 1 (lágt), 5 (hátt)

\begin{tabular}{|c|c|c|c|c|}
\hline Flokkur & \multicolumn{4}{|l|}{ Stigagjöf } \\
\hline $\begin{array}{l}\text { Staðlaðir verkferlar/meðferð } \\
07.11\end{array}$ & $\begin{array}{cc}1 & 2 \\
\text { Lágt } & \end{array}$ & 3 & & Iátt \\
\hline $\begin{array}{l}\text { Breytileiki eða undantekningar } \\
07.12\end{array}$ & $\begin{array}{cc}1 & 2 \\
\text { Lágt } & \end{array}$ & 3 & & Hátt \\
\hline $\begin{array}{l}\text { Faglegt mat, reynsla, innsæi } \\
07.13\end{array}$ & $\begin{array}{cc}1 & 2 \\
\text { Lágt } & \\
\end{array}$ & 3 & & Iátt \\
\hline $\begin{array}{l}\text { Stig sérpekkingar } \\
07.14\end{array}$ & $\begin{array}{cc}1 & 1 \\
\text { Lágt } & \end{array}$ & 3 & & Hátt \\
\hline
\end{tabular}




\subsection{Tölvuvæðing}

Metið hversu mikil tölvuvæðing er til staðar á deildinni/starfseiningunni.

Vinsamlegast setjið hring utan um viðeigandi tölustaf í töflunni hér fyrir neðan. Mælikvarði: 1 (lágt), 5 (hátt)

\begin{tabular}{|c|c|c|c|}
\hline Hugbúnaður/Lausnir & Stigagjöf & & \\
\hline $\begin{array}{l}\text { Heilsufarssaga/mat } \\
07.201\end{array}$ & $\begin{array}{c}1 \\
\text { Slæmt aðgengi }\end{array}$ & 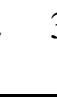 & $\begin{array}{l}45 \\
\text { Gott aðgengi }\end{array}$ \\
\hline $\begin{array}{l}\text { Skráning } \\
07.202\end{array}$ & $\begin{array}{c}1 \\
\text { Slæmt aðgengi }\end{array}$ & 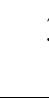 & $\begin{array}{l}45 \\
\text { Gott aðgengi }\end{array}$ \\
\hline $\begin{array}{l}\text { Útskriftaráætlun } \\
07.203\end{array}$ & $\begin{array}{c}1 \\
\text { Slæmt aðgengi }\end{array}$ & i & $\begin{array}{l}5 \\
\text { Gott aðgengi }\end{array}$ \\
\hline $\begin{array}{l}\text { Hjúkrunaráætlun } \\
07.204\end{array}$ & $\begin{array}{c}1 \\
\text { Slæmt aðgengi }\end{array}$ & 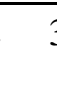 & $\begin{array}{l}45 \\
\text { Gott aðgengi }\end{array}$ \\
\hline $\begin{array}{l}\text { Myndræn og stafræn birting gagna } \\
07.205\end{array}$ & $\begin{array}{c}1 \\
\text { Slæmt aðgengi }\end{array}$ & ? & $\begin{array}{l}45 \\
\text { Gott aðgengi }\end{array}$ \\
\hline $\begin{array}{l}\text { Lyfjagjöf } \\
07.206\end{array}$ & $\begin{array}{c}1 \\
\text { Slæmt aðgengi }\end{array}$ & ? & $\begin{array}{l}45 \\
\text { Gott aðgengi }\end{array}$ \\
\hline $\begin{array}{l}\text { Lífeðlisfræðilegt eftirlit } \\
07.207\end{array}$ & $\begin{array}{c}1 \\
\text { Slæmt aðgengi } \\
\end{array}$ & 3 & $\begin{array}{l}45 \\
\text { Gott aðgengi }\end{array}$ \\
\hline $\begin{array}{l}\text { Vöruhús gagna } \\
07.208\end{array}$ & $\begin{array}{c}1 \\
\text { Slæmt aðgengi } \\
\end{array}$ & & $\begin{array}{l}4 \quad 5 \\
\text { Gott aðgengi }\end{array}$ \\
\hline $\begin{array}{l}\text { Stjórnunar upplýsingar } \\
07.209\end{array}$ & $\begin{array}{c}1 \\
\text { Slæmt aðgengi }\end{array}$ & & $\begin{array}{l}45 \\
\text { Gott aðgengi } \\
\end{array}$ \\
\hline $\begin{array}{l}\text { Stuðningur við ákvarðanatöku } \\
07.210\end{array}$ & $\begin{array}{c}1 \\
\text { Slæmt aðgengi }\end{array}$ & & $\begin{array}{ll}4 & 5 \\
\text { Gott aðgengi }\end{array}$ \\
\hline $\begin{array}{l}\text { Bráðleiki/vinnuálag } \\
07.211\end{array}$ & $\begin{array}{c}1 \\
\text { Slæmt aðgengi }\end{array}$ & & $\begin{array}{l}5 \\
\text { Gott aðgengi }\end{array}$ \\
\hline $\begin{array}{l}\text { Stöðluð flokkunarkerfi } \\
07.212\end{array}$ & $\begin{array}{c}1 \\
\text { Slæmt aðgengi }\end{array}$ & & $\begin{array}{l}5 \\
5 \\
\text { Gott aðgengi }\end{array}$ \\
\hline
\end{tabular}




\section{Fjölbreytileiki umhverfisins}

Metið upplifun ykkar á umsetningu sjúklinga (turnover), fjölbreytileika sjúklingahópsins og stöðugleika deildarmórals á deildinni/starfseiningunni

Vinsamlegast setjið hring utan um viðeigandi tölustaf í töflunni hér fyrir neðan. Mælikvarði: 1 stöðugur/líkir), 5 (óstöðugur/breytilegur)

\begin{tabular}{|c|c|c|c|c|}
\hline & Stigagjöf & & & \\
\hline $\begin{array}{l}\text { Umsetning sjúklinga/skjólstæðinga } \\
\text { (p.e. hversu hratt sj. koma og fara) } \\
08.01\end{array}$ & $\begin{array}{c}1 \\
\text { Stöðug } \\
\end{array}$ & 3 & 4 & $\begin{array}{l}5 \\
\text { Breytileg } \\
\end{array}$ \\
\hline $\begin{array}{l}\text { Fjölbreytileiki sjúklinga/skjólstæðinga } \\
08.02\end{array}$ & Líkir ${ }^{1}$ & 3 & 4 & $\begin{array}{l}5 \\
\text { Fjölbreyttir }\end{array}$ \\
\hline $\begin{array}{l}\text { Deildarmórall } \\
08.03\end{array}$ & $\begin{array}{c}1 \\
\text { Stöðugur }\end{array}$ & 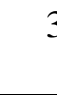 & 4 & 5 Óstöðugul \\
\hline
\end{tabular}




\section{Sjálfrææði}

Skráið hverja stjórnunarstöðu í hjúkrun í dálkinn lengst til vinstri, frá deildarstjóra til framkvæmdastjóra hjúkrunar (sbr.dæmi hér að neðan). Skráið síðan fyrir hverja stöðu í hvern dálk hve oft pú álítur hvern stjórnanda taka pátt í ákvörðunum á stofnanavísu.

Kvarði: $1=$ aldrei; 2= sjaldan; 3= stundum; 4= oft; 5= alltaf

\begin{tabular}{|c|c|c|c|c|c|c|}
\hline $\begin{array}{l}\text { Stig } \\
\text { stjórnunar }\end{array}$ & $\begin{array}{l}\text { Klínískt } \\
\text { sjálf- } \\
\text { ræði }\end{array}$ & $\begin{array}{l}\text { Faglegt } \\
\text { sjálf- } \\
\text { ræði }\end{array}$ & $\begin{array}{l}\text { Sjálfræði } \\
\text { yfir } \\
\text { hjúkrunar- } \\
\text { starfinu }\end{array}$ & $\begin{array}{l}\text { Frelsi til } \\
\text { athafna } \\
\text { á } \\
\text { grundvelli } \\
\text { eigin } \\
\text { pekkingar }\end{array}$ & $\begin{array}{l}\text { Frelsi } \\
\text { frá } \\
\text { höftum } \\
\text { skrifræðis }\end{array}$ & $\begin{array}{l}\text { Hefur } \\
\text { ábyrgðar- } \\
\text { skyldu } \\
\text { og vald } \\
\text { til } \\
\text { ákvarðana- } \\
\text { töku }\end{array}$ \\
\hline $\begin{array}{l}\text { Hjúkrunar- } \\
\text { deildarstjóri } \\
09.01\end{array}$ & & & & & & \\
\hline $\begin{array}{l}\text { Hjúkrunar- } \\
\text { stjórn } \\
09.02\end{array}$ & & & & & & \\
\hline $\begin{array}{l}\text { Stofnun (b.e. } \\
\text { framkvæmda- } \\
\text { stjóri } \\
\text { hjúkrunar) } \\
09.03\end{array}$ & & & & & & \\
\hline $\begin{array}{l}\text { Kerfið (sjálft) } \\
09.04\end{array}$ & & & & & & \\
\hline
\end{tabular}




\section{Auðlindir, aðföng hjúkrunar}

\section{Lýðfræðilegar upplýsingar um hjúkrunarstjórnendur}

Fyllið út eftirfarandi form fyrir hjúkrunardeildarstjórann á deildinni: p.e. pann sem (hvaða titil sem hann ber) stjórnar deildinni/starfseinunginni og hefur ábyrgðarskyldu á hjúkrunarbjónustunni sem veitt er á deildinni allan sólarhringinn. Ef fleiri en einn deildarstjóri (eða aðstoðardeildarstjóri) pá parf að fylla út formið fyrir báða aðila.

\begin{tabular}{|c|c|c|}
\hline 11.1 & Deildarstjóri 1 & $\begin{array}{l}\text { Vinsamlegast } \\
\text { tilgr. }\end{array}$ \\
\hline \multirow[t]{9}{*}{11.10} & Menntun: & \\
\hline & 11.102 Hjúkrunarpróf frá hjúkrunarskóla & \\
\hline & 11.103 BSc gráða í hjúkrun & \\
\hline & 11.104 BSc gráða; annað en hjúkrun & \\
\hline & 11.105 Meistara gráða í hjúkrun & \\
\hline & 11.106 Meistara gráða; annað en hjúkrun & \\
\hline & 11.107 Doktors gráða í hjúkrun & \\
\hline & 11.108 Doktors gráða; annað en hjúkrun & \\
\hline & 11.109 Diplomanám á háskólastigi & \\
\hline 11.11 & Starfsréttindi önnur, tilgreinið hver & \\
\hline \multirow[t]{3}{*}{11.12} & Kyn & \\
\hline & $11.121 \mathrm{Karl}$ & \\
\hline & 11.122 Kona & \\
\hline \multirow[t]{3}{*}{11.13} & Starfseynsla & \\
\hline & 11.131 Starfsreynsla sem deildarstjóri/árafjöldi & \\
\hline & 11.132 Starfsreynsla sem hjúkrunarfræðingur/árafjöldi & \\
\hline 11.14 & Númer hjúkrunarleyfis & \\
\hline 11.15 & Titill, tilgreinið & \\
\hline
\end{tabular}




\begin{tabular}{|c|c|c|}
\hline 11.1 & Aðstoðardeildarstjóri & $\begin{array}{l}\text { Vinsamlegast } \\
\text { tilgr. }\end{array}$ \\
\hline \multirow[t]{9}{*}{1.10} & Menntun: & \\
\hline & 11.102 Hjúkrunarpróf frá hjúkrunarskóla & \\
\hline & 11.103 BSc gráða í hjúkrun & \\
\hline & 11.104 BSc gráða; annað en hjúkrun & \\
\hline & 11.105 Meistara gráða í hjúkrun & \\
\hline & 11.106 Meistara gráða; annað en hjúkrun & \\
\hline & 11.107 Doktors gráða í hjúkrun & \\
\hline & 11.108 Doktors gráða; annað en hjúkrun & \\
\hline & 11.109 Diplomanám á háskólastigi & \\
\hline 1.11 & Starfsréttindi önnur, tilgreinið hver & \\
\hline \multirow[t]{3}{*}{1.12} & Kyn & \\
\hline & 11.121 Karl & \\
\hline & 11.122 Kona & \\
\hline \multirow[t]{3}{*}{1.13} & Starfseynsla & \\
\hline & 11.131 Starfsreynsla sem deildarstjóri/árafjöldi & \\
\hline & 11.132 Starfsreynsla sem hjúkrunarfræðingur/árafjöldi & \\
\hline 1.14 & Númer hjúkrunarleyfis & \\
\hline 1.15 & Titill, tilgreinið & \\
\hline
\end{tabular}




\section{Lýðfræðilegar upplýsingar/Starfsfólk}

Fyllið út petta form fyrir allt starfsfólk deildarinnar/starfseiningarinnar sem tilheyrir hjúkrun.

\subsection{Starfsfólk í beinni hjúkrun}

\begin{tabular}{|l|l|l|l|l|l|}
\hline Hlutverk & \multicolumn{2}{|c|}{} & \multicolumn{2}{|c|}{ Meðal starfsaldur } \\
\hline $\begin{array}{l}\text { Hjúkrunarfræðingur } \\
12.12\end{array}$ & $\begin{array}{l}\text { Heildar- } \\
\text { fjöldi } \\
\text { starfs- } \\
\text { manna }\end{array}$ & $\begin{array}{l}\text { Heildar- } \\
\text { fjöldi } \\
\text { stöðu- } \\
\text { gilda }\end{array}$ & á stofnuninni & $\begin{array}{c}\text { í } \\
\text { núverandi } \\
\text { stöðu }\end{array}$ & $\begin{array}{c}\text { í } \\
\text { hjúkrunar- } \\
\text { starfi }\end{array}$ \\
\hline $\begin{array}{l}\text { Menntun: } \\
12.121\end{array}$ & & & & & \\
\hline $\begin{array}{l}\text { Hjúkrunarpróf frá } \\
\text { hjúkrunarskóla } \\
12.123\end{array}$ & & & & & \\
\hline $\begin{array}{l}\text { BSc gráða í hjúkrun } \\
12.124\end{array}$ & & & & & \\
\hline $\begin{array}{l}\text { BSc gráða; annað en } \\
\text { hjúkrun } \\
12.125\end{array}$ & & & & & \\
\hline $\begin{array}{l}\text { Meistara gráða í } \\
\text { hjúkrun } \\
12.126\end{array}$ & & & & & \\
\hline $\begin{array}{l}\text { Meistara gráða; annað } \\
\text { en hjúkrun } \\
12.127\end{array}$ & & & & & \\
\hline $\begin{array}{l}\text { Doktors gráða í } \\
\text { hjúkrun } \\
12.128\end{array}$ & & & & & \\
\hline $\begin{array}{l}\text { Doktors gráða; annað } \\
\text { en hjúkrun } \\
12.129\end{array}$ & & & & & \\
\hline $\begin{array}{l}\text { Díplomanám á } \\
\text { háskólastigi } \\
12.1214\end{array}$ & & & & & \\
\hline $\begin{array}{l}\text { Starfsréttindi, } \\
\text { tilgreinið hver } \\
12.1210\end{array}$ & & & & & \\
\hline $\begin{array}{l}\text { Meðlimur í } \\
\text { fagfélagi/fagdeild } \\
12.1211\end{array}$ & & & & & \\
\hline $\begin{array}{l}\text { Meðalaldur } \\
12.1212\end{array}$ & & & & & \\
\hline $\begin{array}{l}\text { Fjöldi barna eða } \\
\text { annarra í umsjá viðk. } \\
12.1213\end{array}$ & & & & & \\
\hline & & & & & \\
\hline
\end{tabular}




\begin{tabular}{|l|l|l|l|l|l|}
\hline \multirow{2}{*}{ Hlutverk } & \multicolumn{2}{|c|}{ Meðal starfsaldur } \\
\cline { 2 - 6 } & $\begin{array}{l}\text { Heildar- } \\
\text { fjöldi } \\
\text { Starfs- } \\
\text { manna }\end{array}$ & $\begin{array}{l}\text { Heildar- } \\
\text { fjöldi } \\
\text { stöðu- } \\
\text { gilda }\end{array}$ & $\begin{array}{c}\text { á } \\
\text { stofnuninni }\end{array}$ & $\begin{array}{c}\text { í } \\
\text { núverandi } \\
\text { stöðu }\end{array}$ & í starfi \\
\hline $\begin{array}{l}\text { Sjúkraliðar } \\
12.13\end{array}$ & & & & & \\
\hline $\begin{array}{l}\text { Meðalaldur } \\
12.131\end{array}$ & & & & & \\
\hline $\begin{array}{l}\text { Fjöldi barna eða } \\
\text { annarra í umsjá } \\
\text { viðkomandi } \\
12.132\end{array}$ & & & & & \\
\hline
\end{tabular}

\begin{tabular}{|l|l|l|l|l|c|}
\hline \multirow{2}{*}{ Hlutverk } & \multicolumn{3}{|c|}{ Meðal starfsaldur } \\
\cline { 2 - 6 } & $\begin{array}{l}\text { Heildar- } \\
\text { fjöldi } \\
\text { Starfs- } \\
\text { manna }\end{array}$ & $\begin{array}{l}\text { Heildar- } \\
\text { fjöldi } \\
\text { stöðu- } \\
\text { gilda }\end{array}$ & $\begin{array}{c}\text { á } \\
\text { stofnuninni }\end{array}$ & $\begin{array}{c}\text { í } \\
\text { núverandi } \\
\text { stöðu }\end{array}$ & í starfi \\
\hline $\begin{array}{l}\text { Ófaglærðir } \\
12.14\end{array}$ & & & & & \\
\hline $\begin{array}{l}\text { Meðalaldur } \\
12.141\end{array}$ & & & & & \\
\hline $\begin{array}{l}\text { Fjöldi barna eða } \\
\text { annarra í umsjá } \\
\text { viðkomandi } \\
12.142\end{array}$ & & & & & \\
\hline
\end{tabular}




\section{Mönnun}

Fyllið út sérhvern af eftirfarandi liðum fyrir hverja starfsgrein sem heyrir undir deildarstjóra/ stjórnanda deildarinnar/starfseiningar fyrir árið 2010

\subsection{Fjöldi}

\begin{tabular}{|c|c|c|c|c|c|}
\hline \multirow[t]{2}{*}{ Starfsgrein } & \multicolumn{2}{|c|}{$\begin{array}{l}\text { Allt starfsfólk á } \\
\text { ábyrgð deildarstjóra } \\
\text { sem ekki er } \\
\text { fastráðið }\end{array}$} & \multicolumn{2}{|c|}{$\begin{array}{c}\text { Fastráðið starfsfólk/ } \\
\text { Starfsfólk á } \\
\text { launaskrá }\end{array}$} & \multirow{2}{*}{$\begin{array}{l}\begin{array}{l}\text { Hámarks } \\
\text { mönnun á } \\
\text { sólarhring }\end{array} \\
\text { Stöðugildi }^{1}\end{array}$} \\
\hline & Fjöldi & Stöðugildi $^{1}$ & Fjöldi & Stöðugildi $^{1}$ & \\
\hline \multicolumn{6}{|c|}{$\begin{array}{l}\text { Starfsfólk í umönnun } \\
13.10\end{array}$} \\
\hline \multicolumn{6}{|c|}{$\begin{array}{l}\text { Hjúkrunarfræðingar með } \\
\text { sérfræðimenntun } \\
13.101\end{array}$} \\
\hline \multicolumn{6}{|c|}{$\begin{array}{l}\text { Hjúkrunarfræðingar } \\
13.102\end{array}$} \\
\hline \multicolumn{6}{|l|}{$\begin{array}{l}\text { Sjúkraliðar } \\
13.103\end{array}$} \\
\hline \multicolumn{6}{|l|}{$\begin{array}{l}\text { Ófaglærðir } \\
13.104 \\
\end{array}$} \\
\hline \multicolumn{6}{|l|}{$\begin{array}{l}\text { Hjúkrunarfræðinemar } \\
13.105\end{array}$} \\
\hline \multicolumn{6}{|c|}{$\begin{array}{l}\text { Hjúkrunarfr. sem vinna } \\
\text { hjá starfsmannaleigum } \\
13.106\end{array}$} \\
\hline \multicolumn{6}{|c|}{$\begin{array}{l}\text { Sjálfstæðir verktakar } \\
13.107\end{array}$} \\
\hline \multicolumn{6}{|l|}{$\begin{array}{l}\text { Stjórnendur og } \\
\text { stoðpjónusta } \\
13.11\end{array}$} \\
\hline \multicolumn{6}{|l|}{$\begin{array}{l}\text { Hjúkrunardeildarstjóri } \\
13.112\end{array}$} \\
\hline \multicolumn{6}{|l|}{$\begin{array}{l}\text { Starfspróunarstjóri/ } \\
\text { Fræðslustjóri } \\
13.113 \\
\end{array}$} \\
\hline \multicolumn{6}{|l|}{$\begin{array}{l}\text { Rannsakendur } \\
13.114\end{array}$} \\
\hline \multicolumn{6}{|l|}{$\begin{array}{l}\text { Gæðastjórar } \\
13.115\end{array}$} \\
\hline $\begin{array}{l}\text { Stoðpjónusta } \\
\text { (hjúkrunarritarar og } \\
\text { annað er við á) } \\
13.116 \\
\end{array}$ & & & & & \\
\hline
\end{tabular}

${ }^{1}$ Fullt stöðugildi = 2080 klst. á ári (40 klst. á viku).

${ }^{2}$ Framleiðslugeta $=$ allt starfslið sem völ er á til umönnunar að undanskildu veikindum og leyfi 
13.2 Starfsmannavelta

\begin{tabular}{|c|c|c|c|c|c|}
\hline Starfsgrein & $\begin{array}{l}\text { Sjálfviljug } \\
\text { starfs- } \\
\text { manna- } \\
\text { velta }^{1}\end{array}$ & $\begin{array}{l}\text { Ósjálfviljug } \\
\text { starfs- } \\
\text { manna- } \\
\text { velta }^{2}\end{array}$ & $\begin{array}{l}\text { Meðaltal } \\
\text { starfs- } \\
\text { manna } \\
\text { veltu }^{3}\end{array}$ & $\begin{array}{l}\text { Meðaltal } \\
\text { ósetinna } \\
\text { stöðugilda }{ }^{4}\end{array}$ & $\begin{array}{l}\text { Fjöldi } \\
\text { setinna } \\
\text { stöðugilda } \\
\text { á launaskrá }\end{array}$ \\
\hline $\begin{array}{l}\text { Starfsfólk í umönnun } \\
13.20\end{array}$ & & & & & \\
\hline $\begin{array}{l}\text { Hjúkrunarfræðingar } \\
\text { með sérfræðimenntun } \\
13.201\end{array}$ & & & & & \\
\hline $\begin{array}{l}\text { Hjúkrunarfræðingar } \\
13.202\end{array}$ & & & & & \\
\hline $\begin{array}{l}\text { Sjúkraliðar } \\
13.203 \\
\end{array}$ & & & & & \\
\hline $\begin{array}{l}\text { Ófaglærðir } \\
13.204 \\
\end{array}$ & & & & & \\
\hline $\begin{array}{l}\text { Hjúkrunarfræðinemar } \\
13.205\end{array}$ & & & & & \\
\hline $\begin{array}{l}\text { Hjúkrunarfr. sem vinna } \\
\text { hjá starfsmannaleigum } \\
13.206\end{array}$ & & & & & \\
\hline $\begin{array}{l}\text { Sjálfstæðir verktakar } \\
13.207\end{array}$ & & & & & \\
\hline $\begin{array}{l}\text { Stjórnendur og } \\
\text { stoðpjónusta } \\
13.21 \\
\end{array}$ & & & & & \\
\hline $\begin{array}{l}\text { Hjúkrunardeildarstjóri } \\
13.212\end{array}$ & & & & & \\
\hline $\begin{array}{l}\text { Starfspróunarstjóri/ } \\
\text { Fræðslustjóri } \\
13.213 \\
\end{array}$ & & & & & \\
\hline $\begin{array}{l}\text { Rannsakendur } \\
13.214 \\
\end{array}$ & & & & & \\
\hline Gæðastjórar $\quad 13.215$ & & & & & \\
\hline $\begin{array}{l}\text { Stoðbjónusta } \\
\text { (hjúkrunarritarar og } \\
\text { annað er við á) } \\
13.216\end{array}$ & & & & & \\
\hline
\end{tabular}

${ }^{1}$ Sjálfviljug starfsmannavelta - starfsmaður hættir að eigin frumkvæði (Voluntary Turnover).

${ }^{2}$ Ósjálfviljug starfsmannavelta - starfsmanni er sagt upp störfum (Involuntary Turnover).

${ }^{3}$ Meðaltal starfsmannaveltu - hlutfall (\%) starfsmanna_sem hætta störfum (Average Turnover).

${ }^{4}$ Meðaltal ósetinna stöðugilda - hlutfall (\%) stöðugilda sem eru laus (Average Vacancy). 
13.3 Festa í starfi

\begin{tabular}{|c|c|c|c|c|c|c|}
\hline Starfsgrein & $\begin{array}{c}\text { Festa } \\
\text { ný- } \\
\text { útskrifaðra }{ }^{1}\end{array}$ & $\begin{array}{c}\text { Stöðug } \\
\text { leika } \\
\text { hlutfall }^{2}\end{array}$ & $\begin{array}{c}\text { Óstöðug- } \\
\text { leika } \\
\text { hlutfall }^{3}\end{array}$ & $\begin{array}{l}\text { Brottfalls } \\
\text { hlutfall }^{4}\end{array}$ & $\begin{array}{c}\text { Festa } \\
\text { nýráðinna }\end{array}$ & $\begin{array}{c}\text { Brottfall } \\
\text { ný- } \\
\text { ráoinna }^{6}\end{array}$ \\
\hline $\begin{array}{l}\text { Starfsfólk í } \\
\text { umönnun } \\
13.30\end{array}$ & & & & & & \\
\hline $\begin{array}{l}\text { Hjúkrunarfræðingar } \\
\text { með } \\
\text { sérfræðimenntun } \\
13.301 \\
\end{array}$ & & & & & & \\
\hline $\begin{array}{l}\text { Hjúkrunarfræðingar } \\
13.302\end{array}$ & & & & & & \\
\hline $\begin{array}{l}\text { Sjúkraliðar } \\
13.303\end{array}$ & & & & & & \\
\hline $\begin{array}{l}\text { Ófaglærðir } \\
13.304\end{array}$ & & & & & & \\
\hline $\begin{array}{l}\text { Hjúkrunarfræðinem } \\
\text { ar } \\
13.305 \\
\end{array}$ & & & & & & \\
\hline $\begin{array}{l}\text { Hjúkrunarfr. sem } \\
\text { vinna hjá } \\
\text { starfsmannaleigum } \\
13.306\end{array}$ & & & & & & \\
\hline $\begin{array}{l}\text { Sjálfstæðirverkt. } \\
13.307\end{array}$ & & & & & & \\
\hline $\begin{array}{l}\text { Stjórnendur og } \\
\text { stoðpjónusta } \\
13.31 \\
\end{array}$ & & & & & & \\
\hline $\begin{array}{l}\text { Hjúkrunardeildarstj } \\
13.312\end{array}$ & & & & & & \\
\hline $\begin{array}{l}\text { Starfspróunarstjóri/ } \\
\text { Fræðslustjóri } \\
13.313 \\
\end{array}$ & & & & & & \\
\hline $\begin{array}{l}\text { Rannsakendur } \\
13.314 \\
\end{array}$ & & & & & & \\
\hline $\begin{array}{l}\text { Gæðastjórar } \\
13.315\end{array}$ & & & & & & \\
\hline $\begin{array}{l}\text { Stoðpjónusta } \\
\text { (hjúkrunarritarar } \\
\text { og annað er við á) } \\
13.316\end{array}$ & & & & & & \\
\hline
\end{tabular}


${ }^{1}$ Festa nýútskrifaðra - hlutfall (\%) nýútskrifaðra hjúkrunarfræðinga sem hafa haldist í starfi yfir ákveðið tímabil

${ }^{2}$ Stöðugleika hlutfall - hlutfall (\%) hjúkrunarfræðinga sem voru í starfi í

byrjun (ákveðins tímabils) og voru enn í starfi í lok sama tímabils

3 Óstöðugleika hlutfall - hlutfall (\%) hjúkrunarfræðinga sem voru í starfi í

byrjun (ákveðins tímabils) en hættu störfum í lok sama tímabils

${ }^{4}$ Brottfalls hlutfall - hlutfall (\%) hjúkrunarfræðinga sem hættu störfum á ákveðnu tímabili

${ }^{5}$ Festa nýráðinna sem endast í starfi- hlutfall (\%) nýráðinna hjúkrunarfræðinga sem héldu áfram starfi á ákveðnu tímabili

${ }^{6}$ Brottfall nýráðinna sem falla úr starfi- hlutfall (\%) nýráðinna

hjúkrunarfræðinga sem hættu störfum á ákveðnu tímabili

* Heimild: P. B. Hofmann. (1981). Accurate measurement of nursing turnover: The first step in its reduction. Journal of Nursing Administration, 11(11/12), 37-39. 


\section{Starfsánægja}

\subsection{Staða}

\subsection{Yfirstjórn, hjúkrunardeildarstjórar, stoðpjónusta}

Vinsamlegast fyllið út pessa töflu fyrir yfirstjórnendur, hjúkrunardeildarstjóra og starfsfólk í stoðpjónustu á deildinni/starfseiningunni. Upplýsingarnar ber að leggja saman og flokka eftir starfsfgrein. Gerið grein fyrir heildarfjölda peirra sem svara hverjum pætti (1-5) og heildarfjölda svara hverrar starfsgreinar.

Kvarði: 1= mjög ósammála; 2= ósammála; 3= hlutlaus; 4= sammála; 5= mjög sammála

\begin{tabular}{|l|l|l|l|l|l|}
\hline \multicolumn{1}{|c|}{ Atriði } & $\mathbf{1}$ & $\mathbf{2}$ & $\mathbf{3}$ & $\mathbf{4}$ & $\mathbf{5}$ \\
\hline $\begin{array}{l}\text { Almennt séð, er ég mjög ánægð-(ur) með starf mitt. } \\
14.121\end{array}$ & & & & & \\
\hline $\begin{array}{l}\text { Ég hugsa sjaldan um að hætta í pessu starfi. } \\
14.122\end{array}$ & & & & & \\
\hline $\begin{array}{l}\text { Almennt séð, er ég ánægð(ur) með vinnuna sem ég inni af hendi í } \\
\text { pessu starfi. }\end{array}$ & & & & & \\
14.123 & & & & & \\
\hline $\begin{array}{l}\text { Flestir hjúkrunarfræðingar/ljósmæður í pessu starfi eru mjög } \\
\text { ánægðir með starfið. } \\
14.124\end{array}$ & & & & & \\
\hline $\begin{array}{l}\text { Hjúkrunarfræðingar/ljósmæður í pessu starfi hugsa sjaldan um að } \\
\text { hætta. } \\
14.125\end{array}$ & & & & & \\
\hline
\end{tabular}

* Ánægju pættir eru aðlagaðir frá mælitæki Hackman og Oldham (1975; 1980) um starfsánægju. Heimild Journal of Applied Psychology, 60:159-170 and Work Redesign published by Addison-Wesley

\subsection{Aðstæður}

14.22 Yfirstjórn, hjúkrunardeildarstjórar, stoðpjónusta

Kvarði: 1= mjög ósammála; 2= ósammála; 3= hlutlaus; 4= sammála; 5= mjög sammála

\begin{tabular}{|l|l|l|l|l|l|}
\hline Atriði & $\mathbf{1}$ & $\mathbf{2}$ & $\mathbf{3}$ & $\mathbf{4}$ & $\mathbf{5}$ \\
\hline $\begin{array}{l}\text { Almennt séð, er ég mjög ánægð(ur) með deildarstjórnunina. } \\
14.221\end{array}$ & & & & & \\
\hline $\begin{array}{l}\text { Almennt séð, er ég mjög ánægð(ur) með yfirstjórn hjúkrunar. } \\
14.222\end{array}$ & & & & & \\
\hline $\begin{array}{l}\text { Almennt séð, er ég mjög ánægð(ur) með samskipti við lækna. } \\
14.223\end{array}$ & & & & & \\
\hline $\begin{array}{l}\text { Almennt séð, er ég mjög ánægð(ur) með samskipti við aðrar } \\
\text { samstarfsstéttir en lækna. } \\
14.224\end{array}$ & & & & & \\
\hline $\begin{array}{l}\text { Almennt séð, er ég mjög ánægð(ur) með sjálfræði mitt í starfi. } \\
14.225\end{array}$ & & & & & \\
\hline
\end{tabular}




\section{FJÁRMÖGNUN}

\section{Greiðandi}

\subsection{Hjúkrun - deild/starfseining}

Reiknaðu hlutfall (\%) heildargreiðslu hvers eftirfarandi greiðanda fyrir veitta bjónustu eftir aðkomu að samskiptum við sjúkling (sbr."Magn hjúkrunarpjónustu atriði 0.4 á bls.5 ). fyrir viðkomandi deild/ starfseiningu eftir pví sem við á fyrir árið 2010.

\begin{tabular}{|l|l|l|l|l|l|}
\hline Tegund greiðslu & $\begin{array}{l}\text { Göngudeild } \\
\text { dagdeild }\end{array}$ & Legudeild & Vitjanir & Hópmeðferð & Námskeið \\
\hline $\begin{array}{l}\text { Fjárlög ríkisins } \\
15.41\end{array}$ & & & & & \\
\hline $\begin{array}{l}\text { Komugjöld } \\
15.4208\end{array}$ & & & & & \\
\hline $\begin{array}{l}\text { Ósjúkratryggðir } \\
15.45\end{array}$ & & & & & \\
\hline
\end{tabular}

\section{$\underline{16 \text { Tekjur }}$}

\subsection{Hjúkrun - deild/starfseining}

Tilgreindu hlutfall (\%) tekna eftirfarandi greiðslupátta fyrir hjúkrun á deildinni/starfseiningunni, eftir pví sem við á fyrir árið 2010. Á eingöngu við ef deildin fær beinar tekjur að pjónustu.

\begin{tabular}{|l|l|l|}
\hline Greiðsla & \% af veittri pjónustu & \% Tekjur \\
\hline Greiðsla fyrir pjónustu & & \\
16.41 & & \\
\hline Greiðsla fyrir bjónustu með & & \\
afslætti & & \\
16.42 & & \\
Daggjöld & & \\
\hline Sjúkdómamiðuð flokkun (DRG & & \\
16.44 & & \\
\hline Komugjöld & & \\
16.46 & & \\
\hline 16.47 Aðrar sértekjur & & \\
\hline
\end{tabular}




\section{Fjárhagsáætlun hjúkrunarbiónustu deild/starfseining}

\subsection{Kostnaður}

\subsection{Hjúkrunarbjónusta deild/starfseining - Hjúkrunarsvið}

Tilgreinið áætlaða og raunverulega fjárhagsáætlun hjúkrunar sem hlutfall (\%) af árlegri sundurliðaðri kostnaðaráætlun deildarinnar/starfseiningarinnar fyrir árið 2010. Upplýsingar fást líklega úr fjárhagskerfi.

\begin{tabular}{|l|l|l|}
\hline $\begin{array}{l}\text { Hjúkrunarbjónusta } \\
\text { deild/starfseining kostnaður }\end{array}$ & $\begin{array}{l}\text { Fjárheimild deildar } \\
\text { Aæatlaður kostnaður }\end{array}$ & $\begin{array}{l}\text { Fjárheimild deildar } \\
\text { Raunverulegur } \\
\text { kostnaður }\end{array}$ \\
\hline $\begin{array}{l}\text { Yfirvinna/vaktgreiðslur } \\
17.131\end{array}$ & & \\
\hline Laun & & \\
\hline 17.132 & Launatengd gjöld & \\
17.133 & & \\
\hline $\begin{array}{l}\text { Afskriftir } \\
17.134\end{array}$ & & \\
\hline $\begin{array}{l}\text { Annar rekstrarkostnaður } \\
17.135 \text { and } 17.139\end{array}$ & & \\
\hline
\end{tabular}

\subsection{Hjúkrunarpjónusta deild/ starfseining - Hjúkrunarsvið}

Tilgreinið áætlaðar og raunverulegar tekjur hjúkrunar á deildinni/starfseiningunni sem hlutfall (\%) af árlegri tekjuáætlun hjúkrunarsviðs fyrir árið 2010. Upplýsingar fást líklega úr fjárhaldskerfi ef pær eiga við.

\begin{tabular}{|l|l|l|}
\hline $\begin{array}{l}\text { Hjúkrun } \\
\text { Deild/starfseining } \\
\text { Tekjur }\end{array}$ & $\begin{array}{l}\text { Hjúkrunarsvið } \\
\text { Áætlaðar tekjur }\end{array}$ & $\begin{array}{l}\text { Hjúkrunarsvið } \\
\text { Raunverulegar tekjur }\end{array}$ \\
\hline $\begin{array}{l}\text { Tekjur } \\
17.231\end{array}$ & & \\
\hline
\end{tabular}




\section{8 Útgiöld}

\subsection{Hjúkrunarbjónusta deild/starfseining}

Tilgreinið eftirfarandi útgjöld hjúkrunarbjónustu á deildinni/starfseiningunni sem hlutfall (\%) af heildarútgjöldum hjúkrunarsviðs fyrir síðastliðið ár 2010. Upplýsingar fást líklega úr fjárhaldskerfi.

\begin{tabular}{|l|l|}
\hline Mælikvarði & \% af heildarútgjöldum \\
\hline Launakostnaður: & \\
Samanlagður kostnaður vegna vinnuafls á deildum, & \\
p.m.t. laun og launatengd gjöld, fríðindi, ferðir, nýliðun & \\
og starfspróunarkostnaður á ári. & \\
18.31 & \\
\hline Rekstrargjöld: & \\
Samanlagður efnislegur kostnaður til að sinna pjónustu & \\
við sjúklinga á deild á ári, p.m.t.rekstrarvörur (s.s. & \\
hjúkrunarvörur, lækningavörur, lyf, rannsóknir o.fl.). & \\
18.32 & \\
\hline Samkostnaður: & \\
Húsnæði/fasteignir; tækjabúnaður; afskriftir yfir tíma; & \\
stjórnun; kostnaður við vinnuafl sem er sameginlegt & \\
fyrir deildir/ starfseiningar; próun klínískrar bjónustu og & \\
útgjöld vegna framtíðarpróunar á ári. & \\
18.33 & \\
\hline
\end{tabular}




\section{Fylgiskjal: Upplýsingasöfnunar eyðublað - Einstaklingur}

\subsection{Starfsánægja: Staða}

\subsection{Starfsfólk í beinni umönnun}

Vinsamlegast fylltu út í töflurnar hér fyrir neðan

*Kvarði: 1= mjög ósammála; 2= ósammála; 3= hlutlaus; 4= sammála; 5= mjög sammála

\begin{tabular}{|l|l|l|l|l|l|}
\hline Atriði & $\mathbf{1}$ & $\mathbf{2}$ & $\mathbf{3}$ & $\mathbf{4}$ & $\mathbf{5}$ \\
\hline $\begin{array}{l}\text { Almennt séð, er ég mjög ánægð-(ur) með starf mitt. } \\
14.111\end{array}$ & & & & & \\
\hline $\begin{array}{l}\text { Ég hugsa sjaldan um að hætta í pessu starfi. } \\
14.112\end{array}$ & & & & & \\
\hline $\begin{array}{l}\text { Almennt séð, er ég ánægð(ur) með vinnuna sem ég inni af hendi í } \\
\text { pessu starfi. }\end{array}$ & & & & & \\
14.113 & & & & & \\
\hline $\begin{array}{l}\text { Flestir hjúkrunarfræðingar/ljósmæður í pessu starfi eru mjög } \\
\text { ánægðir með starfið. } \\
14.114\end{array}$ & & & & & \\
\hline $\begin{array}{l}\text { Hjúkrunarfræðingar/ljósmæður í pessu starfi hugsa sjaldan um að } \\
\text { hætta. } \\
14.115\end{array}$ & & & & & \\
\hline
\end{tabular}

\section{2 Ánægja: Aðstæður}

\subsection{Starfsfólk í beinni umönnun}

*Kvarði: 1= mjög ósammála; 2= ósammála; 3= hlutlaus; 4= sammála; 5= mjög sammála

\begin{tabular}{|l|l|l|l|l|l|}
\hline Atriði & $\mathbf{1}$ & $\mathbf{2}$ & $\mathbf{3}$ & $\mathbf{4}$ & $\mathbf{5}$ \\
\hline $\begin{array}{l}\text { Almennt séð, er ég mjög ánægð(ur) með deildarstjórnunina. } \\
14.211\end{array}$ & & & & & \\
\hline $\begin{array}{l}\text { Almennt séð, er ég mjög ánægð(ur) með yfirstjórn hjúkrunar. } \\
14.212\end{array}$ & & & & & \\
\hline $\begin{array}{l}\text { Almennt séð, er ég mjög ánægð(ur) með samskipti við lækna. } \\
14.213\end{array}$ & & & & & \\
\hline $\begin{array}{l}\text { Almennt séð, er ég mjög ánægð(ur) með samskipti við aðrar } \\
\text { samstarfsstéttir en lækna. } \\
14.214\end{array}$ & & & & & \\
\hline $\begin{array}{l}\text { Almennt séð, er ég mjög ánægð(ur) með sjálfræði mitt í starfi. } \\
14.215\end{array}$ & & & & & \\
\hline
\end{tabular}


APPENDIX C: STATISTICAL ANALYSIS TABLES C1, C2, C3, AND

C4 
Table C1. Descriptive Statistical Analysis of the NMMDS-ICE Elements

\begin{tabular}{|l|l|l|}
\hline Collected & $\begin{array}{l}\text { NMMDS-ICE } \\
\text { Elements }\end{array}$ & $\begin{array}{l}\text { Statistical Analysis } \\
\text { Technique }\end{array}$ \\
\hline \#1 Unit/Service Unique Identifier & Environment & Descriptive \\
\hline \#2 Type of Nursing Delivery Unit/Service & Environment & Descriptive \\
\hline \#3 Patient/Client Population & Environment & Descriptive \\
\hline \#4 Volume of Nursing Delivery Unit/Service & Environment & Descriptive \\
\hline \#5 Care Delivery Structure and Outcomes & Environment & Descriptive \\
\hline \#7 Clinical Decision Making Complexity & Environment & Descriptive \\
\hline \#8 Environmental Complexity & Environment & Descriptive \\
\hline \#9 Autonomy & Environment & Descriptive \\
\hline \#11 Management Demographic Profile & Nursing Care Resources & Descriptive \\
\hline \#12 Staff Demographic Profile & Nursing Care Resources & Descriptive \\
\hline \#13 Staffing & Nursing Care Resources & Descriptive \\
\hline \#14 Satisfaction & Nursing Care Resources & Descriptive \\
\hline \#15 Payer Type & Financial Resources & Descriptive \\
\hline \#16 Reimbursement & Financial Resources & Descriptive \\
\hline \#17 Nursing Delivery Unit/Service Budget & Financial Resources & Descriptive \\
\hline \#18 Expenses & Financial Resources & Descriptive \\
\hline
\end{tabular}

Table C2. Mann Whitney U Test for Statistical Analysis of the NMMDS-ICE Elements

\begin{tabular}{|l|l|l|}
\hline Collected & $\begin{array}{l}\text { NMMDS-ICE } \\
\text { Elements }\end{array}$ & $\begin{array}{l}\text { Statistical Analysis } \\
\text { Technique }\end{array}$ \\
\hline \#2 Type of Nursing Delivery Unit/Service & Environment & Mann Whitney U test \\
\hline \#3 Patient/Client Population & Environment & Mann Whitney U test \\
\hline \#4 Volume of Nursing Delivery Unit/Service & Environment & Mann Whitney U test \\
\hline \#5 Care Delivery Structure and Outcomes & Environment & Mann Whitney U test \\
\hline \#7 Clinical Decision Making Complexity & Environment & Mann Whitney U test \\
\hline \#8 Environmental Complexity & Environment & Mann Whitney U test \\
\hline \#9 Autonomy & Environment & Mann Whitney U test \\
\hline \#11 Management Demographic Profile & Nursing Care Resources & Mann Whitney U test
\end{tabular}


Table C2. Continued

\begin{tabular}{|l|l|l|}
\hline \#12 Staff Demographic Profile & Nursing Care Resources & Mann Whitney U test \\
\hline \#13 Staffing & Nursing Care Resources & Mann Whitney U test \\
\hline \#14 Satisfaction & Nursing Care Resources & Mann Whitney U test \\
\hline
\end{tabular}

Table C3. Spearman's Rank Order Statistical Analysis of the NMMDS-ICE Elements

\begin{tabular}{|l|l|l|}
\hline Collected & $\begin{array}{l}\text { NMMDS-ICE } \\
\text { Elements }\end{array}$ & $\begin{array}{c}\text { Statistical Analysis } \\
\text { Technique }\end{array}$ \\
\hline \#9 Autonomy & Environment & Spearman rank-order \\
\hline \#14 Satisfaction & Nursing Care Resources & Spearman rank-order \\
\hline
\end{tabular}

Table C4. Cronbach's Alpha Analysis of the NMMDS-ICE Elements

\begin{tabular}{|l|l|l|}
\hline Collected & $\begin{array}{l}\text { NMMDS-ICE } \\
\text { Elements }\end{array}$ & $\begin{array}{l}\text { Statistical Analysis } \\
\text { Technique }\end{array}$ \\
\hline \#5 Care Delivery Structure and Outcomes & Environment & Cronbach's Alpha \\
\hline \#7 Clinical Decision Making Complexity & Environment & Cronbach's Alpha \\
\hline \#8 Environmental Complexity & Environment & Cronbach's Alpha \\
\hline \#9 Autonomy & Environment & Cronbach's Alpha \\
\hline \#14 Satisfaction & Nursing Care Resources & Cronbach's Alpha \\
\hline
\end{tabular}


APPENDIX D: SCRIPT USED IN TELEPHONE CALLS 
Good morning. My name is Gudrun Audur Hardardottir. I am a doctoral student in the College of Nursing at The University of Iowa. I am currently working on my doctoral thesis and I would like to invite you to participate in my research. My advisor is Dr. Diane L. Huber who is a professor at the College of Nursing.. The study has been approved by Human Subjects Review Committee at The University of Iowa College of Nursing, and the Icelandic Data Protection Authority (and the hospital review board where applicable).

The purpose of the study is national adaptation and clinical testing of the Nursing Management Minimum Data Set (NMMDS) in acute adult inpatient care units in Iceland. The aim of the study is to describe the environment, nursing care resources, and financial resources across acute adult inpatient care units in Iceland, using the Icelandic version of the Nursing Management Minimum Data Set (NMMDS). The NMMDS was developed to help nurse managers and administrators to capture the data needs within the system which health care is delivered. It offers a standardized method to collect administrative data for Nurse Managers at the unit level.

If you agree to participate, I'll mail you additional information about the study, the NMMDS survey, and a self-addressed stamped envelope will be provided.

The NMMDS consists of seventeen contextual variables and three parts; environment measured by nine contextual variables, nursing care resources measured by four contextual variables, and financial resources measure by four contextual variables.

As a part of Q\#14, you are asked to provide information on unit nurse staff satisfaction with job. The Data Collection Form - Individual is provided for this purpose. I will ask you to give the Data Collection Form- Individual to the nurses on your unit and collect their completed forms. To protect the nurses' confidentiality the collection form will not have any name or ID which could link answers to an individual nurse. You will be given a study packet with the consent information, the individual satisfaction data collection form, and plain return envelope to give to the staff nurses on your unit. The 
staff nurses who agree to participate in the study will be asked to complete the data collection form and seal it in the envelope. You are asked to provide a closed paper box which will be placed within the nursing station for three days for the nurses to return the sealed envelopes with the data collection form. The sealed envelopes will be returned to the PI for data entry and analysis with the NMMDS form in the provided self-addressed stamped envelope. It takes a maximum of three to three and a half hours to complete the NMMDS questionnaire and approximately five minutes to complete the individual collection form

You are free to skip any questions that you prefer not to answer. The questionnaire will be numbered (1-38) to identify the nursing unit and link the individual data collections forms to this unit. Study findings will be presented in such a way that it will not be possible to link results to individual managers, staff nurses, units, or hospital.

Taking part in this research study is completely voluntary. Would you be willing to participate? I would be happy to share summary of findings with you.

(If potential participants agree to participate I will add this sentence): If you change your mind and do not wish to participate in this study, you can return the survey without answering any of the questions. You can withdraw from the study at any given point in time.

Thank you for your time! 
APPENDIX E: COVER LETTERS 
Dear Nurse Manager:

FOR IRB USE ONLY

APPROVED BY: IRB-02

IRB ID \#2 201101756

APPROVAL DATE: 03/10/11

EXPIRATION DATE: NIA

We invite you to participate in a research study being conducted by investigators from The University of Iowa. The study is in partial fulfillment of the requirements for my doctoral studies at the UI. My advisor is Dr. Diane L. Huber, PhD, RN, FAAN, College of Nursing (email: diane-huber@iowa.edu). The purpose of the study is national adaptation and clinical testing of the Nursing Management Minimum Data Set (NMMDS) in acute adult inpatient care units in the country of Iceland. The aim of the study is to describe the environment, nursing care resources, and financial resources across acute adult inpatient care units in Iceland, using the Icelandic version of the Nursing Management Minimum Data Set (NMMDS). The NMMDS was developed to help nurse managers and administrators to capture the data needs within the system which health care is delivered. It offers a standardized method to collect administrative data for Nurse Managers at the unit level.

If you agree to participate, we would like you to complete the enclosed NMMDS survey and mail back to the PI, Gudrun Audur Hardardottir, PhD(c), RN, using the self-addressed stamped envelope enclosed. The NMMDS consists of seventeen contextual variables and three parts; environment measured by nine contextual variables, nursing care resources measured by four contextual variables, and financial resources measure by four contextual variables.

As a part of Q\#14, you are asked to provide information on unit nurse staff satisfaction with job. The Data Collection Form - Individual is provided for this purpose. You are asked to give the Data Collection Form- Individual to the nurses on your unit along with the study information sheet which informs them about their participation in this study and a blank envelope (enclosed). To protect the nurses' confidentiality the collection form will not have any name or ID which could link answers to an individual nurse. The staff nurses who agree to participate in the study will be asked to complete the data collection form and return it in the sealed envelope. You are asked to provide a closed paper box which will be placed within the nursing station for 
three days for the nurses to return the sealed envelopes with the data collection form. The sealed envelopes will be returned to the PI for data entry and analysis with the NMMDS form in the provided self-addressed stamped envelope.

You are free to skip any questions that you prefer not to answer. It takes a maximum of three to three and a half hours to complete the NMMDS questionnaire.

The questionnaire will be numbered (1-39) to answer the study question on whether there are measurable differences in environmental, nursing resources and financial resources among hospitals in Iceland depending on their geographic location and size. The list linking the number assigned to your unit will be stored separately from the data and will be accessible only to the PI. All reports of the study findings will be primarily descriptive and aggregated data and reported in such way that it will not be possible to link any study findings to either individual managers, individual staff nurses, individual units or hospital.

Taking part in this research study is completely voluntary. If you do not wish to participate in this study, you can return the survey without answering any of the questions. You can withdraw from the study at any given point in time.

If you have questions about the rights of research subjects, please contact the Human Subjects Office, 105 Hardin Library for the Health Sciences, 600 Newton Rd, The University of Iowa, Iowa City, IA 52242-1098, (319) 335-6564, or e-mail irb@uiowa.edu.

And Persónuvernd (The Data Protection Authority), Rauðarárstíg 10, 105 Reykjavík, Iceland, 510-9600 or e-mail postur@personuvernd.is

Thank you very much for your consideration of this research study.

Gudrun Audur Hardardottir PI, PhD(c), RN

The University of Iowa, College of Nursing

e-mail: gudrun.audur@vel.is

Mobile: 8600-772 
Reykjavík, XXXX 2011

Kæri hjúkrunardeildarstjóri.

Við bjóðum pér að taka pátt í rannsókn á vegum rannsakenda við Háskólann í Iowa í Bandaríkjunum. Rannsóknin er hluti af námi mínu til doktorsgráðu við háskólann. Aðalleiðbeinandi minn er Dr. Diane L. Huber, PhD, FAAN, kennari við hjúkrunarfræðideild háskólans. Tilgangur rannsóknarinnar er að pýða og staðhæfa the Nursing Management Minimum Data Set (NMMDS) að íslenskum aðstæðum. Markmið rannsóknarinnar er að lýsa starfsumhverfi, mannauð hjúkrunar og fjármögnun/kostnaði bráða legudeilda á sjúkrahúsum á Íslandi. NMMDS er gagnasafn próað sérstaklega fyrir stjórnendur í hjúkrun og gefur möguleika á að safna lykilupplýsingum um starfsemi deilda á staðlaðan hátt auk pess að styðja rafræna upplýsingasöfnun.

Ef pú sampykkir að taka pátt í rannsókninni bið ég pig að svara NMMDS spurningalistanum og senda til baka í meðfylgjandi frímerktu umslagi til Guðrúnar Auðar Harðardóttur sem er ábyrgðarmaður rannsóknarinnar. Spurningaistinn inniheldur 17 aðalspurningar og skiptist í 3 hluta; umhverfi með 9 spurningum, aðföng hjúkrunar með 4 spurningum og fjármögnun með 4 spurningum.

Einn hluti af spurningu\#14 felst í pví að pú ert beðin um að safna upplýsingum um starfsánægju hjúkrunarfræðinganna á deildinni pinni. Meðfylgjandi upplýsingaeyðublað Einstaklingur er ætlað fyrir pessa upplýsingasöfnun. Dú ert beðin um að afhenda hjúkrunarfræðingum deildarinnar spurningalistann ásamt upplýsingabréfi um rannsóknina og umslagi til að setja spurningalistann í. Til að tryggja nafnleynd hjúkrunarfræðinganna mun engum persónulegum upplýsingum vera safnað. Peir hjúkrunarfræðingar sem eru sampykkir pátttöku eru beðnir um að svara könnuninni og setja hana í umslag og loka. pú er beðin um að koma fyrir lokuðum kassa á deildinni í 3 daga til að safna umslögunum í. pú ert síðan beðin um 
að senda pessi umslög óopnuð til rannsakanda, sem mun sjá um úrvinnsluna, og setja pau í meðfylgjandi frímerkt umslag ásamt NMMDS spurningalistanum sem pú svarar.

pú getur sleppt að svara hvaða spurningu sem er. •að tekur um 3-3,5 klst. að svara öllum spurningunum og er gert ráð fyrir að pú svarir beim í vinnutíma.

Spurningalistarnir verða númeraðir frá 1-39 til að svara rannsóknaspurningu hvort marktækur munur sé á starfsumhverfi, mannauð og fjármögnun á milli sjúkrahúsa á Íslandi eftir stærð og landfræðilegri staðsetningu. Listi sem tengir númer spurningalistans við pína deild verður geymdur á öðrum stað en gagnasafnið og aðeins aðgengilegur aðalrannsakanda. Rannsóknarniðurstöður verða aðallega lýsandi og pannig fram settar að ekki verður möguleiki að tengja niðurstöður við svör einstaka deildarstjóra né hjúkrunarfræðinga deildarinnar, pekkja einstaka deildir né tengja svör ákveðnum sjúkrahúsum.

Pátttaka í rannsókninni er algerlega frjáls. Ef pú vilt ekki taka pátt í rannsóknininni getur pú skilað spurningalistanum án pess að svara nokkurri spurningu. pú getur hætt pátttöku í rannsókninni hvenær sem er.

Ef pú hefur spurningar um rétt pinn sem pátttakandi í pessari rannsókn getur pú snúið pér til the Human Subjects Office, 105 Hardin Library for the Health Sciences, 600 Newton Rd, The University of Iowa, Iowa City, IA 52242-1098, (319) 335-6564, or e-mail irb@uiowa.edu.

Persónuvernd (The Data Protection Authority), Rauðarárstíg 10, 105 Reykjavík, Iceland, 5109600 or e-mail postur@personuvernd.is

Dakka pér kærlega fyrir pína pátttöku í pessari rannsókn.

Guðrun Auður Harðardóttir PI, PhD(c), RN

The University of Iowa, College of Nursing

e-mail: gudrun.audur@vel.is

gsm: 8600-772

s. $545-8764$ 
Dear Nurse/Midwife:

FOR IRB USE ONLY

\$OTAMP_JRE

SOTAMP_APPRV_DT

ЭOTAMP_EXP_DT

We invite you to participate in a research study being conducted by investigators from The University of Iowa. The study is in partial fulfillment of the requirements for my doctoral studies at the UI. My advisor is Dr. Diane L. Huber, PhD, RN, FAAN, College of Nursing (email: diane-huber@iowa.edu). The purpose of the study is national adaptation and clinical testing of the Nursing Management Minimum Data Set (NMMDS) in acute adult inpatient care units in the country of Iceland. The aim of the study is to describe the environment, nursing care resources, and financial resources across acute adult inpatient care units in Iceland, using the Icelandic version of the Nursing Management Minimum Data Set (NMMDS). The NMMDS was developed to help nurse managers and administrators to capture the data needs within the system which health care is delivered. It offers a standardized method to collect administrative data for Nurse Managers at the unit level.

If you agree to participate, I would like you to complete the enclosed staff satisfaction survey which is part of the NMMDS questionnaire and after completion put it in the enclosed envelope, seal the envelope and return it in the closed paper box which your Nurse Manager will place within the nursing station. The Nurse Manager will collect the sealed envelopes and return them to me for data entry and analysis. The staff satisfaction survey has 10 questions. You are asked to rank each question on a scale from 1 (strongly disagree) to 5 (strongly agree). It will take approximately five minutes to complete the survey.

To protect your confidentiality, the collection form will not include your name or any ID which could be linked to your individual answers.

You are free to skip any questions that you prefer not to answer

I will not collect your name or any identifying information about you. The NMMDS questionnaire provided to the Nurse Managers will be numbered (1-39) to answer the study question on whether there are measurable differences in environmental, nursing resources and financial resources among hospitals in Iceland depending on their geographic location and size. 
The list linking the number assigned to your unit will be stored separately from the data and will be accessible only to me. All reports of the study findings will be primarily descriptive and aggregated data and reported in such way that it will not be possible to link any study findings to either individual staff nurses, individual managers, individual units or hospital

Taking part in this research study is completely voluntary. If you do not wish to participate in this study, you can return the survey without answering any of the questions. You can withdraw from the study at any given point in time.

If you have questions about the rights of research subjects, please contact the Human Subjects Office, 105 Hardin Library for the Health Sciences, 600 Newton Rd, The University of Iowa, Iowa City, IA 52242-1098, (319) 335-6564, or e-mail irb@uiowa.edu.

And Persónuvernd (The Data Protection Authority), Rauðarárstíg 10, 105 Reykjavík, Iceland, 510-9600 or e-mail postur@personuvernd.is

Thank you very much for your consideration of this research study.

\author{
Gudrun Audur HardardottirPI, PhD(c), RN \\ The University of Iowa, College of Nursing \\ e-mail: gudrun.audur@vel.is
}

Mobile: 8600-772 
Reykjavík, XXXX 2011

Kæri hjúkrunarfræðingur/ ljósmóðir.

Við bjóðum pér að taka pátt í rannsókn á vegum rannsakenda við Háskólann í Iowa í Bandaríkjunum. Rannsóknin er hluti af námi mínu til doktorsgráðu við háskólann. Aðalleiðbeinandi minn er Dr. Diane L. Huber, PhD, FAAN, kennari við hjúkrunarfræðideild háskólans. Tilgangur rannsóknarinnar er að pýða og staðhæfa the Nursing Management Minimum Data Set (NMMDS) að íslenskum aðstæðum. Markmið rannsóknarinnar er að lýsa starfsumhverfi, mannauð hjúkrunar og fjármögnun/kostnaði bráða legudeilda á sjúkrahúsum á Íslandi. NMMDS er gagnasafn próað sérstaklega fyrir stjórnendur í hjúkrun og gefur möguleika á að safna lykilupplýsingum um starfsemi deilda á staðlaðan hátt auk pess að styðja rafræna upplýsingasöfnun.

Ef pú sampykkir að taka pátt í rannsókninni bið ég pig að svara nokkrum spurningum sem tengjast starfsánægju og eru hluti af NMMDS spurningalistanum og skila í meðfylgjandi lokuðu umslagi til baka í lokaðan pappakassa sem deildarstjórinn pinn mun koma fyrir á vaktinni. Deildarstjórinn pinn mun síðan sjá unm að senda mér umslögin óopnuð og mun ég vinna niðurstöðurnar. Starfsánægjukönnunin inniheldur 10 spurningar par sem merkt er við á 5 stiga Likert skala, par sem 1 merkir (algerlega ósammála) og 5 merkir (algerlega sammála). Dað tekur um 5 mín. að svara spurningunum. Til að tryggja nafnleynd verður engum persónulgum upplýsingum safnað og pví verður ekki hægt að rekja svör bín til pín.

pú getur sleppt að svara hvaða spurningu sem er.

Við munum ekki safna neinum persónulegum upplýsingum um pig. Spurningalistinn sem deildarstjórarnir fá er númeraður (1-39) til að geta svarað rannsóknaspurningu hvort marktækur munur sé á starfsumhverfi, mannauð og fjármögnun á milli sjúkrahúsa á Íslandi eftir stærð og landfræðilegri staðsetningu. Listi sem tengir númer spurningalistans við pína deild verður geymdur á öðrum stað en gagnasafnið og aðeins aðgengilegur aðalrannsakanda. Rannsóknarniðurstöður verða aðallega lýsandi og pannig fram settar að ekki verður möguleiki að 
tengja niðurstöður við svör einstaka deildarstjóra né hjúkrunarfræðinga deildarinnar, pekkja einstaka deildir né tengja svör ákveðnum sjúkrahúsum.

Dátttaka í rannsókninni er algerlega frjáls. . Ef pú vilt ekki taka pátt í rannsóknininni getur pú skilað spurningalistanum án pess að svara nokkurri spurningu. Dú getur hætt pátttöku í rannsókninni hvenær sem er.

Ef pú hefur spurningar um rétt pinn sem pátttakandi í pessari rannsókn

getur pú snúið pér til the Human Subjects Office, 105 Hardin Library for the Health Sciences, 600 Newton Rd, The University of Iowa, Iowa City, IA 52242-1098, (319) 335-6564, or e-mail irb@uiowa.edu.

Persónuvernd (The Data Protection Authority), Rauðarárstíg 10, 105 Reykjavík, Iceland, 5109600 or e-mail postur@personuvernd.is

Dakka pér kærlega fyrir pína pátttöku í pessari rannsókn.

Guðrun Auður Harðardóttir, PhD(c), RN

The University of Iowa, College of Nursing

e-mail: gudrun.audur@vel.is

gsm: 8600-772

s. $545-8764$. 
APPENDIX F: PERMISSIONS 


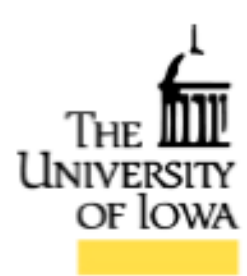

Human Subjects Office/

Institutional Review Board (IRB)

105 Hardin Library for the Health Sciences

600 Newton Road

lowa City, lowa 52242-1098

319-335-6564 Fax 319-335-7310

irberuiowa.edu

http:/fresearch uiowa.edu/hso

IRB ID \#: 201101756

To: $\quad$ Gudrun Hardardottir

From: IRB-02 DHHS Registration \# IRB00000100,

Univ of lowa, DHHS Federalwide Assurance \# FWA00003007

Re: $\quad$ Translation and National Clinical Validation of the Nursing Management Minimum Data Set (NMMDS) in Hospitals in the Country of Iceland

Approval Date:

$03 / 10 / 11$

Next IRB Approval

Due Before:

Type of Application:

$\bigotimes$ New Project

$\square$ Continuing Review

$\square$ Modification

Source of Support:
N/A

Type of Application Review:

$\square$ Full Board:

Meeting Date:

$\square$ Expedited

区xempt

The Icelandic Nurses'Association
Approved for Populations:

$\square$ Children

Prisoners

$\square$ Pregnant Women, Fetuses, Neonates

This approval has been electronically signed by IRB Chair:

Elona McLees, CIP

03/10/11 1318 
Guð̃rín Auður Harõardóttir

Baugholti 11

230 Keflavik

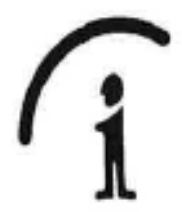

Persónuvernd

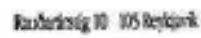

$$
\begin{aligned}
& \text { ini } 500900 \text { betwint } 503906
\end{aligned}
$$

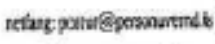

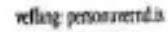

Reykjavik 27. april 2007 Tilvisune $\$ 3416 / 2007 /$ AGG/L-

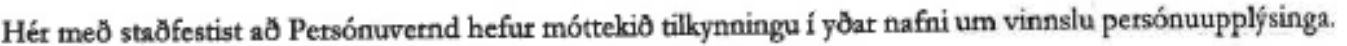
Tilkynningin er nr. S3416/2007 og fylgir afrit hennar hjálagt.

Allar tilkynningar sem berast Persónuvernd birtast sjálfkrafa á heimasíðu stofnunarinnar. Tekið̋ skal fram að̆ með̄ móttöku og birtingu tilkynninga hefur engin afstað̄a veriō tekin af hálfu Persónuverndar um efni peirra.

Viròingarfyllst,

Ambildur G. Guð̃mundsdóttir 
Guðrún Auður Harðardóttir

Baugholti 11

230 Keflavík

\author{
Persónuvernd \\ Rauðárstíg 10 \\ 105 Reykjavík \\ postur@personuvernd.is \\ Reykjavík 27. Apríl 2007 \\ Tilvísun: S3416/2007/AGG/-
}

It is hereby confirmed that The Data Protection Authority has received your report on the processing of personal information. The report is number S3416/2007 and a copy is enclosed.

All reports received by The Data Protection Authority are automatically uploaded to the institution's homepage. It shall be stated that reception and publication of reports does not mean that a stance has been taken to their content on behalf of The Data Protection Authority.

\author{
Sincerely, \\ Rauðárstíg 10 \\ Arnhildur G. Guðmundsdóttir
}




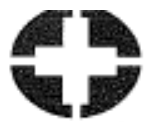 \\ LANDSPÍTALI}

Guốrún Auơur Harôardóttir

Baugholt 11

230 Reykjanesbæ

Reykjavík, 3, júní 2009

Tilvisun $16 \mathrm{EE} / \mathrm{ks}$

Varōar: Erindi 06/2009 til siðanefndar stjórnsýslurannsókna á LSH

"Translation and National Clinical Validation of the Nursing Management Minimum

Data Set (NMMDS) in Hospitals in the Country of Iceland".

Fjallað var um umsókn/viðbótargögn pín dags. 2. júní s.l. vegna rannsóknar 06/2009 á fundi nefndarinnar $i$ dag. Erindiỗ var aó fullu sampykkt.

Ein ábending kom fram um hvort íslenska heitiơ á rannsókninni ætti ekki líka aơ vera í fyrirsögninni á bréfi til hjúkrunardeildarstjóra.

Tengiliður spítalans vegna rannsóknarinnar verôur Gưorún Björg Sigurbjörnsdóttir, netfang gudrbsig@landspitali.is, sími 8245580.

Siðanefnd stjórnsýslurannsókna óskar eftir pví fyrir hönd Landspítala aô fá afrit af niðurstőðum úr rannsókninni aơ henni lokinni.

Gangi pér vel við̋ rannsóknarstörfin.

Virőingarfyllst fyrir hönd sióanefndar stjórnsýslurannsókna á LSH,

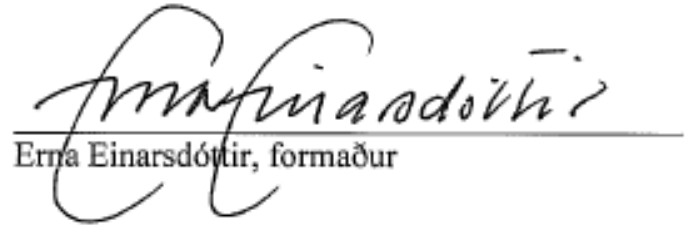

Afrit:

Anna Stefánsdóttir, framkvæmdastjóri hjúkrunar

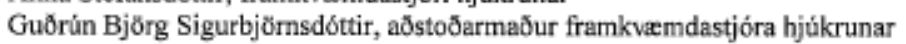

Siðanefnd stjórnsýslurannsókna,

Skrifstofu mannauósmála

Eiriksgötu 5, LSH
Formaốur: Erna Einarsdóttir, svið̌sstjóri

Netfang: erna@landspitali,is

Ritari: Karólína Sveinsdóttir

Netfang: karolins@landspitali.is 


\section{Landspítali \\ University Hospital}

Guðrún Auður Harðardóttir

Baugholti 11

230 Reykjanesbæ

Reykjavík, 3. June 2009

Reference $16 \mathrm{EE} / \mathrm{ks}$

\section{Regarding: Request 06/2009 to the LSH Institutional Review Board}

„Translation and National Clinical Validation of the Nursing Management Minimum Data Set (NMMDS) in Hospitals in the Country of Iceland“.

Your request 06/2009 was discussed by the committee on June 2. Your request was fully approved.

One comment was made; perhaps to include an Icelandic translation of the study title of the letter to the Nurse Managers.

Your contact within the hospital will be Guðrún Björg Sigurbjörnsdóttir, e-mail gudrbsig@landspitali.is tel: 8245580.

The Institutional Review Board, on behalf of Landspitali, requests sharing of summary findings.

Wishing you all the best in your scientific work.

Sincerely, on behalf of the LSH Institutional Review Board,

Erna Einarsdóttir, Chair

Copy:

Anna Stefánsdóttir, Director of Nursing Services

Guðrún Björg Sigurbjörnsdóttir, Director of Nursing Services Assistant 


\section{SIĐANEFND}

Netndarmena:

Kristian Kristjansson

prófessor

Margetet borsteinsdonit

hjüknnardeiklarstjón

Ragribeiour Baidursdótin

kvensjükoómalaknir

Sigmundur Sigfrusson

forstoroul arknir

Gữrín Aữur Harŏardóttir

Hjúkrunarfræőingur

Furuhliô 15

220 Hafnarfirði

Akureyri, 11. febrúar 2011

151. mál Sið̋anefndar FSA: Umsókn dags. 2. febrúar 2011 um leyfi til ad framkvæma rannsóknina: Translation and National Validation of the Nursing Management Minimum Data Set (NMMDS) in Hospitals in the Country of Iceland.

Ábyrgð̋armaður rannsóknarinnar er Guơrún Auður Harðardóttir hjúkrunarfræðingur.

Sið̋anefnd Sjúkrahússins á Akureyri sampykkir aõ pessi rannsókn verđi framkvæmd án athugasemda.

Virðingarfyllst,

f.h. Siðanefndar FSA

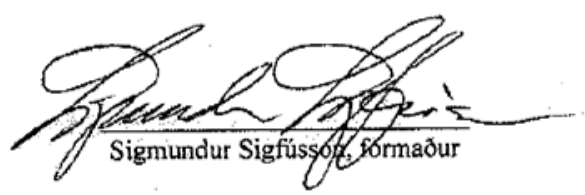


fsa The Akureyri Hospital

Institutional Review Board

Committee:

Kristján Kristjánsson

Professor

Margrét Thorsteinsdóttir

Nurse Manager

Ragnheiður Baldursdóttir

Gynecologist

Sigmundur Sigfússon

Head of Department

Guðrún Auður Harðardóttir

Nurse

Furuhlíð 15

220 Hafnarfirði

Akureyri, 11 February, 2011

Request 151. to the FSA Institutional Review Board: Request on February

2., 2011 to conduct the research: Translation and National Validation of the Nursing Management Minimum Data Set (NMMDS) in Hospitals in the Country of Iceland.

The PI is Guðrún Auður Harðardóttir, RN.

The Akureyri Hospital Institutional Review Board has fully approved this research.

Sincerely,

On behalf of the FSA Institutional Review Board

Sigmundur Sigfússon, Chair 


\section{HEILBRIGĐISSTOFNUN}

- VESTURLANDS

1 AKRANES - BORGARNES * GUEARDALUR * GRUNDARFJOREUR * HOLMAVIK * HYAMMSTANGI * OLAFSVIK • STYKKISHOLMUR

Guơrún Auður Harơardóttir

Furuhlíð 15

221 Hafnarfirồi

Akranesi 7. febrúar 2011

pér er hér með̃ heimilað̃ að̃ framkvæma rannsókn pína "Translation and National Clinical Validation of the Nursing Management Minimum Data Set (NMMDS) in Hospitals in the Country of Iceland" á

Heilbrigðisstofnun Vesturlands

Með vinsemd

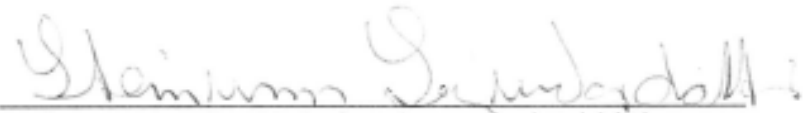

Steinunn Sigurðardóttir framkvæmdasjtóri hjúkrunar og rekstrar HVE 


\section{HEILBRIGĐISSTOFNUN - VESTURLANDS

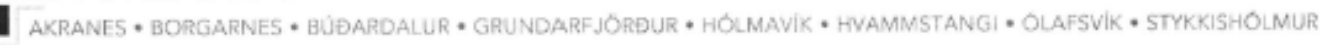

Guơrún Auơur Harơardóttir

Furuhliðð 15

221 Hafnarfirði

Akranesi February 7. 2011

You are hereby permitted to conduct your research "Translation and National Clinical Validation of the Nursing Management Minimum Data Set (NMMDS) in Hospitals in the Country of Iceland" at the Vesturland Healthcare Center.

Sincerely,

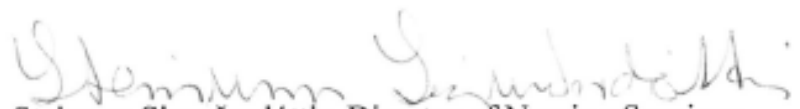
Steinunn Siguroardóttir, Director of Nursing Services Heilbrigōisstofnun Vesturlands Merkigerő 9 300 Akranesi steinunn.sigurdardottir@hve.is 
Heibrigotsatolnun Buburlande

Bjolkrahús og helougenala

vifirvog - oco Solloed

$\sin 4806100+\operatorname{tax} 4805101$

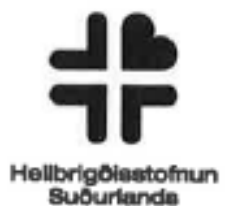

Guơnún Aươr Harồardóttir

Furuhliō 15

221 Hafnarfiröi

Selfossi, 4. febrúar 2011

bér er hér með heimilå að framkvæema rannsókn pina "Translation and National Clinical Validation of the Nursing Management Minimum Data Set (NMMDS) in Hospitals in the Country of lceland" a HeilbrigOisstofnun Suðurlands.

English translation:

You are hereby permitted to conduct your research "Translation and National Clinical Validation of the Nursing Management Minimum Data Set (NMMDS) in Hospitals in the Country of Iceland" at the Healthcare Institution of South Iceland.

Sincerely,

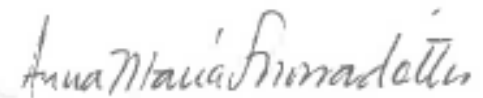

Anna Maria Snorradóttir, RN, MSc.

Director of Nursing Services

The Healthcare Institution of South Iceland

Selfoss, Iceland

Phone: 354-480-5186

Email: annamaria@hsu.is 


\section{Heilbrigōisstofnun Pingeyinga} Húsavík

Guđrún Auður Harðardóttir

Furuhlíð 15

221 Hafnarfirøi

Húsavík, 4. febrúar 2011

Dér er hér međ heimilað ađ framkvæma rannsókn pína "Translation and National Clinical Validation of the Nursing Management Minimum Data Set (NMMDS) in Hospitals in the Country of Iceland" á Heilbrigdisstofnun pingeyinga.

\section{English translation:}

You are hereby permitted to conduct your research "Translation and National Clinical Validation of the Nursing Management Minimum Data Set (NMMDS) in Hospitals in the Country of Iceland" at the Health Center of Thingeyjarsyslur.

Sincerely,

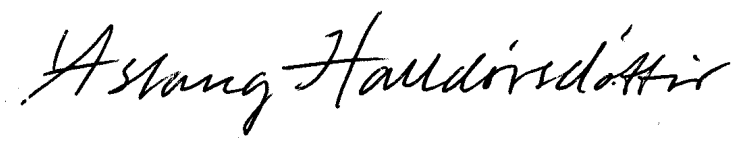

Áslaug Halldórsdóttir,

framkvæmdastjóri hjúkrunar, Director of Nursing

Heilbrigdisstofnun pingeyinga, The Health Center of Thingeyjarsyslur

Simi +354 4640500/+3548607736.

Netfang/email: aslaug@heilthing.is

Heimilisfang
Auðbrekka 4

640 Húsavik

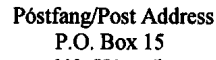

P.O. Box 15
640 Húsavik
Simi/Telefon

464-0500 $+354-464-0500$
Póstfax/Telefax 464-0575 $+354-464-0575$
Kennitala 450100-3310 Heimasióa www heilhus.is 


\section{Heilbrigðisstofnun Austurlands}

Mýrargata 20, 740 Neskaupstadur, sími 470-1404, bréfs. 470-1408, kt 610199-2839

Guònin Auður Harðaardóttir

Furuhlio 15

221 Hafnarfiròi

Neskaupsstad 4. februiar 2011

Pér er hér med heimilad ad framkvæma rannsókn pina "Translation and National Clinical Validation of the Nursing Management Minimum Data Set (NMMDS) in Hospitals in the Country of Iceland" á

Heilbrigðisstofnun Austurlands.

English translation:

You are hereby permitted to conduct your research "Translation and National Clinical Validation of the Nursing Management Minimum Data Set (NMMDS) in Hospitals in the Country of Iceland" at the Health Directorate of East Iceland

Sincerely,

Lilja Adalsteinsdóttir, Director of Nursing Services

Heilbrigdisstofnun Austurlands

Mýrargötu 20

740 Neskaupsstad

lilia hsa.is 
Guđrún Auđur Harđardóttir

Furuhtlio 15

221 Hafnarfiroi

Reykjanesbar, 4. febrúar 2011

pér er hér meỏ heimilađ a đ framkvaema rannsókn pina "Translation and National Clinical Validation of the Nursing Management Minimum Data Set (NMMDS) in Hospitals in the Country of iceland" á Heilbrigðisstofnun Suđurnesja.

Enqlish translotion:

You are hereby permitted to conduct your research "Translation and National Clinical Validation of the Nursing Manogement Minimum Data Set (NMMDS) in Hospitals in the Country of Iceland" at Sudurnes Healthcare Center.

Sincerely,

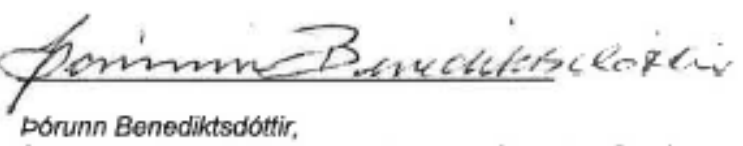

framkv®mdastjóri hjúkrunar -Director of Nursing Services

Hen̈brigdisstofnun Sudurnesja - Sudurnes Healthcare Center

Skolavagi 6, 230 Reykjanesbro, lceland

Simi: 422-0500/8600165

Netfang: thb@hss.is 


\section{Heilbriqõisstofnunin Blönduósi}

Flúdabakka 2540 Blōnduósi, sími 455-4100, - Veffang hsb.is, - Netfang hsb@hsb.is

Guðrún Auður Harðardóttir

Furuhlið 15

221 Hafnarfjörður

Blönduósi 5. febrúar 2011

You are hereby permitted to conduct your research "Translation and National Clinical Validation of the Nursing Management Minimum Data Set (NMMDS) in Hospitals in the Country of Iceland" at Blönduós Healthcare Center.

Sincerely,

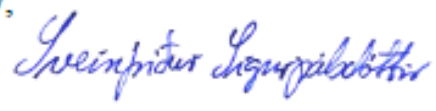

Sveinfriður Sigurpálsdóttir

framkvæmdastjóri hjúkrunar -Director of Nursing Services

Heilbrigðisstofnuni Blönduósi - Blönduós Healthcare Center

Flúðabakki 2, 540 Blönduós, Iceland

Simi: 455-4128

Netfang: sveinfr@hsb.is 


\section{Heilbrigð̄isstofnun Vestfjarða}

Framkvaemdastjóri hjúkrunar

\{safirði 7, febrúar 2011

GuŨıùn AuOur Harøardóttir

Furuhliø 15

221 Hafnarfirđi

Pér er hér međ heimilađ að framkvæma rannsókn pina "Translation and Notional Clinical validation of the Nursing Manogement Minimum Dato Set (NMMDS) in Hospitals in the Country of Iceland" á Heilbrigđisstofnun Vestfjard̂a.

English translation:

You are hereby permitted to conduct your research "Translation and National Clinical Validation of the Nursing Manaqement Minimum Data Set (NMMDS) in Hospitols in the Country of Iceland" at the Healthcare Center of Westfjords.

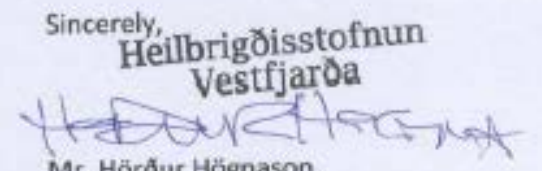

Mr. Hörôur Högnason,

Director of Nursing Services

Heilbrigðisstofnun Vestfjarða

Torfnesi

400 isafirōi

hordur@hvest.is 
Guđ̃rún Auður Harðardóttir

Furuhlið̃ 15

221 Hafnarfirdi

Dér er hér međ heimilađ̃ ađ̃ framkvæma rannsókn bína „Translation and National Clinical Validation of the Nursing Management Minimum Data Set (NMMDS) in Hospitals in the Country of Iceland" á Heilbrigđisstofnuninni Sauđárkróki.

\section{English translation:}

You are hereby permitted to conduct your research "Translation and National Clinical Validation of the Nursing Management Minimum Data Set (NMMDS) in Hospitals in the Country of Iceland" at the Healthcare Center of Sauđárkrókur.

Sincerely,

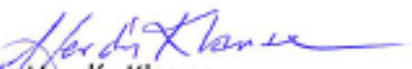

Herdis Klausen

Director of Nursing Services

Heilbrigđ̃isstofnunin Sauđaárkróki

Sauđ̋́rhæỡum

herdis@hskrokur.is
} 


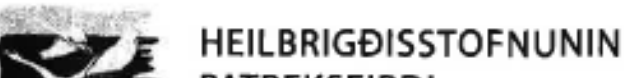 \\ $\checkmark$ PATREKSFIRĐI}

Patreksfirøi 7. febrúar 2011

pér er hér meỡ heimilađ̆ ađ̛ framkvæma rannsókn pína "Translation and National Clinical Validation of the Nursing Management Minimum Data Set (NMMDS) in Hospitals in the Country of Iceland" á Heilbrigöisstofnuninni Patreksfirøi.

English translation:

You are hereby permitted to conduct your research "Translation and National Clinical Validation of the Nursing Management Minimum Data Set (NMMDS) in Hospitals in the Country of Iceland" at the Healthcare Center of Patreksfjordur.

Sincerely,

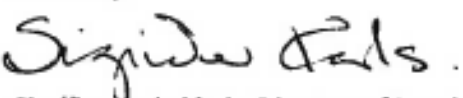

Sigriøur Karlsdóttir, Director of Nursing Services

Hellbrigđisstofnuninni Patreksfiroi

Stekkum 1

450 Patreksfirøi

siggak@hsp.is 


\section{$\frac{11}{11}$}

Guơrún Auður Harðardóttir

Furuhlío 15

221 Hafnarfirði

Vestmannaeyjum, 4. febrúar 2011

pér er hér með heimilað að̃ framkvæma rannsókn pína „Translation and National Clinical

Validation of the Nursing Management Minimum Data Set (NMMDS) in Hospitals in the Country of Iceland" á HeilbrigðisstofnunVestmannaeyja.

English translation:

You are hereby permitted to conduct your research "Translation and National Clinical Validation of the Nursing Management Minimum Data Set (NMMDS) in Hospitals in the Country of Iceland" at the Healthcare Center of Vestmannaislands.

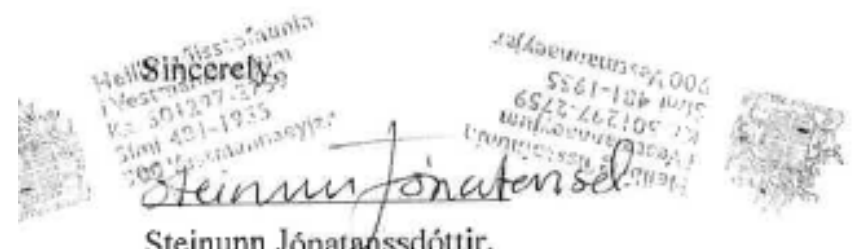

Steinunn Jónatarsssdóttir,

framkvæmdastjóri hjúkrunar-Director of Nursing Services Heilbrigð̃isstofnun Vestmannaeyja Healthcare Center of Vestmannaislands Sólhlío 610 Vestmannaeyjar, Iceland

Netfang: sihv@eyjar.is 


\section{Heilbrigoisstotnun ᄁ Suôausturlands}

Hornafirgi 7. febrúar 2011

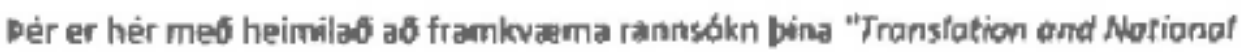
Chinicat Validation of the Nusing Manogement Minimum Data Set (NMMDS) in Hospitals in the Country of Icelond" a Heilbrigoisstofnun Subausturitands.

\section{English translation:}

You are hereby permitted to conduct your rosearch "Transtation and Notianal Cinical Volidation of the Nursing Manogement Minimum Dota Set (MMMDS) in Hospritals in the Cowrtry of tcelond" at the Healthtore Center of South-East iceland.

SIncerely,

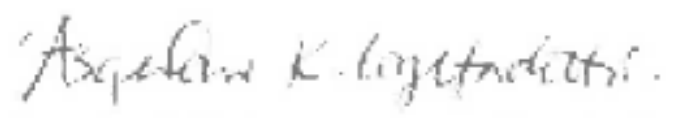

Asserbur Gytfadóttir, Director of Nursing Services

Heilbrigotisstolnun Subausburlands

Vincurbraut 26-31

780 Höfn i Harnafiroti

asgerdur@inssa,is 